\author{
Universidade de São Paulo \\ Faculdade de Medicina de Ribeirão Preto \\ Departamento de Fisiologia
}

\title{
INTERAÇÃO FUNCIONAL ENTRE O SISTEMA COLINÉRGICO E ADRENÉRGICO NA MANUTENÇÃO DA MASSA MUSCULAR E DA PLACA MOTORA
}

Danilo Lustrino Borges

Ribeirão Preto

2015 


\section{INTERAÇÃO FUNCIONAL ENTRE O SISTEMA COLINÉRGICO E ADRENÉRGICO NA MANUTENÇÃO DA MASSA MUSCULAR E DA PLACA MOTORA}

Tese apresentada ao Departamento de Fisiologia da Faculdade de Medicina de Ribeirão Preto USP para obtenção do título de Doutor em Ciências.

Área de concentração: Fisiologia

Orientador: Luiz Carlos Carvalho Navegantes

Ribeirão Preto, 
AUTORIZO A REPRODUÇÃO E DIVULGAÇÃO TOTAL OU PARCIAL DESTE

TRABALHO, POR QUALQUER MEIO CONVENCIONAL OU ELETRÔNICO, PARA FINS DE ESTUDO E PESQUISA, DESDE QUE CITADA A FONTE.

FICHA CATALOGRÁFICA

Borges, Danilo Lustrino

Interação funcional entre o sistema colinérgico e adrenérgico na manutenção da massa muscular e da placa motora/Danilo Lustrino Borges; Orientador: Luiz Carlos Carvalho Navegantes - Ribeirão Preto, 2015.

$100 f .30 \mathrm{~cm}$

Tese (Doutorado - Programa de Pós Graduação em Fisiologia. Área de concentração: Fisiologia) Faculdade de Medicina de Ribeirão Preto da Universidade de São Paulo.

1. Atrofia muscular, 2. AMPc/PKA, 3. $\beta 2$-agonista, 4. Acetilcolina, 5. Junção neuromuscular 
BORGES, Danilo Lustrino. Interação funcional entre o sistema colinérgico e adrenérgico na manutenção da massa muscular e da placa motora.

Tese apresentada à Faculdade de Medicina de Ribeirão Preto da Universidade de São Paulo para obtenção do título de Doutor em Ciências.

Aprovada em:

Banca Examinadora

Prof. Dr. Instituição:

Julgamento: Assinatura:

Prof. Dr. Instituição:

Julgamento: Assinatura:

Prof. Dr. Instituição:

Julgamento: Assinatura:

Prof. Dr. Instituição:

Julgamento: Assinatura:

Prof. Dr. Instituição:

Julgamento: Assinatura: 
"Do ponto de vista da aparência, o ramo é a origem do fruto, mas em realidade, o ramo veio à existência em função do fruto." "Se não tivesse havido um desejo e uma esperança pelo fruto, como o jardineiro teria plantado a raiz da árvore?" "É por isso que, em realidade, a árvore nasceu do fruto, mesmo que na aparência o fruto tenha sido concebido pela árvore" 


\section{DEDICATÓRIA}

Ao теи irmão Wardsson, pelo constante incentivo e apoio durante toda minha formação acadêmica $e$ por me fornecer ensinamentos valiosos com a sua dedicação, objetividade e sua inteligência imensurável. Sou seu fã número 1. 


\section{AGRADECIMENTOS}

Ao Dr. Luiz Carlos Carvalho Navegantes por me aceitar como seu orientado, por se preocupar com minha formação científica e pessoal e até mesmo quando distante fisicamente se fez presente. Além disso, agradeço por todas as oportunidades concedidas (foram muitas e sempre delineadas por boas surpresas) e por sempre estar um passo à frente para me ajudar a tomar as decisões sobre o meu futuro. Agradeço também pelas constantes palavras de incentivo, pelo carinho dedicado a mim e pelos elogios que foram um motivo adicional para

que eu me dedicasse e me davam uma sensação de estar "protegido" pela sua imagem. Término esta etapa muito orgulhoso e muito satisfeito de ter recebido sua orientação e amizade.

À Dra Ísis do Carmo Kettelhut por ter estabelecido nossa linha de pesquisa que permitiu a formação de diversos alunos, mas especialmente por ter me recebido em seu laboratório, por acompanhar o andamento do nosso projeto e sempre tecer comentários valiosos, por me orientar durante os dois últimos anos de pós-graduação e sempre estar disposta às discussões. Contudo, agradeço por se preocupar com minha formação da biologia ao português, por me ensinar a importância de se manter um ambiente de trabalho harmonioso e que as coisas mais importantes na nossa vida são saúde e família. Jamais esquecerei nossa conversa antes de minha viagem para o estágio no exterior e a importância que ela teve durante todo o período que estive fora do país!!!

Ao corpo técnico do Laboratório de Controle do Metabolismo, Elza Filipin, Lilian do Carmo, Maria Antonieta Garófalo, Neusa Zanom e Vitor Galban por serem sempre tão solícitos e por nos proporcionarem diversos momentos agradáveis. Em especial, à Neusa por ter me recebido de braços abertos desde a época do curso de verão em Fisiologia-2010, pela 
sua disponibilidade e por ser a mão que eu sempre pude contar. Além disso, pela sua amizade, pelo seu ombro e pelos diversos conselhos e conversas.

Aos amigos do Laboratório de Controle do Metabolismo Dawit, Flávia, Franciele, Graziela, Juliano, Leandro, Natália, Priscila, Rafael, Samira, Silvia e Wilian pelo convívio agradável, pelos momentos de descontração, pelas ajudas constantes e pelo exemplo de dedicação a ciência. Guardarei um pouco de cada um de vocês comigo.

Ao prof. Dr Rüdiger Rudolf e todo seu grupo, Dr Siegfried Strack, Muzamil Khan e Franziska Wild por me acolherem em seu laboratório no Karlsruhe Institute of Technology, Alemanha e por me auxiliarem na condução dos experimentos in vivo.

Aos amigos Ailin Lepletier, André Mecawi, Elaine Liporage, Fabricia Fonseca, Iracema Araujo, Victor Tunholi e Vinicius Tunholi. Jamais esquecerei da reunião que tivemos quando eu ainda estava no segundo período de faculdade e traçamos como metas nos tornarmos todos monitores, bolsistas de iniciação científica, mestrandos, doutorandos e por fim uma carreira acadêmica e felizmente todos nós obtivemos êxito e alguns de vocês já chegaram ao objetivo final. Obrigado por terem me propiciado os melhores momentos de toda minha vida!!!

Aos amigos Rodrigo Mencalha, Anderson Silveira, Érica de Freitas e Wesley David. A amizade e o companheirismo de vocês são indiscutíveis e imensuráveis. Agradeço também aos amigos Caio Kashihabara e Marcos Ferreira por me proporcionarem momentos tão felizes em Ribeirão Preto e por serem meu escape do ambiente acadêmico.

Aos amigos Aline, Jéssica, Nayara, Procópio, Teddy e Robertinho pela amizade e por compartilharem as felicidades e as angústias durante as disciplinas da pós-graduação. Gostaria também de agradecer à Marlusa Karen, Melina Pires, Davi Moraes, Pedro Cedraz, João Paulo Sabino e Silvia Ruiz que se tornaram amigos valiosos que a pós-graduação me deu.

Aos professores do Departamento de Fisiologia da Faculdade de Medicina de Ribeirão Preto (FMRP) pelos ensinamentos e pelo compromisso na minha formação como fisiologista; 
e aos funcionários da secretaria Claúdia, Eliza e Fernandinho pela dedicação, pela disponibilidade e pela simpatia com a qual eu sempre fui tratado.

Aos meus primeiros orientadores, Dr. Jairo Pinheiro da Silva e Dr. Luis Carlos Reis por terem despertado em mim o interesse pela ciência e por serem um exemplo indiscutível de dedicação à Universidade e a comunidade acadêmica e sem dúvida alguma, uns dos melhores professores que tive. Agradeço pelo crédito que vocês sempre me deram e pelo incentivo, por me mostrarem que muito mais que paper é a formação de recursos humanos e por sempre terem um olhar compreensível e cuidadoso com cada aluno. Vocês não foram somente os orientadores que eu procurei, mas também foram os amigos que eu sempre precisei !!!

Agradeço também todos os professores do Departamento de Ciências Fisiológicas da Universidade Federal Rural do Rio de Janeiro que contribuíram sobremaneira para minha formação e pela amizade a mim depositada. Vocês certamente fazem parte desta conquista.

À minha mãe, Maria Antônia pelo seu amor incondicional. A Sra sempre será minha força motriz. Te amo.

À minha família: meus irmãos Titta, Wallysson, Wardsson e Sheila e ao meu cunhado Jair, vocês são todo meu suporte. Felizmente o destino me levou a vocês e pude compartilhar da convivência de pessoas tão honestas, responsáveis e inteligentes; aos melhores sobrinhos do mundo Lucas, Lúcia e Eduarda vocês são a fonte de minhas energias e são a melhor parte de nossa família; e todos os meus tios e tias em especial, minhas tias Edna e Leonice que desde quando criança me pegaram no colo e me incentivaram a seguir um caminho sempre melhor.

E por fim, mas não menos importante à Fundação de Amparo à Pesquisa do Estado de São Paulo (FAPESP) pela concessão da bolsa (Processo 2012/05697-7) e pelo auxilio financeiro para realização dos experimentos desta tese (Processos 2012/24524-6 e 2012/51456-1) 


\section{RESUMO}

BORGES, D.L. Interação funcional entre o sistema colinérgico e adrenérgico na manutenção da massa muscular e da placa motora. 100f. Tese (Doutorado) Faculdade de Medicina de Ribeirão Preto, Universidade de São Paulo, Ribeirão Preto, 2015.

Estudos anteriores de nosso laboratório demonstraram que a estimulação aguda dos receptores $\beta_{2}$-adrenérgicos $\left(\beta_{2}\right.$-AR) atenua a perda de massa muscular induzida pela desnervação motora (DEN) por meio de uma via dependente de AMPc/PKA. No entanto os mecanismos moleculares envolvidos na ativação crônica destes receptores ainda são pouco conhecidos. Por outro lado, a ativação desta via de sinalização também está envolvida no controle da estabilidade dos receptores nicotínicos (AChR) na junção neuromuscular (JNM), sugerindo que a densidade dos AChR possa estar sob controle neuro-humoral. Desta forma, aventou-se a possibilidade de que além dos efeitos protetores na massa muscular, a ativação dos receptores $\beta_{2}$-AR pudesse mediar a estabilização dos AChR na placa motora. Para testar essa hipótese, camundongos foram submetidos à DEN através da secção do nervo ciático, um protocolo clássico de indução de atrofia muscular e desestabilização dos $\mathrm{AChR}$, e tratados com salina ou clembuterol (CB), um $\beta_{2}$-agonista seletivo, por até 14 dias. Após 3 dias de DEN, observou-se redução da massa muscular e aumento do conteúdo proteico e expressão do RNAm de genes relacionados à ativação do sistema Ubiquitina-Proteassoma (atrogina-1 e MuRF1) e do sistema autofágico/lisossomal (catepsina L e LC3). A DEN também promoveu aumento no turnover dos $\mathrm{AChR}$, no número de vesículas endocíticas e na expressão do RNAm para a subunidade $\alpha 1$ dos AChR. Após 7 dias, a DEN reduziu a expressão dos genes relacionados à atrofia e aumentou a atividade da via do AMPc/PKA independentemente do tratamento com $\mathrm{CB}$. Na tentativa de elucidar os sinais extracelulares que produziam esta resposta adaptativa, foi demonstrado que neurônios catecolaminérgicos trafegam ao longo do 
nervo ciático e sua ablação pela DEN reduziu o conteúdo de noradrenalina muscular. Baseados nestes resultados, foi postulado a existência de uma hipersenbilidade às catecolaminas em músculos desnervados cronicamente. $\mathrm{O}$ tratamento com $\mathrm{CB}$ por 3 dias aboliu o aumento da expressão dos atrogenes induzido pela DEN e este efeito foi associado ao maior conteúdo de AMPc e de substratos fosforilados pela PKA. Além disso, o CB diminuiu a hiperexpressão do RNAm para catepsina L e LC3 induzida pela DEN de 7 dias. Embora o $\mathrm{CB}$ não tenha alterado a meia-vida dos $\mathrm{AChR}$ em músculos inervados e desnervados, houve um total bloqueio do aumento do número de vesículas endocíticas contendo o AChR em músculos desnervados e tratados com $\mathrm{CB}$. Corroborando estes dados, o $\mathrm{CB}$ aumentou a incorporação de AChR "novos" nas JNM e este efeito foi também associado à maior expressão do RNAm para a subunidade $\alpha 1-A C h R$ em músculos desnervados. Esta ação do CB no turnover dos AChR parece ser direta uma vez que neuroniôs catecolaminérgicos presentes no nervo ciático ativam receptores $\beta_{2}$-ARe a produção de AMPc especificamente na JNM.

Em estudos in vitro, foi demonstrado que a estimulação colinérgica produzida pelo carbacol $\left(10^{-4} \mathrm{M}\right)$ diminuiu a velocidade de síntese de proteínas, aumentou a proteólise total e a atividade do sistema proteolítico $\mathrm{Ca}^{2+}$-dependente em músculos soleus de ratos por meio da ativação dos receptores nicotínicos. Este efeito catabólico do carbacol foi completamente bloqueado pela adição de CB $\left(10^{-4} \mathrm{M}\right)$ ao meio de incubação.

Os dados obtidos no presente estudo permitem sugerir que a estimulação crônica dos $\beta_{2^{-}}$ AR no músculo esquelético induz um efeito anti-catabólico pela supressão dos sistemas proteolíticos proteassomal e lisossomal, provavelmente através da via de sinalização do AMPc/PKA. A inibição destes sistemas pode estar relacionada ao aumento do turnover dos AChR, uma vez que a velocidade de incorporação destes receptores na JNM foi aumentada pelo CB. Além disso, os achados que mostram a associação entre neurônios noradrenérgicos e colinérgicos no nervo ciático, que conjuntamente inervam as JNM, e a co-localização de 
receptores $\beta_{2}-\mathrm{AR}$ e $\mathrm{AChR}$ na sinapse permitem sugerir a existência de uma interação funcional entre o sistema colinérgico e adrenérgico na manutenção da massa muscular e da placa motora.

Palavras-chave: Atrofia muscular, AMPc/PKA, $\beta_{2}$-agonista, Acetilcolina, Junção neuromuscular. 


\begin{abstract}
BORGES, D.L. Functional interaction between Cholinergic and Adrenergic systems in the maintenance of muscle mass and motor endplate, 100f. Thesis (Doctorate) - Ribeirão Preto Medical School, University of São Paulo, Ribeirão Preto, 2015.
\end{abstract}

Previous studies from our laboratory have shown that the acute stimulation of $\beta_{2}$ adrenergic receptor $\left(\beta_{2}-\mathrm{AR}\right)$ attenuates the muscle loss induced by motor denervation (DEN) through a cAMP/PKA dependent pathway. However, the molecular mechanisms involved in the chronic activation of these receptors are poorly understood. Furthermore, the activation of this signaling pathway is also involved in controlling the stability of nicotinic receptors $(\mathrm{AChR})$ at the neuromuscular junction (NMJ), suggesting that the density of AChR may be under neurohumoral control. Thus, we postulated that besides the protective effects on muscle mass the activation of $\beta_{2}$-AR receptors could mediate the stabilization of $\mathrm{AChR}$ in the motor plate. To test this hypothesis, mice were submitted to DEN through of the sciatic nerve section, a classical protocol of induction muscle atrophy and destabilization of AChR, and were treated with saline or clenbuterol (CB), a selective $\beta_{2}$-agonist for 14 days. DEN decreased the muscle mass and increased the protein content and mRNA expression of genes related to the activation of the ubiquitin-proteasome system (atrogin-1 and MuRF1) and autophagic/lysosomal system (cathepsin L and LC3). DEN also promoted an increase in the turnover of AChR, number of endocytic vesicles and the expression of mRNA for the $\alpha 1$ subunit of AChR. Interestingly, chronic DEN induced down-regulation of atrophy relatedgenes, and increased the activity of cAMP/PKA pathway independently of CB treatment. In an attempt to elucidate the extracellular signals that produced this adaptive response, it was demonstrated that catecholaminergic neurons travels along the sciatic nerve and its ablation 
by DEN reduces muscle norepinephrine content. Based on these results, it was postulated the existence of a muscle adrenergic hypersensitivity to circulating catecholamines induced by chronic DEN. CB treatment for 3 days completely abolished the higher expression of atrogenes and this effect was associated with increased Camp content and PKA phosphorylated substrates. Furthermore, CB decreased the DEN-induced hyperexpression of cathepsin L and LC3 mRNA at 7 days. Although CB has not altered the half-life of AChR in innervated and denervated muscles, it produced a total blockage of the increased number of endocytic vesicles containing the AChR in denervated muscles. Consistently, CB increased the incorporation of "new" AChR and this effect was associated with an increased expression of the $\alpha 1$-subunit AChR mRNA in denervated muscles. This action of CB on AChR turnover appears to be direct, since catecholaminergic neurons are present in the sciatic nerve stimulating $\beta_{2}$-AR and cAMP production specifically in the NMJ.

Furthermore, in vitro studies demonstrated that cholinergic stimulation produced by carbachol $\left(10^{-4} \mathrm{M}\right)$ decreased the rate of protein synthesis and increased the proteolytic activity of $\mathrm{Ca}^{2+}$-dependent system in rat soleus muscle through activation of nicotinic receptors. This catabolic effect of carbachol was completely blocked by the addition of $\mathrm{CB}\left(10^{-4} \mathrm{M}\right)$ to the incubation medium.

These data suggest that chronic stimulation of $\beta_{2}$-AR in skeletal muscle induces an anticatabolic effect by suppressing proteasomal and lysosomal proteolytic systems, probably through the cAMP/PKA signaling. The inhibition of these systems seems to be related to the increased $\mathrm{AChR}$ incorporation into NMJ induced by $\mathrm{CB}$ treatment. Moreover, the association between noradrenergic and cholinergic neurons in the sciatic nerve, both of which innervate the motor endplates, and the co-localization of AChR and $\beta_{2}$-ARat the synapse suggest the existence of a functional interaction between cholinergic and adrenergic systems in the maintenance of muscle mass and motor endplate. 
Keywords: muscular atrophy, cAMP / PKA, $\beta_{2}$-agonist, acetylcholine, neuromuscular junction. 


\section{LISTA DE SIGLAS}

6-BNZ-cAMP $\quad \mathrm{N}^{6}$ - Benzoil-3'-5'- Adenosina Monofosfato

6-OH-DOPA 6-hidroxi-dopamina

$\mathrm{ACh}$

Acetilcolina

$\mathrm{AChR}$

Receptores colinérgicos nicotínicos

ADMX

Adrenodemedulação

AF555

Alexafluor 555

AF647

Alexafluor 647

AKAPs

Proteínas ancoradoras de PKA

AKT

$v$-akt murine thymoma viral oncogene or protein kinase $B$

AMPc

3',5'- adenosina monofosfato cíclico

ANOVA

Análise de variância

ARs

Receptores adrenérgicos

BCAA

Aminoácidos de cadeia ramificada

BGT

$\alpha$-bungarotoxina

Bif-1

Endofilina B1

$\mathrm{CB}$

Clembuterol

CETEA

Comissão de Ética em Experimentação Animal

CFP

Cyan fluorescent protein

CLAE

Cromatografia líquida de alta eficiência

CREB

Proteína de ligação do elemento de resposta do AMPc

DB-AMPc

Dibutiril-AMPc

DEN

Desnervação motora

E1

Enzima ativadora da ubiquitina

E2a

Enzima carreadora da ubiquitina 
E3

E64

EDL

EDTA

EPAC

EPM

ERK1/2

FRET

GABARAP

GMPc

JNM

LC3

MAFbx

$m d x$

MG132

MuRF1

PCARP

PDE

PKA

PMSF

$\mathrm{RI} \alpha$

RT-PCR

SDS

SDS-PAGE

TA

TCA
Enzima ligadora da ubiquitina

Trans-epoxisuccinil-L-leucilamido-(4-guanidino) butano

Extensor longo dos dedos

Ácido etilenodiamino tetra-acético

Proteína trocadora de guanina diretamente ativada pelo AMPc

Erro padrão da média

Extracellular signal-regulated kinases $1 / 2$

Fluorescência pela transferência de energia de ressonância

$\gamma$-aminobutyric acid receptor-associated protein

Monofosfato cíclico de guanosina

Junção neuromuscular

Microtubule-associated protein 1 light chain 3

Muscle Atrophy F-box

Distrofia muscular de Duchenne

$\mathrm{N}$-carboxibenzoxi-Leu-Leu-Leucina

Muscle RING (Really Interesting New Gene) Finger 1

Prefeitura do Campus Administrativo da USP de Ribeirão Preto

Fosfodiesterase

Proteína quinase dependente de AMPc

Fluoreto de Fenilmetilsulfonil

Subunidade regulatória $\alpha$

Real-time reverse-transcription - Polymerase Chain Reaction

Dodecil sulfato de sódio

Gel de poliacrilamida-dodecil sulfato de sódio

Músculo tibial anterior

Ácido tricloroacético 
TyrH

$\mathrm{Ub}$

WGA

YFP
Tirosina hidroxilase

Ubiquitina

Wheat germ agglutin

Yellow fluorescent protein 


\section{LISTA DE FIGURAS}

Figura 1. Modelo esquemático para realização de fluorescência pela transferência de energia de ressonância (FRET) em músculos transfectados com o plasmídeo contendo o gene para o $\beta_{2}$-AR-s-pep. 22

Figura 2. Modelo esquemático para realização de fluorescência pela transferência de energia de ressonância (FRET) em músculos transfectados com o plasmídeo contendo o gene para o CFP-rapsina_EPAC-YFP.

Figura 3. Esquema representativo da avaliação do efeito do tratamento diário com clembuterol na taxa de degradação do receptor colinérgico nicotínico (AChR) em músculos esqueléticos de camundongos anestesiados 25

Figura 4. Esquema representativo da avaliação do efeito do tratamento diário com clembuterol na estabilidade do receptor colinérgico nicotínico (AChR) em músculos esqueléticos de camundongos anestesiados 26

Figura 5. Efeito do tratamento com clembuterol (CB; $3 \mathrm{mg} / \mathrm{kg} / \mathrm{dia}$, s.c.) ou salina (Sal) na massa de músculos tibialis desnervados (DEN). 37

Figura 6. Efeito do tratamento com clembuterol (CB; $3 \mathrm{mg} / \mathrm{kg} / \mathrm{dia}$, s.c.) ou salina (Sal) na expressão do RNAm para atrogina-1 (A) e MuRF1 (D) e no conteúdo das proteínas atrogina-1 (B) e MuRF1 (E) em músculos tibiais desnervados (DEN). As bandas (blots) representativas de atrogina-1 e MuRF1 são mostradas em C e F, respectivamente. Os níveis de expressão gênica foram normalizados utilizando a subunidade de RNA 18S como controle endógeno.. 38 Figura 7. Efeito do tratamento com clembuterol (CB; $3 \mathrm{mg} / \mathrm{kg} / \mathrm{dia}$, s.c.) ou salina (Sal) na expressão do RNAm para catepsina L (A) e LC3 (B) e no conteúdo proteico de LC3 I e II (C) em músculos tibiais desnervados (DEN).

Figura 8. Conteúdo de adenosina 3',5'-monofosfato cíclico (AMPc, A) e de substratos fosforilados pela PKA (B) em músculos tibialis desnervados (DEN) obtidos de 
camundongos tratados com salina (Sal) ou clembuterol $\left(\mathrm{CB} ; 3 \mathrm{mg} \cdot \mathrm{kg}^{-1} \cdot \mathrm{dia}^{-1}\right.$, s.c.) por 14 dias. Em $\mathbf{C}$, as imagens (blots) representativas de cada grupo.

Figura 9. Esquema representativo do perfil temporal da expressão dos atrogenes (MuRF1 e atrogina-1) e da atividade da via de sinalização do AMPc/PKA em músculos desnervados...44

Figura 10. Identificação de fibras noradrenérgicas no nervo ciático de camundongos. 45

Figura 11. Conteúdo de noradrenalina em músculos gastrocnêmicos de camundongos após três dias de desnervação motora (DEN) B: Imagens representativas do conteúdo proteíco de atrogina-1 e MuRF1 em músculos tibial anterior de camundongos submetidos previamente à cirurgia de remoção da porção medular da adrenal (ADMX) e à DEN por sete dias. C: Concentração plasmática de corticosterona após sete dias de ADMX 46

Figura 12. Identificação de fibras noradrenérgicas na junção neuromuscular (JNM).

Figura 13. A: Identificação de receptores $\beta_{2}$-adrenérgicos (AR) em sinapses musculares de camundongos. B: Após transfecção do plasmídeo contendo o gene $\beta_{2}$-AR-sPep foi observada co-localização do $\beta_{2}$-AR e do receptor colinérgico nicotínico (AChR). C: A estimulação elétrica do nervo ciático promoveu a ativação do receptor $\beta_{2}$-AR mensurada pela técnica de transferência de energia de ressonância por fluorescência (FRET). 50

Figura 14. A: Imagens representativas do aumento da produção de AMPc nas sinapses musculares induzido pela estimulação elétrica do nervo ciático após transfecção do músculo tibial anterior com o plamídeo Rapsina-EPAC. B: Quantificação da produção do AMPc ......51 Figura 15. Efeito do tratamento com clembuterol (CB; 3mg.kg-1.dia-1, s.c.) ou salina (Sal) na taxa de degradação do receptor colinérgico nicotínico (AChR), avaliado pela taxa de decaimento de ${ }^{125}$ I-bungarotoxina (BGT), em músculo tibial anterior inervado e desnervado (DEN) de camundongos. 53

Figura 16. Imagens representativas do efeito do tratamento com clembuterol (CB; $3 \mathrm{mg} \cdot \mathrm{kg}^{-}$ ${ }^{1}$.dia $^{-1}$, s.c.) ou salina (Sal) na estabilidade do receptor colinérgico nicotínico (AChR) em 
músculo tibial de camundongos submetidos à desnervação motora unilateral (DEN). Os AChR foram marcados com BGT-AlexaFluor 647 ("para visualização dos receptores antigos") e depois de 10 dias com BGT-AlexaFluor 555 (para visualização dos "receptores novos"). 54

Figura 17. Efeito do tratamento com clembuterol (CB; $3 \mathrm{mg} \cdot \mathrm{kg}^{-1} \cdot \mathrm{dia}^{-1}$, s.c.) ou salina (Sal) na estabilização do receptor colinérgico nicotínico $(\mathrm{AChR})$ em músculo tibial de camundongos submetidos à desnervação motora unilateral (DEN). 55

Figura 18. Efeito do tratamento com clembuterol (CB; $3 \mathrm{mg} \cdot \mathrm{kg}^{-1} \cdot \mathrm{dia}^{-1}$, s.c.) ou salina (Sal) por 14 dias no conteúdo de vesículas endocíticas marcadas com bungarotoxina (BGTAF647/AF555) (A) e na expressão do RNAm para a subunidade $\alpha 1$ do receptor colinérgico nicotínico $(\alpha 1-\mathrm{AChR})$ (B) em músculo tibial anterior inervado e desnervado (DEN) de camundongo. Os níveis de expressão gênica foram normalizados utilizando a subunidade de RNA 18S como controle endógeno. 57

Figura 19. A: Imagens representativas do efeito do tratamento com clembuterol $\left(\mathrm{CB} ; 3 \mathrm{mg} \cdot \mathrm{kg}^{-}\right.$ ${ }^{1}$.dia $^{-1}$, s.c.) ou salina (Sal) na estabilidade do receptor colinérgico nicotínico (AChR) em músculo tibial anterior de camundongos com a mutação AChR-عL269F. (A) Os AChR foram marcados com BGT-AlexaFluor 647 ("para visualização dos receptores antigos”) e depois de 10 dias com BGT-AlexaFluor 555 (para visualização dos "receptores novos"); barra de escala, $50 \mu \mathrm{m}$. B: Análise quantitativa da relação de pixels dominantes de ambos os sinais dos receptores "novos" e "antigos" por fragmentos de junção neuromuscular (JNM) 58

Figura 20. Efeito in vitro do carbacol $\left(10^{-7}\right.$ a $\left.10^{-3} \mathrm{M}\right)$ na atividade proteolítica total de músculos soleus (A) e EDL (B) normais de ratos. 60

Figura 21. Efeito in vitro do carbacol $\left(10^{-4} \mathrm{M}\right)$ na presença ou não de D-tubocurarina $\left(10^{-4} \mathrm{M}\right)$ na proteólise total em músculos soleus de ratos normais. 61 
Figura 22. Efeito in vitro do carbacol $\left(10^{-3} \mathrm{M}\right)$ na velocidade de síntese proteica em músculos soleus e EDL de ratos.

Figura 23. Efeito in vitro do carbacol $\left(10^{-4} \mathrm{M}\right)$ nas atividades proteolíticas lisossomal (A), dependente de Ubiquitina-Proteassoma (UPS) (B) e dependente de $\mathrm{Ca}^{2+}$ (C) em músculos soleus de ratos normais. 63

Figura 24. Efeito in vitro do carbacol $\left(10^{-4} \mathrm{M}\right)$ e/ou do clembuterol $\left(\mathrm{CB}, 10^{-4} \mathrm{M}\right)$ na proteólise total em músculos soleus de ratos normais. 64 


\section{LISTA DE TABELAS}

Tabela 1. Protocolo utilizado para quantificação da proteólise total e lisossomal. 29

Tabela 2. Protocolo utilizado para quantificação da atividade do sistema proteolítico dependente de $\mathrm{Ca}^{2+}$ 30

Tabela 3. Protocolo utilizado para a quantificação da proteólise dependente de Ubproteassoma 32

Tabela 4. Aminoácidos presentes no meio de incubação para quantificação da velocidade de síntese de proteínas totais. 


\section{SUMÁRIO}

1. INTRODUÇÃO.

1.1. Características Estruturais e Funcionais da Junção Neuromuscular ......................................... 3

1.1.1. Manutenção da placa motora pela via do AMPc/PKA ……............................................... 4

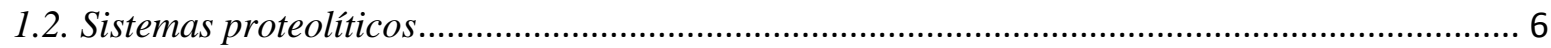

1.3. Papel anabólico da inervação adrenérgica na manutenção da massa muscular ....................... 9

1.3.1. Mecanismos anti-proteoliticos dependentes da via do AMPc/PKA .................................. 10

2. OBJETIVOS .14

3. MATERIAL E MÉtodos .16

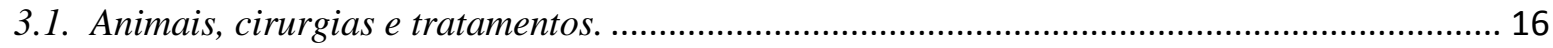

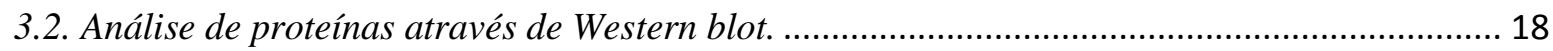

3.3. Reação em cadeia da polimerase em tempo real (RT-PCR).................................................... 19

3.4. Determinação do conteúdo de AMPc................................................................................. 19

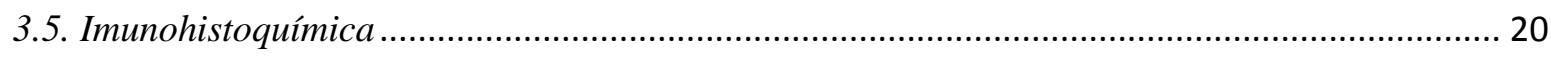

3.6. Cromatografia Liquida de Alta Eficiência (CLAE) e Radioimunoensaio (RIA) ........................ 20

3.7. Transfecção in vivo por eletroporação e fluorescência pela transferência de energia de

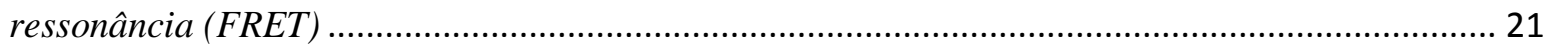

3.8. Determinação da meia-vida do AChR através da ligação com ${ }^{125} I-\alpha$-bungarotoxina $\left({ }^{125} I-\right.$

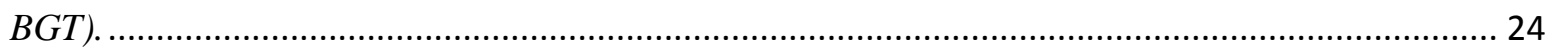

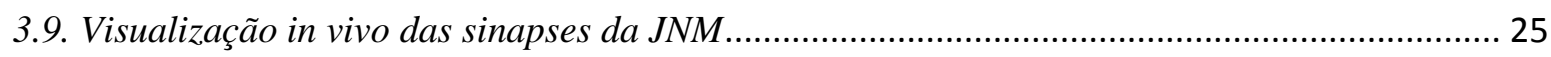

3.10. Procedimento para análise das vesículas positivas $B G T$.................................................... 26

3.11. Procedimento experimental para o estudo da proteólise em músculos esqueléticos de ratos 27

3.12. Atividade dos Sistemas Proteolíticos ................................................................................... 28

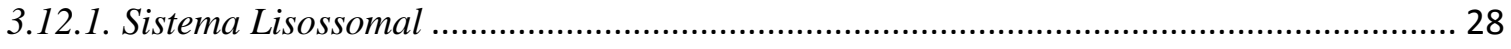

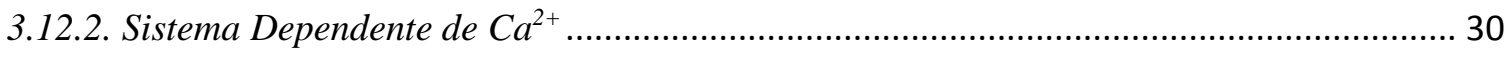

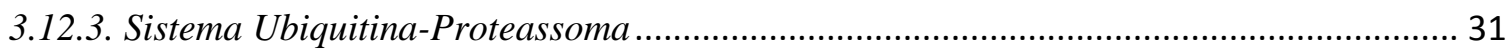

3.13. Procedimento experimental para a avaliação da síntese total de proteínas em músculos esqueléticos de ratos .............................................................................................................. 33

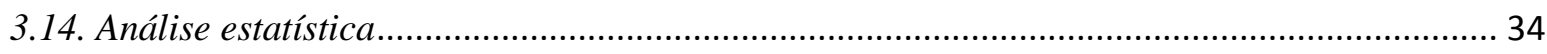


4.1. Efeito do tratamento crônico com CB na massa muscular e na expressão dos genes relacionados à atrofia e autofagia induzidos pela DEN.

4.2. Efeito do tratamento crônico com CB na atividade da via do AMPc/PKA em músculos desnervados

4.3. Participação do SNS na resposta adaptativa induzida pela desnervação

4.4. Evidências anatômicas da interação entre o sistema adrenérgico e colinérgico na placa motora

4.5. Efeito do tratamento com CB no turnover dos AChR 52

4.6. Efeito da estimulação colinérgica no metabolismo de proteínas em músculos isolados de ratos

5.1. Efeitos anti-atróficos da estimulação crônica dos receptores $\beta_{2}$-AR em músculos desnervados

5.2. Mecanismos subsinápticos envolvidos na ativação simpática das JNM..................................... 72

5.3. Efeito do tratamento com CB no turnover dos AChR na JNM de músculos desnervados

5.4. Efeito da estimulação colinérgica no metabolismo de proteínas em músculos isolados de ratos

6. CONCLUSÃo 
Introducãa 


\section{INTRODUÇão}

Os músculos esqueléticos são inervados por neurônios motores cujos corpos celulares encontram-se no corno ventral da medula espinal. Cada neurônio envia um axônio através de um plexo de nervos periféricos para um único músculo esquelético. Este axônio ramifica-se para inervar dezenas a centenas de fibras musculares. À medida que cada ramo axonal chega a sua fibra alvo, ele perde sua bainha de mielina formando diversos ramos terminais sobre a superfície da célula muscular em uma região altamente especializada denominada junção neuromuscular (JNM) ou placa motora (HALL; SANES, 1993).

A função clássica da JNM é mediar a contração muscular induzida pela acetilcolina (ACh) liberada pelos neurônios motores e para isso é absolutamente necessária a manutenção da integridade das proteínas miofibrilares assim como a interação do tecido muscular com o sistema nervoso (SCHMALBRUCH; AL-AMOOD; LEWIS, 1991). A perda desta inervação, como ocorre na secção experimental do nervo cíatico ou pós-traumatismos, é responsável pela inatividade muscular e é um modelo clássico de indução de atrofia que se caracteriza por uma grande perda de proteínas musculares associada à desestabilização da JNM (ANDREOSE; FUMAGALLI; LØMO, 1995).

Poucas evidências anatômicas indicam que terminais nervosos simpáticos também são distribuídos ao longo das fibras musculares estabelecendo contato direto com fibras intra e extrafusais, independentemente da vasculatura (BARKER; SAITO, 1981). Outros estudos também demonstram que cerca de $23 \%$ dos neurônios presentes no nervo ciático são noradrenérgicos (SCHMALBRUCH, 1986) e que a noradrenalina exerce ações de facilitação da transmissão neuromuscular produzindo aumento da liberação de ACh (BUKHARAEVA; NIKOLSKY, 2002). No entanto, a importância funcional da interação entre as inervações colinérgica e simpática na manutenção da massa muscular e da placa motora ainda é completamente desconhecida. 


\subsection{Características Estruturais e Funcionais da Junção Neuromuscular}

Os eventos que promovem a contração muscular iniciam a partir da despolarização dos neurônios motores e a propagação do impulso nervoso através dos axônios até os músculos por eles inervados na região da placa motora (HALL; SANES, 1993). Como em toda sinapse, a JNM apresenta os componentes básicos pré- e pós-sinápticos, os quais incluem a porção terminal do neurônio motor e a membrana sarcoplasmática, respectivamente. Quando o impulso nervoso atinge a JNM, o neurônio motor libera vesículas contendo o neurotransmissor $\mathrm{ACh}$, o qual se liga a receptores colinérgicos denominados nicotínicos (AChR) presentes na membrana sarcoplasmática. A ligação da ACh ou outros agonistas colinérgicos aos AChR desencadeia um processo reversível tornando a membrana sarcoplasmática permeável a $\mathrm{Na}^{+}$e $\mathrm{K}^{+}$(MICHLER; SAKMANN, 1980). Desencadeia-se então o potencial de ação que se propaga ao longo da fibra muscular resultando no aumento do influxo de $\mathrm{Ca}^{2+}$ e na contração muscular.

Na JNM, o AChR é um canal iônico que medeia a resposta pós-sináptica excitatória rápida no músculo. Este receptor é um complexo proteico de $250 \mathrm{kDa}$ composto de quatro subunidades homólogas em uma estequiometria de $\alpha_{2} \beta \gamma \delta$ sendo bem caracterizado estrutural e funcionalmente (TANK et al., 1983). AChR musculares contém dois sítios de ligação para ACh e outros ligantes colinérgicos, que se formam nas interfaces entre uma subunidade $\alpha$ e uma subunidade $\gamma$ ou $\delta$ adjacentes (BLOUNT; MERLIE, 1989).

As características ontogenéticas deste receptor demonstram que durante os estágios iniciais do desenvolvimento, os AChR estão localizados em toda a superfície da membrana de fibras musculares esqueléticas possuindo meia-vida $\left(\mathrm{t}_{1 / 2}\right)$ de $\sim 1$ dia. Com a maturação e subsequente inervação, os $\mathrm{AChR}$ desaparecem quase completamente ao longo das fibras musculares, exceto na JNM, onde se tornam metabolicamente mais estáveis $\left(\mathrm{t}_{1 / 2}\right.$ de $\sim 10$ dias) 
e atingem densidade característica de cerca de 10.000 receptores por $\mu^{2}$ (MATTHEWSBELLINGER; SALPETER, 1983). Hoje, sabe-se que a estabilidade metabólica dos AChR na JNM é regulada pelo neurônio motor. Diferentes estudos mostram que após a desnervação tais receptores são substituídos por AChR com taxa de degradação rápida ( $\mathrm{t}_{1 / 2}$ de 1 dia) (SHYNG; SALPETER, 1989). Porém, até o momento, não é conhecido se a alteração na estabilidade dos AChR após a desnervação é resultado da atrofia muscular decorrente das alterações do metabolismo proteico (ativação da proteólise e redução de síntese proteica), atividade mecânica anormal ou ausência de fatores neurotróficos.

\subsubsection{Manutenção da placa motora pela via do AMPc/PKA}

A via de sinalização do AMPc é muito bem descrita na musculatura esquelética e envolve a ligação do agonista a seu receptor de membrana ( $\left.\beta_{2}-\mathrm{AR}\right)$, o qual é um receptor acoplado à proteína-G heterotrimérica $(\mathrm{G} \alpha \beta \gamma)$. Após estimulação, a subunidade $\mathrm{G} \alpha$ estimulatória (Gas), acoplada à enzima adenilato ciclase, leva à formação de AMPc à partir do ATP com subsequente ativação da proteína quinase dependente de AMPc (PKA) (LYNCH; RYALL, 2008). Evidências experimentais indicam a presença de proteínas quinases na JNM que, especificamente, fosforilam as subunidades $\gamma$ e $\delta$ do AChR e aumentam a sua estabilidade. A partir dessas observações, sugeriu-se que tal efeito seria mediado pela PKA , visto que a adição de H89, inibidor desta enzima, abolia tal resposta (HUGANIR; GREENGARD, 1983). Além disso, o dibutiril-AMPc (DB-AMPc), análogo do AMPc ou a forskolina, ativador da enzima adenilato ciclase, foram capazes de estabilizar a acelerada taxa de degradação do receptor (GREEN; ROSS; CLAUDIO, 1991). Neste contexto, a PKA tem sido diretamente envolvida na regulação da dessensibilização do AChR (HUGANIR et al., 1986), bem como na montagem e síntese do mesmo (GREEN; ROSS; CLAUDIO, 1991). 
Alternativamente, tal enzima também pode ativar a transcrição de genes responsáveis pela expressão de proteínas que podem se ligar aos AChR ou nas suas imediações e, assim, melhorar a estabilidade deste receptor (XU; SALPETER, 1995). Röder et al. (2010) também demonstraram que a subunidade regulatória RI $\alpha$ da PKA localiza-se na JNM e é essencial para os processos de fosforilação que mantém a estabilidade dos AChR.

Por outro lado, a estrutura e estabilidade dos AChR são bastante alteradas nos músculos de camundongos $m d x$ (modelo animal para distrofia muscular de Duchenne) (GRADY et al., 2000; SHIAO et al., 2004), no qual a sinalização do AMPc é modificada (REYNOLDS et al., 2008). Isto não significa que a sinalização alterada é a causa para os fenômenos na JNM, mas o enriquecimento subsináptico típico da subunidade RI $\alpha$ da PKA somente está presente em metade de todas as fibras musculares dos camundongos $m d x$ e é inversamente correlacionado com o turnover dos AChR (RÖDER et al., 2012), sugerindo uma correlação entre a organização estrutural dos microdomínios subsinápticos da via do AMPc/PKA nos músculos distróficos e as alterações observadas na morfologia da JNM e na estabilidade dos AChR.

A participação do AMPc na estabilização dos AChR também foi testada em portadores de síndromes miastênicas congênitas. Estas são doenças genéticas raras que afetam componentes pré- ou pós-sinápticos da JNM e levam a alterações na transmissão neuromuscular e fraqueza muscular (PALACE; BEESON, 2008). Muitas formas de miastenias também apresentam densidades reduzidas de AChR (ENGEL et al., 2010). Embora as características moleculares possam variar em função das diferentes mutações, a constatação clínica de que drogas simpatomiméticas, tais como a efedrina (adrenalina sintética) e salbutamol ( $\beta_{2}$-agonista), podem melhorar significativamente os sintomas desses pacientes, sugere um envolvimento das catecolaminas no turnover dos AChR (FINLAYSON et al., 2013; LASHLEY et al., 2010; SCHARA et al., 2009). Uma vez que tanto a efedrina como o salbutamol podem ativar os receptores $\beta_{2}$-adrenérgicos (AR) e, portanto, aumentar a produção 
de AMPc, é possível especular que o AMPc seja um segundo mensageiro chave na estabilização e/ou na expressão dos AChR em resposta aos simpatomiméticos. No entanto, nada se conhece acerca do papel fisiológico de fatores hormonais e neurais que, por meio desta via de sinalização, regulem a estabilidade da JNM em situações in vivo.

\subsection{Sistemas proteolíticos}

Além de sua importância funcional na integridade estrutural e funcional da JNM, diferentes estudos indicam que a inervação motora regula o metabolismo de proteínas musculares e com isso contribui diretamente para a manutenção da massa muscular (SACHECK et al., 2007). Embora a perda desta inervação resulte em perda de massa muscular consequente à ativação dos três principais sistemas proteolíticos na musculatura esquelética, i.e. dependente de $\mathrm{Ca}^{2+}$, lisossomal e dependente de ubiquitina (Ub)-proteassoma (GONÇALVES et al., 2012; SACHECK et al., 2007), muito pouco se conhece sobre o papel específico da ACh na regulação das diferentes vias de degradação de proteínas e nos processos de síntese.

O sistema proteolítico dependente de $\mathrm{Ca}^{2+}$ é formado por cisteína proteases denominadas de calpaínas (CONG et al., 1989). Além de ser regulada pelo $\mathrm{Ca}^{2+}$, a atividade das calpaínas é controlada pela calpastatina, um inibidor endógeno destas proteases (PARR et al., 1992). Uma vez ativadas, as calpaínas são responsáveis por degradar proteínas miofibrilares, assim como outras proteínas do citoesqueleto e de membrana incluindo proteínas associadas aos AChR na JNM. De fato, músculos de camundongos $m d x$ apresentam aumento da atividade das calpaínas (XU; SALPETER, 1997) e altas taxas de degradação dos AChR juncionais (SPENCER; CROALL; TIDBALL, 1995). De forma similar, camundongos miastênicos portadores da síndrome do canal-lento que mostram fraqueza muscular, 
transmissão neuromuscular disfuncional e alteração da morfologia da JNM apresentam melhoras destes parâmetros quando são submetidos à superexpressão da calpastatina (GROSHONG et al., 2007).

Embora tenha sido o primeiro sistema proteolítico a ser descoberto ainda na década de 1960 (MANTLE; PREEDY, 2002), pouco se estudou a respeito do papel dos lisossomos na atrofia muscular. O lisossomo constitui o sítio de degradação do sistema lisossomal devido a sua alta concentração de proteases conhecidas como catepsinas, que se apresentam em diferentes isoformas: L, B, D e H (BECHET et al., 2005; FINN; DICE, 2006). Essas enzimas são responsáveis por degradar grande parte das proteínas extracelulares e de membrana endocitadas (ex.: receptores), bem como proteínas citoplasmáticas e organelas (SANDRI, 2011). O acesso do substrato às enzimas lisossomais depende de diferentes processos intracelulares, sendo a macroautofagia o mais importante no músculo esquelético. Este processo inicia-se com a formação de uma vesícula limitada por membrana contendo pequenas proteínas como a LC3 (do inglês, microtubule-associated protein light chain 3), GABARAP (do inglês, $\gamma$-aminobutyric acid receptor-associated protein), entres outras, que são importantes para a formação do autofagossomo que, por sua vez, funde-se com o lisossomo e permite que o substrato seja então degradado (SANDRI, 2011). Há evidências de que os lisossomos participem do processo de remodelamento da placa motora. Por exemplo, a inibição do sistema lisossomal pela adição de leupeptina ou cloroquina reduz a taxa de degradação de AChR em culturas de células musculares (HYMAN; FROEHNER, 1983; LIBBY; BURSZTAJN; GOLDBERG, 1980). Em concordância com esses achados, os marcadores do sistema lisossomal/autofágico como Bif-1 (endofilina B1), LC3 e p62 foram colocalizados com AChR em vesículas endocíticas (KHAN et al., 2014).

O principal sistema proteolítico no músculo é o dependente de Ub-proteassoma, o qual é responsável pela degradação de aproximadamente $80 \%$ das proteínas miofibrilares 
(LECKER et al., 1999). Atualmente, sabe-se que o processo de ubiquitinação das proteínas é finamente regulado e depende da ação de três famílias de enzimas: a E1 ou enzima ativadora da Ub, a E2 ou enzima carreadora e a enzima E3 ou Ub-ligase (JAGOE; GOLDBERG, 2001). Esta última enzima é a limitante desse processo uma vez que ela tem a capacidade de reconhecer, especificamente, os substratos proteicos a serem degradados e de ligá-los à Ub formando complexos poliubiquitinados (GLICKMAN; CIECHANOVER, 2002) que serão reconhecidos e degradados pelo proteassoma. Entre os diferentes tipos de Ub-ligases conhecidas, as mais estudadas são a MuRF1 (do inglês, Muscle RING Finger 1) e a atrogina-1 [também conhecida como MAFbx (do inglês, Muscle Atrophy F-box)] (Bodine et al. 2001a; Gomes et al. 2001). Tem-se demonstrado que a expressão do RNAm da atrogina-1 e MuRF1 é aumentada em diferentes modelos experimentais de atrofia muscular (Bodine et al. 2001a). Por outro lado, músculos de animais nocautes para estas proteínas apresentam menor velocidade de degradação proteica muscular após a secção do nervo ciático (Bodine et al. 2001a). Além disso, foi observada uma grande quantidade e diversidade de ubiquitinas na JNM de músculos humanos (SERDAROGLU; ASKANAS; ENGEL, 1992). A adição de inibidores do proteassoma aumentou o conteúdo e montagem de AChR em cultura de miotúbulos (CHRISTIANSON; GREEN, 2004). Rudolf et al. (2013) também demonstraram que MuRF1 co-precipita com AChR e a estabilidade deste receptor em resposta à desnervação motora é aumentada em camundongos nocautes para esta Ub-ligase, indicando a participação do sistema Ub-proteassoma na manutenção da placa motora.

Pode-se então concluir que, a ativação patológica dos diferentes sistemas proteolíticos está associada à indução da atrofia muscular e desestruturação das JNM. Desta forma, o conhecimento dos mecanismos fisiológicos que atenuam esta resposta pode fornecer estratégias terapêuticas para o tratamento de diversas patologias relacionadas à perda de proteínas musculares e à instabilidade dos AChR. 


\subsection{Papel anabólico da inervação adrenérgica na manutenção da massa muscular}

Um grande número de evidências demonstra que o sistema nervoso simpático (SNS) é capaz de induzir efeitos anabólicos em músculos esqueléticos de várias espécies animais, por meio da ativação de receptores $\beta_{2}$-adrenérgicos, os quais estão presentes em alta densidade nestes tecidos (KIM; SAINZ, 1992; MARTIN; MURPHREE; SAFFITZ, 1989). Nesse sentido, nosso laboratório vem se dedicando a desvendar o papel fisiológico do SNS no controle do metabolismo de proteínas em músculos esqueléticos de roedores, em condições basais e atróficas.

Navegantes et al. (1999) relataram que a simpatectomia química induzida por guanetidina, um inibidor pré-sináptico das terminações simpáticas, foi capaz de aumentar a proteólise total em músculos soleus de ratos, sendo este efeito correlacionado com redução de 90\% do conteúdo de noradrenalina tecidual e aumento da atividade proteolítica da via dependente de $\mathrm{Ca}^{2+}$. Resultados similares foram observados em músculos soleus e extensor digital longo (EDL) de ratos submetidos à adrenodemedulação, um modelo de simpatectomia cirúrgica que consiste na remoção da porção medular da adrenal (NAVEGANTES et al., 2001). Neste mesmo estudo, os autores observaram diminuição da atividade proteolítica em músculos de ratos normais incubados na presença de adrenalina, noradrenalina ou clembuterol, um agonista seletivo de $\beta_{2}$-AR. A partir dessas evidências foi sugerido que as ações anti-proteolíticas das catecolaminas na musculatura esquelética são mediadas pela ativação de receptores $\beta_{2}$-AR(NAVEGANTES et al., 2001).

Estudos posteriores demonstraram redução na velocidade de síntese proteica em músculos soleus de ratos tratados com guanetidina ou submetidos à desnervação lombar (remoção cirúrgica dos gânglios simpáticos que inervam os músculos das patas inferiores) (NAVEGANTES et al., 2004). Desta forma, postulou-se que os processos de síntese de 
proteínas também eram estimulados por esta inervação noradrenérgica direta em músculos oxidativos de roedores. Se esta inervação autonômica termina ou não na JNM é ainda uma questão em aberto e que merece ser investigada. Estudos in vitro indicam que a adrenalina ou noradrenalina aumentam o número de AChR na membrana de células musculares (BLOSSER, 1983). Contudo, a importância funcional da inervação simpática e dos receptores adrenérgicos na manutenção da placa motora e, mais especificamente, na estabilização dos AChR ainda é completamente desconhecida.

\subsubsection{Mecanismos anti-proteolíticos dependentes da via do AMPc/PKA}

Grande parte do que se sabe acerca dos mecanismos anti-proteolíticos dependentes da via de sinalização do AMPc/PKA provém de estudos que utilizaram o tratamento com agonistas dos $\beta_{2 / 3}-\mathrm{AR}$ (LYNCH; RYALL, 2008; NAVEGANTES; MIGLIORINI; KETTELHUT, 2002). Embora ainda controverso, acredita-se que o efeito anti-catabólico mediado pela via do AMPc/PKA seja decorrente da inibição da via dependente de $\mathrm{Ca}^{2+}$ e da via Ub-proteassoma (LYNCH; RYALL, 2008; NAVEGANTES; BAVIERA; KETTELHUT, 2009). Foi demonstrado que a atividade proteolítica dependente de $\mathrm{Ca}^{2+}$ é reduzida em aproximadamente $40 \%$ em músculos soleus e EDL incubados na presença de clembuterol (NAVEGANTES et al., 2001). Outros estudos indicam que a PKA ativa a proteína de ligação do elemento de resposta do AMPc (CREB) e esta, ao se ligar na região promotora alvo do DNA, estimula a transcrição da calpastatina, que por sua vez inibe a atividade das calpaínas (NAVEGANTES; BAVIERA; KETTELHUT, 2009).

Além de suas ações sobre as calpaínas e calpastatina, os $\beta_{2}$-agonistas também estão associados com alterações no processo de ubiquitinação das proteínas. O tratamento crônico de ratos portadores de tumor com clembuterol diminuiu a expressão do RNAm da Ub 
(COSTELLI et al., 1995). Outros estudos têm indicado que os $\beta_{2}$-agonistas podem reduzir a atividade do proteassoma 26S (BUSQUETS et al., 2004; YIMLAMAI et al., 2005). Trabalhos de nosso laboratório demonstraram que a administração de clembuterol em camundongos aumentou os níveis de AMPc e suprimiu a expressão induzida pelo jejum do RNAm da atrogina-1 e da MuRF1 na musculatura esquelética (GONÇALVES et al., 2009). Efeitos semelhantes são observados quando músculos de animais normais são perfundidos com rolipram, um inibidor seletivo da fosfodiesterase (PDE) do AMPc do tipo IV, a isoforma predominante na musculatura de roedores (LIRA et al., 2011).

Embora grande parte das ações mediadas pela ativação simpática in vivo na musculatura esquelética sejam relacionadas à manutenção da massa muscular, nada se sabe acerca do papel das catecolaminas no controle de proteínas localizadas na membrana sarcoplasmática e, mais especificamente, naquelas envolvidas na manutenção da JNM. Uma explicação aparente para isso é a dificuldade metodológica de avaliar a estabilidade e estrutura da placa motora em condições in vivo. Nesse sentido, Strack et al. (2011), padronizaram uma nova abordagem que permite acompanhar a cinética da meia-vida do AChR in vivo após a aplicação de $\alpha$ bungarotoxina marcada com ${ }^{125}$ I no músculo tibial de camundongos. Este método possibilita a investigação in vivo da integridade da JNM, por meio da análise da curva de decaimento do pulso radioativo ao longo do tempo e a posterior quantificação da taxa de degradação dos receptores colinérgicos. Sendo assim, foram identificados três graus de estabilidade dos AChR que variam de acordo com a presença ou ausência de inervação: um conjunto de receptores com meia-vida longa de $\sim 13$ dias, um segundo com meia-vida intermediária de $\sim 8$ dias, e um terceiro com meia-vida curta de $\sim 1$ dia (STRACK et al., 2011). Em relação a outros métodos, este possui a grande vantagem de investigar o músculo do mesmo animal durante um período longo de experimentação. Além disso, a morfologia e estabilidade da placa motora podem também ser estimadas por meio da análise in vivo das sinapses 
colinérgicas as quais são obtidas por meio da microscopia confocal do músculo tibial de camundongos anestesiados (RÖDER et al., 2010; STRACK et al., 2011). Desta forma, com estas duas abordagens experimentais torna-se possível avaliar o papel do SNS nos processos que regulam o turnover proteico na JNM e se estes são similares aos que ocorrem no citosol da fibra muscular.

Tendo em vistas as evidências de que o pacientes portadores de síndromes miastênicas congênitas apresentaram melhora após a terapia com simpatomiméticos (ENGEL et al., 2010) e que o tratamento agudo com clembuterol (um $\beta_{2}$-agonista seletivo)previne a perda de massa muscular em ratos desnervados por um mecanismo que atenua a hiperatividade da proteólise proteassomal e lisossomal de forma dependente de AMPc/PKA (GONÇALVES et al., 2012), o presente estudo testará a hipótese de que a ativação farmacológica crônica dos $\beta_{2}$-AR possa estabilizar a placa motora e exercer efeitos anti-atróficos em músculos esqueléticos de camundongos desnervados. 
Objetivas 


\section{OBJeTIVOS}

O objetivo principal do presente estudo foi investigar o papel da estimulação adrenérgica e colinérgica na manutenção da placa motora e no metabolismo proteico em situações basais e atróficas.

Mais especificamente, os objetivos foram:

$\checkmark$ Avaliar o efeito temporal do tratamento crônico com clembuterol (CB), um $\beta_{2}-$ agonista seletivo, na massa muscular de animais atrofiados (pela desnervação motora).

$\checkmark$ Correlacionar o efeito do tratamento com CB com a expressão de genes e proteínas relacionados à atrofia e autofagia e a via de sinalização do AMPc/PKA em músculos desnervados.

$\checkmark$ Identificar a presença da inervação noradrenérgica direta, da sua origem anatômica e da via de sinalização ativada na JNM.

$\checkmark$ Avaliar o efeito do tratamento crônico com CB na taxa de degradação de AChR e na integridade da placa motora em músculos de animais desnervados e de animais miastênicos e correlacionar com aqueles obtidos na massa muscular.

$\checkmark$ Identificar o efeito in vitro de agonistas colinérgicos nas atividades das diferentes vias proteolíticas e na velocidade de síntese proteica em músculos de animais normais.

$\checkmark$ Avaliar a possível interação entre os agonistas colinérgicos e adrenérgicos no controle da proteólise total em músculos isolados. 
15

Material e Métados 


\section{MAterial e Métodos}

\subsection{Animais, cirurgias e tratamentos.}

Foram utilizados camundongos machos da linhagem C57B16J, com massa corporal entre 25-30g, provenientes do Serviço de Biotério da Prefeitura do Campus Administrativo da USP de Ribeirão Preto (PCARP) na maioria dos experimentos e do Biotério do Karlsruher Institut für Technologie, Alemanha. Outro grupo de animais transgênicos, que apresentam miastenia congênita, devido a uma mutação na subunidade $\varepsilon$ do $\mathrm{AChR}$ que confere baixa velocidade de abertura deste canal iônico, aqui referido como slow-channel AChR-عL269F, foi também usado. Para os experimentos in vitro para estudo da proteólise e síntese proteica foram utilizados ratos machos Wistar ( 60 a 90g). Todos os animais receberam dieta balanceada para roedores e água ad libitum em ambiente com ciclos luz-escuro de 12 horas e temperatura de $25^{\circ} \mathrm{C}$. Os experimentos foram realizados pela manhã e os animais sacrificados por deslocamento cervical. Todo protocolo experimental foi aprovado pela Comissão de Ética em Experimentação Animal (CETEA) da Universidade de São Paulo (Processo 044/2012) e pelas autoridades alemãs de pesquisa experimental em animais (2010/63/EU).

Uma vez que a desnervação motora (DEN) é capaz de induzir a perda de massa muscular e, concomitantemente, a desestabilização dos AChR (GONÇALVES et al., 2012; STRACK et al., 2011), este modelo de atrofia foi usado para avaliar o efeito da estimulação crônica dos $\beta_{2}$-AR na manutenção da massa muscular e dos AChR. Assim, sob anestesia (10 mg.kg ${ }^{-1}$ de ketamina e 85 mg. $\mathrm{kg}^{-1}$ de xilazina), os camundongos foram submetidos à DEN unilateral (secção de 2 mm de nervo ciático) e acompanhados por 3, 7, 14 dias ou 25 dias. No mesmo dia da cirurgia, os animais foram tratados com clembuterol (CB), um agonista $\beta_{2^{-}}$ AR seletivo (3mg. $\mathrm{Kg}^{-1} . \mathrm{dia}^{-1}$, s.c.; Sigma-Aldrich, St. Louis, MO) ou salina. Esta dose foi escolhida pela capacidade de atenuar a perda de massa muscular induzida pela DEN em um tratamento de curta duração (GONÇALVES et al., 2012). Deste modo, no mesmo animal, os 
músculos da pata contralateral foram controles da pata desnervada. Os animais foram submetidos à eutanásia por deslocamento cervical e músculos tibiais anteriores (TA) foram utilizados para as análises por western blot, RT-PCR e conteúdo de AMPc e músculos gastrocnêmicos foram utilizados para as medidas de catecolaminas.

Para cirurgia de adrenodemulação (ADMX), isto é, remoção da porção medular da adrenal, camundongos anestesiados tiveram o dorso tricotomizado e duas incisões, paralelas à coluna vertebral imediatamente abaixo da última costela, foram feitas. As glândulas adrenais depois de visualizadas foram pinçadas pela gordura peri-renal e cortadas na extremidade superior (córtex) com o auxílio de uma pequena lâmina. Em seguida, a glândula foi suavemente pressionada para retirada somente da medula adrenal. Após a excisão da porção medular, a glândula foi devolvida à cavidade peritoneal, o animal suturado com fio de nylon 4 e o campo cirúrgico limpo com álcool iodado para evitar infecções secundárias. O grupo controle sofreu o mesmo procedimento, exceto a remoção das glândulas adrenais.

Para realização dos experimentos descritos na seção 3.7. (Material e Métodos), um grupo de animais foi simpatectomizado quimicamente através do tratamento com 6-OHDOPA, uma neurotoxina que inibe irreversivelmente a liberação de noradrenalina pelos terminais neurais (SACHS; JONSSON, 1972), na dose de $100 \mathrm{mg}^{\mathrm{k}} \mathrm{kg}^{-1}$ (0,3\% de ácido ascórbico) por via intramuscular em dias alternados durante duas semanas antes da realização das imagens (THOENEN; TRANZER, 1968). Um segundo grupo de animais foi tratado com ICI 118-551, um antagonista seletivo de receptores $\beta 2-\mathrm{AR}$, na dose de $5 \mathrm{mg} \cdot \mathrm{kg}^{-1}$ (diluído em tampão salina-fosfato) por dois dias (um dia e $1 \mathrm{~h}$ antes da realização da microscopia in vivo) (MURPHY et al., 1997). 


\subsection{Análise de proteínas através de Western blot.}

Os músculos foram homogeneizados em tampão Tris- $\mathrm{HCl}\left(50 \mathrm{mM} ; \mathrm{pH} 7,4 ; 4^{\circ} \mathrm{C}\right)$ contendo $150 \mathrm{mM}$ de $\mathrm{NaCl}, 1 \mathrm{mM}$ de EDTA, $1 \%$ de Triton $\mathrm{X}-100,1 \%$ de deoxicolato de sódio, $1 \%$ de SDS, inibidores de proteases $(5 \mu \mathrm{g} / \mathrm{ml}$ de aprotinina, $1 \mu \mathrm{g} / \mathrm{mL}$ de leupeptina, $1 \mathrm{mM}$ de PMSF) e inibidores de fosfatases (10mM de pirofosfato de sódio, 100mM de fluoreto de sódio, $10 \mathrm{mM}$ de ortovanadato de sódio). O homogenado foi centrifugado a $14000 \mathrm{~g} \mathrm{e} 4^{\circ} \mathrm{C}$, o sobrenadante separado para a eletroforese e determinação do conteúdo de proteína. Volumes iguais de sobrenadante e tampão da amostra (20\% de glicerol, 125mM de Tris-HCl, 4\% SDS, 100mM de ditiotreitol, 0,02\% de azul de bromofenol, $\mathrm{pH}$ 6,8) foram misturados, fervidos e submetidos à eletroforese em gel de SDS-PAGE de 8 a 16\%. A eletrotransferência das proteínas do gel para membrana foi realizada a $20 \mathrm{~V}$ em aparato de transferência semiseco por 30min. Após o bloqueio, as membranas foram incubadas com anticorpos primários específicos e posteriormente com anticorpo secundário conjugado com HRP. Posteriormente, as membranas foram lavadas para remoção do excesso de anticorpo secundário não ligado e então utilizadas para revelação no aparelho ChemiDoc BioRad® por aproximadamente 40 minutos após a adição de partes iguais dos reagentes do kit de quimioluminescência amplificada (ECL, Amersham $\left.{ }^{\circledR}\right)$. As bandas reveladas foram quantificadas por densitometria utilizando o software ImageLab BioRad®. Após a quantificação densitométrica das proteínas, o valor obtido na análise foi dividido pela densitometria da $\beta$-actina, proteína constitutiva utilizada como referência em todos os experimentos. Os resultados obtidos foram comparados com os respectivos grupos controles, os quais foram considerados como $100 \%$.

Anticorpos policlonais anti-substratos fosforilados pela PKA (diluição: 1:1.000) e antiLC3 I e II (1:1000) foram adquiridos da Cell Signaling Technology (Danvers, MA); anti- 
atrogina-1 (1:500), anti-MuRF1 (1:500) e anti- $\beta$-actina (1:1000) foram adquiridos da Santa Cruz Biotechnology (Santa Cruz, CA).

\subsection{Reação em cadeia da polimerase em tempo real (RT-PCR).}

A extração de RNA total das amostras, bem como a síntese de DNA complementar (cDNA) e a técnica de PCR em tempo real foram realizadas por meio de métodos específicos como descrito por Gonçalves et al. (2009; 2012). O gene de referência utilizado foi o Rn18S. A sequência dos primers foi obtida a partir da sequência dos genes depositadas no GenBank para atrogina-1 (forward 5'-GCAGAGAGTCGGCAAGTC-3' e reverse 5'CAGGTCGGTGATCGTGAG-3'), MuRF1 (forward 5'-TGTGCAAGGAACACGAAG-3' e reverse 5'-TGAGAGATGATCGTCTGC-3'), LC3 (forward 5'CGTCCTGGACAAGACCAAGT-3' e reverse 5'-ATTGCTGTCCCGAATGTCTC-3'), catepsina L (forward 5'-GTG GAC TGT TCT CAC GCT CAAG-3' e reverse 5'-TCC GTC CTT CGC TTC ATA GG-3'), $\alpha 1$-AChR (forward 5'-TGCGGAAGGTTTTTATCGAC-3' e reverse 5'-CGGAGAGTGAAAGCCCATAG-3'), e Rn18S (forward 5'GAAACGGCTACCACATCCAAG-3' e reverse 5'-CCTCCAATGGATCCTCGTTAA -3').

\subsection{Determinação do conteúdo de AMPc.}

No dia do experimento, os músculos TA foram imediatamente removidos após o deslocamento cervical, embalados em papel alumínio e congelados a $-80^{\circ} \mathrm{C}$. Após processamento, o conteúdo de AMPc foi mensurado através do método imunoenzimático comercial da Amersham Biosciences (cAMP Biotrak Enzyme immunoassay EIA system RPN225). Os resultados foram expressos em fmol de AMPc/mg de músculo e plotados como $\%$ do controle (músculos inervados de animais tratados com salina). 


\subsection{Imunohistoquímica}

Músculos TA foram lavados duas vezes com PBS e fixados em uma solução de 4\% de paraformaldeído a $4^{\circ} \mathrm{C}$ durante $24 \mathrm{~h}$. Posteriormente, foram preparadas seções transversais de $50 \mu \mathrm{m}$ de espessura. Para identificar AChR foi utilizada $\alpha$-bungarotoxina (BGT) marcada com AlexaFluor 488 (BGT-AF488; Invitrogen, 1:200); para os receptores $\beta_{2}$-AR, o anticorpo anti$\beta_{2}$-AR (Santa Cruz Biotechnology, Santa Cruz, CA; 1:200) e para marcar neurônios catecolaminérgicos, anticorpo anti-tirosina hidroxilase (TyrH, Millipore, 1:250), uma enzima específica da síntese de catecolaminas. Secções transversais foram também obtidas do nervo ciático $(100 \mu \mathrm{m}$ de espessura). Neste wheat germ agglutin (WGA, Invitrogen, 1:5000) foi usado para marcação de membranas plasmáticas, uma vez que esta toxina se liga a carboidratos presentes nas membranas e anticorpo anti-dopamina- $\beta$-hidroxilase (1:200; Santa Cruz Biotechnology, Santa Cruz, CA) para marcar neurônios catecolaminérgicos. Todas as colorações foram realizadas utilizando protocolos padrões como descrito anteriormente (CHOI et al., 2012; RÖDER et al., 2010).

\subsection{Cromatografia Liquida de Alta Eficiência (CLAE) e Radioimunoensaio (RIA)}

Músculos gastrocnêmicos foram transferidos para tubos de plásticos contendo $50 \mathrm{mg}$ de alumina ativada previamente em estufa a $100^{\circ} \mathrm{C}$ (30 minutos), $50 \mathrm{mg}$ de metabissulfito de sódio e tampão Tris-HCl 2M (pH 8,9), homogeneizados e então centrifugados por 20minutos a 3000rpm. Diidroxibenzilamina foi utilizado como padrão interno. Após a aspiração do sobrenadante, a alumina foi lavada repetidamente. A noradrenalina foi extraída da alumina pela adição de solução eluidora contendo ácido perclórico $0,1 \mathrm{~N}$ por 10 minutos sob agitação mecânica (KRSTULOVIĆ, 1982). Após a extração das catecolaminas, alíquotas de $250 \mu 1$ foram analisadas através de cromatografia líquida de alta eficiência (CLAE) em cromatógrafo modelo LC-74, equipado com uma coluna de fase reversa Spherisorb ODS II (Sigma- 
Aldrich), acoplado a um detector eletroquímico modelo L-ESD-6A e a um polígrafo modelo C-R5A, todos de marca Shimadzu (Garófalo et al. 1996). Os resultados foram expressos em ng de noradrenalina/g tecido.

Nos animais que foram submetidos à cirurgia de ADMX, o plasma foi coletado para quantificação dos níveis de corticosterona através da técnica de RIA utilizando Kits comercias GE Healthcare Life Sciences. Os resultados foram expressos em $\mu \mathrm{g} / \mathrm{dl}$.

\subsection{Transfecção in vivo por eletroporação e fluorescência pela transferência de energia de} ressonância (FRET)

O sensor de AMPc, rapsina-EPAC associado ao FRET, foi clonado em pcDNA3 (NIKOLAEV et al., 2004) e o sensor $\beta_{2}$-AR-sPep FRET (plasmídeo \# 47438) foi obtido da Addgene (Cambridge, MA, EUA). Após anestesia, o músculo TA foi isolado através de uma pequena incisão na pele e o DNA plasmidial (para o receptor $\beta_{2}$-AR acoplado aos sensores fluorescentes mCitrina e mCerulean ou para rapsina-EPAC acoplado aos sensores fluorescentes YFP e CFP), foi injetado ao longo do comprimento do músculo com uma seringa de insulina. Foi utilizado o eletroporador CUY21 (Nepagene, Japão) e os pulsos aplicados por meio de dois eletrodos, modelo pinça, dispostos em paralelo às fibras musculares na região do ventre. Após 8-10 dias, os animais foram levados para visualização dos músculos em microscópio confocal e avaliados por meio de um conjunto específico de filtros para emissão dos sensores fluorescentes (mCitrina, mCerulean, YFP e CFP) e submetidos à estimulação elétrica do nervo ciático. Na figura 1 está representado o modelo esquemático da técnica de FRET para os músculos transfectados com o plasmídeo contendo o gene para o $\beta_{2}$-AR-sPep (MALIK et al., 2013). Em condições normais, o receptor acoplado a proteína G (GPCR), neste caso o receptor $\beta_{2}$-AR está inativo e mantem os dois sensores fluorescentes mCitrina (mCit, FRET aceptor) e mCerulean (mCer, FRET doador) afastados. 
Quando há ativação deste receptor há uma mudança conformacional que permite a aproximação dos dois sensores resultando no FRET que ocorre devido à diminuição da fluorescência emitida pelo mCer e aumento da emitida pelo mCit.

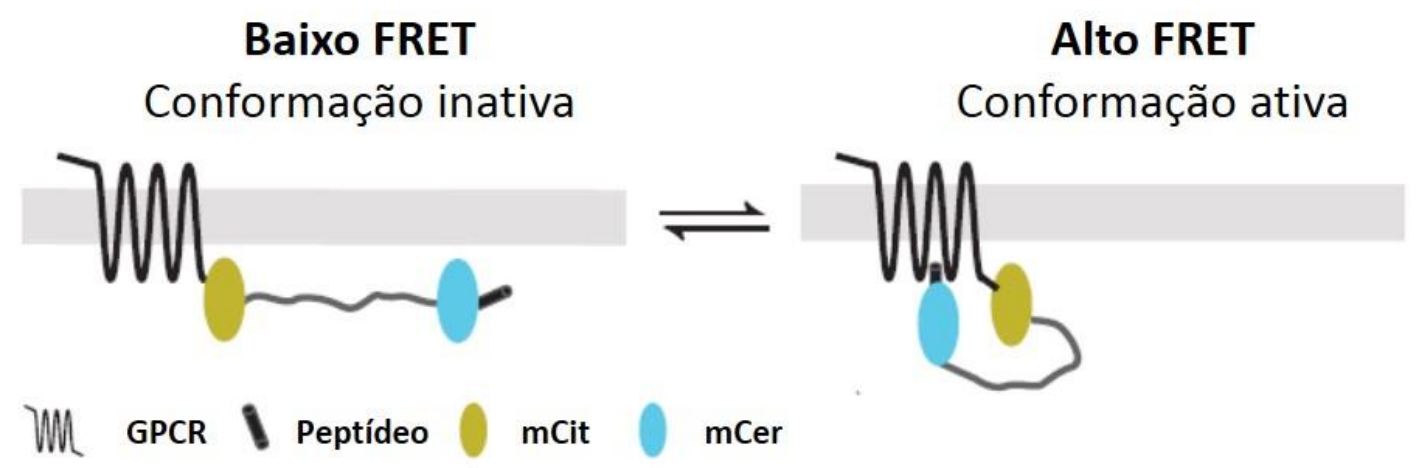

Figura 1. Modelo esquemático para realização de fluorescência pela transferência de energia de ressonância (FRET) em músculos transfectados com o plasmídeo contendo o gene para o $\beta_{2}$-AR-s-pep.

Para avaliação da produção de AMPc, foi utilizado o plasmídeo contendo o gene que codifica rapsina-EPAC. Este plasmídeo contém sequências que codificam os sensores YFP (do inglês, yellow fluorescent protein; FRET aceptor), CFP (do inglês, cyan fluorescent protein, FRET doador), a proteína rapsina que dá especificidade a JNM uma vez que ela está associada aos AChR (CHOI et al., 2012) e por fim, a EPAC (do inglês, Exchange Protein Directly Activated by cAMP) que se liga ao AMPc (CHOI et al., 2012; MALIK et al., 2013). Desta forma, com este sensor é possível determinar a produção do AMPc especificamente na JNM. A Fig. 2 apresenta um modelo esquemático para o funcionamento do sensor rapsinaEPAC. Em condições normais a concentração de AMPc está em níveis basais e os sensores CFP e YFP estão próximos, o que permite o FRET. Após a estimulação ocorre aumento dos níveis do AMPc intracelular. Este AMPc liga-se à EPAC promovendo uma mudança 
conformacional que afastará os sensores CFP e YFP resultando em diminuição da fluorescência emitida pelo YFP e aumento da emitida pelo CFP. Essa diferença entre as fluorescências emitidas pelos sensores CFP e YFP permite estimar a formação do AMPc (Choi et al. 2012).

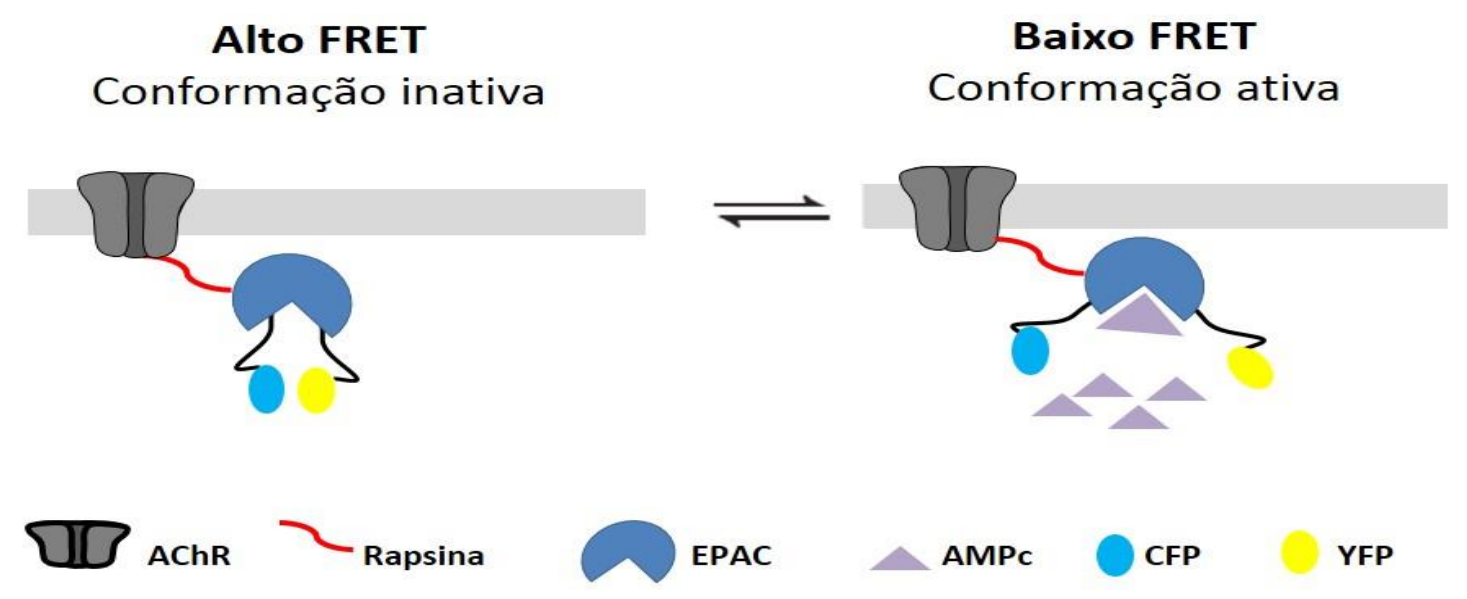

Figura 2. Modelo esquemático para realização de fluorescência pela transferência de energia de ressonância (FRET) em músculos transfectados com o plasmídeo contendo o gene para o CFP-rapsina_EPAC-YFP.

A estimulação do nervo ciático foi realizada utilizando o aparelho A.M.P.I. master-8 CP e microeletrodos obtidos da Harvard Apparatus (Holliston, MA, EUA). A voltagem limite para induzir a contração muscular visível foi de > 0.2V (ALLEN et al., 2011). A estimulação abaixo deste valor não induziu a contração muscular e foi denominada como "estimulação fraca". Cada estimulo elétrico (fraco ou acima do limiar) consistiu de 10 pulsos tetânicos como descrito anteriormente (ALLEN et al., 2011). 
3.8. Determinação da meia-vida do AChR através da ligação com ${ }^{125}$ I- $\alpha$-bungarotoxina $\left({ }^{125} I\right.$ $-B G T)$.

Para avaliação da meia-vida do AChR foi utilizada a técnica descrita por Strack et al. (2011). Brevemente, cinco dias após a desnervação motora unilateral, $10 \mu \mathrm{l}$ da solução contendo ${ }^{125} \mathrm{I}$-BGT $\left(0,46 \mathrm{MBq}\right.$ [2,5 mCi] de $\left.{ }^{125} \mathrm{I}\right)$ foram injetados nos músculos TA dos dois membros posteriores dos camundongos. O intervalo de cinco dias entre a cirurgia e a injeção da BGT foi usado devido a capacidade da desnervação aumentar a densidade de AChR nesta faixa temporal, sendo assim a população de receptores de meia-vida curta também poderia ser estimada, por outro lado eles não seriam detectados caso a BGT fosse injetada no dia da cirurgia (RUDOLF et al., 2013; STRACK et al., 2011). Estes mesmo princípio foi usado nos experimentos descritos na seção 3.9. de Material e Métodos.

O músculo da pata contralateral, inervado, serviu de controle para o músculo desnervado, no mesmo animal, durante todo o período experimental. Considerando que a $\alpha$ BGT liga-se de forma irreversível ao receptor colinérgico, o curso temporal descrito pela taxa de decaimento da radioatividade emitida pela ${ }^{125} \mathrm{I}-\gamma$-BGT, prediz a taxa de degradação dos AChR presentes na JNM no momento da injeção deste ligante. Para isso, a radioatividade emitida por cada pata foi mensurada através de Germanium semiconductor counter (modelo GX3018, Canberra, Bélgica). Um resumo deste protocolo é apresentado na Fig. 3. Na parte superior é demonstrada uma representação do procedimento para mensuração da radioatividade emitida pelo músculo injetado com $\alpha$-bungarotoxina-I ${ }^{125}$. 


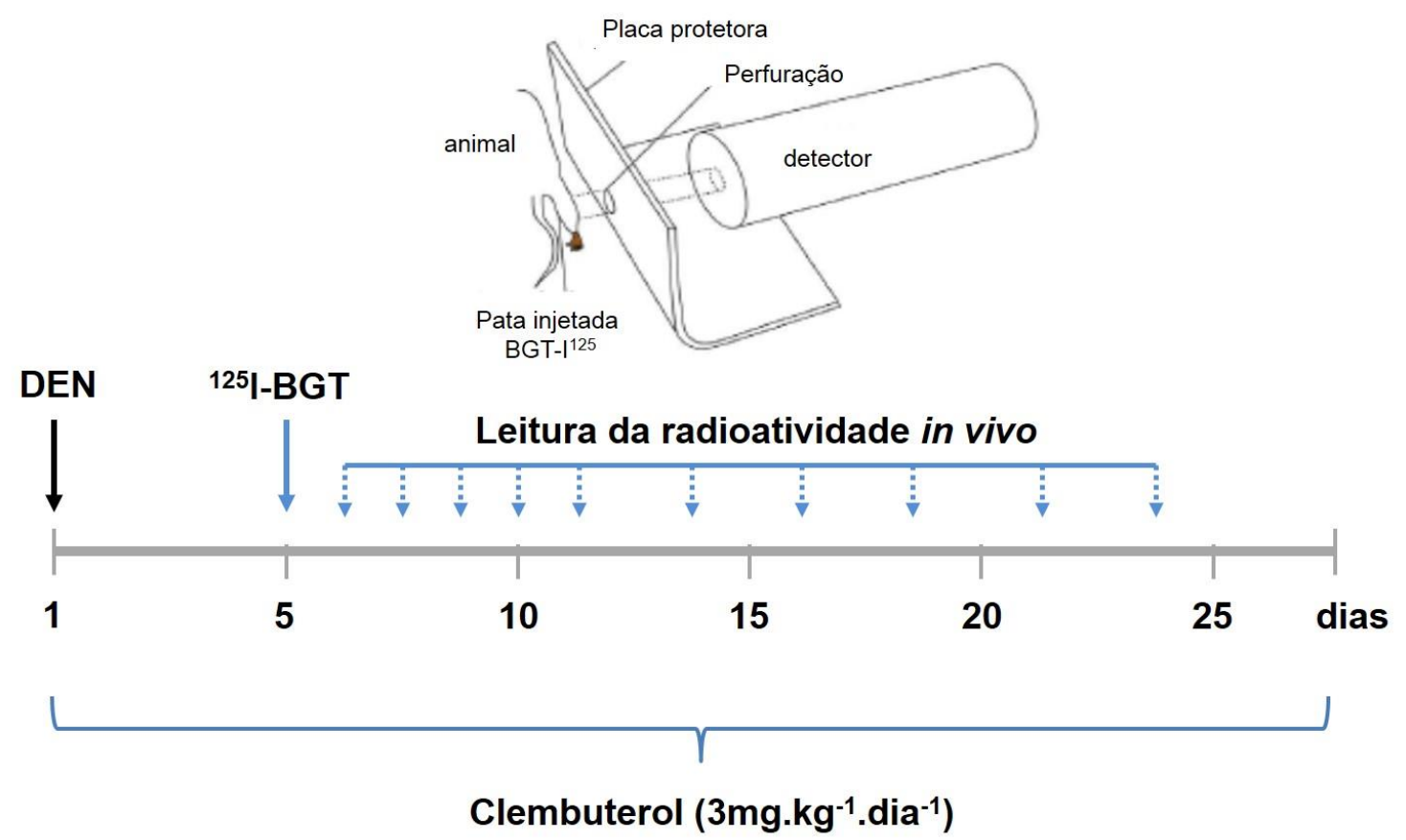

Figura 3. Esquema representativo da avaliação do efeito do tratamento diário com clembuterol na taxa de degradação do receptor colinérgico nicotínico (AChR) em músculos esqueléticos de camundongos anestesiados.

\subsection{Visualização in vivo das sinapses da JNM}

A estabilidade do AChR foi mensurada como descrito anteriormente (CHOI et al., 2012; RÖDER et al., 2009, 2010). Para isso, BGT- AlexaFluor 647 (1:200, Life Technologies, \# B35450) e BGT - AlexaFluor 555 (1:200, Life Technologies, \# B35451) foram injetadas sequencialmente em uma distância temporal de 10 dias, para marcar o "pool de receptores antigos e os novos", respectivamente. Após a segunda injeção, os músculos foram examinados in vivo com o uso de um microscópio confocal Leica SP2 equipado com uma objetiva de imersão em 63x/1.2NA. As análises automatizadas do conteúdo de AChR foram realizadas como descrito anteriormente (RÖDER et al., 2010). Resumidamente, imagens 3D de 512 x 512 pixels de resolução foram segmentadas, assim os valores de intensidade de sinal em pixels para AlexaFluor-555 e AlexaFluor-647 foram extraídos. Em 
seguida, a fração de pixels por JNM, tendo BGT-AF555 intensidade de sinal mais elevada do que a de BGT-AF647 foi calculada. A fig. 4 representa um resumo deste protocolo experimental. Na parte superior é demonstrada uma representação do procedimento de microscopia confocal para mensuração da fluorescência emitida pela $\alpha$-bungarotoxina (BGT)AF647 e-AF555.

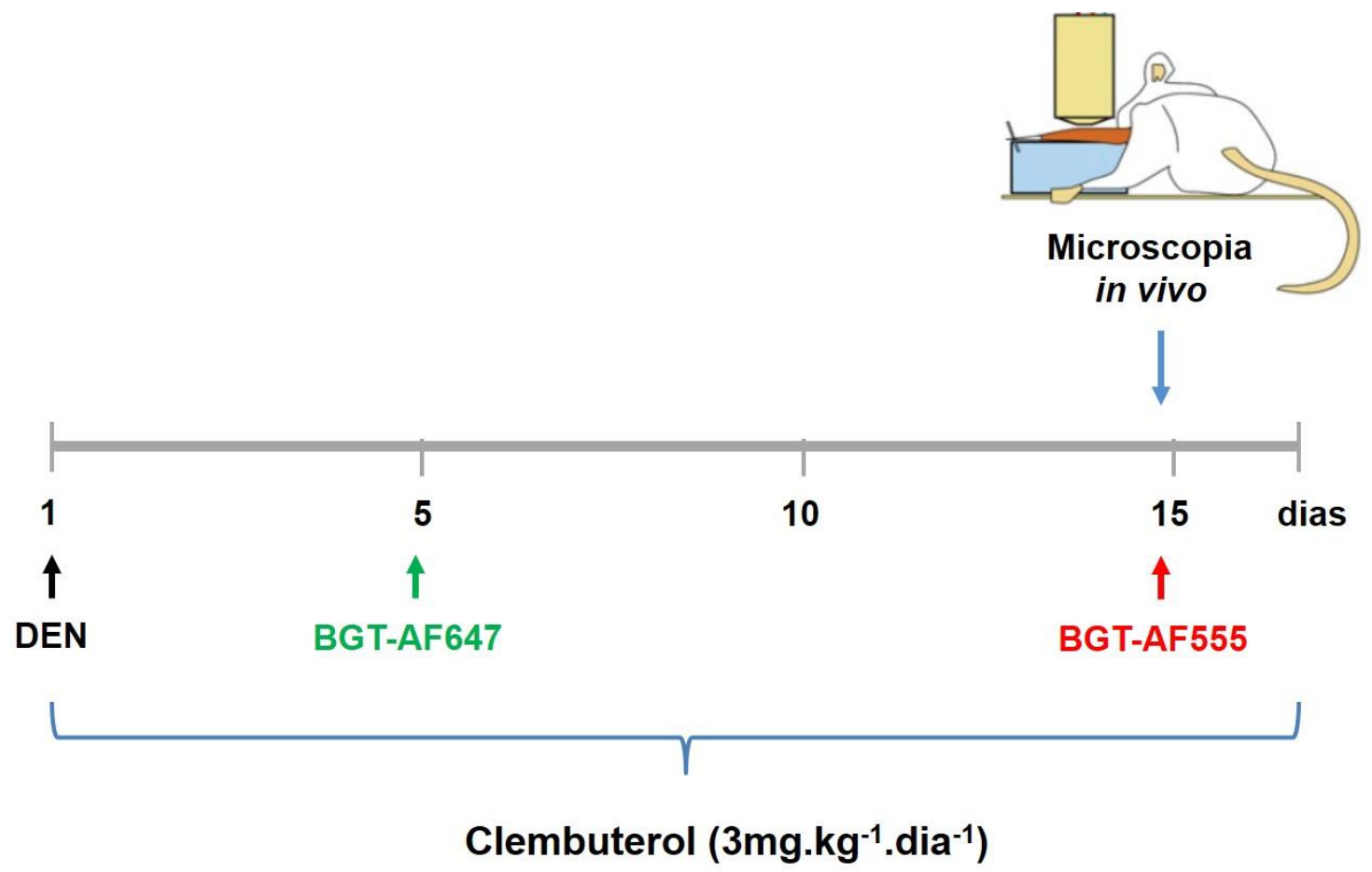

Figura 4. Esquema representativo da avaliação do efeito do tratamento diário com clembuterol na estabilidade do receptor colinérgico nicotínico (AChR) em músculos esqueléticos de camundongos anestesiados.

\subsection{Procedimento para análise das vesículas positivas BGT}

As imagens obtidas do experimento descrito no item 3.9. de Material e Métodos foram utilizadas para quantificação das vesículas endocíticas. Assim, as sinapses foram analisadas com software FiJi-ImageJ, para cada filtro (AF555 ou AF647), e em seguida, o número de pontos ao redor das sinapses foram contados, assumindo que os mesmos seriam os carreadores/vesículas do receptor que foi previamente marcado com BGT. 


\subsection{Procedimento experimental para o estudo da proteólise em músculos esqueléticos de} ratos

Para avaliar o papel da estimulação colinérgica na proteólise total de ratos normais, os músculos soleus e EDL foram incubados na presença de carbacol (um agonista colinérgico, $\left.10^{-9}-10^{-3} \mathrm{M}\right)$, D-tubocurarina (um antagonista nicotínico, $\left.10^{-4} \mathrm{M}\right)$ e $\mathrm{CB}\left(10^{-4} \mathrm{M}\right)$ por três horas. Todos os reagentes foram obtidos da Sigma-Aldrich. Nos experimentos utilizando Dtubocurarina, os músculos foram incubados com essa droga 1 hora antes da adição do carbacol.

A preparação de músculos isolados de pequenos roedores foi utilizada para avaliar o metabolismo de proteínas in vitro. Imediatamente após a eutanásia dos animais por deslocamento cervical, os músculos soleus e EDL de ratos foram rapidamente extraídos e fixados por meio dos seus tendões em suportes de alumínio (soleus) ou de acrílico (EDL), mantendo-os no comprimento de repouso, incubados em tampão Krebs Ringer bicarbonato $\left(0,120 \mathrm{M}\right.$ de $\mathrm{NaCl} ; 0,015 \mathrm{M}$ de $\mathrm{NaHCO}_{3} ; 4,828 \mathrm{mM}$ de $\mathrm{KCl} ; 1,2 \mathrm{mM}$ de $\mathrm{MgSO}_{4} ; 1,212 \mathrm{mM}$ de $\mathrm{KH}_{2} \mathrm{PO}_{4} ; 2,4 \mathrm{mM}$ de $\left.\mathrm{CaCl}_{2}-\mathrm{pH} 7,4\right)$ e aerados com carbogênio $\left(95 \%\right.$ de $\mathrm{O}_{2}$ e $5 \%$ de $\mathrm{CO}_{2}$ ). Estas condições permitem que todas as fibras musculares estejam na mesma condição nutricional, evitando-se o comprometimento das fibras musculares centrais. Esta preparação garante a manutenção dos níveis intracelulares de ATP, fosfocreatina e glicogênio, reproduzindo in vitro o estado energético in vivo do músculo, tornando este ensaio viável por até 9 horas de incubação para o estudo do metabolismo proteico (KETTELHUT; WING; GOLDBERG, 1988). Os músculos foram incubados por 1 hora em banho-maria a $37^{\circ} \mathrm{C}$ (préincubação), sob agitação constante, a fim de estabelecer o equilíbrio da velocidade de liberação da tirosina para o meio de incubação. Após a pré-incubação, os meios foram renovados e incubados com o mesmo meio por 2 horas. No final do período de incubação, 1 
$\mathrm{ml}$ do meio foi coletado e adicionado a $0,25 \mathrm{ml}$ de ácido perclórico $(1,5 \mathrm{~N})$ para a determinação da tirosina liberada.

A degradação de proteínas musculares in vitro foi estimada pela liberação de tirosina no meio de incubação na presença de cicloheximida, um inibidor de síntese proteica. Este aminoácido é usado como referência para avaliação do metabolismo de proteínas, uma vez que não é metabolizado e nem sintetizado de novo pela célula muscular, além de ser facilmente dosado e com grande sensibilidade pelo método fluorimétrico (WAALKES; UDENFRIEND, 1957). De tal modo que a concentração de tirosina presente no meio de incubação reflete diretamente a velocidade de degradação de proteínas totais pela célula muscular esquelética (JEFFERSON; LI; RANNELS, 1977).

\subsection{Atividade dos Sistemas Proteolíticos}

A preparação in vitro com músculos isolados de pequenos roedores permite avaliar a participação individual dos principais sistemas proteolíticos no músculo esquelético. Para isto, inibidores específicos dos sistemas lisossomal (metilamina e os aminoácidos de cadeia ramificada leucina, isoleucina e valina), dependente de $\mathrm{Ca}^{2+}$ (leupeptina e o E64) e Ubproteassoma (MG132, inibidor específico da atividade do proteassoma 26S) foram usados no meio de incubação de acordo com o objetivo específico de cada experimento. A diferença da liberação de tirosina pelo músculo incubado na presença e na ausência destes inibidores reflete a atividade proteolítica do sistema de interesse.

\subsubsection{Sistema Lisossomal}

O sistema lisossomal foi inibido com a incubação dos músculos soleus na presença da metilamina e aminoácidos de cadeia ramificada (BCAA). A metilamina (base fraca) se acumula nos lisossomos, elevando o $\mathrm{pH}$ desta organela a valores próximos da neutralidade 
( $\mathrm{pH}$ 5,9-6,2), inibindo a atividade das proteases lisossomais, as catepsinas e as hidrolase ácidas (KETTELHUT; WING; GOLDBERG, 1988; MORTIMORE, 1982). Os BCAA bloqueiam a formação dos vacúolos autofágicos e reduzem a instabilidade lisossomal. Em conjunto, esses inibidores bloqueiam a degradação proteica lisossomal, sem modificar o conteúdo total das enzimas lisossomais (JEFFERSON; LI; RANNELS, 1977; KETTELHUT; WING; GOLDBERG, 1988; RANNELS; KAO; MORGAN, 1975). A tabela abaixo ilustra o protocolo experimental utilizado para determinar a proteólise total, a qual representa a atividade de todos os sistemas proteolíticos e a proteólise lisossomal.

A liberação de tirosina dos músculos da pata direita, incubados na ausência dos inibidores farmacológicos, corresponde à proteólise total. Logo, a diferença entre a liberação de tirosina das patas direita e esquerda reflete a participação do sistema lisossomal na proteólise muscular (tabela 1).

Tabela 1. Protocolo utilizado para quantificação da proteólise total e lisossomal.

\section{Músculos soleus retirados das 2 patas e fixados pelos tendões a suportes apropriados para incubação in vitro}

\section{Componentes do meio de incubação $\quad$ Músculos}

\begin{tabular}{lll}
\hline & Pata direita & Pata esquerda \\
Tampão Krebs Ringer Bicarbonato $(\mathrm{pH} 7,4)$ & + & + \\
Glicose $(5 \mathrm{mM})$ & + & + \\
Cicloheximida $(0,5 \mathrm{mM})$ & + & + \\
Metilamina $(10 \mathrm{mM})$ e *BCAA & - & + \\
\hline *Leucina $(0,5 \mathrm{mM})$; Isoleucina $(0,85 \mathrm{mM})$ e Valina $(1,0 \mathrm{mM})$. &
\end{tabular}




\subsubsection{Sistema Dependente de $\mathrm{Ca}^{2+}$}

Para avaliação deste sistema proteolítico, todos os dois músculos soleus de cada pata foram fixados a suportes, sendo um deles incubado em meio Krebs sem $\mathrm{Ca}^{2+}$ e com a adição de inibidores das proteases do grupo tiol como o E64 e a leupeptina. O objetivo desse procedimento é inibir as calpaínas in vitro. Assim, a diferença entre os valores de proteólise do músculo incubado em condições basais (pata direita) com o músculo apresentando o sistema enzimático das calpaínas inibido (pata esquerda) reflete a participação do sistema proteolítico dependente de $\mathrm{Ca}^{2+}$. A diferença na liberação de tirosina dos músculos incubados com ou sem os inibidores representa a atividade do sistema dependente de cálcio (tabela 2).

Tabela 2. Protocolo utilizado para quantificação da atividade do sistema proteolítico dependente de $\mathrm{Ca}^{2+}$.

\section{Músculos soleus retirados das 2 patas incubados in vitro}

\begin{tabular}{lll}
\hline \multicolumn{2}{c}{ Componentes do meio de incubação } & Músculos \\
\hline & Pata Direita & Pata Esquerda \\
Tampão Krebs Ringer Bicarbonato $(\mathrm{pH} 7,4)$ & + & + \\
Glicose $(5 \mathrm{mM})$ & + & + \\
Cicloheximida $(0,5 \mathrm{mM})$ & + & + \\
Metilamina $(10 \mathrm{mM})$ e *BCAA & + & + \\
E64 ${ }^{1}(25 \mu \mathrm{M})$ e leupeptina $(50 \mu \mathrm{M})$ & - & + \\
Cálcio & - & \\
\hline *Leucina $(0,5 \mathrm{mM})$; Isoleucina $(0,85 \mathrm{mM})$ e Valina $(1,0 \mathrm{mM})$. & \\
$1_{\text {trans-epoxisuccinil-L-leucilamido-(4-guanidino }) \text { butano }}$ & +
\end{tabular}




\subsubsection{Sistema Ubiquitina-Proteassoma}

Foram utilizados músculos soleus fixados pelos tendões a suportes apropriados e incubados em meio sem cálcio e na presença dos inibidores metilamina, BCAA, E64 e leupeptina para o bloqueio concomitante dos sistemas proteolíticos lisossomal e dependente de $\mathrm{Ca}^{2+}$, respectivamente. Para inibir a atividade direta do proteassoma 20S, subpartícula do proteassoma $26 \mathrm{~S}$, onde acontece efetivamente a degradação de proteínas por ação das proteases deste sistema, foi utilizado o MG132 (N-carboxibenzoxi-Leu-Leu-Leucina).

A liberação de tirosina dos músculos incubados na presença de todos os inibidores reflete a proteólise não lisossomal e independente de $\mathrm{Ca}^{2+}$, denominada basal. A diferença entre a tirosina liberada na proteólise basal e aquela liberada dos músculos incubados na presença do MG132 representa a atividade do sistema Ub-proteassoma (tabela 3).

Este protocolo ainda permite avaliar a liberação de tirosina pela proteólise não lisossomal, independe de $\mathrm{Ca}^{2+}$ e do sistema Ub-proteassoma, denominada residual, cujos mecanismos de controle ainda são pouco conhecidos. 
Tabela 3. Protocolo utilizado para a quantificação da proteólise dependente de Ubproteassoma

Músculos soleus retirados das 2 patas e fixados pelos tendões a suportes apropriados para incubação in vitro

\begin{tabular}{|c|c|c|}
\hline \multirow[t]{2}{*}{ Componentes do meio de incubação } & \multicolumn{2}{|c|}{ Músculos } \\
\hline & Pata Direita & Pata Esquerda \\
\hline Tampão Krebs Ringer Bicarbonato (pH 7,4) & + & + \\
\hline Glicose $(5 \mathrm{mM})$ & + & + \\
\hline Cicloheximida $(0,5 \mathrm{mM})$ & + & + \\
\hline Metilamina $(10 \mathrm{mM})$ e $*$ BCAA & + & + \\
\hline **E64 $(25 \mu \mathrm{M})$, leupeptina $(50 \mu \mathrm{M})$ & + & + \\
\hline$* * * \operatorname{MG} 132(20 \mu \mathrm{M})$ & - & + \\
\hline \multicolumn{3}{|c|}{ *Leucina $(0,5 \mathrm{mM})$; Isoleucina $(0,85 \mathrm{mM})$ e Valina $(1,0 \mathrm{mM})$} \\
\hline
\end{tabular}




\subsection{Procedimento experimental para a avaliação da síntese total de proteínas em músculos} esqueléticos de ratos

A síntese de proteínas totais foi determinada em músculos soleus e EDL de ratos após 3 horas de incubação com carbacol $\left(10^{-4} \mathrm{M}\right)$. Os músculos foram incubados com os tendões fixos a suportes próprios para manutenção do comprimento de repouso em tampão Krebs Ringer Bicarbonato, contendo glicose $(5 \mathrm{mM})$ e todos os 20 aminoácidos, em concentrações semelhantes ao plasma, conforme apresentado na tabela 4.

Após um período de 1 hora de pré-incubação, o meio de incubação foi substituído por meio idêntico acrescido de tirosina marcada ([U-14-C] tirosina; $0,05 \mu \mathrm{Ci} / \mathrm{ml}$ ). Após a incubação de 2 horas, os músculos foram lavados com água destilada, secos em papel de filtro e colocados em $2 \mathrm{ml}$ de ácido tricloroacético (TCA) 10\% para homogeneização. Em seguida, as amostras foram centrifugadas a $3.000 \mathrm{~g}$ por 15 minutos a $24^{\circ} \mathrm{C}$ e $1 \mathrm{ml}$ do sobrenadante foi recolhido para avaliação da tirosina total livre no músculo. Uma alíquota de $100 \mu$ foi utilizada para quantificação da radioatividade e determinação da atividade específica da tirosina de cada músculo separadamente. Na etapa seguinte, a amostra foi lavada 3 vezes com $2 \mathrm{ml}$ de TCA 10\%. O precipitado restante foi solubilizado com dodecil sulfato de sódio (SDS) $10 \%$ overnight em banho-maria a $40^{\circ} \mathrm{C}$. A seguir, foram adicionados $10 \mathrm{ml}$ de coquetel de cintilação para contagem da radioatividade em espectrômetro de cintilação líquida (TRICARB 2100TR, Packard BioScience Company, EUA). 
Tabela 4. Aminoácidos presentes no meio de incubação para quantificação da velocidade de síntese de proteínas totais.

\begin{tabular}{lc|lc}
\hline \multicolumn{1}{c|}{ Aminoácidos } & $\begin{array}{c}\text { Concentração } \\
(\mathbf{m M})\end{array}$ & \multicolumn{1}{|c}{ Aminoácidos } & Concentração \\
& 0,035 & Isoleucina & 0,100 \\
\hline Ácido aspártico & 0,174 & Leucina & 0,170 \\
Ácido glutâmico & 0,450 & Lisina & 0,400 \\
Alanina & 0,200 & Metionina & 0,070 \\
Arginina & 0,061 & Prolina & 0,180 \\
Asparagina & 0,070 & Serina & 0,280 \\
Cisteína & 0,500 & Tirosina & 0,100 \\
Fenilalanina & 0,400 & Treonina & 0,300 \\
Glicina & 0,350 & Triptofano & 0,070 \\
Glutamina & 0,080 & Valina & 0,200 \\
Histidina & & & \\
\hline
\end{tabular}

\subsection{Análise estatística}

A análise das imagens foi realizada utilizando o programa ImageJ (NIH, Bethesda, MD) ou como descrito (RÖDER et al., 2010). Os resultados foram expressos como média \pm EPM (erro padrão da média). Para a análise estatística dos resultados foi empregado o teste "t"de Student ou teste de Welch e a análise de variância (ANOVA), seguido do teste de Bonferroni. O nível de significância aceito foi de $5 \%$ (i.e., $\mathrm{P} \leq 0,05$ ). 


\section{RESUltados}

4.1. Efeito do tratamento crônico com CB na massa muscular e na expressão dos genes relacionados à atrofia e autofagia induzidos pela DEN

A desnervação motora por 3 dias não alterou a massa dos músculos TA. No entanto, a partir do sétimo dia, foi observada perda significativa (13\%) de massa nos músculos desnervados do grupo tratado com salina tornando-se gradativamente maior até o décimo quarto dia quando então os animais perderam 34\% de massa (Fig. 5). No grupo desnervado e tratado com CB por 3 dias observou-se aumento de $7 \%$ na massa muscular que foi significativamente diferente dos desnervados tratados com salina. Este efeito anti-atrófico do CB foi mantido até o décimo quarto dia após a desnervação

A atrofia induzida pela DEN foi associada ao aumento do RNAm das duas Ubligases músculo-específicas, atrogina-1 e MuRF1, após 3 dias de desnervação (243\% e 453\%, respectivamente). Como pode ser observado na Fig. 6A, o pico de ativação de atrogina-1 acontece no terceiro dia de desnervação sendo este efeito completamente revertido para níveis de expressão semelhantes aos músculos inervados já após o sétimo dia. Um perfil semelhante de resposta foi observado para o RNAm de MuRF1 (Fig. 6B). Entretanto, o tratamento com CB completamente aboliu o aumento da expressão destes genes (Fig. 6A e D) 3 dias após a cirurgia e reduziu para valores abaixo dos controles o RNAm para atrogina-1 em todo o período analisado. Efeitos semelhantes foram observados no conteúdo proteico de ambos atrogenes (Fig. 6C-F) 


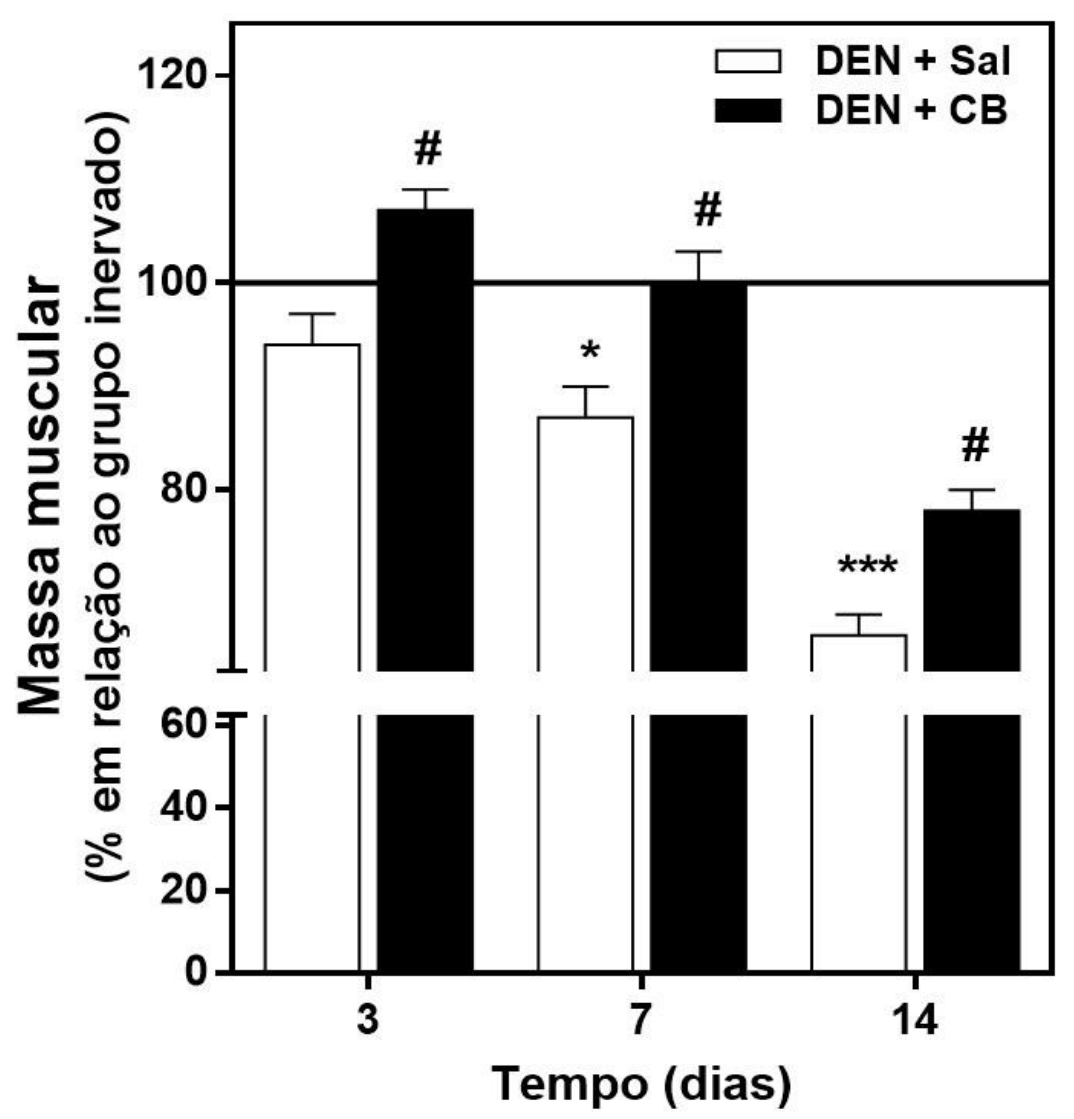

Figura 5. Efeito do tratamento com clembuterol (CB; $3 \mathrm{mg} / \mathrm{kg} / \mathrm{dia}$, s.c.) ou salina (Sal) na massa de músculos tibialis desnervados (DEN). Os resultados são expressos como médias percentuais \pm EPM ( $\mathrm{n}=7-10)$ das massas de músculos desnervados em relação aos controles inervados (considerados como 100\%). $* \mathrm{P}<0,05$; *** $\mathrm{P}<0,001 \mathrm{DEN}+\mathrm{Sal}$ vs. inervado. ${ }^{\#} \mathrm{P}<0,05 \mathrm{DEN}+\mathrm{CB}$ vs. $\mathrm{DEN}+$ Sal. Os valores médios das massas dos músculos inervados foram $18,19 \pm 0,54 \mathrm{mg} / 10 \mathrm{~g}$ de massa corporal. 

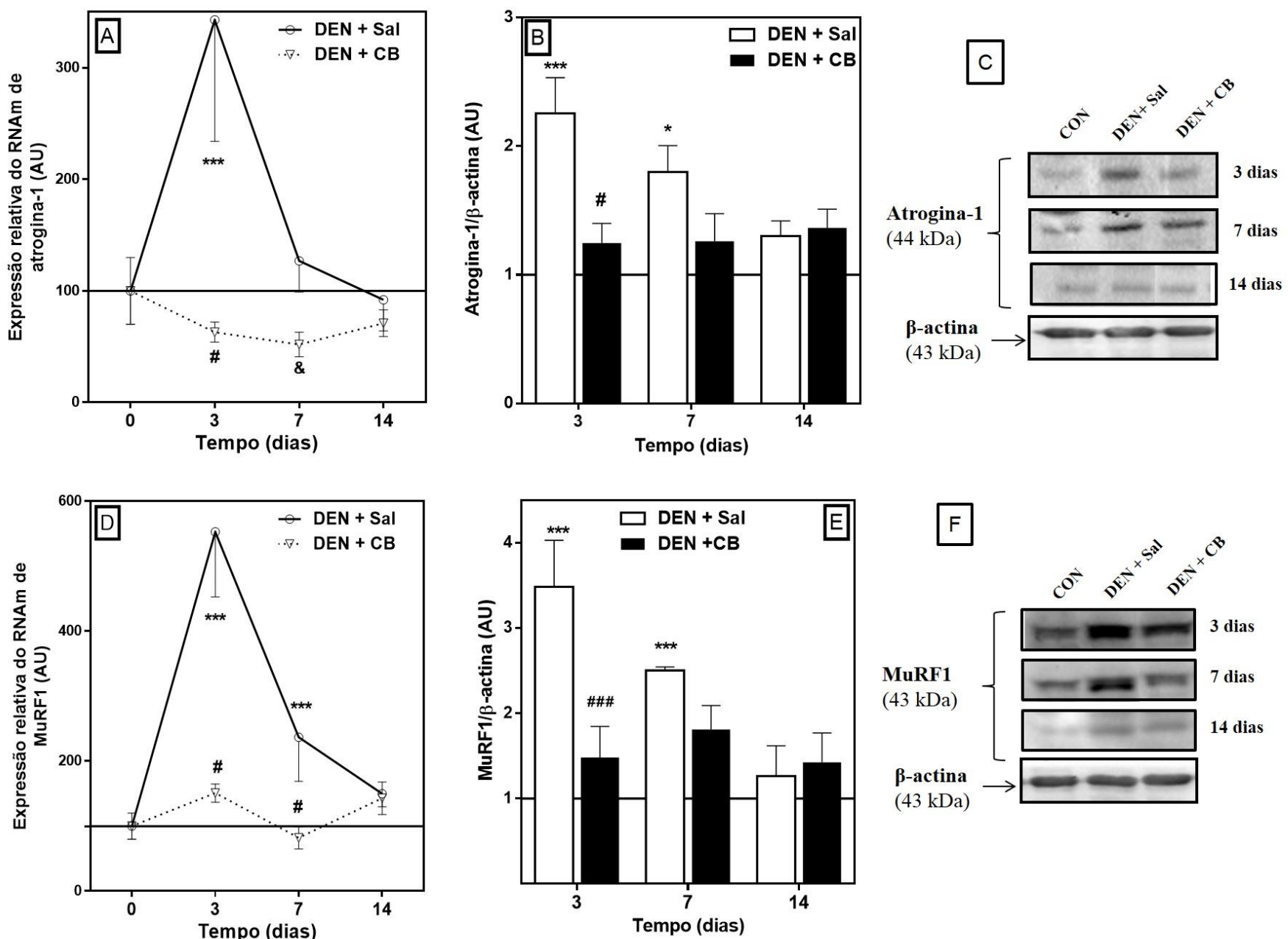

Figura 6. Efeito do tratamento com clembuterol (CB; $3 \mathrm{mg} / \mathrm{kg} /$ dia, s.c.) ou salina (Sal) na expressão do RNAm para atrogina-1 (A) e MuRF1 (D) e no conteúdo das proteínas atrogina-1 (B) e MuRF1 (E) em músculos tibiais desnervados (DEN). As bandas (blots) representativas de atrogina1 e MuRF1 são mostradas em $\mathbf{C}$ e $\mathbf{F}$, respectivamente. Os níveis de expressão gênica foram normalizados utilizando a subunidade de RNA 18S como controle endógeno. Os resultados são expressos como Média $\pm \mathrm{EPM}$. ${ }^{*} \mathrm{P}<0,01-* * * \mathrm{P}<0,01 \mathrm{DEN}+$ Sal vs. controle, inervado $(100 \%)$; ${ }^{\#} \mathrm{P}<0,05-{ }^{\&} \mathrm{P}<0,05-{ }^{\# \# \#} \mathrm{P}<0,01 \mathrm{DEN}+\mathrm{CB}$ vs. DEN + Sal. 
Além da modulação do sistema Ub-proteassoma, nossos resultados mostram que a desnervação promoveu up-regulation dos genes relacionados ao sistema autofágico/lisossomal, isto é, catepsina L e LC3b (Fig. 7 A e B). No entanto, o pico de expressão destes genes autofágicos ocorreu sete dias após a cirurgia demonstrando que durante o processo catabólico induzido pela desnervação há um programa atrófico que coordena temporalmente a ativação dos diferentes sistemas proteolíticos celulares (SACHECK et al., 2007). Por sua vez, o CB bloqueou o pico de expressão da catepsina L (Fig. 7A) e atenuou o de LC3 (Fig. 7B) aos 7 dias pós-DEN. Embora não tenha sido observado alterações no conteúdo proteico da catepsina L (dados não mostrados), o conteúdo de LC3I e II aumentou $288 \%$ e $400 \%$ após sete e quatorze dias de DEN, respectivamente e o tratamento com $\mathrm{CB}$ atenuou esta resposta em ambos os períodos (Fig. 7C). 

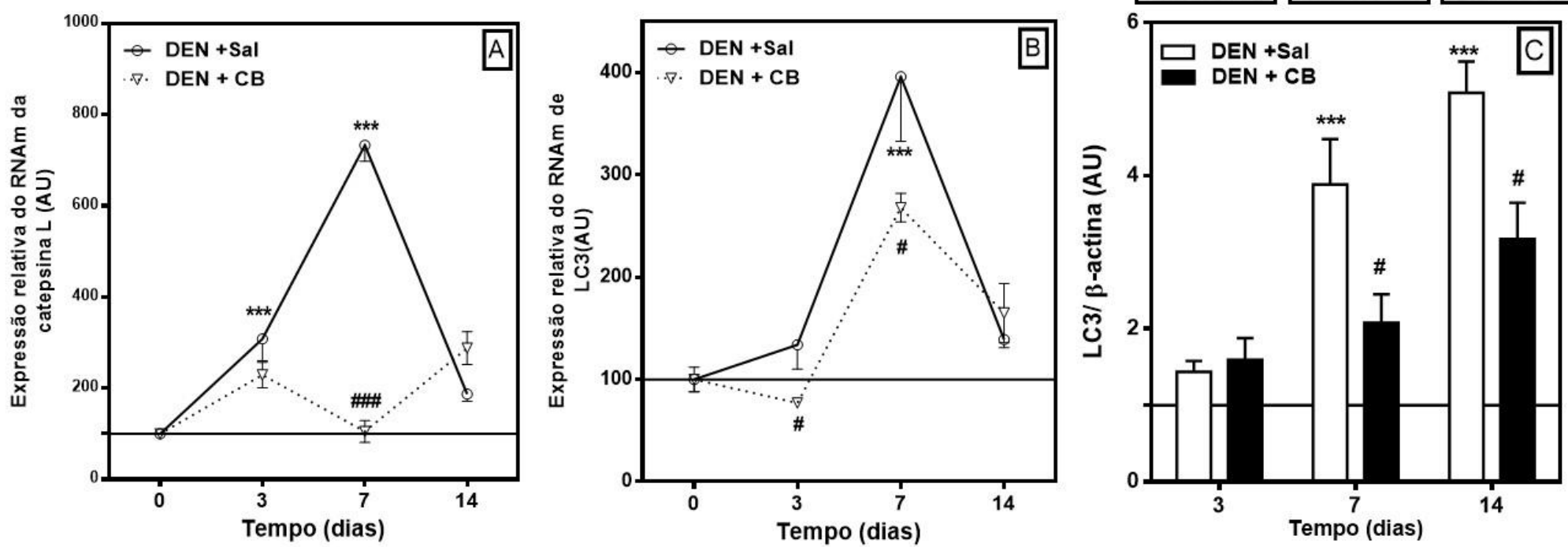

LC3b I-II (14-16Kd)

$\beta$ - actina $(43 \mathrm{Kd})$

Figura 7. Efeito do tratamento com clembuterol (CB; 3mg/kg/dia, s.c.) ou salina (Sal) na expressão do RNAm para catepsina L (A) e LC3 (B) e no conteúdo proteico de LC3 I e II (C) em músculos tibiais desnervados (DEN). Os níveis de expressão gênica foram normalizados utilizando a subunidade de RNA $18 \mathrm{~S}$ como controle endógeno. Os resultados são expressos como Média \pm EPM. $* * * P<0,01 \mathrm{DEN}+$ Sal vs. controle, inervado (100\%); ${ }^{\#} \mathrm{P}<0,05,{ }^{\# \#} \mathrm{P}<0,001 \mathrm{CB}+\mathrm{DEN}$ vs. DEN + Sal. 
4.2. Efeito do tratamento crônico com $C B$ na atividade da via do AMPc/PKA em músculos desnervados

A via de sinalização clássica ativada pelos $\beta_{2}-$ ARs é a do AMPc/PKA e esta parece ser a responsável pelos efeitos hipertróficos induzidos pelos $\beta_{2}$-agonistas (LYNCH; RYALL, 2008). Nesse sentido, foram analisados o conteúdo de AMPc e de substratos fosforilados pela PKA em músculos desnervados de camundongos tratados com salina ou CB. O tratamento com CB durante 3 dias aumentou o conteúdo de AMPc (Fig. 8A) em músculos desnervados. Em concordância com estes resultados, o conteúdo de substratos fosforilados pela PKA também foi aumentado (165\%) pelo CB (Fig. 8BC), indicando de forma indireta que a atividade desta quinase foi elevada pelo AMPc. De forma bastante interessante, nossos dados mostram que o próprio estado da desnervação, independentemente do tratamento com CB, foi capaz de induzir aumento (25\%) do AMPc intracelular (Fig. 8A) e do conteúdo de substratos fosforilados pela PKA $(110 \%)$ após o $7^{\circ}$ dia (Fig. 8B). Vale a pena ressaltar que neste mesmo período foi também observado down-regulation dos atrogenes, atrogina-1 e MuRF1 (Fig. 6A-F) em músculos desnervados e tratados com salina. Com base nesses resultados, especulou-se que a via do AMPc/PKA poderia fazer parte de um mecanismo intrínseco de autoproteção do tecido muscular no sentido de atenuar a hiperexpressão dos atrogenes induzida pela perda da inervação motora. Um resumo destes achados é apresentado esquematicamente na Fig.9. 

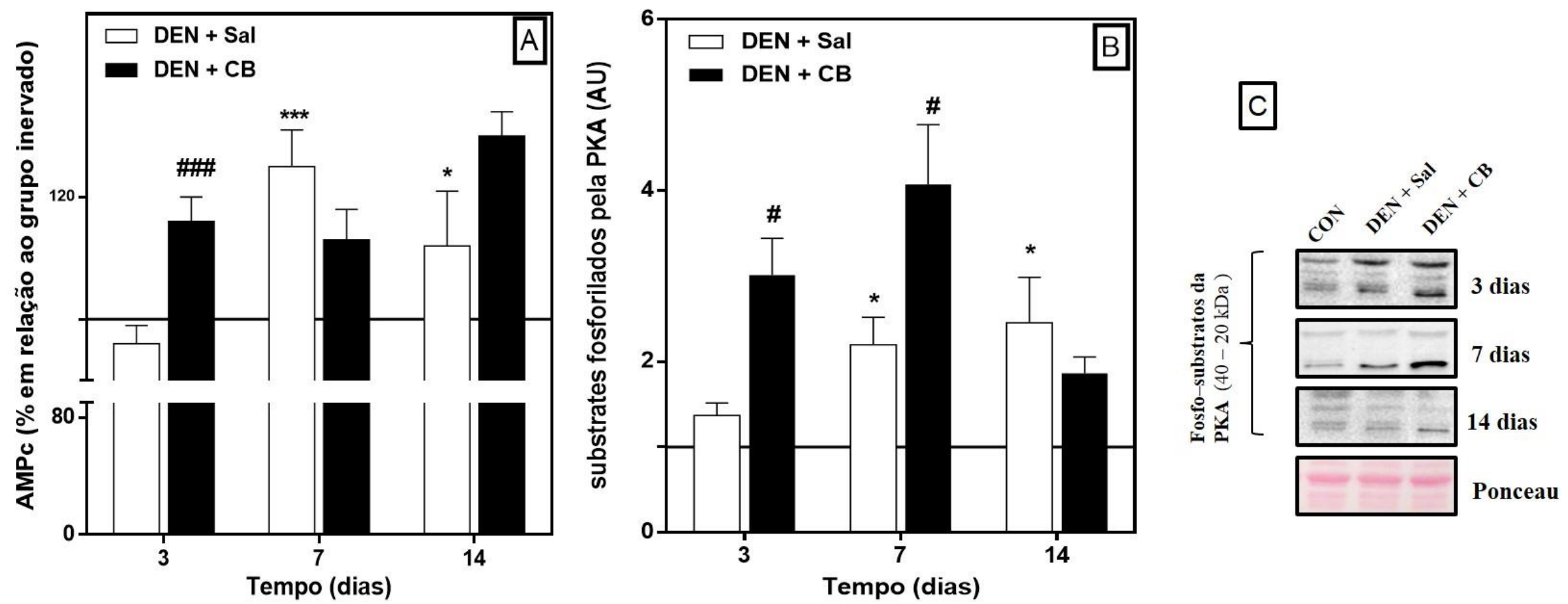

Figura 8. Conteúdo de adenosina 3',5'-monofosfato cíclico (AMPc, A) e de substratos fosforilados pela PKA (B) em músculos tibialis

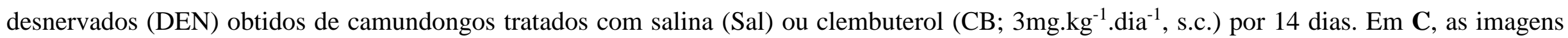
(blots) representativas de cada grupo ilustram os valores expressos como Média \pm EPM (n=5-6) no histograma $\mathrm{B}$. ${ }^{*} \mathrm{P}<0,05$, *** $\mathrm{P}<0,001 \mathrm{DEN}+$ Sal vs. controle inervado; ${ }^{\#} \mathrm{P}<0,05,{ }^{\# \#} \mathrm{P}<0,001 \mathrm{DEN}+\mathrm{CB}$ vs. DEN + Sal. Os valores médios do conteúdo de AMPc dos músculos inervados foram $863,62 \pm 71,78 \mathrm{fnmol} / \mathrm{mg}$ de músculo. 


\subsection{Participação do SNS na resposta adaptativa induzida pela desnervação}

Com base nos resultados anteriores, especulou-se que fibras simpáticas poderiam estar associadas a neurônios motores do nervo ciático e sua ablação pela DEN aumentaria a sensibilidade do tecido muscular às catecolaminas circulantes culminando no aumento de AMPc. Utilizando-se métodos de imunohistoquímica, observou-se no nervo ciático uma alta densidade de neurônios catecolaminérgicos identificados pela presença de dopamina- $\beta$-hidroxilase, uma enzima responsável pela síntese de catecolaminas (Fig. 10). Em concordância com esses resultados, a secção do nervo ciático promoveu uma redução $(80 \%)$ do conteúdo de noradrenalina muscular Fig. 11A). Para testar a hipótese da sensibilidade adrenérgica induzida pela desnervação motora, um grupo de animais desnervados por 7 dias foi previamente submetido à cirurgia de $\mathrm{ADMX}$ (3 dias antes da cirurgia de DEN). O tempo de 7 dias de desnervação motora foi selecionado pois neste momento o conteúdo dos atrogenes nos músculos desnervados está retornando aos valores normais e a atividade da via do AMPc/PKA está elevada. Embora trabalhos anteriores de nosso laboratório já tenham demonstrado que a ADMX é um procedimento eficaz na redução drástica da adrenalina circulante em ratos (GRAÇA et al., 2013; NAVEGANTES et al., 2001), não foi possível determinar a concentração plasmática desta catecolamina nos camundongos adrenodemedulados em virtude da alta quantidade de plasma exigida pelo método do CLAE. A concentração plasmática de corticosterona não foi afetada pela ADMX (Fig. 11C). Como pode ser observado na Fig 11B, a ADMX promoveu um leve aumento adicional no conteúdo de atrogina-1 e MuRF1 nos músculos desnervados sugerindo que a adrenalina circulante possa estar contribuindo para a atenuação da resposta catabólica nos músculos que perdem a inervação motora, no entanto a quantificação do conteúdo de AMPc e atividade da PKA neste modelo é fundamental para comprovar esta hipótese. 


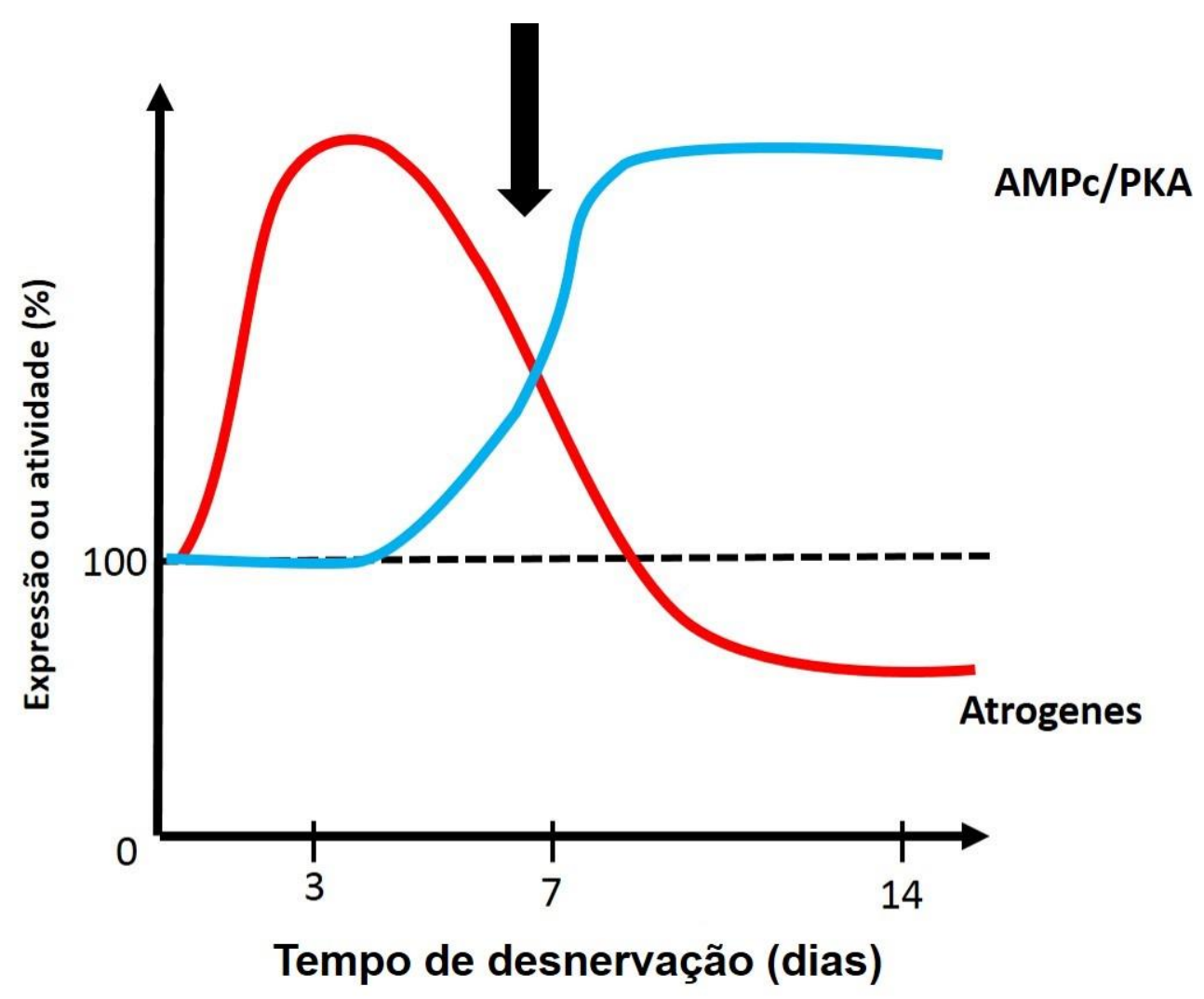

Figura 9. Esquema representativo do perfil temporal da expressão dos atrogenes (MuRF1 e atrogina-1) e da atividade da via de sinalização do AMPc/PKA em músculos desnervados. A seta indica o momento no qual ambos os fenômenos possam estar interagindo e a linha pontilhada representa os valores obtidos no grupo de músculos inervado, considerados como $100 \%$. 

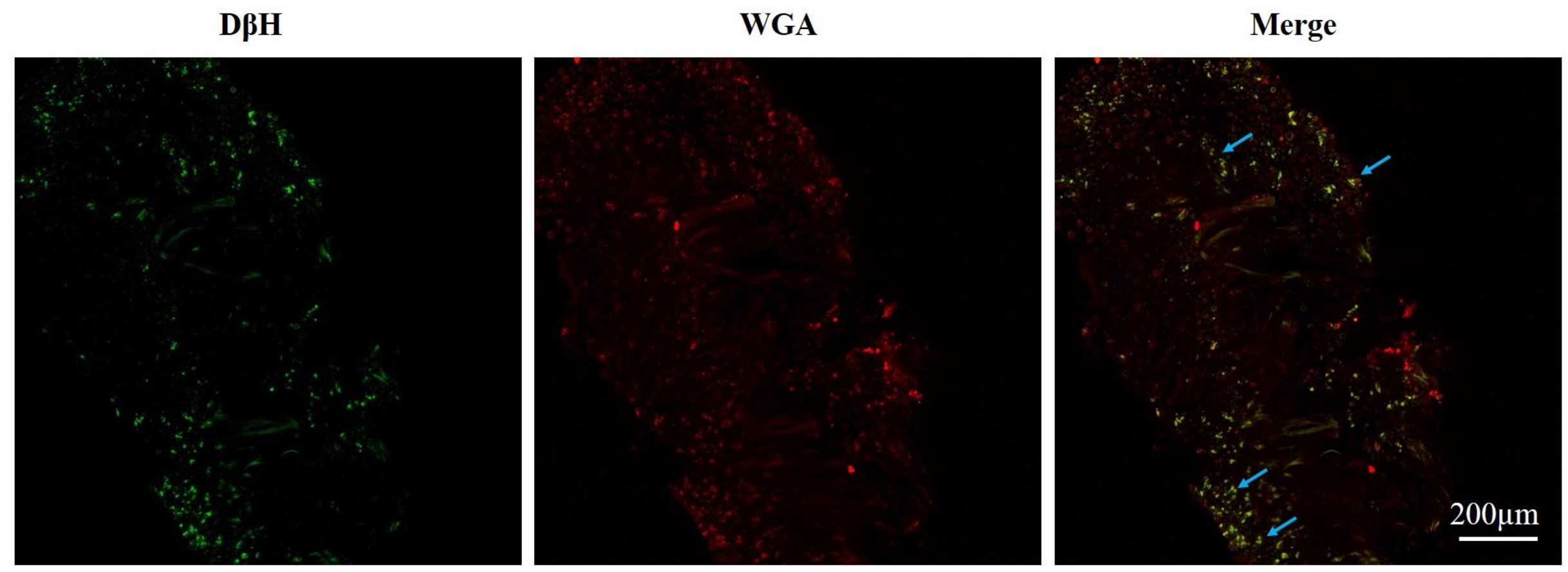

Figura 10. Identificação de fibras noradrenérgicas no nervo ciático de camundongos. Nervos ciáticos foram fixados em solução contendo $4 \%$ de paraformaldeído a $4{ }^{\circ} \mathrm{C}$. Secções transversais de $100 \mu \mathrm{m}$ de espessura foram preparadas. Para identificar os neurônios simpáticos foi utilizado anticorpo anti-dopamina- $\beta$-hidroxilase $(\mathrm{D} \beta \mathrm{H})$, uma enzima responsável pela síntese de catecolaminas. Wheat germ agglutinin (WGA) foi também utilizada para marcar as membranas celulares e, em seguida, as imagens foram obtidas através de microscopia confocal. Escala $=200$ $\mu \mathrm{m}$. As setas azuis identificam os neurônios noradrenérgicos marcados para $\mathrm{D} \beta \mathrm{H}$. 

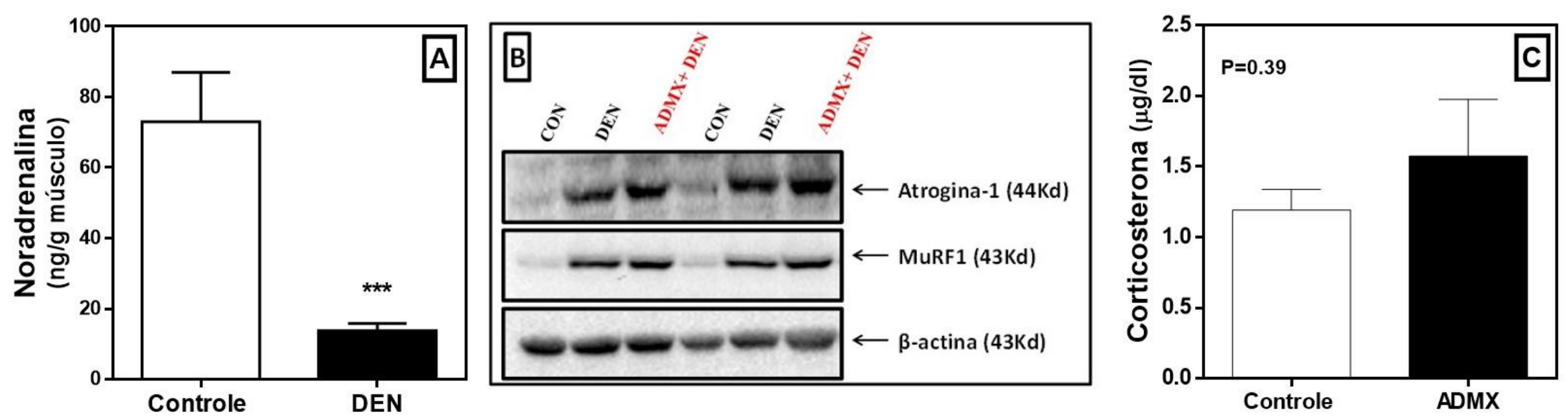

Figura 11. Conteúdo de noradrenalina em músculos gastrocnêmicos de camundongos após três dias de desnervação motora (DEN) B: Imagens representativas do conteúdo proteíco de atrogina-1 e MuRF1 em músculos tibial anterior de camundongos submetidos previamente à cirurgia de remoção da porção medular da adrenal (ADMX) e à DEN por sete dias. C: Concentração plasmática de corticosterona após sete dias de ADMX em camundongos. $* * * \mathrm{P}<0,001 \mathrm{DEN}$ vs. controle inervado, $\mathrm{n}=5$. 


\subsection{Evidências anatômicas da interação entre o sistema adrenérgico e colinérgico na placa motora}

Com a identificação de fibras noradrenérgicas no nervo motor (Fig. 10) tornou-se interessante investigar se esta inervação pudesse também alcançar a região da placa motora. Para isso foram utilizados diferentes métodos de imagens para investigar: i) a presença da inervação noradrenérgica por meio da localização da tirosina hidroxilase (TyrH) que é a proteína chave no processo de síntese de noradrenalina, ii) a expressão dos $\beta_{2}$-AR e iii) a produção de AMPc na JNM de músculos TA de camundongos normais. Foi observado uma grande marcação para TyrH na região subjacente às JNM pela técnica de imunohistoquímica (Fig. 12A-C), indicando que neurônios simpáticos fazem contato direto com a placa motora e também com as fibras musculares.

Utilizando-se técnicas de imunohistoquímica, foi possível observar uma grande densidade de $\beta_{2}$-AR ao longo de toda a membrana sarcoplasmática (Fig. 13A). Posteriormente, músculos TA foram transfectados com plasmídeos contendo o gene que codifica $\beta_{2}$-AR-sPep acoplado aos sensores fluorescentes mCit (FRET aceptor) e mCer (FRET doador). Com esta técnica foi possível confirmar que o $\beta_{2}$-AR está realmente presente na JNM, como demonstrado pela co-localização com AChR (Fig. 13B). Após estimulação elétrica do nervo ciático $(<1 \mathrm{~V})$ estes receptores tornaram-se ativos (Fig. 13C), apresentando um aumento máximo de $\sim 10 \%$ da razão entre F535/F485 (maior fluorescência emitida por mCit e diminuição da fluorescência emitida pelo mCer).

Com o objetivo de identificar a produção e localização do AMPc especificamente na JNM, o plasmídeo contendo o gene para rapsina-EPAC associado aos sensores YFP e CFP foi superexpresso em músculos TA de camundongos. Após estimulação elétrica do nervo ciático foi observado um aumento da produção de AMPc (Fig. 14A). Este efeito foi bloqueado pelo tratamento prévio com 6-OH-DOPA, uma neurotoxina que 
bloqueia a liberação de noradrenalina pelo terminal pré-sináptico e pelo tratamento com ICI 118-551, um antagonista dos $\beta_{2}$-AR (Fig. 14B).

Em conjunto, esses dados mostram que fibras noradrenérgicas que trafegam pelo nervo motor de músculos de camundongos estabelecem contato direto com os receptores nicotínicos por meio da ativação dos $\beta_{2}$-AR e consequente aumento da produção do AMPc. 

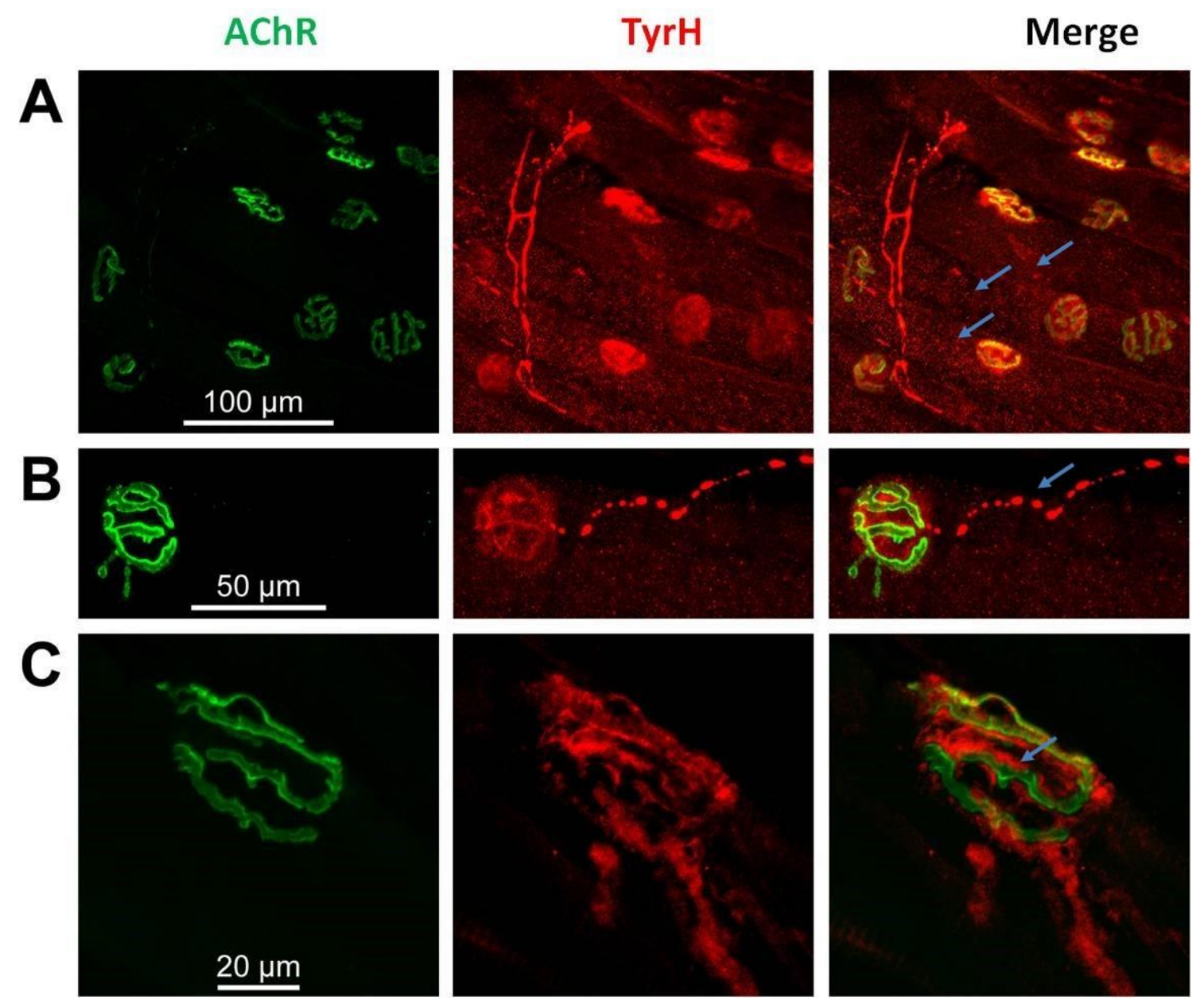

Figura 12. Identificação de fibras noradrenérgicas na junção neuromuscular (JNM). As JNM foram identificadas por meio da localização do receptor colinérgico nicotínico (AChR, verde). Para a identificação dos terminais noradrenérgicos utilizou-se anticorpo anti-tirosina hidroxilase (TyrH, vermelho), enzima chave na síntese das catecolaminas. As setas mostram a marcação de fibras noradrérgicas adjacentes as fibras musculares (A) e a co-localização com AChR em músculo tibial anterior de camundongos (B-C). A) escala $=100 \mu \mathrm{m}, \mathbf{B})$ escala $=50 \mu \mathrm{m} \mathrm{e} \mathrm{C)} \mathrm{escala}=20 \mu \mathrm{m}$. 

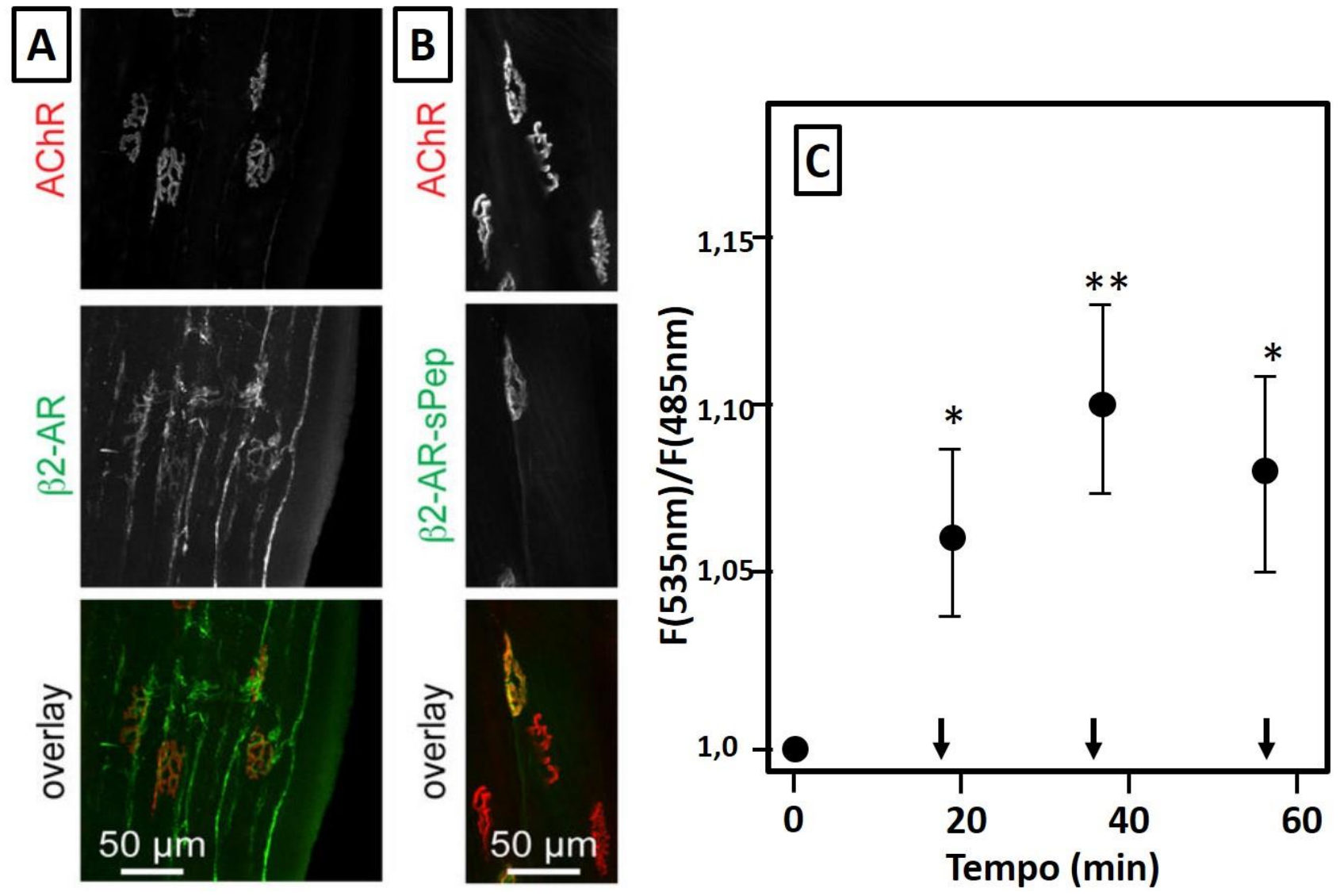

Figura 13. A: Identificação de receptores $\beta_{2}$-adrenérgicos (AR) em sinapses musculares de camundongos. B: Após transfecção do plasmídeo contendo o gene $\beta_{2}$-AR-sPep foi observada co-localização do $\beta_{2}$-AR e do receptor colinérgico nicotínico (AChR). C: A estimulação elétrica do nervo ciático promoveu a ativação do receptor $\beta_{2}$-AR mensurada pela técnica de transferência de energia de ressonância por fluorescência (FRET). Os valores representam as Médias \pm EPM da razão entre $\mathrm{mCit} / \mathrm{mCer}$ ou $\mathrm{F}(535 \mathrm{~nm}) / \mathrm{F}(485 \mathrm{~nm})$ ). * $\mathrm{P}<0,05, * * \mathrm{P}<0,01(\mathrm{n}=5)$. 

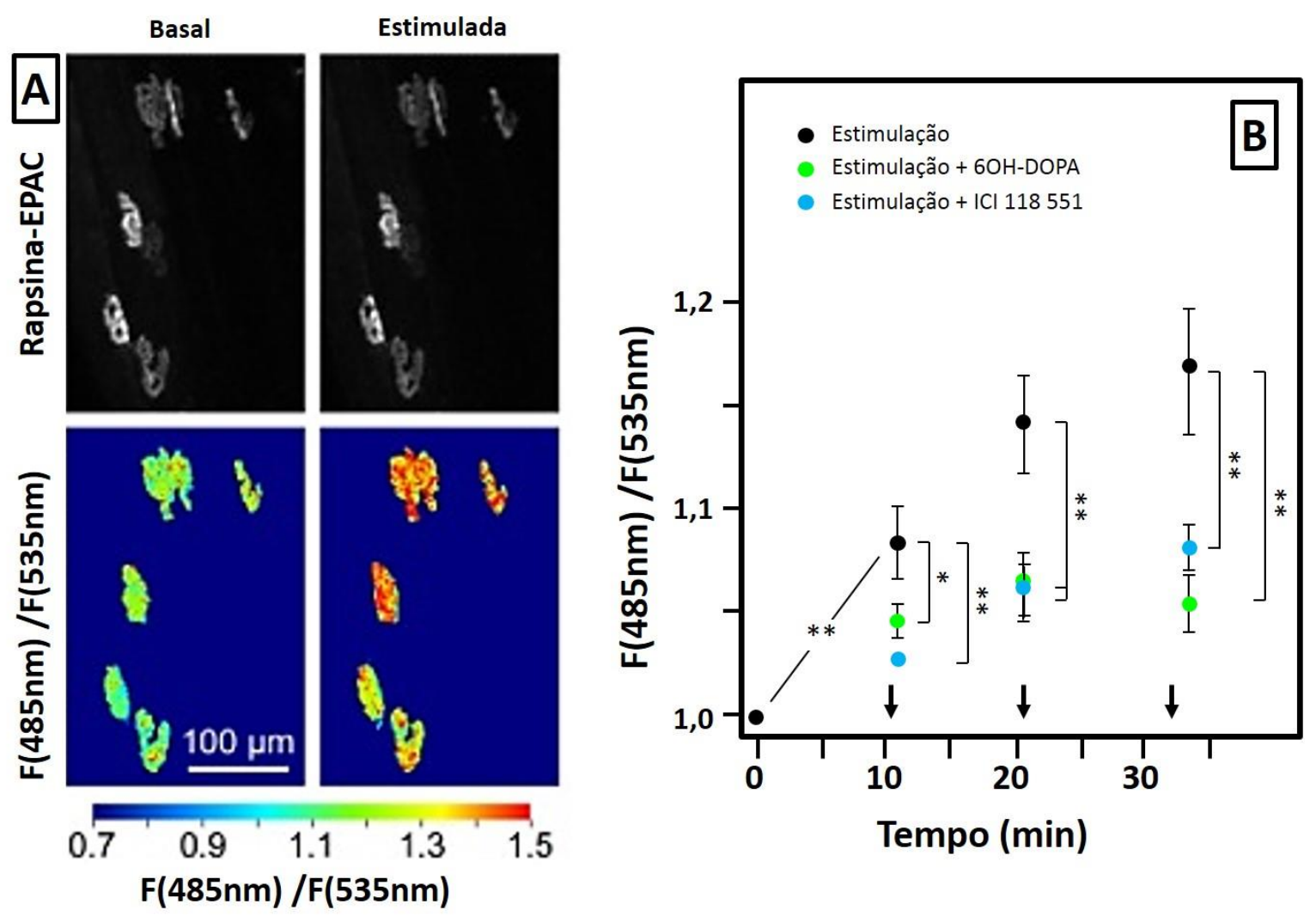

Figura 14. A: Imagens representativas do aumento da produção de AMPc nas sinapses musculares induzido pela estimulação elétrica do nervo ciático após transfecção do músculo tibial anterior com o plamídeo Rapsina-EPAC. B: Quantificação da produção do AMPc em músculos controles (•). O aumento do AMPc foi bloqueado pelo pré-tratamento com 6-hidroxidopamina (6-OH-DOPA; 100mg.kg-1) (•) e pelo IC1 118$551\left(5 \mathrm{mg} \cdot \mathrm{kg}^{-1}\right)$, um antagonista dos receptores $\beta 2$-adrenergicos $(\bullet)$. Os valores representam as Médias \pm EPM da razão entre CFP/YFP ou $\mathrm{F}(485 \mathrm{~nm}) / \mathrm{F}(535 \mathrm{~nm}){ }^{*} \mathrm{P}<0,05 ; * * \mathrm{P}<0,01(\mathrm{n}=5-7)$. 


\subsection{Efeito do tratamento com CB no turnover dos AChR}

Considerando a importância funcional da via do AMPc/PKA na regulação do turnover do AChR (GREEN; ROSS; CLAUDIO, 1991) e as evidências anatômicas da interação entre o sistema adrenérgico e colinérgico na placa motora postulou-se que os $\beta 2-\mathrm{AR}$ fossem funcionalmente importantes para manter a estabilidade do AChR nas JNM. Neste contexto, foi realizada a desnervação motora unilateral e os animais foram tratados diariamente com CB. A taxa de degradação do AChR foi avaliada, inicialmente, pelo método radioativo como descrito na seção 3.8. de Material e Métodos. Como esperado, a DEN induziu redução na meia-vida do pool de receptores de longa vida de 14,5 para 8,5 dias (Fig. 15). No entanto, o tratamento com CB foi insuficiente para induzir qualquer alteração detectável na meia-vida dos $\mathrm{AChR}$, em músculos inervados e desnervados (Fig. 15).

Em seguida, a integridade da placa motora foi estimada por meio da análise in vivo das imagens das sinapses colinérgicas, as quais foram obtidas por meio da microscopia confocal do músculo TA de camundongos anestesiados. Por meio deste método é possível identificar dois pools de receptores de acetilcolina, diferencialmente acoplados à bungarotoxina marcada a diferentes fluoróforos: um pool de receptores de meia-vida longa (antigos, marcados em verde) e os recém sintetizados (novos, marcados em vermelho). A análise quantitativa da relação entre as duas cores (“em pixels”) em uma determinada sinapse indica o grau de estabilização da mesma. Em concordância com os achados anteriores, verificou-se que a DEN induziu aumento de $\sim 310 \%$ (P < 0,05; $\mathrm{n}=4-5)$ no pool de receptores de "novos" indicando assim o aumento do turnover de AChR. O tratamento com CB por 14 dias produziu um aumento adicional no pool de receptores de "novos" tanto nos músculos inervados ( 208\%) como nos DEN ( 46\%) (Fig. 16 e 17). 


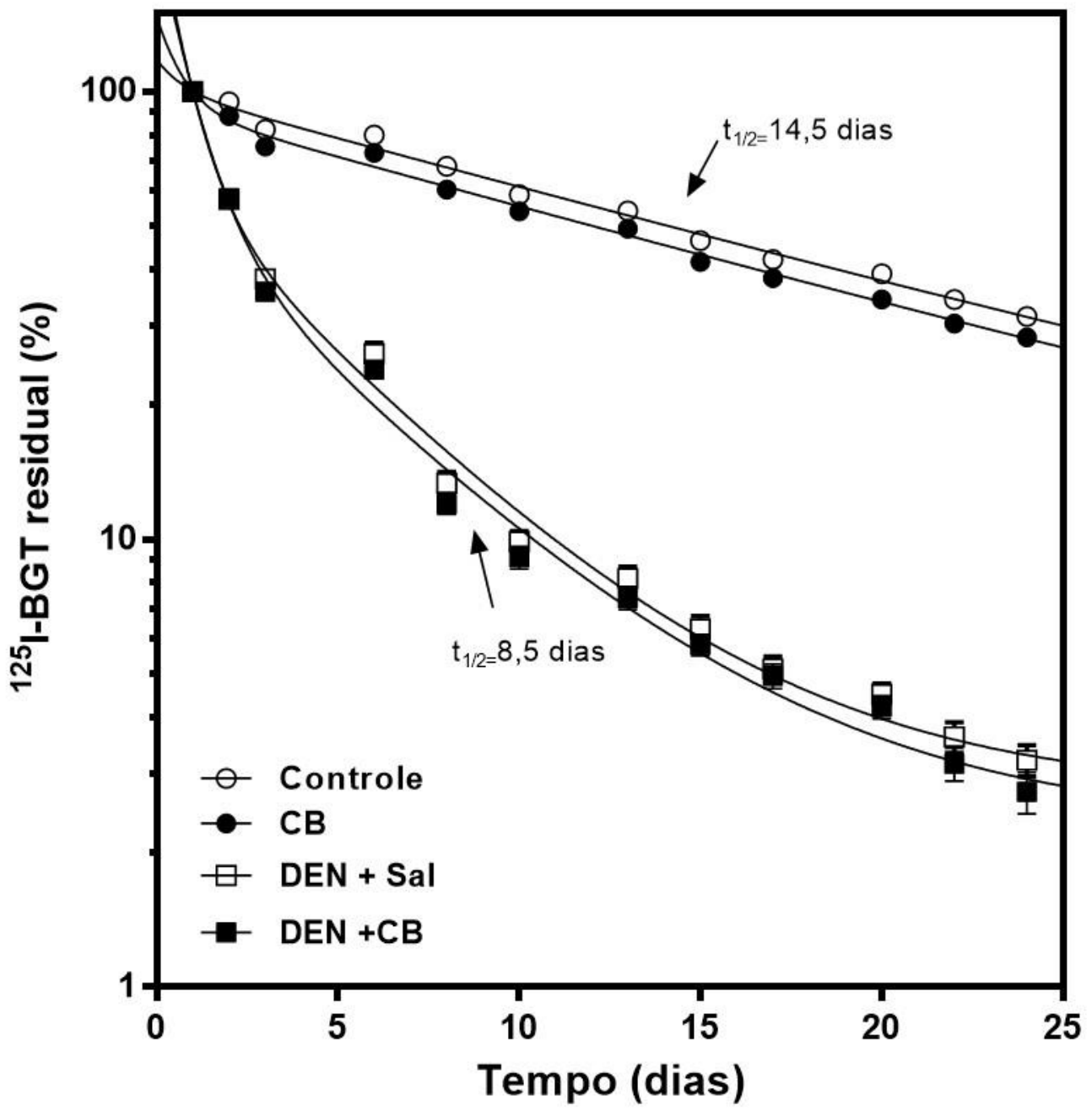

Figura 15. Efeito do tratamento com clembuterol (CB; 3mg.kg-1.dia-1, s.c.) ou salina (Sal) na taxa de degradação do receptor colinérgico nicotínico (AChR), avaliado pela taxa de decaimento de ${ }^{125}$ I-bungarotoxina (BGT), em músculo tibial anterior inervado e desnervado (DEN) de camundongos. $\mathrm{t} 1 / 2=$ tempo de meia vida, $\mathrm{n}=5-7$. 


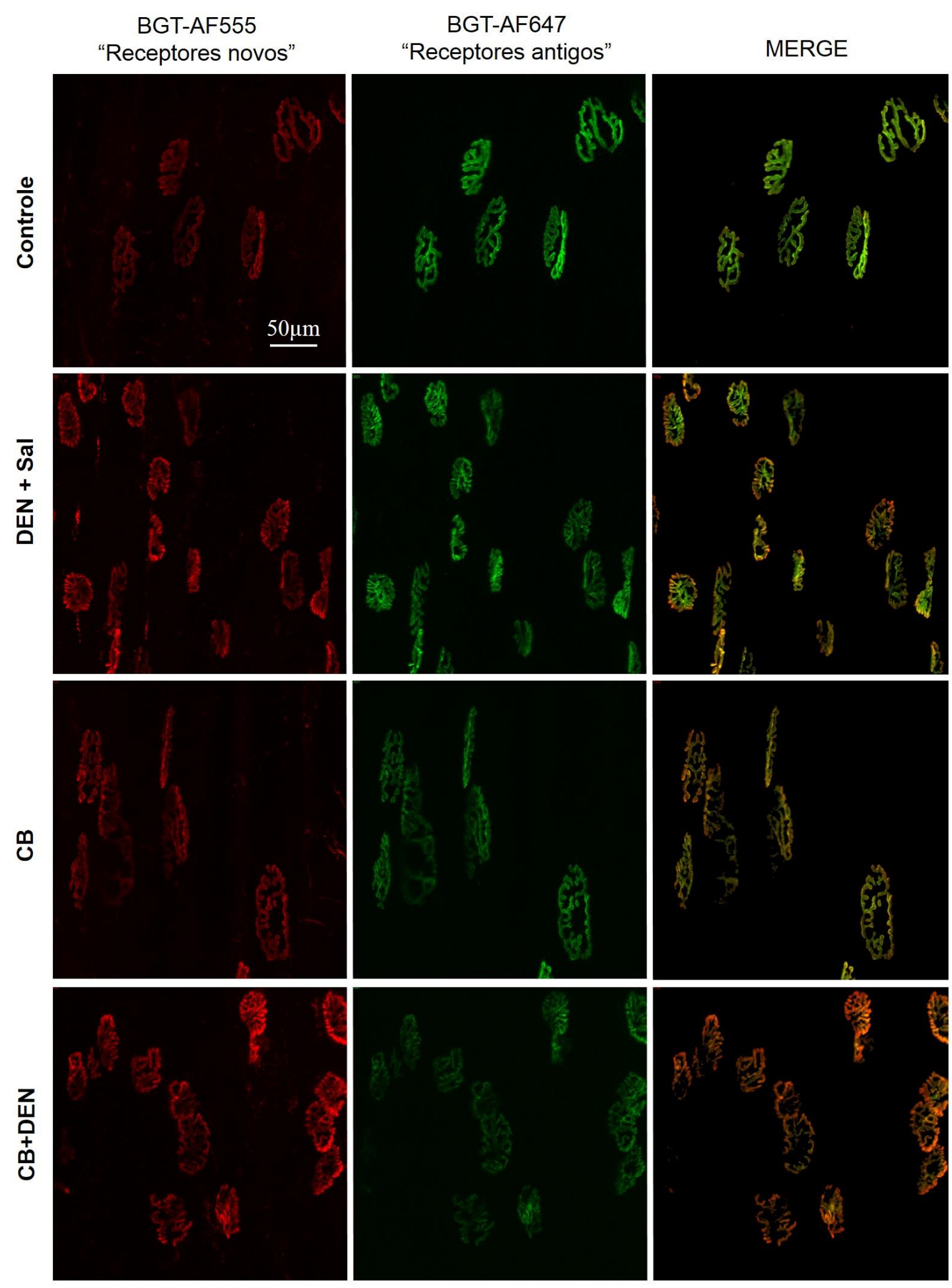

Figura 16. Imagens representativas do efeito do tratamento com clembuterol (CB; $3 \mathrm{mg} \cdot \mathrm{kg}^{-1} \cdot \mathrm{dia}^{-1}$, s.c.) ou salina (Sal) na estabilidade do receptor colinérgico nicotínico (AChR) em músculo tibial de camundongos submetidos à desnervação motora unilateral (DEN). Os AChR foram marcados com BGT-AlexaFluor 647 ("para visualização dos receptores antigos") e depois de 10 dias com BGT-AlexaFluor 555 (para visualização dos "receptores novos"). Escala= $50 \mu \mathrm{m}$. 


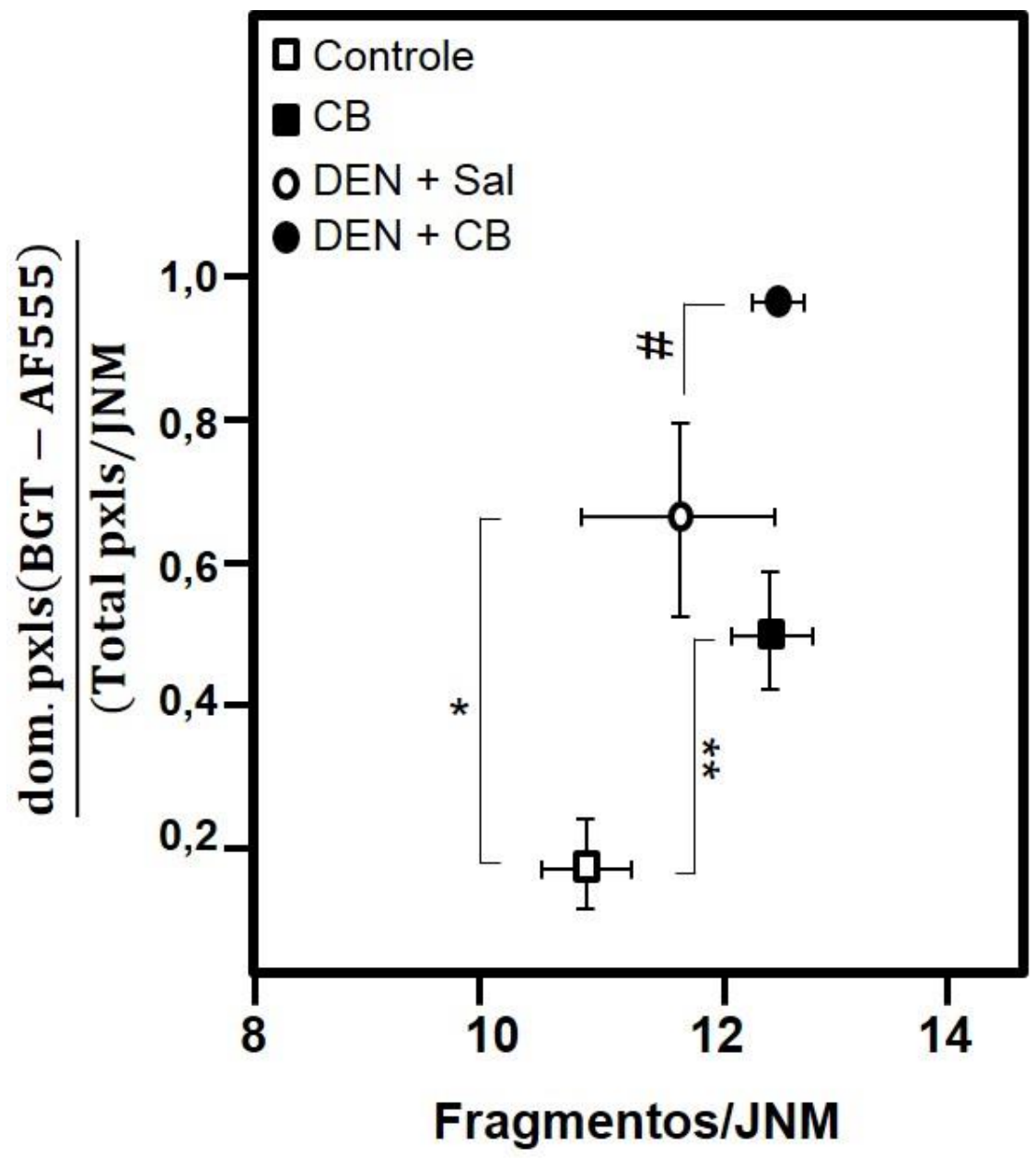

Figura 17. Efeito do tratamento com clembuterol (CB; $3 \mathrm{mg} \cdot \mathrm{kg}^{-1} \cdot \mathrm{dia}^{-1}$, s.c.) ou salina (Sal) na estabilização do receptor colinérgico nicotínico (AChR) em músculo tibial de camundongos submetidos à desnervação motora unilateral (DEN). Os resultados são expressos como Média \pm EPM da fração de pixels da marcação feita por BGT-AF555 em função do número médio de fragmentos/junção neuromuscular (JNM). * $\mathrm{P}<0,05$; ** $\mathrm{P}<0,01$ vs. músculos controles (inervados tratados com salina); ${ }^{\#} \mathrm{P}<0,05$ vs músculos DEN + Sal; $(n=4-5$ para cada grupo $)$. 
Com a finalidade de investigar a incorporação do AChR na membrana sarcoplasmática, avaliou-se a presença de vesículas endocíticas marcadas para BGT na JNM. Como esperado, foi observado aumento de cerca de 2,5 vezes no número de vesículas contendo o $\mathrm{AChR}$ em músculos $\mathrm{DEN}$ em relação aos músculos inervados (Fig. 18A). Este efeito da desnervação foi completamente abolido pelo tratamento com CB (Fig. 18 A). Nestes animais foi também avaliada por RT-PCR a expressão gênica da subunidade $\alpha 1$-AChR. Observou-se aumento de $~ 90$ vezes na expressão do RNAm da subunidade $\alpha 1$-AChR em músculos DEN em comparação com o inervado (Fig. 18B). O tratamento com CB promoveu um aumento adicional ( 200 vezes) nesta resposta (Fig. 18 B). Não foi observada diferença entre os grupos inervados tratados com salina ou CB em ambas as análises. 

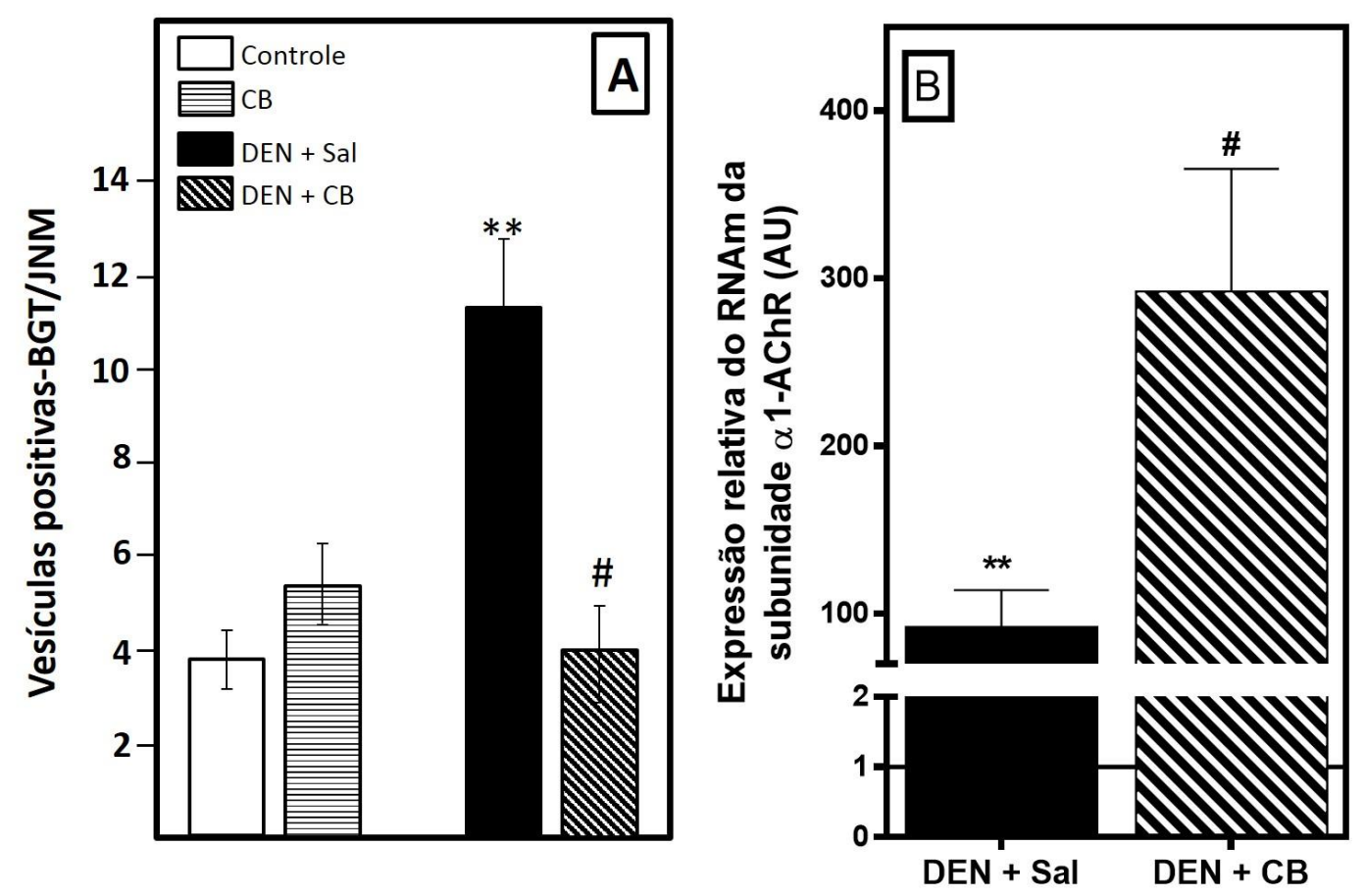

Figura 18. Efeito do tratamento com clembuterol (CB; $3 \mathrm{mg} \cdot \mathrm{kg}^{-1} \cdot \mathrm{dia}^{-1}$, s.c.) ou salina (Sal) por 14 dias no conteúdo de vesículas endocíticas marcadas com bungarotoxina (BGT-AF647/AF555) (A) e na expressão do RNAm para a subunidade $\alpha 1$ do receptor colinérgico nicotínico ( $\alpha 1-\mathrm{AChR})(\mathbf{B})$ em músculo tibial anterior inervado e desnervado (DEN) de camundongo. Os níveis de expressão gênica foram normalizados utilizando a subunidade de RNA 18S como controle endógeno. Os resultados são expressos como média \pm EPM. $* * P<0,01$ DEN vs. controle, inervado $(100 \%) ;{ }^{\#} \mathrm{P}<0,05, \mathrm{DEN}+\mathrm{CB}$ vs. $\mathrm{DEN}+$ Sal.

Além do modelo catabólico induzido pela DEN, foi também analisado o efeito do tratamento crônico com $\mathrm{CB}$ na estabilização dos $\mathrm{AChR}$ em animais miastênicos que apresentam uma mutação na subunidade $\varepsilon$ do receptor nicotínico (AChR-عL269F). Estes animais exibem miopatia específica na placa motora (GROSHONG et al., 2007), sendo assim, nestes animais não foi realizada a cirurgia de desnervação. Em comparação com os camundongos $\varepsilon \mathrm{L} 269 \mathrm{~F}$ tratados com salina, o tratamento com $\mathrm{CB}$ produziu aumento adicional do pool de AChR de meia vida curta na placa motora (Fig. 19A-B). 

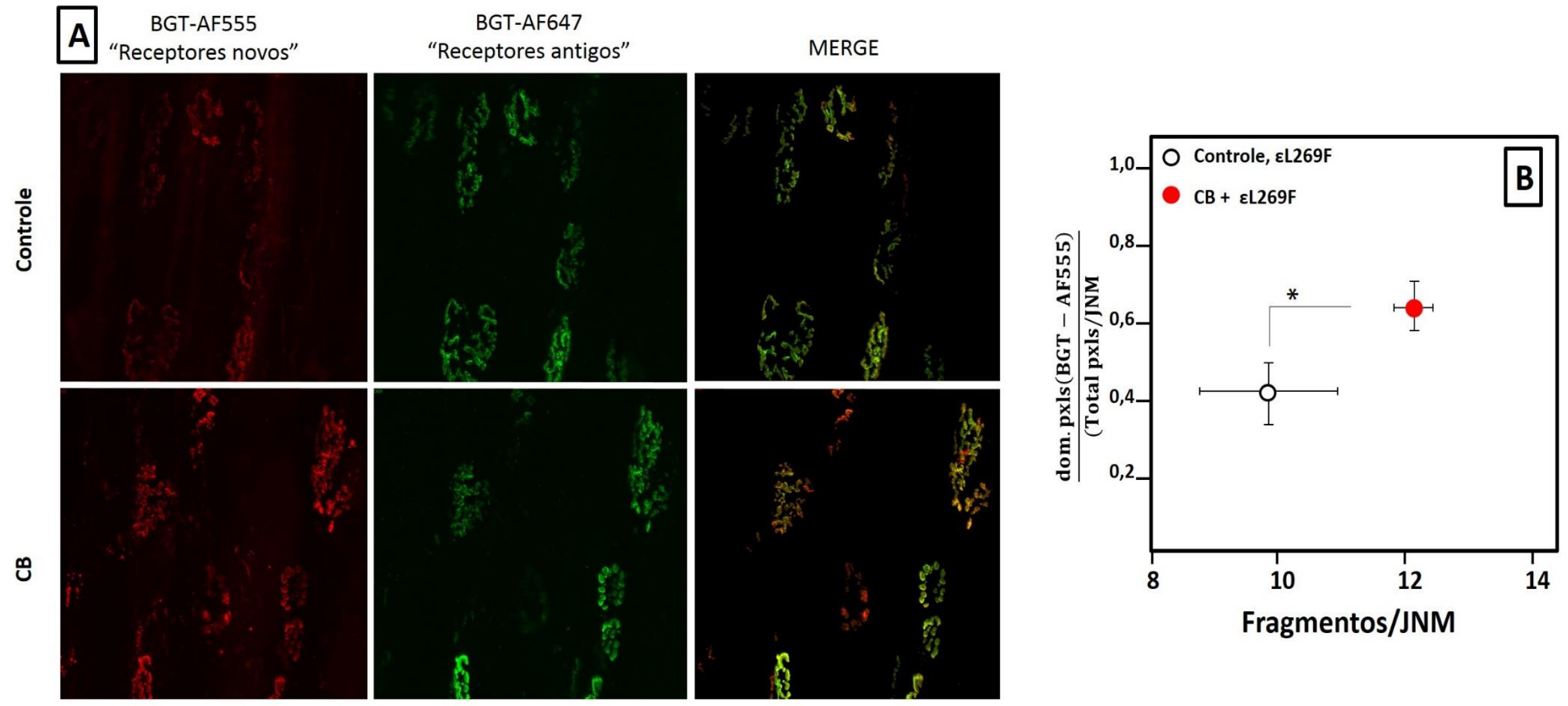

Figura 19. A: Imagens representativas do efeito do tratamento com clembuterol (CB; $3 \mathrm{mg} \cdot \mathrm{kg}^{-1} \cdot \mathrm{dia}^{-1}$, s.c.) ou salina (Sal) na estabilidade do receptor colinérgico nicotínico (AChR) em músculo tibial anterior de camundongos com a mutação AChR-eL269F. (A) Os AChR foram marcados com BGT-AlexaFluor 647 ("para visualização dos receptores antigos”) e depois de 10 dias com BGT-AlexaFluor 555 (para visualização dos "receptores novos"); barra de escala, $50 \mu \mathrm{m}$. B: Análise quantitativa da relação de pixels dominantes de ambos os sinais dos receptores "novos" e "antigos" por fragmentos de junção neuromuscular (JNM). Os resultados são expressos como média \pm EPM (n = 6). * P $<0,05$. 
4.6. Efeito da estimulação colinérgica no metabolismo de proteínas em músculos isolados de ratos

Embora a ACh seja o principal neurotransmissor presente na sinapse neuromuscular (Chen et al. 2007), muito pouco se conhece sobre o efeito da estimulação colinérgica no metabolismo de proteínas em músculos esqueléticos. Com esta finalidade, músculos soleus (oxidaticos) e EDL (glicolíticos) de ratos foram utilizados nesses estudos in vitro, uma vez que eles são facilmente removidos e há menor probabilidade de lesão quando comparados a músculos de camundongos.

Para avaliar o efeito da estimulação colinérgica na degradação de proteínas totais, músculos soleus e EDL de animais normais foram incubados na presença de diferentes concentrações de carbacol $\left(10^{-7}\right.$ a $\left.10^{-3} \mathrm{M}\right)$, um agonista colinérgico. A Fig. 20A mostra que o carbacol aumentou a proteólise total de forma concentração-dependente em músculos soleus. O efeito máximo na proteólise causado pelo carbacol $\left(10^{-4} \mathrm{M}\right)$ foi de 52\% (Fig. 20A) no soleus. Este aumento da atividade proteolítica foi completamente bloqueado quando os músculos soleus foram incubados na presença de concentrações equimolares de carbacol e D-tubocurarina, um antagonista de receptores nicotínicos, (Fig. 21). Concentrações menores de carbacol $\left(10^{-7}-10^{-6} \mathrm{M}\right)$ não alteraram a proteólise total. Não houve qualquer alteração na degradação proteica em músculos EDL incubados com as diferentes concentrações de carbacol (Fig. 20B). Para confirmar se os dados obtidos acima não eram decorrentes de alterações do transporte do aminoácido foi mensurado o pool de tirosina em músculos soleus e EDL após incubação com $10^{-3} \mathrm{M}$ de carbacol. Não houve diferença no pool de tirosina em nenhum dos músculos incubados em relação ao controle (dados não apresentados).

Posteriormente, a velocidade de síntese proteica foi avaliada em músculos soleus e EDL incubados com carbacol $\left(10^{-4} \mathrm{M}\right)$, sendo observada uma redução de cerca de $24 \%$ 
na incorporação de tirosina marcada em proteínas totais de músculos soleus, mas não em EDL (Fig. 22).
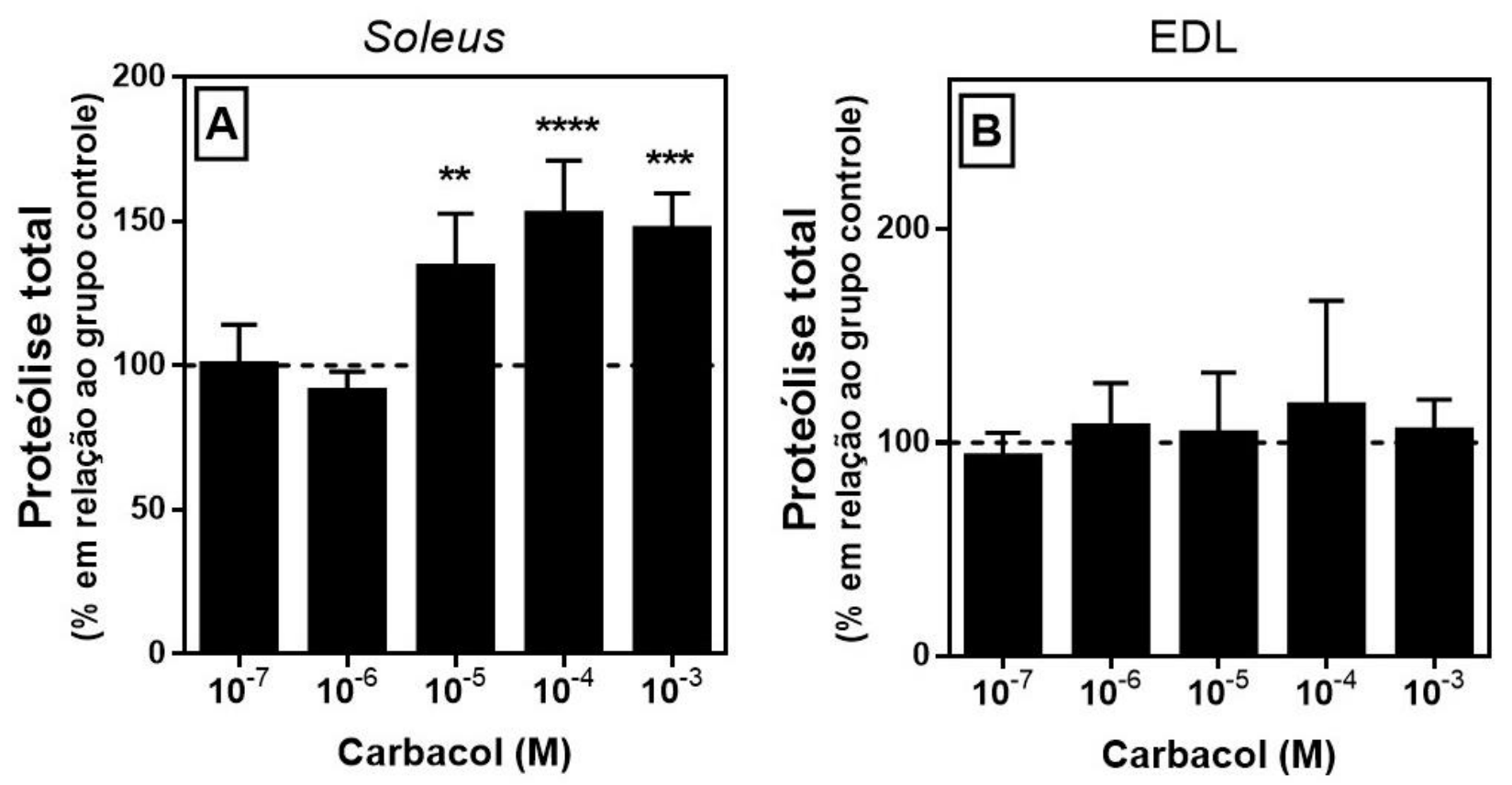

Figura 20. Efeito in vitro do carbacol $\left(10^{-7}\right.$ a $\left.10^{-3} \mathrm{M}\right)$ na atividade proteolítica total de músculos soleus (A) e EDL (B) normais de ratos. Os resultados são expressos como médias percentuais \pm EPM $(n=4-5)$ dos valores de liberação de tirosina (nmol Tyr.mg${ }^{1} .2 \mathrm{~h}^{-1}$ ) de músculos incubados na presença de carbacol em relação aos controles (considerados como 100\%). * $\mathrm{P}<0.05 ; * * \mathrm{P}<0.01$; $* * * * \mathrm{P}<0.001$ controle $(100 \%)$ vs. carbacol. Os valores médios do grupo controle foram $0,330 \pm 0,023 \mathrm{nmol}$ Tyr.mg ${ }^{-1} \cdot 2 \mathrm{~h}^{-1}$

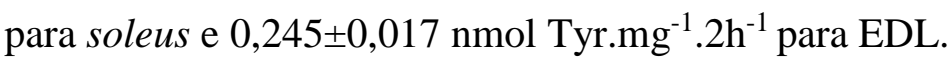




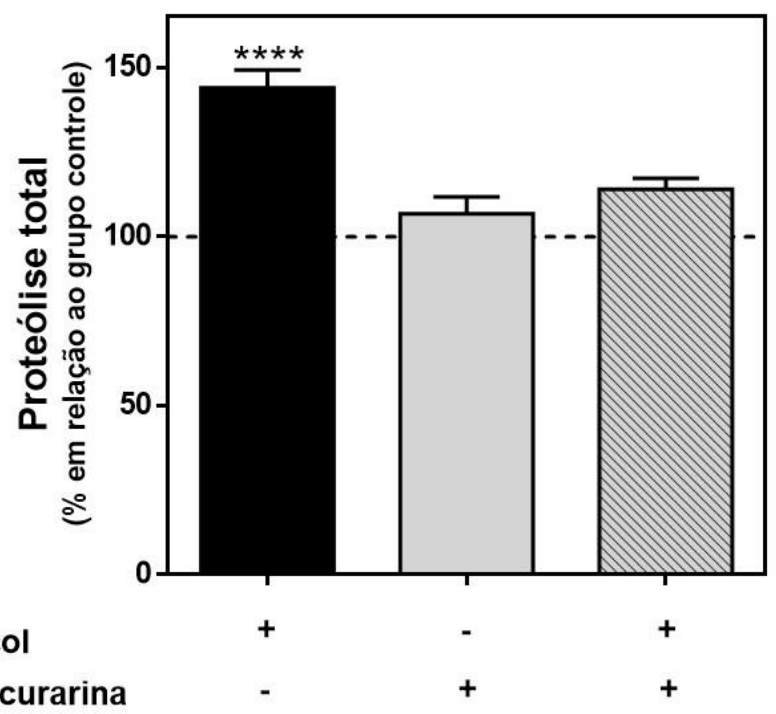

Figura 21. Efeito in vitro do carbacol $\left(10^{-4} \mathrm{M}\right)$ na presença ou não de D-tubocurarina $\left(10^{-4} \mathrm{M}\right)$ na proteólise total em músculos soleus de ratos normais. Os valores são expressos como média \pm EPM $(\mathrm{n}=7)$. $* * * * \mathrm{P}<0,0001$ Controle vs Carbacol. $\mathrm{O}$ valor médio do grupo controle foi $0,380 \pm 0,021 \mathrm{nmol}$ Tyr.mg músculo ${ }^{-1} \cdot 2 \mathrm{~h}^{-1}$.

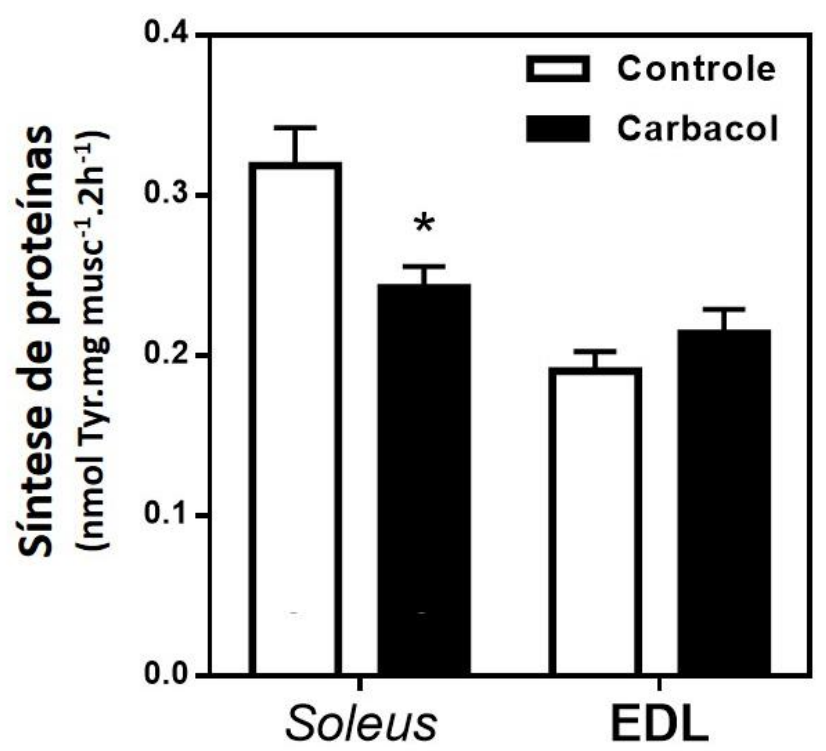

Figura 22. Efeito in vitro do carbacol $\left(10^{-3} \mathrm{M}\right)$ na velocidade de síntese proteica em músculos soleus e EDL de ratos. Os dados são expressos como média \pm EPM. $*$ P $<0,05$ controle vs carbacol; $\mathrm{n}=5-7$. 
Após a demonstração do efeito proteolítico exercido pela estimulação colinérgica nicotínica in vitro, este estudo teve como objetivo investigar qual (quais) das diferentes vias proteolíticas seria $(\mathrm{m})$ a(s) responsável (eis) por tal resposta biológica em situações basais. Para isto, foram investigadas as participações das vias lisossomal, dependente de Ub-proteassoma e dependente de $\mathrm{Ca}^{2+}$ em músculos soleus de ratos incubados na presença do carbacol $\left(10^{-3} \mathrm{M}\right)$.

A figura 23 mostra que a incubação de músculos de ratos normais na presença do carbacol aumentou a atividade proteolítica do sistema dependente de $\mathrm{Ca}^{2+}(140 \%)$ sem produzir qualquer alteração na atividade dos sistemas Ub-proteassoma e lisossomal (Fig. 23A-C). Em conjunto, esses resultados demonstram que a acetilcolina é capaz de induzir efeitos catabólicos no metabolismo de proteínas musculares por meio da ativação da proteólise dependente de $\mathrm{Ca}^{2+}$ e da diminuição da síntese proteica através da estimulação de receptores nicotínicos. 

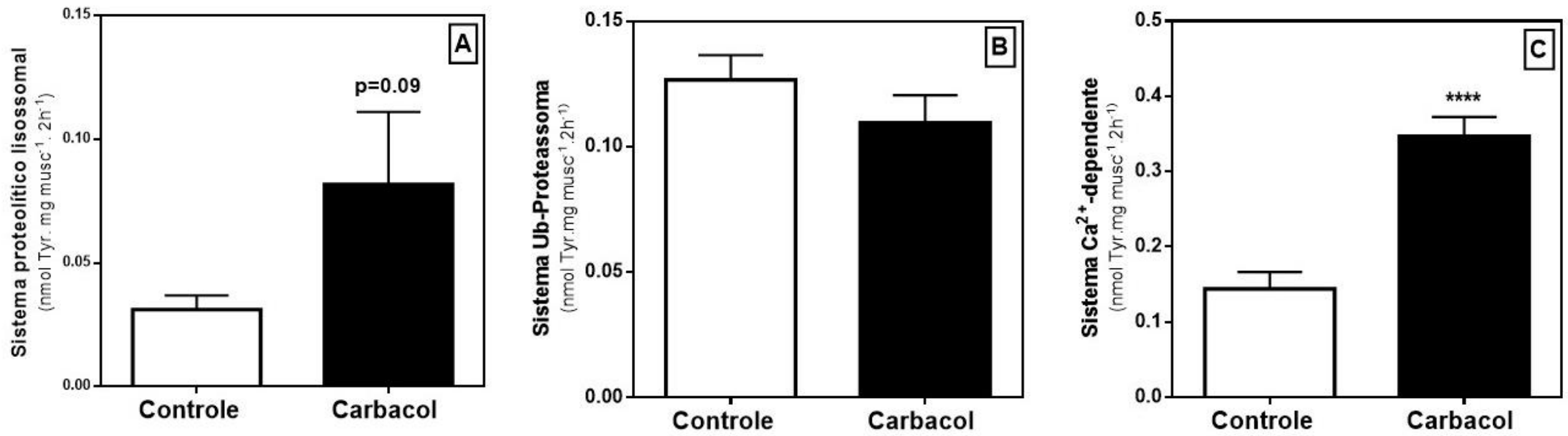

Figura 23. Efeito in vitro do carbacol $\left(10^{-4} \mathrm{M}\right)$ nas atividades proteolíticas lisossomal (A), dependente de Ubiquitina-Proteassoma (UPS) (B) e dependente de $\mathrm{Ca}^{2+}(\mathrm{C})$ em músculos soleus de ratos normais. Os resultados são expressos como média \pm EPM. $* * * * \mathrm{P}<0,0001 \mathrm{Controle}$ vs Carbacol; $\mathrm{n}=5-7$. 
Considerando que os $\beta_{2}$-AR estão presentes na JNM (Fig.13) e que a ativação dos mesmos diminui a degradação proteica por meio da inibição da proteólise $\mathrm{Ca}^{2+}{ }_{-}$ dependente em músculos soleus de ratos (NAVEGANTES et al., 2001), tornou-se interessante investigar se o CB seria capaz de atenuar a resposta proteolítica induzida pela ativação colinérgica muscular in vitro. Para isto, músculos soleus normais de ratos foram incubados na presença de $10^{-4} \mathrm{M}$ de carbacol e/ou de $10^{-4} \mathrm{M}$ de $\mathrm{CB}$. Como pode ser observado na Fig. 24, o carbacol adicionado isoladamente aumentou drasticamente a proteólise, enquanto o $\mathrm{CB}$ a diminuiu. Quando os músculos foram co-incubados com os dois fármacos, observou-se que o CB foi capaz de bloquear completamente os efeitos do carbacol na indução da proteólise total.

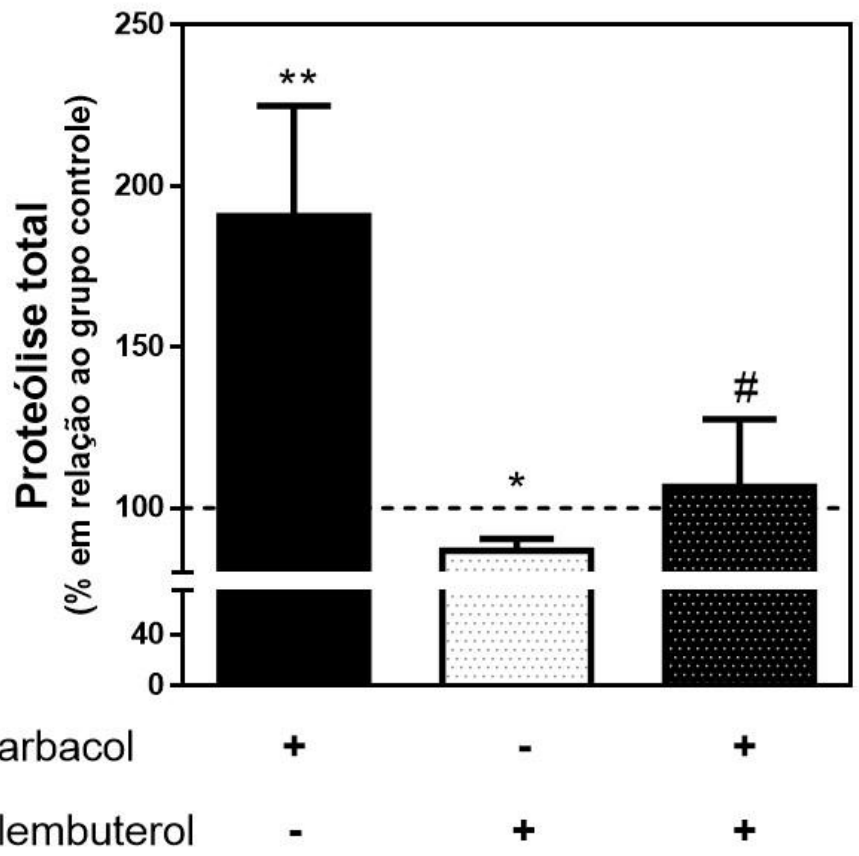

Figura 24. Efeito in vitro do carbacol $\left(10^{-4} \mathrm{M}\right)$ e/ou do clembuterol $\left(\mathrm{CB}, 10^{-4} \mathrm{M}\right)$ na proteólise total em músculos soleus de ratos normais. Os valores são expressos como média \pm EPM. * $\mathrm{P}<0,05$ Carbacol vs controle $(100 \%) ; * * \mathrm{P}<0,001$ Carbacol vs controle (100\%); \# $\mathrm{P}<0,001$ Carbacol vs carbacol $+\mathrm{CB}$; $\mathrm{n}=4-5$. A média obtida do grupo controle foi $0,290 \pm 0,015 \mathrm{nmol}$ Tyr. mg músculo ${ }^{-1} \cdot 2 \mathrm{~h}^{-1}$. 


\section{DisCUSSÃo}

Há um interesse crescente no desenvolvimento de estratégias terapêuticas para combater a perda de massa muscular e a desestruturação da placa motora afim de melhorar a função do músculo e reduzir as complicações desta condição.

Neste sentido, os $\beta_{2}$-agonistas emergem como potenciais candidatos para atenuar a atrofia e a desestabilização da JNM uma vez que: i) os $\beta_{2}$-AR são os receptores adrenérgicos mais expressos na fibra muscular esquelética (KIM et al., 1991); ii) a estimulação aguda e/ou crônica destes receptores pode atenuar a perda de massa muscular em diversas condições atróficas (Ryall \& Lynch 2008) e melhorar a função contrátil muscular em pacientes miastênicos (ENGEL et al., 2010; LIEWLUCK; SELCEN; ENGEL, 2011); iii) a sinalização canônica ativada pelos $\beta_{2}$-AR é a via do AMPc/PKA que está envolvida com a inibição da atividade dos sistemas proteolíticos Ub-proteassoma e lisossomal (COSTELLI et al., 1995; GONÇALVES et al., 2012) e com a manutenção da placa motora (KHAN et al., 2014; LIBBY; BURSZTAJN; GOLDBERG, 1980; RUDOLF et al., 2013). Assim, o principal objetivo deste trabalho foi elucidar o papel do SNS na manutenção da massa muscular e da placa motora e sua possível interação funcional com a inervação colinérgica motora.

Nossos resultados confirmaram que o tratamento crônico com $\mathrm{CB}$, um $\beta_{2}$ agonista seletivo, foi capaz de diminuir a perda de massa muscular e controlar a expressão dos genes relacionados à atrofia e autofagia em músculos desnervados e, concomitantemente, aumentar a síntese/incorporação de AChR na JNM. Além disso, foi demonstrado que neurônios catecolaminérgicos estabelecem contato direto com a JNM sugerindo que os AChR podem estar sob controle neuro-humoral das catecolaminas, as 
quais parecem contra regular os efeitos catabólicos induzidos pela estimulação colinérgica no metabolismo de proteínas musculares em condições in vitro.

\subsection{Efeitos anti-atróficos da estimulação crônica dos receptores $\beta_{2}$-AR em músculos desnervados}

Embora o tratamento com drogas simpatomiméticas seja uma terapia bastante conhecida por induzir aumento de massa muscular em diversas espécies animais (LYNCH; RYALL，2008; NAVEGANTES; MIGLIORINI; KETTELHUT，2002; RYALL; CHURCH; LYNCH, 2010), o efeito do tratamento crônico com $\beta_{2}$-agonistas e os mecanismos moleculares envolvidos nesta resposta ainda precisam ser melhor elucidados. Sendo assim, camundongos foram submetidos à DEN unilateral e tratados com salina ou CB por até 14 dias. A perda desta inervação motora induzida pela secção do nervo isquiático é um modelo experimental com uma importância clínica relevante, uma vez que induz atrofia muscular e, ao mesmo tempo, desestabiliza os AChR e reduz a sua meia vida (KHAN et al., 2014; RUDOLF et al., 2013; STRACK et al., 2011). Como esperado a DEN induziu perda de massa muscular gradativa ao longo do tempo em animais tratados com salina (Fig. 5) e este efeito foi atenuado pelo tratamento diário com CB. Tendo em vista que a DEN induz diminuição da massa muscular por meio da redução da síntese e aumento da degradação proteica (MALTIN et al., 1989), ainda não é conhecido qual desses eventos metabólicos é o determinante para a ação anabólica dos $\beta_{2}$-agonistas. A dificuldade para a compreensão deste mecanismo pode ser devido à utilização de músculos com diferentes perfis metabólicos, uma vez que a atrofia induzida pela desnervação, por razões desconhecidas, apresenta diferentes magnitudes de respostas em músculos oxidativos e glicolíticos (HUEY; BODINE, 1998; MORGAN; LOUGHNA, 1999). Por exemplo, músculos de contração lenta e 
tipicamente oxidativos, como o soleus de ratos, são mais afetados pela desnervação quando comparados a músculos glicolíticos como o extensor digitorium longus (EDL). Mas, curiosamente, as fibras musculares oxidativas têm uma maior densidade de $\beta_{2}$-AR do que a fibras glicolíticas de contração lenta (WILLIAMS; CARON; DANIEL, 1984). Considerando que a estimulação neural é um dos determinantes mais importantes para a expressão gênica nos músculos esqueléticos e a perda da inervação motora culmina com a ativação de diferentes vias de degradação proteica, foi avaliado a expressão de genes e o conteúdo proteico de diferentes componentes dos principais sistemas proteolíticos na musculatura esquelética, isto é, o Ub-proteassoma e lisossomal. A participação destes sistemas tem sido amplamente associada à perda de massa muscular e levou à identificação de um sub-conjunto de genes conhecidos como atrogenes ou genes relacionados à atrofia. Os principais atrogenes são aqueles que codificam as Ub-ligases específicas da musculatura estriada, a atrogina-1/MAFbx e MuRF1, que são as proteínas responsáveis pelo processo de ubiquitinação de proteínas e, consequente, degradação pelo proteassoma (BODINE et al., 2001a; GOMES et al., 2001). De fato, camundongos nocautes para atrogina-1 ou MuRF1 são parcialmente resistentes à perda de massa muscular induzida pela desnervação motora (BODINE et al., 2001a).

Neste estudo, foi observado que após três dias de DEN houve uma superexpressão de atrogina-1 e MuRF1 tanto em nível gênico como no conteúdo proteico indicando aumento da atividade do sistema dependente de Ub-proteassoma em músculos desnervados. Estes resultados estão de acordo àqueles descritos por Medina et al. (1995), os quais foram um dos primeiros a demonstrar que a desnervação atrófica aumenta a atividade proteolítica dependente de Ub-proteassoma, o conteúdo de proteínas miofibrilares conjugadas à Ub e os níveis de RNAm da Ub e das subunidades 
C3 e C9 do proteassoma. Nossos resultados demonstram que o CB completamente aboliu o aumento na expressão destes genes induzidos pela DEN e estão de acordo com aqueles obtidos por Gonçalves et al. (2009; 2012), os quais observaram que o tratamento agudo com $\beta_{2}$-agonista foi capaz de atenuar a expressão dos atrogenes em músculos de animais jejuados ou submetidos à DEN.

Após sete dias de DEN, a expressão de ambos atrogenes foi reduzida e se equiparou aos valores obtidos em músculos inervados. Este perfil bifásico da expressão dos atrogenes foi descrito desde a descoberta do envolvimento de MuRF1 e atrogina-1 na indução do processo atrófico (Bodine et al. 2001a; Gomes et al. 2001). Sacheck et al. (2007) foram os primeiros a associar este fenômeno com a rápida perda de massa muscular que ocorre nos períodos iniciais de DEN e, posteriormente, com a sua diminuição, sugerindo que outros mecanismos possam estar envolvidos com a atrofia em períodos tardios da desnervação. De fato, vários outros genes relacionados à atrofia apresentam interesse, incluindo os genes que codificam os componentes do sistema lisossomal/autofágico como a LC3 e o da protease catepsina L.

Foi observado que a desnervação promoveu aumento da expressão dos genes da LC3 e da catepsina L (Fig. 7). No entanto, o pico de expressão destes genes autofágicos ocorreu sete dias após a cirurgia, o que demonstra que durante o processo catabólico induzido pela desnervação há um programa atrófico que coordena temporalmente a ativação dos diferentes sistemas proteolíticos celulares (SACHECK et al., 2007). Por outro lado, o tratamento com CB foi capaz de reduzir a atividade transcricional destes estes genes. Embora não se tenha investigado o processo de síntese em nosso modelo experimental, é possível sugerir que a atenuação da atrofia induzida pelo CB em músculos desnervados é, pelo menos em parte, mediada pela inibição dos sistemas Ubproteassoma e lisossomal. 
A sinalização do AMPc/PKA é a via clássica ativada pelos $\beta_{2}$-agonistas na musculatura esquelética e é geralmente associada aos efeitos anabólicos e anticatabólicos induzidos pelas catecolaminas (LYNCH; RYALL, 2008). Estudos anteriores do nosso laboratório demonstraram que o tratamento in vivo e in vitro de ratos diabéticos (BAVIERA et al., 2007) ou sépticos (LIRA et al., 2011) com drogas que aumentam o conteúdo de AMPc reduz a atividade do sistema Ub-proteassoma. Mais recentemente, foi demonstrado que o tratamento em curto-prazo com CB suprimiu a hiperexpressão induzida pela DEN do RNAm para MuRF1, atrogina-1 e catepsina L. Este efeito parece ser dependente da via de sinalização do AMPc/PKA, uma vez que o 6-BNZ-cAMP, um antagonista seletivo da PKA, aboliu os efeitos inibitórios do CB na expressão das Ub-ligases e na proteólise (GONÇALVES et al., 2012). Para melhor compreender o papel da via do AMPc em nosso modelo experimental, o conteúdo de AMPc e a atividade da PKA foram avaliados em músculos desnervados de animais tratados com salina ou CB. Observou-se aumento do conteúdo de AMPc e fosfosubstratos de PKA em músculos de camundongos desnervados por 3 dias e tratados com CB. Neste mesmo período de desnervação, o conteúdo dos atrogenes foi reduzido pelo CB (Fig. 6), sugerindo que esta via de sinalização pode ser a responsável pelo efeito anticatabólico do $\beta_{2}$-agonista. De fato, o aumento do AMPc produzido pelo tratamento com inibidores não seletivos da PDE do AMPc bloqueou completamente a hiperexpressão da atrogina- 1 induzida pela dexametasona em linhagens de células $C_{2} C_{12}$ (GONÇALVES et al., 2009). Estes mesmos autores demostraram que a ativação dos $\beta_{2}$ $\mathrm{AR}$ pelo tratamento in vivo com $\mathrm{CB}$ e o consequente aumento do AMPc resultam em inibição da atividade do sistema Ub-proteassoma e da expressão da atrogina-1 em músculo gastrocnêmio de camundongos jejuados (GONÇALVES et al., 2009). Em concordância com estes resultados, foi demonstrado que a expressão de atrogina-1 e 
MuRF1, tanto basal como a induzida pela desnervação, é inibida por ativadores sintéticos da PKA in vitro (GONÇALVES et al., 2012). Em conjunto, esses resultados indicam que a via do AMPc/PKA participa da modulação inibitória do sistema Ubproteassoma em situações basais e atróficas.

Foi também observado que, após sete dias de cirurgia, houve aumento da atividade da via do AMPc/PKA induzida pela própria DEN, sem efeito adicional evidente produzido pelo CB. Neste mesmo período foi observado diminuição da expressão de MuRF1 e atrogina-1 (Fig. 9), indicando que, independentemente do tratamento com CB, a DEN per se pode induzir aumento do AMPc. Resultados semelhantes foram descritos de forma isolada por outros autores que demonstraram que a DEN aumentava a atividade da adenilato ciclase e concomitante a atividade da PKA e do conteúdo de uma de suas subunidades regulatórias, a RI alfa em músculos gastrocnêmios de ratos (HOOVER et al., 2001; SUZUKI et al., 1998). Aventou-se, então, a possibilidade de que o aumento deste segundo mensageiro pudesse fazer parte de um mecanismo adaptativo muscular de hipersensibilidade às catecolaminas circulantes que pudesse levar à supressão dos atrogenes em períodos tardios da DEN. Esta hipótese foi baseada nas evidências anatômicas apresentadas nesse estudo de que fibras simpáticas noradrenérgicas trafegam ao longo do nervo ciático e que a DEN reduz o conteúdo de noradrenalina muscular. Além disso, um estudo recente de nosso laboratório demonstrou que a simpatectomia lombar (remoção seletiva dos gânglios simpáticos que inervam os músculos da pata posterior) aumentou a atividade enzimática da adenilato ciclase e o conteúdo do AMPc muscular e, em paralelo, diminuiu a atividade proteolítica do sistema Ub-proteassoma (SILVEIRA et al., 2014). Os experimentos realizados neste estudo com animais adrenodemedulados e desnervados indicam que a adrenalina plasmática pode ser a responsável por mediar as respostas 
adaptativas induzidas pela DEN, uma vez que a remoção da medula da adrenal potencializou os efeitos da desnervação no conteúdo proteico de MuRF1 e atrogina-1. No entanto, experimentos adicionais precisam ser realizados para confirmar a hipótese da hipersensibilidade adrenérgica em resposta à secção do nervo motor.

\subsection{Mecanismos subsinápticos envolvidos na ativação simpática das JNM}

É bem estabelecido que a estimulação simpática pode ocorrer por meio da liberação de adrenalina no plasma pela medula da adrenal ou a partir da liberação de noradrenalina pelos neurônios catecolaminérgicos diretamente em tecidos-alvo (MASON, 1968). Porém, pouco se sabe acerca da real contribuição destes dois componentes simpáticos nos diferentes tecidos e, mais especificamente, no músculo esquelético (BARKER; SAITO, 1981; TADAKI et al., 1995). Poucos estudos relatam a presença da inervação direta das fibras musculares esqueléticas por fibras não mielinizadas, noradrenérgicas sugerindo que as ações simpáticas no músculo esquelético podem ser mediadas por mecanismos neurais (BARKER; SAITO, 1981). O presente estudo confirma estas observações prévias e mostra, convincentemente, que neurônios noradrenérgicos, identificados pela presença da enzima tirosina-hidroxilase, também fazem contato direto com AChR nas JNM. Embora o papel fisiológico desta inervação ainda permaneça completamente obscuro, diversos relatos na literatura demonstram que simpatomiméticos são capazes de aumentar a força de contração (BOWMAN; RAPER, 1967) e a liberação de ACh pelos neurônios motores (BUKHARAEVA; NIKOLSKY, 2002), indicando que a interação entre o sistema adrenérgico e colinérgico pode ser importante durante situações de "luta e fuga". 
Uma vez que o principal alvo da noradrenalina nas fibras musculares esqueléticas são os $\beta_{2}$-AR(LYNCH; RYALL, 2008), avaliou-se a presença destes receptores nas fibras musculares e nas sinapses de músculos de camundongos em condições in vivo. Como esperado, foi observada por técnicas de imunohistoquímica uma alta densidade de $\beta_{2}$-AR em secções longitudinais musculares, muito provavelmente presentes na região do sarcolema e na vasculatura muscular. Com a superexpressão de um biossensor molecular $\left(\beta_{2}\right.$-AR-sPep) produziu-se evidência adicional da presença de $\beta_{2}$-AR póssinápticos na porção da JNM (Fig. 13). A imagem microscópica do músculo do camundongo anestesiado expressando $\beta_{2}$-AR-sPep demonstrou que os $\beta_{2}$-AR podem ser ativados pela estimulação elétrica do nervo ciático. Posteriormente, com um auxílio de um segundo biossensor para produção de AMPc especificamente na JNM foi demonstrado que a estimulação elétrica do nervo ciático levou a um aumento significativo no conteúdo de AMPc subsináptico. Este aumento é provavelmente mediado por fibras noradrenérgicas que trafegam ao longo do nervo motor (Fig. 14) uma vez que tanto a simpatectomia local induzida pela administração de 6hidroxidopamina, bem como o tratamento com ICI-118551, um antagonista seletivo dos $\beta_{2}$-AR reduziu o aumento na produção de AMPc induzido pela estimulação do nervo ciático. Em conjunto, estes resultados demonstram, pela primeira vez na literatura, que a presença de conexões simpáticas funcionais nas JNM são capazes de ativar os $\beta_{2}$-AR e produzir AMPc. 


\subsection{Efeito do tratamento com CB no turnover dos AChR na JNM de músculos desnervados}

Tendo em vista que a JNM possui $\beta_{2}$-AR e o CB é capaz de atenuar a ativação dos dois principais sistemas proteolíticos no músculo esquelético, investigou-se o possível efeito benéfico da estimulação crônica dos $\beta_{2}$-AR no turnover dos $\mathrm{AChR}$ em músculos desnervados. Esta ideia é consistente com a redução na taxa de degradação de AChR promovida pela inibição dos sistemas proteassomal ou lisossomal em cultura de células musculares (CHRISTIANSON; GREEN, 2004; LIBBY; BURSZTAJN; GOLDBERG, 1980). Além disso, camundongos nocautes para MuRF1 apresentam aumento da meiavida dos AChR em músculos desnervados (RUDOLF et al., 2013).

Como indicado pelo experimento com ${ }^{125}$ I-BGT, o tratamento com CB não alterou a cinética de meia-vida curta ou longa da população de AChR tanto em músculos inervados como em desnervados. Em estudos com diafragmas desnervados de ratos, os análogos de AMPc apenas diminuíram a taxa de degradação de receptores de meia-vida longa sem alterar aqueles de meia-via curta (SHYNG; XU; SALPETER, 1991). Nossos resultados também mostram que a população de $\mathrm{AChR}$ de meia-vida curta em músculos desnervados aumentou substancialmente, sendo este um efeito bastante conhecido na literatura (AXELSSON; THESLEFF, 1959; HARTZELL; FAMBROUGH, 1972) e creditado à maior expressão da subunidade $\gamma$ (fetal) em relação a subunidade $\varepsilon$ presente em músculos adultos (MISSIAS et al., 1996; VILLARROEL; SAKMANN, 1996). Embora a relevância biológica da troca de subunidades $\varepsilon / \gamma$ no músculo desnervado não possa ser explicada a nível molecular, sabe-se que todos os subtipos de AChR são essenciais para a função sináptica normal. Por exemplo, animais nocautes para subunidade $\gamma$ morrem ao nascimento (TAKAHASHI et al., 2002), enquanto que 
camundongos nocautes para subunidade $\varepsilon$ morrem prematuramente devido à grave fraqueza muscular (WITZEMANN et al., 1996). Além disso, estudos prévios demonstraram que o gene que codifica a subunidade $\alpha$ do AChR apresenta região promotora responsiva à CREB (KANG et al., 2003), indicando que o aumento do conteúdo do AChR observado em músculos desnervados pode ser também resultado do aumento intrínseco da via de sinalização do AMPc/PKA.

Vale lembrar que embora nosso método de estudo com o ${ }^{125}$ I-BGT permita determinar a cinética da meia-vida dos AChR in vivo (STRACK et al., 2011) e tenha a vantagem de investigar os músculos do mesmo animal durante todo o período experimental, o mesmo não é capaz de discriminar a população de AChR na membrana celular ou em compartimentos intracelulares. Isto se deve ao fato de que o receptor, para ser degradado, deve ser internalizado. Como a BGT é uma toxina de ligação irreversível, ela permanece acoplada ao receptor no interior da célula até ser clivada. Portanto, para confirmar ou não os resultados obtidos com este protocolo foram realizados experimentos de microscopia confocal in vivo.

Consistente com os efeitos da desnervação motora na hiperexpressão das subunidades do AChR, observou-se um aumento significativo de "novos" receptores nos músculos DEN, porém este aumento foi ainda mais evidente após o tratamento com CB. Resultados similares também foram observados nos músculos de animais com a mutação AChR-єL269F. Por outro lado, observou-se aumento da expressão do RNAm para $\alpha 1$-AChR nos músculos DEN tratados com CB. Este resultado está de acordo com o aumento da expressão do RNAm para as subunidades $\alpha-, \beta-, \gamma^{-}, \varepsilon^{-}$e $\delta$ - AChR induzida pela forscolina (um ativador da adenilato ciclase), CPT-AMPc (um análogo do $\mathrm{AMPc}$ ) ou isobutil-1-metilxantina (um inibidor não seletivo da PDE do $\mathrm{AMPc}$ ) em cultura primária de músculo de ratos (Green et al. 1991; Chahine et al. 1993). 
Corroborando estes dados, foi descrito que o isoproterenol, adrenalina ou noradrenalina produziram efeitos semelhantes nos conteúdos de AChR em cultura de miotubos sem alterar a taxa de degradação do receptor (BLOSSER, 1983). Considerando estes resultados e o fato de que indivíduos miastênicos, em geral, apresentam menor expressão do AChR (ENGEL et al., 2010) é possível sugerir que a eficácia da terapia simpatomimética neste grupo de pacientes não se deva à diminuição da degradação dos AChR, mas sim ao aumento da expressão deste receptor (LIEWLUCK; SELCEN; ENGEL, 2011).

O presente trabalho também demonstra que o número de vesícula endocíticas presentes nas JNM de músculos desnervados e tratados com CB foi diminuída em relação aos músculos DEN. Uma vez que LC3 e MuRF1 estão localizadas em vesículas endocíticas contendo o AChR e que a desnervação motora aumenta o número de vesículas sendo este efeito completamente inibido em animais nocautes para MuRF1 (KHAN et al., 2014), é possível sugerir que a diminuição do conteúdo de MuRF1 e LC3 (Figs. 6-7) produzida pelo tratamento crônico com $\mathrm{CB}$ em músculos desnervados também esteja relacionada com a diminuição do número de vesículas endocíticas na JNM promovida por este $\beta$-agonista.

Este conjunto de dados permitem sugerir que o tratamento in vivo com $\mathrm{CB}$ em músculos desnervados, através da via de sinalização do AMPc/PKA, aumenta a transcrição da subunidade $\alpha$-AChR e reduz o número de vesículas endocíticas nas JNM aumentando a incorporação de receptores nas membranas sarcoplasmáticas. 


\subsection{Efeito da estimulação colinérgica no metabolismo de proteínas em músculos isolados de ratos}

A função primária da neurotransmissão colinérgica em músculos esqueléticos é a geração da contração muscular, a qual possibilita a realização de movimentos e promove locomoção. Esta função está diretamente associada à manutenção da massa muscular uma vez que a perda da inervação motora ou a imobilização leva à atrofia devido à inatividade das fibras musculares. Para melhor compreender o papel da ACh no controle do metabolismo de proteínas em músculos esqueléticos, um dos objetivos desse trabalho foi investigar o efeito direto da estimulação colinérgica, através do uso do carbacol, na degradação total e na velocidade de síntese proteica em músculos soleus e EDL normais de ratos in vitro.

Foi observado que o carbacol aumentou de forma concentração-dependente a proteólise total em músculos soleus através da estimulação de receptores nicotínicos, uma vez que o antagonista deste receptor, D-tubocurarina, inibiu completamente a indução da proteólise promovida por este agonista colinérgico. Curiosamente, não houve alteração em nenhum dos parâmetros estudados em músculos EDL. Esta falta de resposta do músculo EDL ao carbacol é difícil de ser compreendida uma vez que, morfologicamente, a inervação colinérgica e a sinapse neuromuscular é mais vasta em EDL do que em músculos oxidativos como o soleus (PADYKULA; GAUTHIER, 1970; SCHIAFFINO; REGGIANI, 2011). Por outro lado, em músculos de contração rápida como o EDL há um maior conteúdo e atividade da enzima acetilcolinesteare (AChE) (SKETELJ et al., 1997), da bomba para $\mathrm{Ca}^{2+}$, SERCA (SMITH et al., 2013) e o reticulo sarcoplasmático mais desenvolvido que em músculos soleus (SCHIAFFINO; 
MARGRETH, 1969) o que permite especular que a alta velocidade de remoção da estimulação colinérgica em músculos de EDL seja uma das explicações deste fenômeno (CHUA; DULHUNTY, 1988),

O efeito catabólico do carbacol foi associado a uma potente estimulação da proteólise dependente de $\mathrm{Ca}^{2+}$ sem alteração das atividades proteolíticas dos sistemas Ub-proteassoma e lisossomal. Considerando que a ação contrátil da ACh depende do aumento do $\mathrm{Ca}^{2+}$ intracelular no músculo é coerente observar ativação de um sistema proteolítico que dependa do aumento citosólico deste íon. De fato, Chen et al. (2007) demonstraram que miotubos $\mathrm{C}_{2} \mathrm{C}_{12}$ incubados com carbacol apresentaram alta atividade das calpaínas e este efeito foi associado à maior dispersão dos aglomerados dos AChR. Além de promover aumento do $\mathrm{Ca}^{2+}$, há evidências de que a ativação colinérgica possa reduzir o conteúdo intracelular do AMPc, um segundo mensageiro que está envolvido na inibição tônica do sistema proteolítico dependente de $\mathrm{Ca}^{2+}$ (Navegantes et al. 2001). Murad et al. (1962) demonstraram que a incubação de agonistas colinérgicos em células cardíacas foi capaz de inibir a atividade da adenilato ciclase e, consequentemente, a produção de AMPc. Além disso, Menezes-Rodrigues et al. (2013) demonstraram que o aumento do $\mathrm{Ca}^{2+}$ intracelular em diafragma de camundongos, como aquele produzido pela estimulação colinérgica, era responsável pela inibição das isoformas 5 e 6 da adenilato ciclase. Por outro lado, Garber, et al. (1978a;b) sugeriram que parte das ações catabólicas da ACh na musculatura estriada seja mediada pelo GMPc, o qual acredita-se regular positivamente diversas PDEs do AMPc (ZACCOLO; MOVSESIAN, 2007). Embora não haja evidências diretas de um possível papel catabólico do GMPc no controle do metabolismo proteico, Takimoto et al. (2005) observaram que o tratamento crônico com sildenafil, um inibidor da PDE do GMPc e AMPc, bloqueou a hipertrofia cardíaca induzida pela terapia simpatomimética em camundongos. Além disso, o 
aumento de GMPc cardíaco diminuiu os níveis de fosforilação da AKT e ERK1/2 (TAKIMOTO et al., 2005), duas enzimas chaves no processo de síntese proteica (Bodine et al. 2001b; Haddad \& Adams 2004) e que são, pelo menos parcialmente, responsáveis pelas ações anabólicas das catecolaminas em músculos esqueléticos (BAVIERA et al., 2010; SHI et al., 2009).

Em estudos prévios de nosso laboratório, foi demonstrado que parte do efeito antiproteolítico das catecolaminas (adrenalina e noradrenalina) em músculos soleus de ratos normais era mediado pela inibição da proteólise dependente de $\mathrm{Ca}^{2+}$ através de uma via dependente de AMPc sem alteração na atividade dos sistemas Ub-proteassoma e lisossomal. Em concordância com estes resultados, foi demonstrado neste estudo que a estimulação simpatomimética com o CB in vitro diminuiu a proteólise basal e bloqueou completamente o efeito proteolítico do carbacol em músculos soleus. Embora experimentos adicionais sejam necessários para elucidar os mecanismos intracelulares envolvidos na inibição da proteólise muscular induzida pelo $\mathrm{CB}$ em músculos coincubados com carbacol, é possível sugerir que o aumento do AMPc produzido pelo $\beta_{2}$ agonista possa ativar a PKA a qual é responsável por fosforilar proteínas presentes no reticulo sarcoplasmático aumentando o influxo de $\mathrm{Ca}^{2+}$ para esta organela (SCHWARTZ et al., 1976) e diminuindo sua concentração no sarcoplasma. Além disso, o CB via AMPc/PKA poderia fosforilar a calpastatina (SALAMINO et al., 1994) e a calpaína (SHIRAHA et al., 2002) aumentando e diminuindo suas atividades, respectivamente. Desta forma, estes resultados indicam que o aumento do $\mathrm{Ca}^{2+}$ e/ou a diminuição do conteúdo de AMPc pode ser um dos mecanismos pelo qual a estimulação colinérgica in vitro aumenta a degradação de proteínas dependente de $\mathrm{Ca}^{2+}$ em músculos soleus de ratos. 
80

Conlusães 


\section{Conclusão}

Considerando as evidências anteriores de experimentos realizados em nosso laboratório e os resultados obtidos neste trabalho, podemos sugerir que:

a) $\mathrm{O}$ aumento do AMPc induzido pela estimulação dos receptores $\beta_{2}$-AR no músculo esquelético e a consequente redução da expressão das $E_{3}$ ligases (atrogina-1 e MuRF-1) e dos genes autofágicos/lisossomais (catepsina L e LC3) é um dos mecanismos envolvidos na atenuação do catabolismo proteico induzido pelo $\mathrm{CB}$ em músculos desnervados;

b) A ativação intrínseca da via de sinalização do AMPc/PKA e concomitantemente atenuação da expressão dos atrogenes durante períodos tardios de desnervação indicam a existência de um mecanismo adaptativo de controle da perda de massa muscular em músculos desnervados;

c) A resposta adaptativa observada em músculos cronicamente desnervados parece ser mediada pela hipersensibilidade à adrenalina circulante, uma vez que a secção do nervo ciático produz diminuição do conteúdo de noradrenalina muscular e a ADMX potencializa o efeito da DEN na expressão dos atrogenes;

d) Neurônios simpáticos estão associados a neurônios colinérgicos motores no nervo ciático e são capazes de ativar os $\beta 2$-AR e a via de sinalização do AMPc na região da JNM;

e) A ativação crônica dos $\beta_{2}$ - $\mathrm{AR}$ através do tratamento diário com $\mathrm{CB}$ é capaz de aumentar o turnover dos AChR em músculos inervados e 
desnervados de camundongos normais e/ou miastênicos, por meio do aumento da sua síntese e incorporação nas JNM;

f) Em situações in vitro, a estimulação dos $\mathrm{AChR}$ em músculos soleus normais de ratos produz ações catabólicas no metabolismo de proteínas através da diminuição da síntese e aumento da atividade proteolítica $\mathrm{Ca}^{2+}$ dependente, sem nenhum efeito em músculos EDL nas condições testadas;

g) A estimulação dos $\beta_{2}$-AR in vitro é capaz de contra regular a ativação da proteólise induzida pelo carbacol, sugerindo que os sistemas simpático e colinérgico produzem ações antagônicas no metabolismo de proteínas em músculos esqueléticos. 
Referências Bibliagráficas 


\section{REFERÊNCIAS BIBLIOGRÁFICAS}

ALLEN, D. G. et al. Interactions between intracellular calcium and phosphate in intact mouse muscle during fatigue. Journal of applied physiology (Bethesda, Md. : 1985), v. 111, n. 2, p. 358-366, 2011.

ANDREOSE, J. S.; FUMAGALLI, G.; LØMO, T. Number of junctional acetylcholine receptors: control by neural and muscular influences in the rat. The Journal of physiology, v. 483 ( Pt 2, n. 8, p. 397-406, 1995.

AXELSSON, J.; THESLEFF, S. A study of supersensitivity in denervated mammalian skeletal muscle. The Journal of physiology, v. 147, n. 1, p. 178-193, 1959.

BARKER, D.; SAITO, M. Autonomic innervation of receptors and muscle fibres in cat skeletal muscle. Proceedings of the Royal Society of London. Series B, Containing papers of a Biological character. Royal Society (Great Britain), v. 212, n. 1188, p. $317-332,1981$.

BAVIERA, A. M. et al. Pentoxifylline inhibits Ca2+-dependent and ATP proteasomedependent proteolysis in skeletal muscle from acutely diabetic rats. American journal of physiology. Endocrinology and metabolism, v. 292, n. 3, p. E702-E708, 2007.

BAVIERA, A. M. et al. Involvement of cAMP/Epac/PI3K-dependent pathway in the antiproteolytic effect of epinephrine on rat skeletal muscle. Molecular and Cellular Endocrinology, v. 315, n. 1-2, p. 104-112, 2010.

BECHET, D. et al. Lysosomal proteolysis in skeletal muscle. International Journal of Biochemistry and Cell Biology, 2005.

BLOSSER, J. C. beta-Adrenergic receptor activation increases acetylcholine receptor number in cultured skeletal muscle myotubes. Journal of neurochemistry, v. 40, n. 4, p. $1144-1149,1983$. 
BLOUNT, P.; MERLIE, J. P. Molecular basis of the two nonequivalent ligand binding sites of the muscle nicotinic acetylcholine receptor. Neuron, v. 3, n. 3, p. 349-357, 1989.

BODINE, S. C. et al. Identification of ubiquitin ligases required for skeletal muscle atrophy. Science (New York, N.Y.), v. 294, n. 5547, p. 1704-1708, 2001 a.

BODINE, S. C. et al. Akt/mTOR pathway is a crucial regulator of skeletal muscle hypertrophy and can prevent muscle atrophy in vivo. Nature cell biology, v. 3, n. 11, p. 1014-1019, 2001b.

BOWMAN, W. C.; RAPER, C. Adrenotropic receptors in skeletal muscle. Annals of the New York Academy of Sciences, v. 139, n. 3, p. 741-753, 1967.

BUKHARAEVA, E.; NIKOLSKY, E. Effects of Noradrenaline on End-Plate Currents and the Kinetics of Transmitter Release under Long-Lasting Repetitive Stimulation. Neurophysiology, v. 34, p. 120-122, 2002.

BUSQUETS, S. et al. Anticachectic effects of formoterol: A drug for potential treatment of muscle wasting. Cancer Research, v. 64, n. 18, p. 6725-6731, 2004.

CHAHINE, K. G.; BARACCHINI, E.; GOLDMAN, D. Coupling muscle electrical activity to gene expression via a cAMP-dependent second messenger system. Journal of Biological Chemistry, v. 268, n. 4, p. 2893-2898, 1993.

CHEN, F. et al. Rapsyn Interaction with Calpain Stabilizes AChR Clusters at the Neuromuscular Junction. Neuron, v. 55, n. 2, p. 247-260, 2007.

CHOI, K.-R. et al. Rapsyn mediates subsynaptic anchoring of PKA type I and stabilisation of acetylcholine receptor in vivo. 2012.

CHRISTIANSON, J. C.; GREEN, W. N. Regulation of nicotinic receptor expression by the ubiquitin-proteasome system. The EMBO journal, v. 23, n. 21, p. 4156-4165, 2004. 
CHUA, M.; DULHUNTY, A. F. Inactivation of excitation-contraction coupling in rat extensor digitorum longus and soleus muscles. The Journal of general physiology, v. 91, n. 5, p. 737-757, 1988.

CONG, J. et al. The role of autolysis in activity of the Ca2+-dependent proteinases (??calpain and m-calpain). Journal of Biological Chemistry, v. 264, n. 17, p. 1009610103, 1989.

COSTELLI, P. et al. Muscle protein waste in tumor-bearing rats is effectively antagonized by a $\beta 2$-adrenergic agonist (clenbuterol): Role of the ATP-ubiquitindependent proteolytic pathway. Journal of Clinical Investigation, v. 95, n. 5, p. 2367$2372,1995$.

ENGEL, A. G. et al. What have we learned from the congenital myasthenic syndromes. Journal of Molecular Neuroscience, v. 40, n. 1-2, p. 143-53, 2010.

FINLAYSON, S. et al. Slow channel congenital myasthenic syndrome responsive to a combination of fluoxetine and salbutamol. Muscle and Nerve, v. 47, n. 2, p. 279-282, 2013.

FINN, P. F.; DICE, J. F. Proteolytic and lipolytic responses to starvation. Nutrition,v. 22, n. 7-8, p. 830-44 2006.

GARBER, A. J.; ENTMAN, M. L.; BIRNBAUMER, L. Cholinergic stimulation of skeletal muscle alanine and glutamine formation and release. Evidence for mediation by a nicotinic cholinergic receptor and guanosine $3^{\prime}: 5^{\prime}$-monophosphate. Journal of Biological Chemistry, v. 253, n. 21, p. 7924-7930, 1978.

GARBER, A. J.; HARARI, Y.; ENTMAN, M. L. Cholinergic stimulation of alanine and glutamine formation and release from skeletal muscle. Journal of Biological Chemistry, v. 253, n. 21, p. 7918-7923, 1978. 
GARÓFALO, M. A. et al. Effect of acute cold exposure on norepinephrine turnover rates in rat white adipose tissue. Journal of the autonomic nervous system, v. 60, n. 3, p. 206-208, 1996.

GLICKMAN, M. H.; CIECHANOVER, A. The ubiquitin-proteasome proteolytic pathway: destruction for the sake of construction. Physiological reviews, v. 82, n. 2, p. 373-428, 2002.

GOMES, M. D. et al. Atrogin-1, a muscle-specific F-box protein highly expressed during muscle atrophy. Proceedings of the National Academy of Sciences of the United States of America, v. 98, n. 25, p. 14440-14445, 2001.

GONÇALVES, D. A P. et al. Mechanisms involved in $3^{\prime}, 5^{\prime}$-cyclic adenosine monophosphate-mediated inhibition of the ubiquitin-proteasome system in skeletal muscle. Endocrinology, v. 150, n. 12, p. 5395-5404, 2009.

GONÇALVES, D. A. P. et al. Clenbuterol suppresses proteasomal and lysosomal proteolysis and atrophy-related genes in denervated rat soleus muscles independently of Akt. AJP: Endocrinology and Metabolism, v. 302, n. 1, p. E123-E133, 2012.

GRAÇA, F. A et al. Epinephrine depletion exacerbates the fasting-induced protein breakdown in fast-twitch skeletal muscles. American journal of physiology. Endocrinology and metabolism, v. 305, n. 12, p. E1483-94, 2013.

GRADY, R. M. et al. Maturation and maintenance of the neuromuscular synapse: genetic evidence for roles of the dystrophin--glycoprotein complex. Neuron, v. 25, n. 2, p. 279-293, 2000.

GREEN, W. N.; ROSS, A F.; CLAUDIO, T. cAMP stimulation of acetylcholine receptor expression is mediated through posttranslational mechanisms. Proceedings of the National Academy of Sciences of the United States of America, v. 88, n. 3, p. 854-858, 1991. 
GROSHONG, J. S. et al. Calpain activation impairs neuromuscular transmission in a mouse model of the slow-channel myasthenic syndrome. Journal of Clinical Investigation, v. 117, n. 10, p. 2903-2912, 2007.

HADDAD, F.; ADAMS, G. R. Inhibition of MAP/ERK kinase prevents IGF-I-induced hypertrophy in rat muscles. Journal of applied physiology (Bethesda, Md. : 1985), v. 96, n. 1, p. 203-210, 2004.

HALL, Z. W.; SANES, J. R. Synaptic structure and development: the neuromuscular junction. Cell, v. 72 Suppl, p. 99-121, 1993.

HARTZELL, H. C.; FAMBROUGH, D. M. Acetylcholine receptors. Distribution and extrajunctional density in rat diaphragm after denervation correlated with acetylcholine sensitivity. The Journal of general physiology, v. 60, n. 3, p. 248-262, 1972.

HOOVER, F. et al. Differential expression and regulation of the PKA signalling pathway in fast and slow skeletal muscle. Anatomy and embryology, v. 203, n. 3, p. 193-201, 2001.

HUEY, K. A.; BODINE, S. C. Changes in myosin mRNA and protein expression in denervated rat soleus and tibialis anterior. European Journal of Biochemistry, v. 256, n. 1, p. $45-50,1998$.

HUGANIR, R. L. et al. Phosphorylation of the nicotinic acetylcholine receptor regulates its rate of desensitization. Nature, v. 321, n. 6072, p. 774-776, 1986.

HUGANIR, R. L.; GREENGARD, P. cAMP-dependent protein kinase phosphorylates the nicotinic acetylcholine receptor. Proceedings of the National Academy of Sciences of the United States of America, v. 80, n. 4, p. 1130-1134, 1983.

HYMAN, C.; FROEHNER, S. C. Degradation of acetylcholine receptors in muscle cells: Effect of leupeptin on turnover rate, intracellular pool sizes, and receptor properties. Journal of Cell Biology, v. 96, n. 5, p. 1316-1324, 1983. 
JAGOE, R. T.; GOLDBERG, A. L. What do we really know about the ubiquitinproteasome pathway in muscle atrophy? Current opinion in clinical nutrition and metabolic care, v. 4, n. 3, p. 183-190, 2001.

JEFFERSON, L. S.; LI, J. B.; RANNELS, S. R. Regulation by insulin of amino acid release and protein turnover in the perfused rat hemicorpus. The Journal of biological chemistry, v. 252, n. 4, p. 1476-1483, 1977.

KANG, B. H. et al. Cyclic AMP-dependent protein kinase A and CREB are involved in neuregulin-induced synapse-specific expression of acetylcholine receptor gene. Biochemical and Biophysical Research Communications, v. 304, n. 4, p. 758-765, 2003.

KETTELHUT, I. C.; WING, S. S.; GOLDBERG, A. L. Endocrine regulation of protein breakdown in skeletal muscle. Diabetes/metabolism reviews, v. 4, n. 8, p. 751-772, 1988.

KHAN, M. M. et al. Role of autophagy, SQSTM1, SH3GLB1, and TRIM63 in the turnover of nicotinic acetylcholine receptors. Autophagy, v. 10, n. 1, p. 123-136, 2014. KIM, Y. S. et al. Characterization of beta 1- and beta 2-adrenoceptors in rat skeletal muscles. Biochemical pharmacology, v. 42, n. 9, p. 1783-1789, 1991.

KIM, Y. S.; SAINZ, R. D. Beta-adrenergic agonists and hypertrophy of skeletal muscles. Life sciences, v. 50, n. 6, p. 397-407, 1992.

KRSTULOVIĆ, A. M. Investigations of catecholamine metabolism using highperformance liquid chromatography: analytical methodology and clinical applications. Journal of chromatography, v. 229, n. 1, p. 1-34, 1982.

LASHLEY, D. et al. Ephedrine treatment in congenital myasthenic syndrome due to mutations in DOK7(LOE Classification). Neurology, v. 74, n. 19, p. 1517-1523, 2010. 
LECKER, S. H. et al. Muscle protein breakdown and the critical role of the ubiquitinproteasome pathway in normal and disease states. The Journal of nutrition, v. 129, n. 1S Suppl, p. 227S-237S, 1999.

LIBBY, P.; BURSZTAJN, S.; GOLDBERG, A L. Degradation of the acetylcholine receptor in cultured muscle cells: selective inhibitors and the fate of undegraded receptors. Cell, v. 19, n. 2, p. 481-491, 1980.

LIEWLUCK, T.; SELCEN, D.; ENGEL, A. G. Beneficial effects of albuterol in congenital endplate acetylcholinesterase deficiency and dok-7 myasthenia. Muscle and Nerve, v. 44, n. 5, p. 789-794, 2011.

LIRA, E. C. et al. Phosphodiesterase-4 inhibition reduces proteolysis and atrogenes expression in rat skeletal muscles. Muscle and Nerve, v. 44, n. 3, p. 371-381, 2011.

LYNCH, G. S.; RYALL, J. G. Role of beta-adrenoceptor signaling in skeletal muscle: implications for muscle wasting and disease. Physiological reviews, v. 88, n. 2, p. 729$767,2008$.

MALIK, R. U. et al. Detection of $G$ protein-selective $G$ protein-coupled receptor (GPCR) conformations in live cells. Journal of Biological Chemistry, v. 288, n. 24, p. 17167-17178, 2013.

MALTIN, C. A et al. The action of the beta-agonist clenbuterol on protein metabolism in innervated and denervated phasic muscles. The Biochemical journal, v. 261, n. 3, p. 965-971, 1989.

MANTLE, D.; PREEDY, V. R. Adverse and beneficial functions of proteolytic enzymes in skeletal muscle. An overview. Adverse drug reactions and toxicological reviews, v. 21, n. 1-2, p. 31-49, 2002. 
MARTIN, W. H.; MURPHREE, S. S.; SAFFITZ, J. E. Beta-adrenergic receptor distribution among muscle fiber types and resistance arterioles of white, red, and intermediate skeletal muscle. Circulation research, v. 64, n. 6, p. 1096-1105, 1989.

MASON, J. W. A review of psychoendocrine research on the sympathetic-adrenal medullary system. Psychosomatic medicine, v. 30, n. 5, p. Suppl:631-653, 1968.

MATTHEWS-BELLINGER, J. A.; SALPETER, M. M. Fine structural distribution of acetylcholine receptors at developing mouse neuromuscular junctions. The Journal of neuroscience : the official journal of the Society for Neuroscience, v. 3, n. 3, p. 644$657,1983$.

MEDINA, R.; WING, S. S.; GOLDBERG, A. L. Increase in levels of polyubiquitin and proteasome mRNA in skeletal muscle during starvation and denervation atrophy. The Biochemical journal, v. 307 ( Pt 3, p. 631-637, 1995.

MENEZES-RODRIGUES, F. S. et al. Calcium influx through L-type channels attenuates skeletal muscle contraction via inhibition of adenylyl cyclases. European Journal of Pharmacology, v. 720, n. 1-3, p. 326-334, 2013.

MICHLER, A.; SAKMANN, B. Receptor stability and channel conversion in the subsynaptic membrane of the developing mammalian neuromuscular junction. Developmental biology, v. 80, n. 1, p. 1-17, 1980.

MISSIAS, A. C. et al. Maturation of the acetylcholine receptor in skeletal muscle: regulation of the AChR gamma-to-epsilon switch. Developmental biology, v. 179, n. 1, p. 223-238, 1996.

MORGAN, M. J.; LOUGHNA, P. T. Passive stretch modulates denervation induced alterations in skeletal muscle myosin heavy chain mRNA levels. Pflugers Archiv European Journal of Physiology, v. 439, n. 1-2, p. 52-55, 1999. 
MORTIMORE, G. E. Mechanisms of cellular protein catabolism. Nutrition Reviews, v. 40, p. $1-12,1982$.

MURAD, F. et al. Adenyl cyclase. III. The effect of catecholamines and choline esters on the formation of adenosine $3^{\prime}, 5^{\prime}$-phosphate by preparations from cardiac muscle and liver. The Journal of biological chemistry, v. 237, p. 1233-1238, 1962.

MURPHY, R. J. L. et al. Chronic B-blockade increases skeletal muscle B-adrenergicreceptor density and enhances contractile force. Journal of Applied Physiology, v. 83, n. 2, p. 459-465, 1997.

NAVEGANTES, L. C. et al. Effect of guanethidine-induced adrenergic blockade on the different proteolytic systems in rat skeletal muscle. The American journal of physiology, v. 277, n. 5 Pt 1, p. E883-E889, 1999.

NAVEGANTES, L. C. et al. Catecholamines inhibit $\mathrm{Ca}(2+)$-dependent proteolysis in rat skeletal muscle through beta(2)-adrenoceptors and cAMP. American journal of physiology. Endocrinology and metabolism, v. 281, n. 3, p. E449-E454, 2001.

NAVEGANTES, L. C. C. et al. Effect of sympathetic denervation on the rate of protein synthesis in rat skeletal muscle. American journal of physiology. Endocrinology and metabolism, v. 286, n. 4, p. E642-E647, 2004.

NAVEGANTES, L. C. C.; BAVIERA, A M.; KETTELHUT, I. C. The inhibitory role of sympathetic nervous system in the $\mathrm{Ca} 2+$-dependent proteolysis of skeletal muscle. Brazilian journal of medical and biological research, v. 42, n. 1, p. 21-8, 2009.

NAVEGANTES, L. C. C.; MiGliORINI, R. H.; KETTELHUT, I. C. Adrenergic control of protein metabolism in skeletal muscle. Current opinion in clinical nutrition and metabolic care, v. 5, n. 3, p. 281-286, 2002.

NIKOLAEV, V. O. et al. Novel single chain cAMP sensors for receptor-induced signal propagation. Journal of Biological Chemistry, v. 279, n. 36, p. 37215-37218, 2004. 
PADYKULA, H. A.; GAUTHIER, G. F. The ultrastructure of the neuromuscular junctions of mammalian red, white, and intermediate skeletal muscle fibers. Journal of Cell Biology, v. 46, n. 1, p. 27-41, 1970.

PALACE, J.; BEESON, D. The congenital myasthenic syndromes. Journal of Neuroimmunology, v. 201-202, n. C, p. 2-5, 2008.

PARR, T. et al. Changes in calpain and calpastatin mRNA induced by beta-adrenergic stimulation of bovine skeletal muscle. European journal of biochemistry / FEBS, v. 208, n. 2, p. 333-339, 1992.

RANNELS, D. E.; KAO, R.; MORGAN, H. E. Effect of insulin on protein turnover in heart muscle. The Journal of biological chemistry, v. 250, n. 5, p. 1694-1701, 1975.

REYNOLDS, J. G. et al. Deregulated protein kinase A signaling and myospryn expression in muscular dystrophy. Journal of Biological Chemistry, v. 283, n. 13, p. 8070-8074, 2008.

RÖDER, I. V. et al. PKA microdomain organisation and cAMP handling in healthy and dystrophic muscle in vivo. Cellular Signalling, v. 21, n. 5, p. 819-826, 2009.

RÖDER, I. V. et al. Participation of Myosin Va and Pka type I in the regeneration of neuromuscular junctions. PLoS ONE, v. 7, n. 7, 2012.

RÖDER, I. V et al. Myosin Va cooperates with PKA RIalpha to mediate maintenance of the endplate in vivo. Proceedings of the National Academy of Sciences of the United States of America, v. 107, n. 5, p. 2031-2036, 2010.

RUDOLF, R. et al. Regulation of nicotinic acetylcholine receptor turnover by MuRF1 connects muscle activity to endo/lysosomal and atrophy pathways. Age, v. 35, n. 5, p. 1663-1674, 2013. 
RYALL, J. G.; CHURCH, J. E.; LYNCH, G. S. Novel role for B-adrenergic signalling in skeletal muscle growth, development and regeneration. Clinical and experimental pharmacology \& physiology, v. 37, n. 3, p. 397-401, 2010.

RYALL, J. G.; LYNCH, G. S. The potential and the pitfalls of beta-adrenoceptor agonists for the management of skeletal muscle wasting. Pharmacology \& therapeutics, v. 120, n. 3, p. 219-232, 2008.

SACHECK, J. M. et al. Rapid disuse and denervation atrophy involve transcriptional changes similar to those of muscle wasting during systemic diseases. The FASEB journal: official publication of the Federation of American Societies for Experimental Biology, v. 21, n. 1, p. 140-155, 2007.

SACHS, C.; JONSSON, G. Degeneration of central and peripheral noradrenaline neurons produced by 6-hydroxy-DOPA. Journal of neurochemistry, v. 19, n. 6, p. $1561-1575,1972$.

SALAMINO, F. et al. Modulation of calpastatin specificity in rat tissues by reversible phosphorylation and dephosphorylation. Biochemical and biophysical research communications, v. 199, n. 3, p. 1326-1332, 1994.

SANDRI, M. New findings of lysosomal proteolysis in skeletal muscle. Current opinion in clinical nutrition and metabolic care, v. 14, n. 3, p. 223-229, 2011.

SCHARA, U. et al. Ephedrine therapy in eight patients with congenital myasthenic syndrome due to DOK7 mutations. Neuromuscular disorders : NMD, v. 19, n. 12, p. 828-832, 2009.

SCHIAFFINO, S.; MARGRETH, A. Coordinated development of the sarcoplasmic reticulum and $\mathrm{T}$ system during postnatal differentiation of rat skeletal muscle. Journal of Cell Biology, v. 41, n. 3, p. 855-875, 1969. 
SCHIAFFINO, S.; REGGIANI, C. Fiber Types in Mammalian Skeletal Muscles. Physiological Reviews, v. 91, n. 4, p.1447-5312011.

SCHMALBRUCH, H. Fiber composition of the rat sciatic nerve. The Anatomical record, v. 215, n. 1, p. 71-81, 1986.

SCHMALBRUCH, H.; AL-AMOOD, W. S.; LEWIS, D. M. Morphology of long-term denervated rat soleus muscle and the effect of chronic electrical stimulation. The Journal of physiology, v. 441, p. 233-241, 1991.

SCHWARTZ, A et al. The rate of calcium uptake into sarcoplasmic reticulum of cardiac muscle and skeletal muscle. Effects of cyclic AMP-dependent protein kinase and phosphorylase b kinase. Biochimica et biophysica acta, v. 426, n. 1, p. 57-72, 1976.

SERDAROGLU, P.; ASKANAS, V.; ENGEL, W. K. Immunocytochemical localization of ubiquitin at human neuromuscular junctions. Neuropathology and applied neurobiology, v. 18, n. 3, p. 232-236, 1992.

SHI, H. et al. Mitogen-activated protein kinase signaling is necessary for the maintenance of skeletal muscle mass. American journal of physiology. Cell physiology, v. 296, n. 5, p. C1040-C1048, 2009.

SHIAO, T. et al. Defects in neuromuscular junction structure in dystrophic muscle are corrected by expression of a NOS transgene in dystrophin-deficient muscles, but not in muscles lacking ??- and ??1-syntrophins. Human Molecular Genetics, v. 13, n. 17, p. 1873-1884, 2004.

SHIRAHA, H. et al. Activation of m-calpain (calpain II) by epidermal growth factor is limited by protein kinase A phosphorylation of m-calpain. Molecular and cellular biology, v. 22, n. 8, p. 2716-2727, 2002. 
SHYNG, S. L.; SALPETER, M. M. Degradation rate of acetylcholine receptors inserted into denervated vertebrate neuromuscular junctions. Journal of Cell Biology, v. 108, n. 2, p. 647-651, 1989.

SHYNG, S. L.; XU, R.; SALPETER, M. M. Cyclic AMP stabilizes the degradation of original junctional acetylcholine receptors in denervated muscle. Neuron, v. 6, n. 3, p. 469-475, 1991.

SILVEIRA, W. A et al. Activating cAMP/PKA signaling in skeletal muscle suppresses the ubiquitin-proteasome-dependent proteolysis: implications for sympathetic regulation. Journal of applied physiology (Bethesda, Md. : 1985), v. 117, n. 1, p. 11$9,2014$.

SKETELJ, J. et al. Specific impulse patterns regulate acetylcholinesterase activity in skeletal muscles of rats and rabbits. Journal of neuroscience research, v. 47, n. 1, p. 49-57, 1997.

SMITH, I. C. et al. ATP Consumption by Sarcoplasmic Reticulum Ca2+ Pumps Accounts for $40-50 \%$ of Resting Metabolic Rate in Mouse Fast and Slow Twitch Skeletal Muscle. PLoS ONE, v. 8, n. 7, 2013.

SPENCER, M. J.; CROALL, D. E.; TIDBALL, J. G. Calpains are activated in necrotic fibers from mdx dystrophic mice. Journal of Biological Chemistry, v. 270, n. 18, p. 10909-10914, 1995.

STRACK, S. et al. A novel labeling approach identifies three stability levels of acetylcholine receptors in the mouse neuromuscular junction in vivo. PLoS ONE, v. 6, n. $6,2011$.

SUZUKI, Y. et al. Expression of adenylyl cyclase mRNAs in the denervated and in the developing mouse skeletal muscle. The American journal of physiology, v. 274, n. 6 Pt 1, p. C1674-C1685, 1998. 
TADAKI, N. et al. Neurotransmitters for the canine inferior pharyngeal constrictor muscle. Otolaryngology--head and neck surgery: official journal of American Academy of Otolaryngology-Head and Neck Surgery, v. 113, n. 6, p. 755-759, 1995. TAKAHASHI, M. et al. Spontaneous muscle action potentials fail to develop without fetal-type acetylcholine receptors. EMBO Reports, v. 3, n. 7, p. 674-681, 2002. TAKIMOTO, E. et al. Chronic inhibition of cyclic GMP phosphodiesterase 5A prevents and reverses cardiac hypertrophy. Nature medicine, v. 11, n. 2, p. 214-222, 2005.

TANK, D. W. et al. Patch-recorded single-channel currents of the purified and reconstituted Torpedo acetylcholine receptor. Proceedings of the National Academy of Sciences of the United States of America, v. 80, n. 16, p. 5129-5133, 1983.

THOENEN, H.; TRANZER, J. P. Chemical sympathectomy by selective destruction of adrenergic nerve endings with 6-hydroxydopamine. Naunyn-Schmiedebergs Archiv f??r Pharmakologie und Experimentelle Pathologie, v. 261, n. 3, p. 271-288, 1968. VILLARROEL, A.; SAKMANN, B. Calcium permeability increase of endplate channels in rat muscle during postnatal development. The Journal of physiology, v. 496 ( Pt 2, p. 331-338, 1996.

WAALKES, T. P.; UDENFRIEND, S. A fluorometric method for the estimation of tyrosine in plasma and tissues. The Journal of laboratory and clinical medicine, $v$. 50, n. 5, p. 733-736, 1957.

WILLIAMS, R. S.; CARON, M. G.; DANIEL, K. Skeletal muscle beta-adrenergic receptors: variations due to fiber type and training. The American journal of physiology, v. 246, n. 2 Pt 1, p. E160-E167, 1984.

WITZEMANN, V. et al. Acetylcholine receptor epsilon-subunit deletion causes muscle weakness and atrophy in juvenile and adult mice. Proceedings of the National 
Academy of Sciences of the United States of America, v. 93, n. 23, p. 13286-13291, 1996.

XU, R.; SALPETER, M. M. Protein kinase A regulates the degradation rate of Rs acetylcholine receptors. Journal of cellular physiology, v. 165, n. 1, p. 30-39, 1995.

XU, R.; SALPETER, M. M. Acetylcholine receptors in innervated muscles of dystrophic mdx mice degrade as after denervation. The Journal of neuroscience : the official journal of the Society for Neuroscience, v. 17, n. 21, p. 8194-8200, 1997.

YIMLAMAI, T. et al. Clenbuterol induces muscle-specific attenuation of atrophy through effects on the ubiquitin-proteasome pathway. Journal of applied physiology (Bethesda, Md. : 1985), v. 99, n. 1, p. 71-80, 2005.

ZACCOLO, M.; MOVSESIAN, M. A. cAMP and cGMP signaling cross-talk: Role of phosphodiesterases and implications for cardiac pathophysiology. Circulation Research, v. 100, n.11, p.1569-78, 2007. 


\title{
Alterations of cAMP-dependent signaling in dystrophic skeletal muscle
}

\author{
Rüdiger Rudolf 1,2*, Muzamil M. Khan ${ }^{2}$, Danilo Lustrino ${ }^{3}$, Siegfried Labeit ${ }^{4}$, Ísis C. Kettelhut ${ }^{3}$ and \\ Luiz C. C. Navegantes ${ }^{3}$ \\ 1 Institute of Molecular and Cell Biology, University of Applied Sciences Mannheim, Mannheim, Germany \\ 2 Institute of Toxicology and Genetics, Karlsruhe Institute of Technology, Eggenstein-Leopoldshafen, Germany \\ ${ }^{3}$ Departments of Physiology and Biochemistry and Immunology, School of Medicine of Ribeirão Preto, University of São Paulo, Ribeirao Preto, Brazil \\ ${ }^{4}$ Department of Integrative Pathophysiology, Universitätsmedizin Mannheim, Mannheim, Germany
}

\section{Edited by:}

Rasna Sabharwal, University of Iowa, USA

\section{Reviewed by:}

Yutang Wang, James Cook

University, Australia

Abdu Adem, United Arab Emirates

University, United Arab Emirates

\section{${ }^{*}$ Correspondence:}

Rüdiger Rudolf, Institute of

Molecular and Cell Biology,

University of Applied Sciences

Mannheim, Paul-Wittsack-Strasse

10, 68163 Mannheim, Mannheim,

Germany

e-mail: r.rudolf@hs-mannheim.de
Autonomic regulation processes in striated muscles are largely mediated by cAMP/PKA-signaling. In order to achieve specificity of signaling its spatial-temporal compartmentation plays a critical role. We discuss here how specificity of cAMP/PKA-signaling can be achieved in skeletal muscle by spatio-temporal compartmentation. While a microdomain containing PKA type 1 in the region of the neuromuscular junction (NMJ) is important for postsynaptic, activity-dependent stabilization of the nicotinic acetylcholine receptor (AChR), PKA type I and II microdomains in the sarcomeric part of skeletal muscle are likely to play different roles, including the regulation of muscle homeostasis. These microdomains are due to specific A-kinase anchoring proteins, like rapsyn and myospryn. Importantly, recent evidence indicates that compartmentation of the cAMP/PKA-dependent signaling pathway and pharmacological activation of CAMP production are aberrant in different skeletal muscles disorders. Thus, we discuss here their potential as targets for palliative treatment of certain forms of dystrophy and myasthenia. Under physiological conditions, the neuropeptide, $\alpha$-calcitonin-related peptide, as well as catecholamines are the most-mentioned natural triggers for activating CAMP/PKA signaling in skeletal muscle. While the precise domains and functions of these first messengers are still under investigation, agonists of $\beta_{2}$ adrenoceptors clearly exhibit anabolic activity under normal conditions and reduce protein degradation during atrophic periods. Past and recent studies suggest direct sympathetic innervation of skeletal muscle fibers. In summary, the organization and roles of cAMPdependent signaling in skeletal muscle are increasingly understood, revealing crucial functions in processes like nerve-muscle interaction and muscle trophicity.

Keywords: adrenoceptors, AKAP, endplate, dystrophy, PKA, metabolism, neuromuscular junction, skeletal muscle

\section{INTRODUCTION}

A variety of hormones and other first messengers employ cAMPdependent signal transduction to exert their effects (Beavo and Brunton, 2002). Sympathetic activation of adrenergic receptors (or adrenoceptors) by catecholamines is the classical paradigm in this context. In skeletal muscle, catecholamines regulate many physiological functions, including force production (Oliver and Schäfer, 1895; Arreola et al., 1987; Cairns and Dulhunty, 1993a,b; Decostre et al., 2000), blood flow (Marshall, 1982; Saltin et al., 1998; Joyner and Casey, 2009), and metabolism (Gross et al., 1976; Navegantes et al., 2000, 2002). These effects might be mediated through endocrine delivery of epinephrine from the adrenal medulla, but adrenergic nerve terminals make also close contact with striated muscle fibers (Barker and Saito, 1981; Tadaki et al., 1995), suggesting direct release of norepinephrine onto muscle fibers in a neurotransmitter-like or paracrine fashion as it occurs at the heart (Zaglia et al., 2013). However, these aspects of adrenergic signaling on skeletal muscle are far from being established and are currently under investigation (see also below).
In skeletal muscle, catecholamines stimulate primarily $\beta_{2}$-adrenergic receptors $\left(\beta_{2}\right.$-ARs). These are $G$ protein-coupled receptors (GPCRs), which mostly couple to $G \alpha_{s}$ and thus activate adenylyl cyclase (AC) (Liggett and Raymond, 1993), leading to an increase in cAMP levels, activation of cAMP-dependent protein kinase (PKA) and cAMP response element-binding protein (CREB) (Beavo and Brunton, 2002; Altarejos and Montminy, 2011). In parallel, cAMP signals through the "exchange protein activated directly by cAMP" (Epac) (Bos, 2003), and it regulates cyclic-nucleotide gated (CNGs) channels (Beavo and Brunton, 2002). The attenuation of cAMP effects is coordinated by the activation of cyclic nucleotide phosphodiesterases (PDEs), which are classified into 11 major families (PDE1-11) (Bloom, 2002; Omori and Kotera, 2007). In skeletal muscle, PDE4 appears to contribute to the majority of cAMP hydrolysis, accounting for more than $80 \%$ of the total PDE activity in this tissue (Bloom, 2002). Notably, a couple of different cAMP-regulating GPCRs are typically co-expressed in one and the same cell raising the evident issue of how the small inconspicuous molecule, cAMP, can 
trigger specific responses upon activation of a certain GPCR. This is also true for striated muscle where a plethora of physiological functions are subject to cAMP-dependent signaling. For skeletal muscle, Berdeaux and Stewart have recently reviewed the different functions of this pathway very nicely (Berdeaux and Stewart, 2012). Furthermore, lists of GPCRs (albeit likely not complete) expressed in heart and skeletal muscles can be found in reviews from Tang (Tang and Insel, 2004) and Jean-Baptiste (JeanBaptiste et al., 2005), respectively. So, how is specificity gained in cAMP-dependent signaling pathways? The strongest current line of evidence supports a microdomain hypothesis, wherein spatial and temporal segregation of local rises of cAMP plus scaffolding of essential downstream effectors and targets of cAMP play pivotal roles (Steinberg and Brunton, 2001; Zaccolo et al., 2002; Zaccolo, 2011; Edwards et al., 2012). Central players in this scenario are variability of PKA isoforms, A kinase-anchoring proteins (AKAPs), and PDEs. In its inactive state, PKA is comprised of four subunits, i.e., two regulatory (PKA-R) and two catalytic subunits (PKA-C) (Taylor et al., 2008). Upon binding of cAMP to regulatory subunits, catalytic subunits are activated and detach from regulatory subunits in order to phosphorylate targets. In mammals, four isoforms of PKA-R are present, named as type $\mathrm{I} \alpha$, I $\beta$, II $\alpha$, II $\beta$. While PDEs impair cAMP from spreading all over the cell through hydrolysis of the second messenger (Conti and Beavo, 2007; Francis et al., 2011), AKAPs serve as scaffolds integrating and anchoring many relevant partners of a GPCRlinked signaling pathway (Scott et al., 2013). Indeed, AKAPs not only bind to PKA (hence their name) but often also to GPCRs, ACs, PDEs, protein phosphatases, and target molecules (Edwards et al., 2012). Thereby, they integrate entire signaling complexes and guarantee high efficiency and fidelity of signal transduction. AKAPs belong to a large heterogeneous group of proteins, which do not share sequence homology but a set of functional properties. They typically exhibit a subcellular targeting domain, interaction domains with other components of signal pathways, and an amphipathic $\alpha$-helical domain that serves as interaction terminal with PKA-R (Scott et al., 2013). Indeed, the PKA-R expose an N-terminal stretch called dimerization/docking(D/D-) domain that combines with the AKAP $\alpha$-helical parts at varying intensities and specificities. A typical and widely used means to test the functional impact of AKAP-PKA interaction is by introducing "AKAP disruptor peptides" which mimic the AKAP interaction domain and thereby release PKA-R from its normal microdomain (Scott et al., 2013). In summary, a large part of cAMP-dependent signaling specificity appears to arise from the interplay between PDEs and AKAPs and is sometimes subsumed under the term "PKA microdomain hypothesis," recently described in depth in a couple of excellent reviews (Zaccolo, 2011; Edwards et al., 2012; Scott et al., 2013). The present contribution first addresses, how the "PKA microdomain hypothesis" applies to skeletal muscle and what are potential links to skeletal muscle diseases. In a second part, we review the current knowledge on how catecholamines regulate muscle trophicity.

\section{PKA MICRODOMAINS IN SKELETAL MUSCLE}

Investigations dealing with the PKA microdomain hypothesis usually address differential distribution patterns of distinct
PKA-R isoforms. Owing to its highly regular striated patterning of sarcomeres, the contractile units of striated muscle, this tissue is particularly amenable to investigating the distribution of PKA-R isoforms relative to sarcomeric marker proteins. Another region of interest is the nerve-muscle synapse, termed as endplate or neuromuscular junction (NMJ), which instructs the rest of the muscle fiber to contract upon stimulation. For both parts there is now information concerning PKA-R distribution, alterations in diseased muscle, as well as causes underlying and consequences of these alterations. In the following we will describe the current state of knowledge regarding these points.

\section{SUBSYNAPTIC PKA MICRODOMAINS}

The NMJ is the synapse between motoneuron and muscle fiber and as such exerts the control over skeletal muscle contraction. The latter is triggered upon release of the neurotransmitter, acetylcholine, which activates postsynaptic nicotinic acetylcholine receptors (AChR) leading to an endplate potential and ultimately to muscle contraction. Notably, AChR reaches extremely high densities at the postsynaptic membrane of about 10,000 molecules per square micron and under normal conditions AChRs are metabolically very stable with a half-life of about 13 days (Fambrough, 1979). Principal functions attributed to cAMP/PKA-dependent signaling at the NMJ are synapse stabilization and the metabolic control of AChR stability and function (Li et al., 2001; Lanuza et al., 2002; Li et al., 2002; Nelson et al., 2003). In situ hybridization showed a peculiar accumulation of PKA-RI $\alpha$ transcripts in the NMJ region (Imaizumi-Scherrer et al., 1996) and immunohistochemical analyses found both, PKA-RI $\alpha$ and PKA-RII $\alpha$ to be enriched close to the postsynaptic membrane (Perkins et al., 2001). However, different studies using fusions of different PKA-R D/D-domains with fluorescent proteins only revealed PKA-RI $\alpha$ but not PKA-RII $\alpha$ in numerous punctiform structures just beneath the postsynaptic membrane (Barradeau et al., 2001, 2002; Röder et al., 2010; Choi et al., 2012). What do these puncta represent? The involvement of PKA signaling in AChR stabilization suggested them to be intracellular AChR carriers. As bona fide transmembrane proteins, the subunits of the pentameric AChR are generated and assembled in the endoplasmic reticulum, from where they are routed over the Golgi apparatus to the plasma membrane (Marchand et al., 2000, 2002; Marchand and Cartaud, 2002; Wanamaker and Green, 2005, 2007). Using different elegant labeling approaches with the highly AChR-selective snake venom, $\alpha$-bungarotoxin, Engel et al. showed by electron microscopy that AChR is endocytosed in membrane-bound carriers (Engel et al., 1977; Fumagalli et al., 1982) and several groups established an activity-dependent metabolic stabilization of AChR (Fambrough, 1979; Levitt et al., 1980; Loring and Salpeter, 1980; Levitt and Salpeter, 1981; Stanley and Drachman, 1981, 1983; Salpeter and Loring, 1985; Shyng et al., 1991; Xu and Salpeter, 1997, 1999). Next, Akaaboune et al. demonstrated that AChR is recycled to the postsynaptic membrane in an activity-dependent manner (Akaaboune et al., 1999; Bruneau et al., 2005; Bruneau and Akaaboune, 2006). At this point a large part of the lifecycle of AChRs was described phenomenologically. However, amongst other open questions it remained unclear, what molecules underlie the regulatory 
decision-making (e.g., dwell at postsynaptic membrane vs. endocytose; recycle vs. degrade) and which machinery would support these processes. Most knowledge was gathered regarding the clustering of AChRs at the membrane, which is mediated by the release of neuronal agrin (Nitkin et al., 1987), binding of agrin to the MuSK co-receptor, LRP4, and activation of the receptortyrosine kinase MuSK (Kim et al., 2008; Zhang et al., 2008; Zong et al., 2012; Burden et al., 2013; Hubbard and Gnanasambandan, 2013). This then triggers AChR clustering by a yet ill-defined mechanism, which involves the receptor-associated protein of the synapse, rapsyn (Gillespie et al., 1996; Apel et al., 1997; Glass and Yancopoulos, 1997; Ruegg and Bixby, 1998; Fuhrer et al., 1999; Gautam et al., 1999).

As for the metabolic stabilization of AChRs different lines of evidence indicate the involvement of the neuropeptide, $\alpha$-calcitonin-gene related peptide ( $\alpha$ CGRP), and of cAMP/PKAdependent pathways (Poyner, 1992). $\alpha$ CGRP was found to raise postsynaptic cAMP levels in the PKA-RI $\alpha$ microdomain (Röder et al., 2010) and to rapidly phosphorylate the $\alpha$ - and $\delta$-subunit of AChR (Miles et al., 1987, 1989). Furthermore, $\alpha$ CGRP treatment changed the electrophysiological characteristics of AChR (Mulle et al., 1988) and it rescued denervation-induced fragmentation of NMJs (Röder et al., 2010). Furthermore, aCGRP was described to counteract PKC-induced destabilization of AChRs (Li et al., 2001, 2002) and to stimulate AChR gene expression (New and Mudge, 1986; Fontaine et al., 1987) as well as synaptic strength (Lu et al., 1993). Experiments using AKAP disruptor peptides suggested that the proper localization of PKA-RI $\alpha$ on the aforementioned subsynaptic puncta is essential for AChR stabilization (Röder et al., 2010) and in vivo imaging and biochemical assays revealed that many of these structures indeed contain endocytosed AChR (Röder et al., 2010). Altogether these findings suggest that the PKA-RI $\alpha$ positive puncta represent $\alpha$ CGRP-sensitive PKA microdomains on endocytic carriers containing AChR. The actin-dependent motor protein, myosin Va, was found to be crucial for tethering these carriers in close proximity to the NMJ (Röder et al., 2010) (for schematic, see Figure 1), but which is the AKAP used for anchoring PKA-RI $\alpha$ to the AChR-laden carriers? Previous reports suggested D-AKAP1 (Barradeau et al., 2001, 2002; Perkins et al., 2001) as a candidate. However, this was purely based on the general enrichment of this protein underneath the NMJ. A recent study followed another rationale and looked for a protein that would (1) target to AChR, (2) exhibit an AKAP-typical $\alpha$-helical coiled-coil domain and (3) have interaction domains with other signaling components, and, based on these pre-requisites, tested the hypothesis that rapsyn serves as $\mathrm{AKAP}$ at this place. Rapsyn is a $43 \mathrm{kDa}$ protein, that was originally co-purified with AChR from Torpedo electroplax and that quantitatively and strongly interacts with AChR (Sobel et al., 1977; Neubig et al., 1979; Porter and Froehner, 1985; Froehner, 1993). From $\mathrm{N}$ - to C-terminus, rapsyn contains a myristoylation site, seven tetratricopeptide repeats, an amphipathic $\alpha$-helical region, a RING-domain, and PKA- and PKC-phosphorylation consensus sites (Ramarao and Cohen, 1998; Ramarao et al., 2001). Notably, full-length rapsyn but not rapsyn lacking its $\alpha$-helical domain co-precipitated with PKA-RI $\alpha$ (Choi et al., 2012). In silico modeling identified functional sequence homology of that

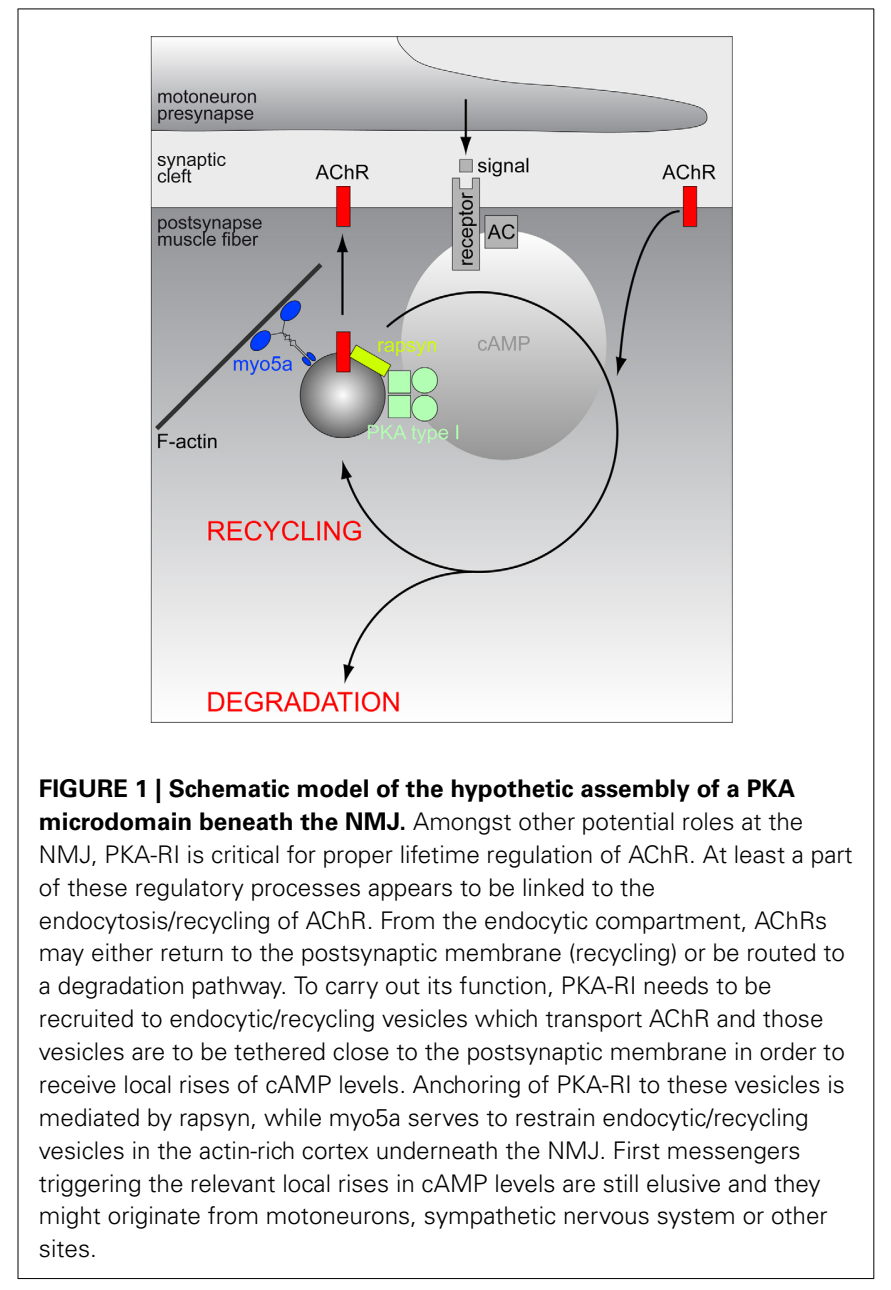

region with PKA-interaction domains of different AKAPs, and rapsyn interacted with PKA-RI $\alpha$ in a bimolecular fluorescence complementation assay both, in cells and in vivo (here in subsynaptic puncta) (Choi et al., 2012). Finally, over-expression of a peptide derived from the rapsyn $\alpha$-helical coiled-coil domain displaced PKA-RI $\alpha$ from the NMJ puncta and severely impaired AChR stability (Choi et al., 2012), strongly arguing for rapsyn as the AKAP responsible for linking PKA-RI $\alpha$ to the subsynaptic PKA microdomain (for schematic, see Figure 1).

NMJ structure and stability of AChR strongly suffer in muscles from the $m d x$ mouse model for Duchenne muscular dystrophy (DMD) (Torres and Duchen, 1987; Lyons and Slater, 1991; Xu and Salpeter, 1997; Grady et al., 2000; Shiao et al., 2004), in which cAMP signaling is aberrant (Reynolds et al., 2008). That does, of course, not mean that the altered signaling is the underlying cause for the NMJ phenomena, but the typical subsynaptic enrichment of PKA-RI $\alpha$ was lacking in about half of all fibers in $m d x$ muscles, microdomain specificity to different GPCR agonists was subverted, and AChR turnover was inversely correlated with PKA-RI $\alpha$ accumulation beneath the NMJ (Röder et al., 2012). Altogether this set of data suggests a link between defect subsynaptic microdomain formation of PKA-RI $\alpha$ in dystrophic muscles and the observed alterations in NMJ morphology and 
AChR stability. In general, the concept of an AChR stabilizing role of cAMP was also tested in the context of another devastating group of muscle diseases, i.e., congenital myasthenic syndromes (CMS). These are rare genetic diseases that affect either preor postsynaptic components of the NMJ and lead to impaired neuromuscular transmission and muscle weakness (Palace and Beeson, 2008). Many forms of CMS also present low levels of AChR at the NMJ. Although the underlying mechanisms for that might differ between distinct mutations, the finding that sympathomimetic substances, such as ephedrine and salbutamol, can significantly improve these patients' symptoms (Edgeworth, 1930; Schara et al., 2009; Lashley et al., 2010; Liewluck et al., 2011; Finlayson et al., 2013), suggests an involvement of catecholamines in AChR turnover. Since ephedrine and salbutamol both can activate $\beta_{2}$-ARs and thus affect cAMP production, this could point to a possible role of cAMP in stabilizing AChR and/or leading to higher AChR expression. Certainly, further research is needed to better understand these effects.

\section{PKA MICRODOMAINS AT THE SARCOMERIC REGION}

Sarcomeric PKA microdomain organization was addressed either by immunohistochemical staining of PKA-R isoforms (Perkins et al., 2001) or by expression studies using fluorescent proteinlabeled Epac-based cAMP biosensors (Nikolaev et al., 2004) targeted to PKA microdomains by virtue of $\mathrm{D} / \mathrm{D}$ domains (Di Benedetto et al., 2008) specific for either PKA-RI $\alpha$ (RI $\alpha$ EPAC-camps) or PKA-RII $\alpha$ (RII $\alpha$-EPAC-camps) (Röder et al., 2009). Both approaches yielded essentially identical results (for schematic, see Figure 2). While PKA-RI $\alpha$ was found in a broad band overlapping with the sarcomeric actin filaments, PKA-RII $\alpha$ exhibited highly confined striated localization that coincided with both, the m-band and the $z$-line. Experiments using overexpression of AKAP disruptor peptides showed that this peculiar distribution pattern is largely based on AKAP-dependent subcellular targeting (Röder et al., 2009). Harnessing the cAMP-sensor domain of the EPAC-camps biosensors furthermore showed a

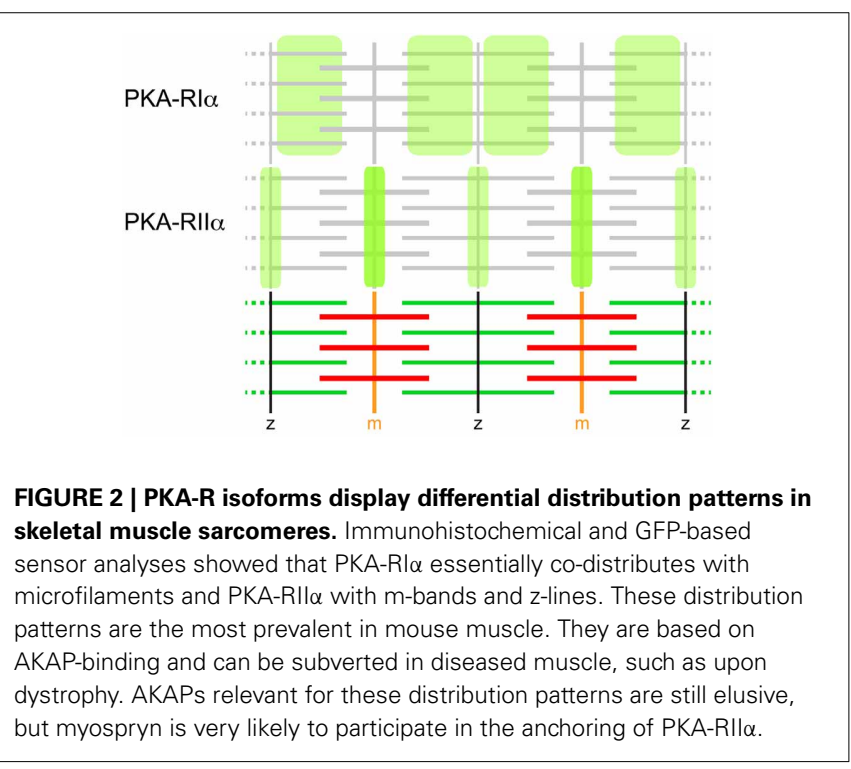

differential sensitivity of the two microdomains. While the cAMP concentration in the RI $\alpha$-microdomain was elevated in the presence of the agonist, $\alpha \mathrm{CGRP}$, the RII $\alpha$-microdomain responded to norepinephrine with increased cAMP levels (Röder et al., 2009). Both effects were ablated by AKAP disruptor peptides (Röder et al., 2009). These data demonstrate that the sarcomeric region of skeletal muscle exhibits clearly defined and functionally distinct PKA microdomains, which are organized by specific AKAPs. At present, it is unclear which $\operatorname{AKAP}(s)$ mediate the anchoring of PKA-RI $\alpha$ and PKA-RII $\alpha$ to the different domains in the sarcomeric region but one eminent protein, myospryn, is certainly carrying out a part of this function. This $449 \mathrm{kDa}$ heavy protein with the official gene name CMYA5 (cardiomyopathyassociated 5) was identified by expression profiling of a cardiac muscle library and has since been found to interact specifically with PKA-RII $\alpha$ but not (or hardly) with the other PKA-R isoforms (Reynolds et al., 2007). Intriguingly, endogenous myospryn localization in the sarcomere exhibited the expected $\mathrm{m}$ - and $\mathrm{z}$-line expression pattern fitting to PKA-RII $\alpha$ distribution (Reynolds et al., 2007) while in another study myospryn showed only faint $\mathrm{m}$-line and strong I-band distribution (Sarparanta et al., 2010). Whether this could indicate natural variability or be due to other factors is unclear, but myospryn is now widely considered to be an important determinant for PKA microdomain formation in skeletal and heart muscle. In the recent past, more and more proteins were found to interact with myospryn, including the structural proteins $\alpha$-actinin (Durham et al., 2006), desmin (Kouloumenta et al., 2007), dystrophin (Reynolds et al., 2008), and titin (Sarparanta et al., 2010), as well as proteolytic enzymes such as the muscle-specific protease, calpain 3 (Sarparanta et al., 2010), and the protein phosphatase calcineurin (Kielbasa et al., 2011). Notably, these proteins all play important roles in muscle integrity and metabolic adaptations suggesting a mediator role of myospryn in these processes (Sarparanta, 2008). This is corroborated by feedback loops: Expression of myospryn is modulated by the cAMP-dependent CREB pathway, and it is known to be a direct target of the myocyte enhancer factor MEF2A (Durham et al., 2006). Furthermore, absence or malfunction of myospryn is observed in a couple of muscle diseases including tibial and limb-girdle muscular dystrophies (TMD and LGMD2J, respectively) (Sarparanta et al., 2010) as well as the most abundant and severe form of muscular dystrophies, i.e., DMD (Reynolds et al., 2008). Notably, in the DMD mouse model, $m d x$, myospryn showed altered subcellular distribution and specific PKA activity was strongly reduced (Reynolds et al., 2008). This also fits to another study, where PKA-RI $\alpha$ distribution in the sarcomeres was altered and, in particular, the microdomain selectivity to respond to the specific agonists, norepinephrine and $\alpha$ CGRP, was completely subverted (Röder et al., 2009). In summary, although the precise function of cAMP microdomain organization in skeletal muscle sarcomeres is still elusive, there are correlations between aberrant cAMP signaling and severe muscle diseases. Based on this rationale, urocortins were tested as therapeutics against muscular dystrophy (Hinkle et al., 2007; ReutenauerPatte et al., 2012). Urocortins are neuropeptides that bind to the GPCRs, corticotropin-releasing factor (CRF) receptors (CRFR), of which $\mathrm{CRF}_{2} \mathrm{R}$ is highly abundant in skeletal muscle. Notably, in 
dystrophic $m d x$ mice treatment with urocortins significantly ameliorated a set of symptoms, ranging from fiber necrosis to muscle function. Possible mechanisms of action might include cAMPinduced activation of PKA and Epac, which in turn may address altered $\mathrm{Ca}^{2+}$ handling in skeletal muscle fibers (Reutenauer-Patte et al., 2012).

\section{MECHANISMS OF cAMP-INDUCED EFFECTS ON SKELETAL MUSCLE PROTEIN METABOLISM}

Skeletal muscle constitutes about $40-60 \%$ of our body masses. It is, thus, not only driving locomotion but also represents a major metabolic organ due to its enormous energy expenditure, its capability to take up glucose in an insulin-dependent manner, and its role as amino acid-source during catabolic conditions (Sandri, 2008; Glass, 2010). All these functions are intimately linked to the sarcomeres, which constitute the vast excess of skeletal muscle tissue. GPCR- and cAMP-mediated signaling can act on different time scales, ranging from the seconds to days range, correlating to either direct activation of targets (e.g., by PKA-dependent phosphorylation) or to changes in transcriptional profiles (e.g., by modulation of CREB activity). In contrast to their catabolic effects on lipids and carbohydrate metabolism, catecholamines exert an anabolic effect on skeletal muscle protein metabolism (Navegantes et al., 2002). This effect is mediated by $\beta_{2}$-ARs and involves cAMP signaling (Navegantes et al., 2000, 2002). Numerous studies have shown that $\beta_{2}$-adrenergic agonists, such as clenbuterol ("older" generation) and formoterol ("newer" generation), induce hypertrophy of skeletal muscle in rodents, large animals and humans (Lynch and Ryall, 2008). $\beta$-agonist-induced hypertrophy seems to be specific for striated muscle, since smooth muscles do not increase in size in response to these agents (Reeds et al., 1986) and $\beta 2$-adrenergic agonists inhibit smooth muscle cell proliferation (Southgate and Newby, 1990; Tomlinson et al., 1994; Indolfi et al., 1997). Experiments conducted in $\beta_{2}$ $\mathrm{AR}^{-/-}$mice (Hinkle et al., 2002) have convincingly shown that $\beta_{2}-\mathrm{AR}$ is responsible for this anabolic effect. Indeed, $\beta_{2}-\mathrm{AR}^{-/-}$ mice display decreased cross-sectional area of type I and IIA fibers compared with age-matched wildtype mice (Bacurau et al., 2009), an effect that is associated with lower muscle cAMP levels (Gonçalves et al., 2009).

The molecular mechanisms by which cAMP signaling induces growth and muscle-sparing responses are uncertain and may involve an increase in the rate of protein synthesis and/or a decrease in protein degradation (Navegantes et al., 2002; Lynch and Ryall, 2008). A large body of evidence indicates that the in vivo effects of cAMP-inducing agents are in part due to inhibition of muscle proteolysis (Figure 3). Indeed, both chemical and surgical sympathectomy in fed rats lead to an increase in the activity of the $\mathrm{Ca}^{2+}$-dependent proteolytic system, which suggests the existence of an adrenergic tonus on skeletal muscle that keeps this pathway inhibited under normal conditions (Navegantes et al., 1999, 2001). Accordingly, the administration of $\beta_{2}$-adrenergic agonists is accompanied by a reduction in calpain 1 activity and an increase in the activity of calpastatin, an endogenous inhibitor of calpains (Bardsley et al., 1992; Parr et al., 1992). More recently, it has been demonstrated that $\beta_{2}$-adrenergic agonists might attenuate muscle atrophy through inhibitory effects on the ubiquitin-proteasome system, the main

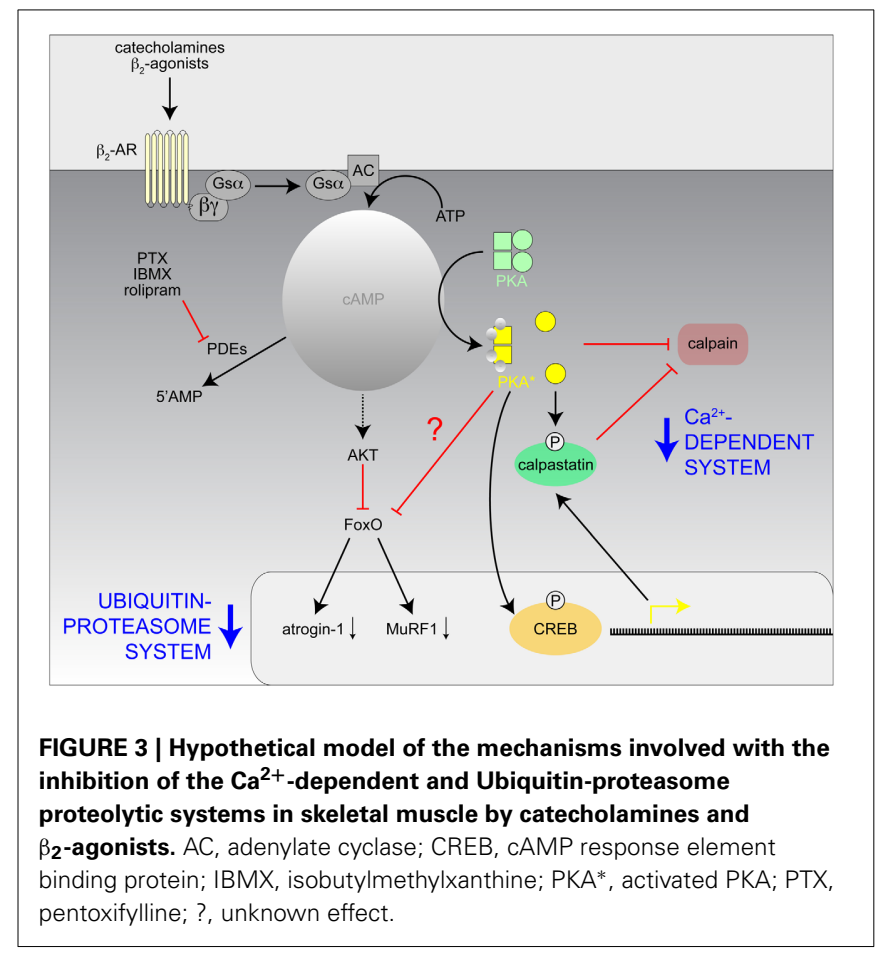

intracellular pathway for protein degradation in skeletal muscle (Yimlamai et al., 2005; Gonçalves et al., 2012). This effect is mediated through a cAMP/Akt-dependent pathway (Kline et al., 2007; Gonçalves et al., 2009, 2012), which leads to the phosphorylation of Foxo3a and, consequently, the suppression of atrogin-1/MAFbx and MuRF1, two ubiquitin E3-ligases involved in muscle atrophy (Bodine et al., 2001; Centner et al., 2001; Lecker et al., 2004; Sandri et al., 2004). Moreover, treatment with PDE inhibitors increased muscle cAMP levels and decreased the rate of total protein degradation in muscles from diabetic (Baviera et al., 2007) and fasted rodents (Lira et al., 2007) through a clear reduction in the activity of the $\mathrm{Ca}^{2+}$-dependent proteolytic system and the ubiquitin-proteasome system. The fact that the antiproteolytic effect of both $\beta_{2}$ agonists (Gonçalves et al., 2012) and PDE inhibitors (Baviera et al., 2007) in vitro was inhibited by $\mathrm{H} 89$, a PKA inhibitor, and mimicked by 6-BNZ-cAMP, a PKA activator, further supports the idea that activation of the cAMP cascade via a PKA-dependent pathway is one of the regulatory mechanism(s) to prevent excessive skeletal muscle protein breakdown. Given that in dystrophic muscle the $\mathrm{Ca}^{2+}$-dependent proteolytic system and the ubiquitin-proteasomal system are activated on the one hand (Kar and Pearson, 1976; Spencer and Tidball, 1996; Kumamoto et al., 2000) and PKA signaling, on the other hand, is disturbed (Reynolds et al., 2008; Röder et al., 2009), it is reasonable to suggest that increased calpain and proteasome activities contribute to dystrophic pathology and, by extension, that protease inhibition by cAMP-inducing agents could be a treatment strategy for DMD.

\section{ON THE ORIGIN AND DESTINATION OF CATECHOLAMINES IN SKELETAL MUSCLE}

It is general knowledge that sympathetic first messengers can be released from either adrenal medulla as hormones or from 
sympathetic neurons as neurotransmitters directly onto target tissues (Mason, 1968). However, surprisingly little is known about the real contributions of these different modes of sympathetic activities in most tissues (Daly and McGrath, 2011) and this holds true also for skeletal muscle. Yet, to our knowledge, there are a few studies reporting on direct innervation of skeletal muscle fibers by non-myelinated, noradrenergic fibers (Boeke, 1909a,b, 1913; Barker and Saito, 1981; Tadaki et al., 1995), suggesting that sympathetic actions on skeletal muscle are at least partially mediated by neural mechanisms. Accordingly, a study using surgical ablation of sympathetic ganglia, which innervate hind limb muscles have shown that direct innervation of skeletal muscles by autonomic nerves is critical for muscle homeostasis (Navegantes et al., 2004) and a wealth of investigations has dealt with the effects of sympathetic agonists on skeletal muscle force potentiation and release of acetylcholine from motoneurons (see, e.g., Oliver and Schäfer, 1895; Goffart and Ritchie, 1952; Krnjevic and Miledi, 1958; Bowman and Raper, 1967). The latter are processes, which are likely to need fast regulation in the course of fight-or-flight situations. This triggered us to reinvestigate the distribution of sympathetic innervation in skeletal muscle and to address differences between sympathetic targets in healthy and dystrophic muscles. Thus, we first studied the distribution of the sympathetic neuron marker, tyrosine hydroxylase $(\mathrm{TOH})$ in longitudinal sections of mouse hindlimb muscle and found this marker protein to be concentrated on top of most NMJs (Figure 4A). This is

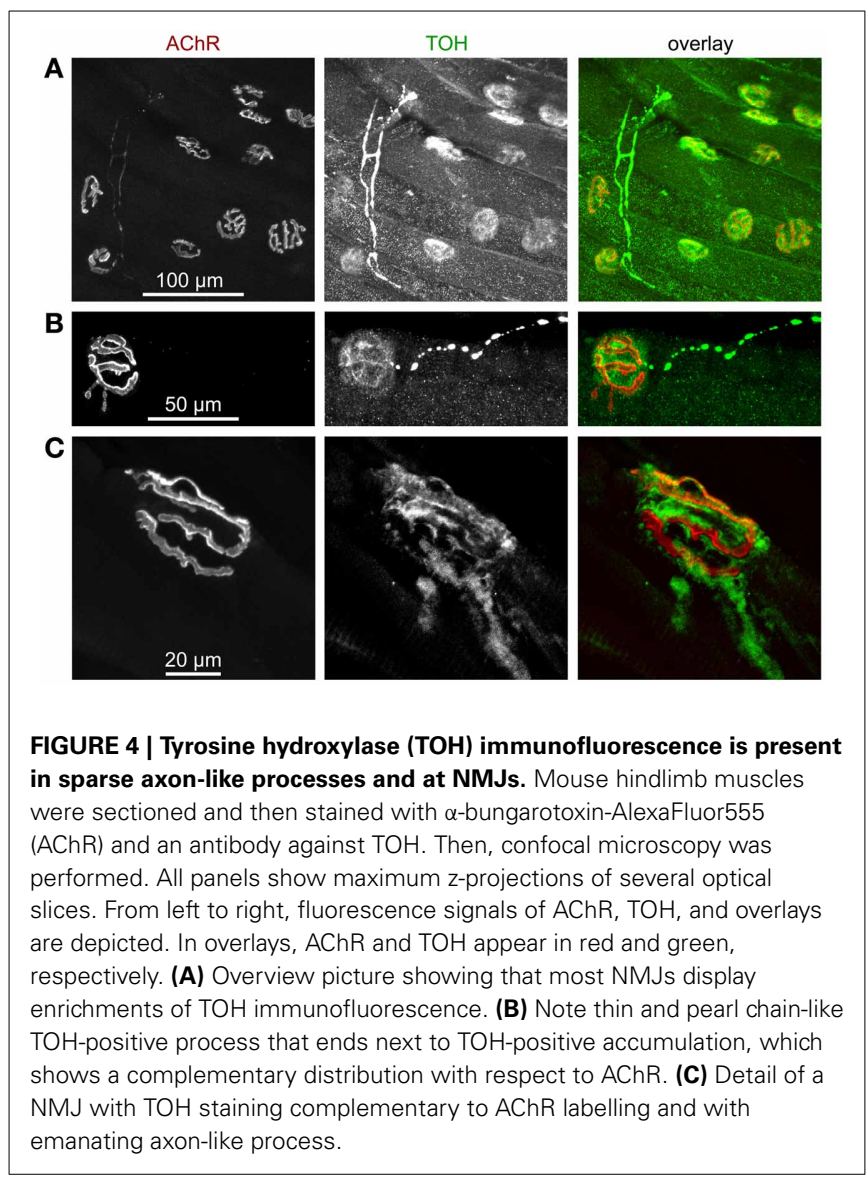

in accordance with previous studies carried out in several vertebrate species, including man (Chan-Palay et al., 1982a,b). In many cases, enrichments of $\mathrm{TOH}$ immunostaining in proximity to NMJs were connected to pearl chain-like processes, which are

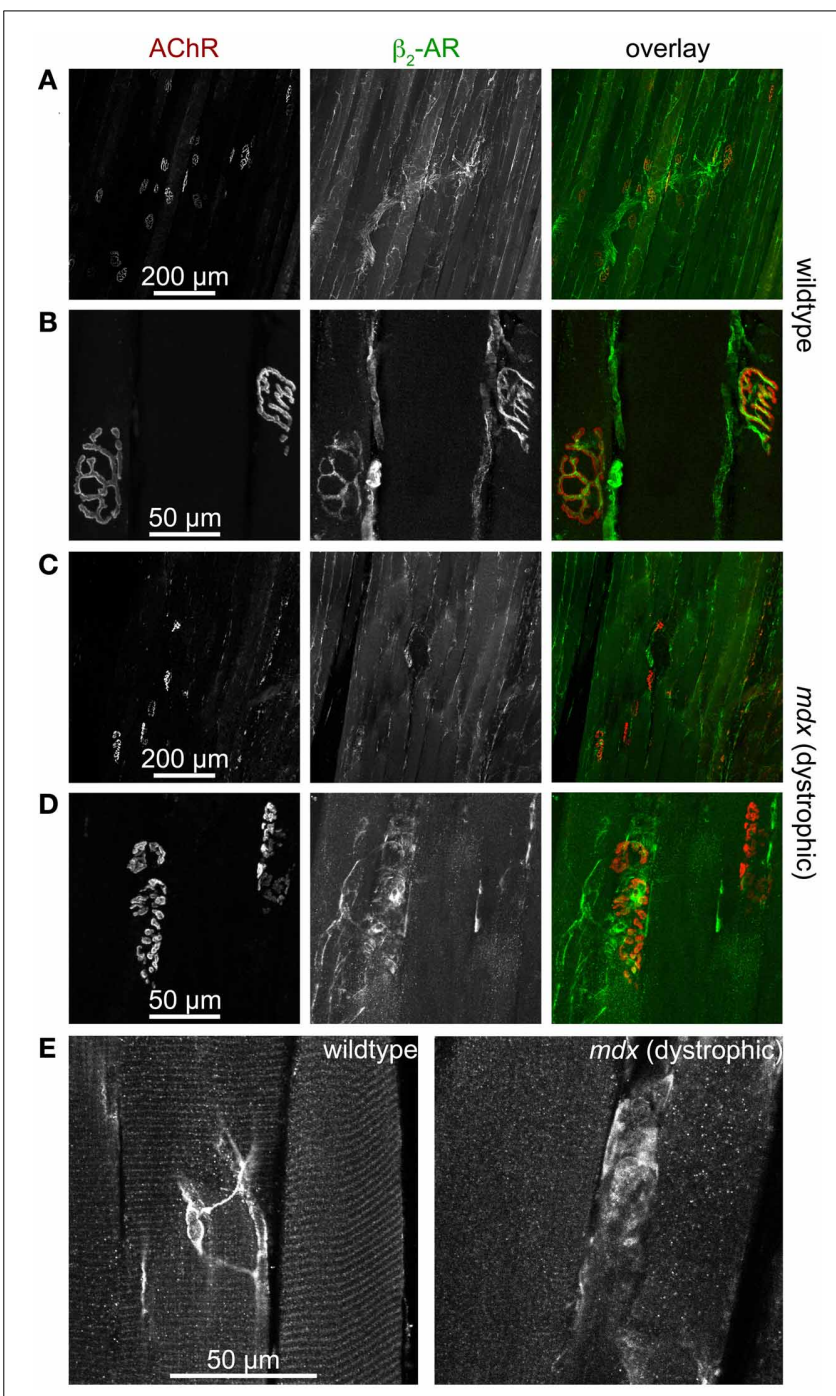

FIGURE 5 | $\beta_{2}$-AR-immunofluorescence is found in motoneurons and muscle fibers and is severely altered in dystrophic muscle. Mouse hindlimb muscles of wildtype (A,B,E left) or dystrophic mdx mice (C,D,E right) were sectioned and then stained with $\alpha$-bungarotoxin-AlexaFluor555 (AChR) and an antibody against $\beta_{2}$-AR. Then, confocal microscopy was performed. (A-D) Show maximum z-projections of several optical slices, in (E) single optical slices are depicted. From left to right, fluorescence signals of $A C h R, \beta_{2}-A R$, and overlays are depicted. In overlays, $A C h R$ and $\beta_{2}-A R$ appear in red and green, respectively. In wildtype muscles, $\beta_{2}$-AR immunofluorescence covers entire motor nerve bundles (A) and perfectly matches the AChR arborized structures in the NMJ (B). This is typical for the distribution of motoneuronal markers. Conversely, $\beta_{2}-\mathrm{AR}$ immunofluorescence is much sparser in dystrophic muscle (C) and exhibits only partial overlap with AChR staining (D). In muscle fibers of wildtype animals ( $E$ left) $\beta_{2}-A R$ is found in triple striations per sarcomer, similar to the distribution of PKA-RIll (see Figure 2). This striation is mostly absent in dystrophic muscle (E right), where $\beta_{2}-A R$ distribution is often uniform along the fibers. Finally, anostomotic $\beta_{2}$-AR-positive, axon-like processes of unknown identity are also often seen running along muscle fibers (E left). 
likely to represent sympathetic axons (Figure 4B). Notably, while previous investigators performed immunostainings on transverse muscle sections and thus proposed $\mathrm{TOH}$ to be present in the motoneuronal presynaptic portion of NMJs (Chan-Palay et al., $1982 \mathrm{a}, \mathrm{b})$, the analysis of our longitudinal slices revealed that $\mathrm{TOH}$ immunofluorescence does not match postsynaptic AChR staining as it would be typical for motoneuronal markers, but was mostly just in the gaps between the NMJ pretzel structure (Figure 4C). That fits to the older observations from Boeke based on tissue silver impregnation (Boeke, 1909a,b, 1913) and corroborates his suggestion that sympathetic neurons run and terminate next to motoneurons. Future investigations should be carried out to further strengthen this finding.

Next, we addressed the expression pattern of $\beta_{2}-\mathrm{AR}$ in hindlimb muscle. This showed immunohistochemical signals of $\beta_{2}$-AR in at least four different locations: (1) larger blood vessels (not depicted), (2) motoneurons (Figures 5A,B), (3) muscle fibers (Figure 5E, left panel), and (4) ill-defined anastomotic fibers (Figure 5E, on left panel see central part of the picture). Since the presence of $\beta_{2}$-AR had been found by staining and anticipated to be present due to functional roles in blood vessels (Daly and McGrath, 2011), motoneurons (Melamed et al., 1976; Wohlberg et al., 1986; Bondok et al., 1988; Adachi et al., 1992; Parkis et al., 1995; Zeman et al., 2004; Tartas et al., 2010; Noga et al., 2011; Baker and Baker, 2012) and muscle fibers (Gross et al., 1976; Cairns and Dulhunty, 1993a,b; Cairns et al., 1993; Kokate et al., 1993; Navegantes et al., 1999, 2000, 2001, 2002, 2003, 2004; Prakash et al., 1999; Decostre et al., 2000; Gonçalves et al., 2012), our findings in wildtype muscles were

\section{REFERENCES}

Adachi, S., Oka, J., Nagao, T., and Fukuda, H. (1992). Activation of beta-adrenergic receptor induces $\mathrm{Na}(+)$-dependent inward currents in acutely dissociated motoneurons of bullfrog spinal cord. Brain Res. 571, 79-88. doi: 10.1016/0006-8993 (92)90511-7

Akaaboune, M., Culican, S. M., Turney, S. G., and Lichtman, J. W. (1999). Rapid and reversible effects of activity on acetylcholine receptor density at the neuromuscular junction in vivo. Science 286, 503-507. doi: 10.1126/science.286.5439.503

Altarejos, J. Y., and Montminy, M. (2011). CREB and the CRTC coactivators: sensors for hormonal and metabolic signals. Nat. Rev. Mol. Cell Biol. 12, 141-151. doi: 10.1038/nrm3072

Apel, E. D., Glass, D. J., Moscoso, L. M., Yancopoulos, G. D., and Sanes, J. R. (1997). Rapsyn is required for MuSK signaling and recruits synaptic components to a MuSK-containing scaffold. Neuron 18, 623-635. doi: 10.1016/S08966273(00)80303-7

Arreola, J., Calvo, J., Garcia, M. C., and Sanchez, J. A. (1987). Modulation of calcium channels of twitch skeletal muscle fibres of the frog by adrenaline and cyclic adenosine monophosphate. J. Physiol. 393, 307-330.

Bacurau, A. V., Jardim, M. A., Ferreira, J. C., Bechara, L. R., Bueno, C. R. Jr., Alba-Loureiro, T. C., et al. (2009). Sympathetic hyperactivity differentially affects skeletal muscle mass in developing heart failure: role of exercise training. J. Appl. Physiol. 106, 1631-1640. doi: 10.1152/japplphysiol.91067.2008 Beta-adrenergic modulation of tremor and corticomuscular coherence in humans. PLoS ONE 7:e49088. doi: 10.1371/journal. pone. 0049088

Bardsley, R. G., Allcock, S. M., Dawson, J. M., Dumelow, N. W., Higgins, J. A., Lasslett, Y. V., et al. (1992). Effect of beta-agonists on expression of calpain and calpastatin activity in skeletal muscle. Biochimie 74, 267-273. doi: 10.1016/03009084(92)90125-X

Barker, D., and Saito, M. (1981). Autonomic innervation of receptors and muscle fibres in cat skeletal muscle. Proc. R. Soc. Lond.
Baker, M. R., and Baker, S. N. (2012).

corroborating previous reports. However, the difference between wildtype and dystrophic $m d x$ muscles was striking, both with respect to neuronal as well as muscle staining: First, while the typical pretzel-shaped postsynaptic AChR signals in wildtype muscle were perfectly mirrored by presynaptic $\beta_{2}$-AR staining (Figures 5A,B) in almost fibers, this was much rarer the case in $m d x$ synapses (Figures 5C,D), which were also highly fragmented as reported previously (Torres and Duchen, 1987; Lyons and Slater, 1991; Grady et al., 2000). Second, while $\beta_{2}$-AR immunofluorescence displayed a highly regular striated patterning in wildtype muscle (Figure 5E, left panel), it was almost uniformly distributed in many fibers from $m d x$ muscles (Figure 5E, right panel). In summary, these data show that there are significant differences in distribution of $\beta_{2}$-AR between healthy and dystrophic muscles. In the context of the PKA microdomain hypothesis this could be an additional level of dysregulation leading to alterations of cAMP with all the sequelae as discussed before.

\section{ACKNOWLEDGMENTS}

We are grateful to Dr. M. Mongillo (Padua/Italy), Dr. S. Schiaffino (Padua/Italy), and Dr. M. Zaccolo (Oxford/UK) for helpful discussions. Rüdiger Rudolf is supported by DFG grants RU923/7-1 and RU923/8-1, Siegfried Labeit by EU-network SarcoSI and DFG grant LA668/15-1, and Danilo Lustrino, Ísis C. Kettelhut and Luiz C. C. Navegantes by CNPQ (305149/2012-1) and FAPESP (12/05697-7 and 12/24524-6.) grants. We acknowledge support by Deutsche Forschungsgemeinschaft and Open Access Publishing Fund of Karlsruhe Institute of Technology.

B Biol. Sci. 212, 317-332. doi: 10.1098/rspb.1981.0042

Barradeau, S., Imaizumi-Scherrer, T., Weiss, M. C., and Faust, D. M. (2001). Muscle-regulated expression and determinants for neuromuscular junctional localization of the mouse RIalpha regulatory subunit of cAMP-dependent protein kinase. Proc. Natl. Acad. Sci. U.S.A. 98, 5037-5042. doi: 10.1073/pnas. 081393598

Barradeau, S., Imaizumi-Scherrer, T., Weiss, M. C., and Faust, D. M. (2002). Intracellular targeting of the type-I alpha regulatory subunit of cAMP-dependent protein kinase. Trends Cardiovasc. Med. 12, 235-241. doi: 10.1016/S1050-1738 (02)00167-6

Baviera, A. M., Zanon, N. M., Carvalho Navegantes, L. C., Migliorini, R. H., and Do Carmo Kettelhut, I. (2007). Pentoxifylline inhibits $\mathrm{Ca} 2+-$ dependent and ATP proteasome-dependent proteolysis in skeletal muscle from acutely diabetic rats. Am. J. Physiol. Endocrinol. Metab. 292, E702-E708. doi: 10.1152/ajpendo.00147.2006

Beavo, J. A., and Brunton, L. L. (2002). Cyclic nucleotide research - still expanding after half a century. Nat. Rev. Mol. Cell Biol. 3, 710-718. doi: 10.1038/nrm911

Berdeaux, R., and Stewart, R. (2012). cAMP signaling in skeletal muscle adaptation: hypertrophy, metabolism, and regeneration. Am. J. Physiol. Endocrinol. Metab. 303, E1-E17. doi: 10.1152/ajpendo. 00555.2011

Bloom, T. J. (2002). Cyclic nucleotide phosphodiesterase isozymes expressed in mouse skeletal muscle. Can. J. Physiol. Pharmacol. 80, 1132-1135. doi: 10.1139/y02-149

Bodine, S. C., Latres, E., Baumhueter, S., Lai, V. K., Nunez, L., Clarke, B. A., et al. (2001). Identification of ubiquitin ligases required for skeletal muscle atrophy. Science 294, 1704-1708. doi: 10.1126/science.1065874

Boeke, J. (1909a). Die motorische Endplatte bei den höheren Vertebraten, ihre Entwickelung, Form und Zusammenhang mit der Muskelfaser. Anat. Anz. 35, 240-256.

Boeke, J. (1909b). Ueber eine aus marklosen Fasern hervorgehende zweite Art von hypolemmalen Nervenendplatten bei den 
quergestreiften Muskelfasern der Vertebraten. Anat. Anz. 35, 481-484.

Boeke, J. (1913). Die doppelte (motorische und sympathische) efferente Innervation der quergestreiften Muskelfasern. Anat. Anz. 44, 343-356.

Bondok, A. A., Botros, K. G., and El-Mohandes, E. A. (1988). Fluorescence histochemical study of the localisation and distribution of beta-adrenergic receptor sites in the spinal cord and cerebellum of the chicken. J. Anat. 160, 167-174.

Bos, J. L. (2003). Epac: a new cAMP target and new avenues in cAMP research. Nat. Rev. Mol. Cell Biol. 4, 733-738. doi: 10.1038/nrm1197

Bowman, W. C., and Raper, C. (1967). Adrenotropic receptors in skeletal muscle. Ann. N.Y. Acad. Sci. 139, 741-753. doi: 10.1111/j.17496632.1967.tb41241.x

Bruneau, E., Sutter, D., Hume, R. I., and Akaaboune, M. (2005). Identification of nicotinic acetylcholine receptor recycling and its role in maintaining receptor density at the neuromuscular junction in vivo. J. Neurosci. 25, 9949-9959. doi: 10.1523/JNEUROSCI.3169-05.2005

Bruneau, E. G., and Akaaboune, M. (2006). The dynamics of recycled acetylcholine receptors at the neuromuscular junction in vivo. Development 133, 4485-4493. doi: $10.1242 /$ dev.02619

Burden, S. J., Yumoto, N., and Zhang, W. (2013). The Role of MuSK in Synapse Formation and Neuromuscular Disease. Cold Spring Harb. Perspect. Biol. 5:a009167. doi: 10.1101/ cshperspect.a009167

Cairns, S. P., and Dulhunty, A. F. (1993a). Beta-adrenergic potentiation of E-C coupling increases force in rat skeletal muscle. Muscle Nerve 16, 1317-1325. doi: $10.1002 /$ mus. 880161208

Cairns, S. P., and Dulhunty, A. F. (1993b). The effects of betaadrenoceptor activation on contraction in isolated fast- and slow-twitch skeletal muscle fibres of the rat. Br. J. Pharmacol. 110, 1133-1141. doi: 10.1111/j.14765381.1993.tb13932.x

Cairns, S. P., Westerblad, H., and Allen, D. G. (1993). Changes of tension and $[\mathrm{Ca} 2+] \mathrm{i}$ during betaadrenoceptor activation of single, intact fibres from mouse skeletal muscle. Pflugers Arch. 425, 150-155. doi: 10.1007/BF00374515

Centner, T., Yano, J., Kimura, E., McElhinny, A. S., Pelin, K., Witt, C. C., et al. (2001). Identification of muscle specific ring finger proteins as potential regulators of the titin kinase domain. J. Mol. Biol. 306, 717-726. doi 10.1006/jmbi.2001.4448

Chan-Palay, V., Engel, A. G., Palay, S. L., and Wu, J. Y. (1982a). Synthesizing enzymes for four neuroactive substances in motor neurons and neuromuscular junctions: light and electron microscopic immunocytochemistry. Proc. Natl. Acad. Sci. U.S.A. 79, 6717-6721. doi: 10.1073/pnas.79.21.6717

Chan-Palay, V., Engel, A. G., Wu, J. Y., and Palay, S. L. (1982b). Coexistence in human and primate neuromuscular junctions of enzymes synthesizing acetylcholine, catecholamine, taurine, and gamma-aminobutyric acid. Proc. Natl. Acad. Sci. U.S.A. 79, 7027-7030. doi: 10.1073/pnas. 79.22.7027

Choi, K. R., Berrera, M., Reischl, M., Strack, S., Albrizio, M., Roder, I. V., et al. (2012). Rapsyn mediates subsynaptic anchoring of PKA type I and stabilisation of acetylcholine receptor in vivo. J. Cell Sci. 125, 714-723. doi: 10.1242/jcs.092361

Conti, M., and Beavo, J. (2007). Biochemistry and physiology of cyclic nucleotide phosphodiesterases: essential components in cyclic nucleotide signaling. Annu. Rev. Biochem. 76, 481-511. doi: $10.1146 /$ annurev.biochem.76. 060305.150444

Daly, C. J., and McGrath, J. C. (2011). Previously unsuspected widespread cellular and tissue distribution of beta-adrenoceptors and its relevance to drug action. Trends Pharmacol. Sci. 32, 219-226. doi: 10.1016/j.tips.2011.02.008

Decostre, V., Gillis, J. M., and Gailly, P. (2000). Effect of adrenaline on the post-tetanic potentiation in mouse skeletal muscle. J. Muscle Res. Cell Motil. 21, 247-254. doi: 10.1023/A:1005685900196

Di Benedetto, G., Zoccarato, A., Lissandron, V., Terrin, A., Li, X., Houslay, M. D., et al. (2008). Protein kinase A type I and type II define distinct intracellular signaling compartments. Circ. Res. 103, 836-844. doi: 10.1161/CIRCRESAHA.108.174813

Durham, J. T., Brand, O. M., Arnold, M., Reynolds, J. G., Muthukumar, L., Weiler, H., et al. (2006). Myospryn is a direct transcriptional target for MEF2A that encodes a striated muscle, alpha-actinininteracting, costamere-localized protein. J. Biol. Chem. 281, 6841-6849. doi: $10.1074 / \mathrm{jbc}$. M510499200
Edgeworth, H. (1930). A report of progress on the use of ephedrine in a case of myasthenia gravis. J. Am. Med. Assoc. 94, 1136. doi: 10.1001/ jama.1930.27120410003009c

Edwards, H. V., Christian, F., and Baillie, G. S. (2012). cAMP: novel concepts in compartmentalised signalling. Semin. Cell Dev. Biol. 23, 181-190. doi: 10.1016/j.semcdb. 2011.09.005

Engel, A. G., Lindstrom, J. M., Lambert, E. H., and Lennon, V. A. (1977). Ultrastructural localization of the acetylcholine receptor in myasthenia gravis and in its experimental autoimmune model. Neurology 27, 307-315. doi: 10.1212/WNL.27.4.307

Fambrough, D. M. (1979). Control of acetylcholine receptors in skeletal muscle. Physiol. Rev. 59, 165-227.

Finlayson, S., Spillane, J., Kullmann, D. M., Howard, R., Webster, R., Palace, J., et al. (2013). Slow channel congenital myasthenic syndrome responsive to a combination of fluoxetine and salbutamol. Muscle Nerve 47, 279-282. doi: 10.1002/mus.23534

Fontaine, B., Klarsfeld, A., and Changeux, J. P. (1987). Calcitonin gene-related peptide and muscle activity regulate acetylcholine receptor alpha-subunit mRNA levels by distinct intracellular pathways. J. Cell Biol. 105, 1337-1342. doi: 10.1083/jcb.105.3.1337

Francis, S. H., Blount, M. A., and Corbin, J. D. (2011). Mammalian cyclic nucleotide phosphodiesterases: molecular mechanisms and physiological functions. Physiol. Rev. 91, 651-690. doi: 10.1152/physrev.00030.2010

Froehner, S. C. (1993). Regulation of ion channel distribution at synapses. Annu. Rev. Neurosci. 16, 347-368. doi: 10.1146/annurev.ne. 16.030193.002023

Fuhrer, C., Gautam, M., Sugiyama, J. E., and Hall, Z. W. (1999). Roles of rapsyn and agrin in interaction of postsynaptic proteins with acetylcholine receptors. J. Neurosci. 19, 6405-6416.

Fumagalli, G., Engel, A. G., and Lindstrom, J. (1982). Ultrastructural aspects of acetylcholine receptor turnover at the normal end-plate and in autoimmune myasthenia gravis. J. Neuropathol. Exp. Neurol. 41, 567-579. doi: 10.1097/00005072198211000-00001

Gautam, M., Dechiara, T. M., Glass, D. J., Yancopoulos, G. D., and Sanes, J. R. (1999). Distinct phenotypes of mutant mice lacking agrin, MuSK, or rapsyn. Brain Res. Dev. Brain Res. 114, 171-178. doi: 10.1016/S01653806(99)00013-9

Gillespie, S. K., Balasubramanian, S., Fung, E. T., and Huganir, R. L. (1996). Rapsyn clusters and activates the synapse-specific receptor tyrosine kinase MuSK. Neuron 16, 953-962. doi: 10.1016/S08966273(00)80118-X

Glass, D. J. (2010). Signaling pathways perturbing muscle mass. Curr. Opin. Clin. Nutr. Metab. Care 13, 225-229. doi: 10.1097/MCO.0b013e32833862df

Glass, D. J., and Yancopoulos, G. D. (1997). Sequential roles of agrin, MuSK and rapsyn during neuromuscular junction formation. Curr. Opin. Neurobiol. 7, 379-384. doi: 10.1016/S0959-4388(97)80066-9

Goffart, M., and Ritchie, J. M. (1952). The effect of adrenaline on the contraction of mammalian skeletal muscle. J. Physiol. 116, 357-371.

Gonçalves, D. A., Lira, E. C., Baviera, A. M., Cao, P., Zanon, N. M., Arany, Z., et al. (2009). Mechanisms involved in 3,5'-cyclic adenosine monophosphate-mediated inhibition of the ubiquitin-proteasome system in skeletal muscle. Endocrinology 150, 5395-5404. doi: 10.1210/en.2009-0428

Gonçalves, D. A., Silveira, W. A., Lira, E. C., Graca, F. A., PaulaGomes, S., Zanon, N. M., et al. (2012). Clenbuterol suppresses proteasomal and lysosomal proteolysis and atrophy-related genes in denervated rat soleus muscles independently of Akt. Am. J. Physiol. Endocrinol. Metab. 302, E123-E133. doi: 10.1152/ajpendo. 00188.2011

Grady, R. M., Zhou, H., Cunningham, J. M., Henry, M. D., Campbell, K. P., and Sanes, J. R. (2000). Maturation and maintenance of the neuromuscular synapse: genetic evidence for roles of the dystrophin-glycoprotein complex. Neuron 25, 279-293. doi: 10.1016/S0896-6273(00)80894-6

Gross, S. R., Mayer, S. E., and Longshore, M. A. (1976). Stimulation of glycogenolysis by beta adrenergic agonists in skeletal muscle of mice with the phosphorylase kinase deficiency mutation (I strain). J. Pharmacol. Exp. Ther. 198, 526-538.

Hinkle, R. T., Hodge, K. M., Cody, D. B., Sheldon, R. J., Kobilka, B. K., and Isfort, R. J. (2002). Skeletal muscle hypertrophy and anti-atrophy effects of clenbuterol are mediated by the beta2-adrenergic receptor. Muscle Nerve 25, 729-734. doi: 10.1002/mus.10092 
Hinkle, R. T., Lefever, F. R., Dolan, E. T., Reichart, D. L., Dietrich, J. A., Gropp, K. E., et al. (2007). Corticortophin releasing factor 2 receptor agonist treatment significantly slows disease progression in mdx mice. BMC Med. 5:18. doi: 10.1186/1741-7015-5-18

Hubbard, S. R., and Gnanasambandan, K. (2013). Structure and activation of MuSK, a receptor tyrosine kinase central to neuromuscular junction formation. Biochim. Biophys. Acta 1834, 2166-2169. doi: 10.1016/j. bbapap.2013.02.034

Imaizumi-Scherrer, T., Faust, D. M., Benichou, J. C., Hellio, R., and Weiss, M. C. (1996). Accumulation in fetal muscle and localization to the neuromuscular junction of cAMP-dependent protein kinase A regulatory and catalytic subunits RI alpha and C alpha. J. Cell Biol. 134, 1241-1254. doi: 10.1083/jcb.134.5.1241

Indolf, C., Avvedimento, E. V., Di Lorenzo, E., Esposito, G., Rapacciuolo, A., Giuliano, P., et al. (1997). Activation of cAMP-PKA signaling in vivo inhibits smooth muscle cell proliferation induced by vascular injury. Nat. Med. 3, 775-779. doi: 10.1038/nm0797-775

Jean-Baptiste, G., Yang, Z., Khoury, C., Gaudio, S., and Greenwood, M. T. (2005). Peptide and non-peptide G-protein coupled receptors (GPCRs) in skeletal muscle. Peptides 26, 1528-1536. doi: 10.1016/j.peptides.2005.03.011

Joyner, M. J., and Casey, D. P. (2009). The catecholamines strike back. What NO does not do. Circ. J. 73, 1783-1792. doi: 10.1253/circj.CJ09-0559

Kar, N. C., and Pearson, C. M. (1976). A calcium-activated neutral protease in normal and dystrophic human muscle. Clin. Chim. Acta 73, 293-297. doi: 10.1016/00098981(76)90175-3

Kielbasa, O. M., Reynolds, J. G., Wu, C. L., Snyder, C. M., Cho, M. Y., Weiler, H., et al. (2011). Myospryn is a calcineurin-interacting protein that negatively modulates slow-fiber-type transformation and skeletal muscle regeneration. FASEB J. 25, 2276-2286. doi: 10.1096/fi.10-169219

Kim, N., Stiegler, A. L., Cameron, T. O., Hallock, P. T., Gomez, A. M., Huang, J. H., et al. (2008). Lrp4 is a receptor for Agrin and forms a complex with MuSK. Cell 135, 334-342. doi: 10.1016/j.cell.2008.10.002

Kline, W. O., Panaro, F. J., Yang, H., and Bodine, S. C. (2007). Rapamycin inhibits the growth and muscle-sparing effects of clenbuterol. J. Appl. Physiol. 102, 740-747. doi: 10.1152/japplphysiol. 00873.2006

Kokate, T. G., Heiny, J. A., and Sperelakis, N. (1993). Stimulation of the slow calcium current in bullfrog skeletal muscle fibers by cAMP and cGMP. Am. J. Physiol. 265, C47-C53.

Kouloumenta, A., Mavroidis, M., and Capetanaki, Y. (2007). Proper perinuclear localization of the TRIM-like protein myospryn requires its binding partner desmin. J. Biol. Chem. 282, 35211-35221. doi: 10.1074/jbc. M704733200

Krnjevic, K., and Miledi, R. (1958). Some effects produced by adrenaline upon neuromuscular propagation in rats. J. Physiol. 141, 291-304.

Kumamoto, T., Fujimoto, S., Ito, T., Horinouchi, H., Ueyama, H., and Tsuda, T. (2000). Proteasome expression in the skeletal muscles of patients with muscular dystrophy. Acta Neuropathol. 100, 595-602. doi: 10.1007/s004010000229

Lanuza, M. A., Garcia, N., Santafe, M., Gonzalez, C. M., Alonso, I., Nelson, P. G., et al. (2002). Pre- and postsynaptic maturation of the neuromuscular junction during neonatal synapse elimination depends on protein kinase C. J. Neurosci. Res. 67, 607-617. doi: 10.1002/jnr. 10122

Lashley, D., Palace, J., Jayawant, S., Robb, S., and Beeson, D. (2010). Ephedrine treatment in congenital myasthenic syndrome due to mutations in DOK7. Neurology 74, 1517-1523. doi: 10.1212/WNL.0b013e3181dd43bf

Lecker, S. H., Jagoe, R. T., Gilbert, A., Gomes, M., Baracos, V., Bailey, J., et al. (2004). Multiple types of skeletal muscle atrophy involve a common program of changes in gene expression. FASEB J. 18, 39-51. doi: 10.1096/fj.03-0610com

Levitt, T. A., Loring, R. H., and Salpeter, M. M. (1980). Neuronal control of acetylcholine receptor turnover rate at a vertebrate neuromuscular junction. Science 210, 550-551. doi: 10.1126/science. 7423205

Levitt, T. A., and Salpeter, M. M. (1981). Denervated endplates have a dual population of junctional acetylcholine receptors. Nature 291, 239-241. doi: 10.1038/291239a0

Li, M. X., Jia, M., Jiang, H., Dunlap, V., and Nelson, P. G. (2001). Opposing actions of protein kinase $\mathrm{A}$ and $\mathrm{C}$ mediate Hebbian synaptic plasticity. Nat. Neurosci. 4, 871-872. doi: 10.1038/nn0901-871
Li, M. X., Jia, M., Yang, L. X., Dunlap, V., and Nelson, P. G. (2002). Pre- and postsynaptic mechanisms in Hebbian activitydependent synapse modification. J. Neurobiol. 52, 241-250. doi: 10.1002/neu.10089

Liewluck, T., Selcen, D., and Engel, A. G. (2011). Beneficial effects of albuterol in congenital endplate acetylcholinesterase deficiency and Dok-7 myasthenia. Muscle Nerve 44, 789-794. doi: 10.1002/mus.22176

Liggett, S. B., and Raymond, J. R. (1993). Pharmacology and molecular biology of adrenergic receptors. Baillieres Clin. Endocrinol. Metab. 7, 279-306. doi: 10.1016/S0950351X(05) 80178-8

Lira, E. C., Graca, F. A., Gonçalves, D. A., Zanon, N. M., Baviera, A. M., Strindberg, L., et al. (2007). Cyclic adenosine monophosphatephosphodiesterase inhibitors reduce skeletal muscle protein catabolism in septic rats. Shock 27, 687-694. doi: $\quad 10.1097 /$ SHK.0b013e31802 e43a6

Loring, R. H., and Salpeter, M. M. (1980). Denervation increases turnover rate of junctional acetylcholine receptors. Proc. Natl. Acad. Sci. U.S.A. 77, 2293-2297. doi: 10.1073/pnas.77.4.2293

Lu, B., Fu, W. M., Greengard, P., and Poo, M. M. (1993). Calcitonin generelated peptide potentiates synaptic responses at developing neuromuscular junction. Nature 363, 76-79. doi: $10.1038 / 363076 \mathrm{a} 0$

Lynch, G. S., and Ryall, J. G. (2008). Role of beta-adrenoceptor signaling in skeletal muscle: implications for muscle wasting and disease. Physiol. Rev. 88, 729-767. doi: 10.1152/physrev.00028.2007

Lyons, P. R., and Slater, C. R. (1991). Structure and function of the neuromuscular junction in young adult $\mathrm{mdx}$ mice. J. Neurocytol. 20, 969-981. doi: 10.1007/ BF01187915

Marchand, S., Bignami, F., StetzkowskiMarden, F., and Cartaud, J. (2000). The myristoylated protein rapsyn is cotargeted with the nicotinic acetylcholine receptor to the postsynaptic membrane via the exocytic pathway. J. Neurosci. 20, 521-528.

Marchand, S., and Cartaud, J. (2002). Targeted trafficking of neurotransmitter receptors to synaptic sites. Mol. Neurobiol. 26, 117-135. doi: 10.1385/MN:26:1:117

Marchand, S., Devillers-Thiery, A., Pons, S., Changeux, J. P., and Cartaud, J. (2002). Rapsyn escorts the nicotinic acetylcholine receptor along the exocytic pathway via association with lipid rafts. J. Neurosci. 22, 8891-8901.

Marshall, J. M. (1982). The influence of the sympathetic nervous system on individual vessels of the microcirculation of skeletal muscle of the rat. J. Physiol. 332, 169-186.

Mason, J. W. (1968). A review of psychoendocrine research on the sympathetic-adrenal medullary system. Psychosom. Med. 30(Suppl.), 631-653.

Melamed, E., Lahav, M., and Atlas, D. (1976). Histochemical evidence for beta-adrenergic receptors in the rat spinal cord. Brain Res. 116, 511-515. doi: 10.1016/0006-8993(76)90499-6

Miles, K., Anthony, D. T., Rubin, L. L., Greengard, P., and Huganir, R. L. (1987). Regulation of nicotinic acetylcholine receptor phosphorylation in rat myotubes by forskolin and cAMP. Proc. Natl. Acad. Sci. U.S.A. 84, 6591-6595. doi: 10.1073/pnas.84.18.6591

Miles, K., Greengard, P., and Huganir, R. L. (1989). Calcitonin gene-related peptide regulates phosphorylation of the nicotinic acetylcholine receptor in rat myotubes. Neuron 2, 1517-1524. doi: 10.1016/0896-6273(89)90198-0

Mulle, C., Benoit, P., Pinset, C., Roa, M., and Changeux, J. P. (1988). Calcitonin gene-related peptide enhances the rate of desensitization of the nicotinic acetylcholine receptor in cultured mouse muscle cells. Proc. Natl. Acad. Sci. U.S.A. 85, 5728-5732. doi: 10.1073/pnas.85.15.5728

Navegantes, L. C., Machado, C. R., Resano, N. M., Migliorini, R. H., and Kettelhut, I. C. (2003). Beta2agonists and cAMP inhibit protein degradation in isolated chick (Gallus domesticus) skeletal muscle. Br. Poult. Sci. 44, 149-154. doi: 10.1080/0007166031000085355

Navegantes, L. C., Migliorini, R. H., and Do Carmo Kettelhut, I. (2002). Adrenergic control of protein metabolism in skeletal muscle. Curr. Opin. Clin. Nutr. Metab. Care 5, 281-286. doi: 10.1097/00075197200205000-00007

Navegantes, L. C., Resano, N. M., Baviera, A. M., Migliorini, R. H., and Kettelhut, I. C. (2004). Effect of sympathetic denervation on the rate of protein synthesis in rat skeletal muscle. Am. J. Physiol. Endocrinol. Metab. 286, E642-E647. doi: 10.1152/ajpendo.00371.2003

Navegantes, L. C., Resano, N. M., Migliorini, R. H., and Kettelhut, I. C. (1999). Effect of guanethidineinduced adrenergic blockade on the different proteolytic systems in rat 
skeletal muscle. Am. J. Physiol. 277, E883-E889.

Navegantes, L. C., Resano, N. M., Migliorini, R. H., and Kettelhut, I. C. (2000). Role of adrenoceptors and cAMP on the catecholamineinduced inhibition of proteolysis in rat skeletal muscle. Am. J. Physiol. Endocrinol. Metab. 279, E663-E668.

Navegantes, L. C., Resano, N. M., Migliorini, R. H., and Kettelhut, I. C. (2001). Catecholamines inhibit $\mathrm{Ca}(2+)$-dependent proteolysis in rat skeletal muscle through beta(2)adrenoceptors and cAMP. Am. J. Physiol. Endocrinol. Metab. 281, E449-E454.

Nelson, P. G., Lanuza, M. A., Jia, M., Li, M. X., and Tomas, J. (2003). Phosphorylation reactions in activity-dependent synapse modification at the neuromuscular junction during development. J. Neurocytol. 32, 803-816. doi: 10.1023/B:NEUR.0000020625. 70284.a6

Neubig, R. R., Krodel, E. K., Boyd, N. D., and Cohen, J. B. (1979). Acetylcholine and local anesthetic binding to Torpedo nicotinic postsynaptic membranes after removal of nonreceptor peptides. Proc. Natl. Acad. Sci. U.S.A. 76, 690-694. doi: 10.1073/pnas.76.2.690

New, H. V., and Mudge, A. W. (1986). Calcitonin gene-related peptide regulates muscle acetylcholine receptor synthesis. Nature 323, 809-811. doi: 10.1038/323809a0

Nikolaev, V. O., Bunemann, M., Hein, L., Hannawacker, A., and Lohse, M. J. (2004). Novel single chain cAMP sensors for receptorinduced signal propagation. J. Biol. Chem. 279, 37215-37218. doi: 10.1074/jbc.C400302200

Nitkin, R. M., Smith, M. A., Magill, C., Fallon, J. R., Yao, Y. M., Wallace, B. G., et al. (1987). Identification of agrin, a synaptic organizing protein from Torpedo electric organ. J. Cell Biol. 105, 2471-2478. doi: 10.1083/jcb.105.6.2471

Noga, B. R., Johnson, D. M., Riesgo, M. I., and Pinzon, A. (2011). Locomotor-activated neurons of the cat. II. Noradrenergic innervation and colocalization with NEalpha $1 \mathrm{a}$ or NEalpha $2 \mathrm{~b}$ receptors in the thoraco-lumbar spinal cord. J. Neurophysiol. 105, 1835-1849. doi: 10.1152/jn.00342.2010

Oliver, G., and Schäfer, E. A. (1895). The physiological effects of the extracts of the suprarenal capsules. J. Physiol. 18, 230-276.

Omori, K., and Kotera, J. (2007). Overview of PDEs and their regulation. Circ. Res. 100, 309-327. doi: 10.1161/01.RES.0000256354. 95791.f1

Palace, J., and Beeson, D. (2008). The congenital myasthenic syndromes. J. Neuroimmunol. 201-202, 2-5. doi: 10.1016/j.jneuroim.2008.05.030

Parkis, M. A., Bayliss, D. A., and Berger, A. J. (1995). Actions of norepinephrine on rat hypoglossal motoneurons. J. Neurophysiol. 74, 1911-1919.

Parr, T., Bardsley, R. G., Gilmour, R. S., and Buttery, P. J. (1992). Changes in calpain and calpastatin mRNA induced by beta-adrenergic stimulation of bovine skeletal muscle. Eur. J. Biochem. 208, 333-339. doi: 10.1111/j.14321033.1992.tb17191.x

Perkins, G. A., Wang, L., Huang, L. J., Humphries, K., Yao, V. J., Martone, M., et al. (2001). PKA, PKC, and AKAP localization in and around the neuromuscular junction. $B M C$ Neurosci. 2:17. doi: 10.1186/14712202-2-17

Porter, S., and Froehner, S. C. (1985). Interaction of the $43 \mathrm{~K}$ protein with components of Torpedo postsynaptic membranes. Biochemistry 24, 425-432. doi: 10.1021/bi00323a028

Poyner, D. R. (1992). Calcitonin gene-related peptide: multiple actions, multiple receptors. Pharmacol. Ther. 56, 23-51. doi: 10.1016/0163-7258(92)90036-Y

Prakash, Y. S., Van Der Heijden, H. F., Gallant, E. M., and Sieck, G. C. (1999). Effect of beta-adrenoceptor activation on $[\mathrm{Ca} 2+]$ i regulation in murine skeletal myotubes. Am. J. Physiol. 276, C1038-C1045.

Ramarao, M. K., Bianchetta, M. J., Lanken, J., and Cohen, J. B. (2001). Role of rapsyn tetratricopeptide repeat and coiled-coil domains in self-association and nicotinic acetylcholine receptor clustering. J. Biol. Chem. 276, 7475-7483. doi: 10.1074/jbc.M009888200

Ramarao, M. K., and Cohen, J. B. (1998). Mechanism of nicotinic acetylcholine receptor cluster formation by rapsyn. Proc. Natl. Acad. Sci. U.S.A. 95, 4007-4012. doi: 10.1073/pnas.95. 7.4007

Reeds, P. J., Hay, S. M., Dorwood, P. M., and Palmer, R. M. (1986). Stimulation of muscle growth by clenbuterol: lack of effect on muscle protein biosynthesis. Br. J. Nutr. 56, 249-258. doi: 10.1079/BJN19860104

Reutenauer-Patte, J., Boittin, F. X., Patthey-Vuadens, O., Ruegg, U. T., and Dorchies, O. M. (2012). Urocortins improve dystrophic skeletal muscle structure and function through both PKAand Epac-dependent pathways. Am. J. Pathol. 180, 749-762. doi: 10.1016/j.ajpath.2011.10.038

Reynolds, J. G., McCalmon, S. A., Donaghey, J. A., and Naya, F. J. (2008). Deregulated protein kinase A signaling and myospryn expression in muscular dystrophy. J. Biol. Chem. 283, 8070-8074. doi: 10.1074/jbc.C700221200

Reynolds, J. G., McCalmon, S. A., Tomczyk, T., and Naya, F. J. (2007). Identification and mapping of protein kinase A binding sites in the costameric protein myospryn. Biochim. Biophys. Acta 1773, 891-902. doi: 10.1016/j.bbamcr.2007.04.004

Röder, I. V., Choi, K. R., Reischl, M., Petersen, Y., Diefenbacher, M. E., Zaccolo, M., et al. (2010). Myosin Va cooperates with PKA RIalpha to mediate maintenance of the endplate in vivo. Proc. Natl. Acad. Sci. U.S.A. 107, 2031-2036. doi: 10.1073/pnas.0914087107

Röder, I. V., Lissandron, V., Martin, J., Petersen, Y., Di Benedetto, G., Zaccolo, M., et al. (2009). PKA microdomain organisation and cAMP handling in healthy and dystrophic muscle in vivo. Cell. Signal. 21, 819-826. doi: 10.1016/j.cellsig.2009.01.029

Röder, I. V., Strack, S., Reischl, M., Dahley, O., Khan, M. M., Kassel, O., et al. (2012). Participation of myosin Va and Pka type I in the regeneration of neuromuscular junctions. PLOS ONE 7:e40860. doi: 10.1371/journal.pone.0040860

Ruegg, M. A., and Bixby, J. L. (1998). Agrin orchestrates synaptic differentiation at the vertebrate neuromuscular junction. Trends Neurosci. 21, 22-27. doi: 10.1016/S0166-2236(97)01154-5

Salpeter, M. M., and Loring, R. H. (1985). Nicotinic acetylcholine receptors in vertebrate muscle: properties, distribution and neural control. Prog. Neurobiol. 25, 297-325. doi: 10.1016/0301-0082(85)90018-8

Saltin, B., Radegran, G., Koskolou, M. D., and Roach, R. C. (1998). Skeletal muscle blood flow in humans and its regulation during exercise. Acta Physiol. Scand. 162, 421-436. doi: 10.1046/j.1365-201X.1998.0293e.x

Sandri, M. (2008). Signaling in muscle atrophy and hypertrophy. Physiology (Bethesda) 23, 160-170. doi: 10.1152/physiol.00041.2007

Sandri, M., Sandri, C., Gilbert, A., Skurk, C., Calabria, E., Picard, A., et al. (2004). Foxo transcription factors induce the atrophy-related ubiquitin ligase atrogin- 1 and cause skeletal muscle atrophy. Cell 117, 399-412. doi: 10.1016/S0092-8674(04)00400-3

Sarparanta, J. (2008). Biology of myospryn: what's known? J. Muscle Res. Cell Motil. 29, 177-180. doi: 10.1007/s10974-008-9165-6

Sarparanta, J., Blandin, G., Charton, K., Vihola, A., Marchand, S., Milic, A., et al. (2010). Interactions with M-band titin and calpain 3 link myospryn (CMYA5) to tibial and limb-girdle muscular dystrophies. J. Biol. Chem. 285, 30304-30315. doi: 10.1074/jbc.M110.108720

Schara, U., Barisic, N., Deschauer, M., Lindberg, C., Straub, V., Strigl-Pill, N., et al. (2009). Ephedrine therapy in eight patients with congenital myasthenic syndrome due to DOK7 mutations. Neuromuscul. Disord. 19, 828-832. doi: 10.1016/j.nmd.2009.09.008

Scott, J. D., Dessauer, C. W., and Tasken, K. (2013). Creating order from chaos: cellular regulation by kinase anchoring. Annu. Rev Pharmacol. Toxicol. 53, 187-210. doi: 10.1146/annurev-pharmtox011112-140204

Shiao, T., Fond, A., Deng, B., WehlingHenricks, M., Adams, M. E. Froehner, S. C., et al. (2004). Defects in neuromuscular junction structure in dystrophic muscle are corrected by expression of a NOS transgene in dystrophin-deficient muscles, but not in muscles lacking alpha- and beta1-syntrophins. Hum. Mol. Genet. 13, 1873-1884. doi: $10.1093 / \mathrm{hmg} / \mathrm{ddh} 204$

Shyng, S. L., Xu, R., and Salpeter, M. M. (1991). Cyclic AMP stabilizes the degradation of original junctional acetylcholine receptors in denervated muscle. Neuron 6, 469-475. doi: 10.1016/0896-6273 (91) $90254-\mathrm{W}$

Sobel, A., Weber, M., and Changeux, J. P. (1977). Large-scale purification of the acetylcholine-receptor protein in its membrane-bound and detergent-extracted forms from Torpedo marmorata electric organ. Eur. J. Biochem. 80, 215-224. doi: 10.1111/j.14321033.1977.tb11874.x

Southgate, K., and Newby, A. C. (1990). Serum-induced proliferation of rabbit aortic smooth muscle cells from the contractile state is inhibited by 8 -Br-cAMP but not 8 -Br-cGMP. Atherosclerosis 82, 113-123. doi: 10.1016/0021-9150(90)90150-H

Spencer, M. J., and Tidball, J. G. (1996). Calpain translocation during muscle fiber necrosis and regeneration in dystrophin-deficient mice. 
Exp. Cell Res. 226, 264-272. doi: 10.1006/excr.1996.0227

Stanley, E. F., and Drachman, D. B. (1981). Denervation accelerates the degradation of junctional acetylcholine receptors. Exp. Neurol. 73, 390-396. doi: 10.1016/0014-4886(81)90274-0

Stanley, E. F., and Drachman, D. B. (1983). Rapid degradation of "new" acetylcholine receptors at neuromuscular junctions. Science 222, 67-69. doi: 10.1126/science.6623057

Steinberg, S. F., and Brunton, L. L. (2001). Compartmentation of $G$ protein-coupled signaling pathways in cardiac myocytes. Annu. Rev. Pharmacol. Toxicol. 41, 751-773. doi: 10.1146/annurev. pharmtox.41.1.751

Tadaki, N., Hisa, Y., Uno, T., Koike, S., Okamura, H., and Ibata, Y. (1995). Neurotransmitters for the canine inferior pharyngeal constrictor muscle. Otolaryngol. Head Neck Surg. 113, 755-759. doi: 10.1016/S0194-5998 (95)70016-1

Tang, C. M., and Insel, P. A. (2004). GPCR expression in the heart; "new" receptors in myocytes and fibroblasts. Trends Cardiovasc. Med. 14, 94-99. doi: 10.1016/j.tcm.2003.12.007

Tartas, M., Morin, F., Barriere, G., Goillandeau, M., Lacaille, J. C., Cazalets, J. R., et al. (2010). Noradrenergic modulation of intrinsic and synaptic properties of lumbar motoneurons in the neonatal rat spinal cord. Front Neural Circuits 4:4. doi: 10.3389/neuro.04.004.2010
Taylor, S. S., Kim, C., Cheng, C. Y., Brown, S. H., Wu, J., and Kannan, N. (2008). Signaling through cAMP and cAMP-dependent protein kinase: diverse strategies for drug design. Biochim. Biophys. Acta 1784, 16-26. doi: 10.1016/j.bbapap.2007.10.002

Tomlinson, P. R., Wilson, J. W., and Stewart, A. G. (1994). Inhibition by salbutamol of the proliferation of human airway smooth muscle cells grown in culture. Br. J. Pharmacol. 111, 641-647. doi: 10.1111/j.14765381.1994.tb14784.x

Torres, L. F., and Duchen, L. W. (1987). The mutant mdx: inherited myopathy in the mouse. Morphological studies of nerves, muscles and endplates. Brain 110(Pt. 2), 269-299. doi: 10.1093/brain/110.2.269

Wanamaker, C. P., and Green, W. N. (2005). N-linked glycosylation is required for nicotinic receptor assembly but not for subunit associations with calnexin. J. Biol. Chem. 280, 33800-33810. doi: 10.1074/jbc.M501813200

Wanamaker, C. P., and Green, W. N. (2007). Endoplasmic reticulum chaperones stabilize nicotinic receptor subunits and regulate receptor assembly. J. Biol. Chem. 282, 31113-31123. doi: 10.1074/jbc.M705369200

Wohlberg, C. J., Davidoff, R. A., and Hackman, J. C. (1986). Analysis of the responses of frog motoneurons to epinephrine and norepinephrine. Neurosci. Lett. 69, 150-155. doi: 10.1016/0304-3940(86)90594-X

Xu, R., and Salpeter, M. M. (1997). Acetylcholine receptors in innervated muscles of dystrophic mdx mice degrade as after denervation. J. Neurosci. 17 8194-8200.

Xu, R., and Salpeter, M. M. (1999). Rate constants of acetylcholine receptor internalization and degradation in mouse muscles. J. Cell. Physiol. 181, 107-112. doi: 10.1002/(SICI)1 097-4652(199910)181:1<107::AIDJCP11>3.3.CO;2-0

Yimlamai, T., Dodd, S. L., Borst, S. E., and Park, S. (2005). Clenbuterol induces muscle-specific attenuation of atrophy through effects on the ubiquitin-proteasome pathway. J. Appl. Physiol. 99, 71-80. doi: 10.1152/japplphysiol.00448.2004

Zaccolo, M. (2011). Spatial control of cAMP signalling in health and disease. Curr. Opin. Pharmacol. 11, 649-655. doi: 10.1016/j.coph.2011.09.014

Zaccolo, M., Magalhaes, P., and Pozzan, T. (2002). Compartmentalisation of cAMP and $\mathrm{Ca}(2+)$ signals. Curr. Opin. Cell Biol. 14, 160-166. doi: 10.1016/S0955-0674(02)00316-2

Zaglia, T., Milan, G., Franzoso, M., Bertaggia, E., Pianca, N., Piasentini, E., et al. (2013). Cardiac sympathetic neurons provide trophic signal to the heart via beta2adrenoceptor-dependent regulation of proteolysis. Cardiovasc. Res. 97, 240-250. doi: 10.1093/cvr/cvs320

Zeman, R. J., Peng, H., and Etlinger, J. D. (2004). Clenbuterol retards loss of motor function in motor neuron degeneration mice. Exp. Neurol. 187, 460-467. doi: 10.1016/j.expneurol.2004.03.006

Zhang, B., Luo, S., Wang, Q., Suzuki, T., Xiong, W. C., and Mei, L. (2008). LRP4 serves as a coreceptor of agrin. Neuron 60, 285-297. doi: 10.1016/j.neuron.2008.10.006

Zong, Y., Zhang, B., Gu, S., Lee, K., Zhou, J., Yao, G., et al. (2012). Structural basis of agrin-LRP4MuSK signaling. Genes Dev. 26, 247-258. doi: 10.1101/gad.1808 85.111

Conflict of Interest Statement: The authors declare that the research was conducted in the absence of any commercial or financial relationships that could be construed as a potential conflict of interest.

Received: 25 June 2013; paper pending published: 18 August 2013; accepted: 24 September 2013; published online: 17 October 2013.

Citation: Rudolf R, Khan MM, Lustrino $D$, Labeit S, Kettelhut ÍC and Navegantes LCC (2013) Alterations of cAMPdependent signaling in dystrophic skeletal muscle. Front. Physiol. 4:290. doi: 10.3389/fphys.2013.00290

This article was submitted to Integrative Physiology, a section of the journal Frontiers in Physiology.

Copyright (c) 2013 Rudolf, Khan, Lustrino, Labeit, Kettelhut and Navegantes. This is an open-access article distributed under the terms of the Creative Commons Attribution License (CC BY). The use, distribution or reproduction in other forums is permitted, provided the original author(s) or licensor are credited and that the original publication in this journal is cited, in accordance with accepted academic practice. No use, distribution or reproduction is permitted which does not comply with these terms. 


\title{
Title
}

Direct Sympathetic Input Promotes Neuromuscular Synapse Homeostasis

\author{
Authors \\ Muzamil Majid Khan ${ }^{\mathrm{a}, \mathrm{b}, \mathrm{c}}$, Danilo Lustrino ${ }^{\mathrm{d}}$, Willian A. Silveira ${ }^{\mathrm{d}}$, Franziska Wild ${ }^{\mathrm{a}, \mathrm{b}, \mathrm{c}}$, \\ Yasmin Issop $^{\mathrm{e}}$, Emily O'Connor ${ }^{\mathrm{e}}$, Dan Cox ${ }^{\mathrm{e}}$, Markus Reischl ${ }^{\mathrm{f}}$, Till Marquardt ${ }^{\mathrm{g}}$, Dittmar \\ Labeit $^{\mathrm{h}}$, Siegfried Labeit ${ }^{\mathrm{h}}$, Evelyne Benoit ${ }^{\mathrm{i}}$, Jordi Molgó ${ }^{\mathrm{i}}$, Hanns Lochmüller ${ }^{\mathrm{e}}$, Veit \\ Witzemann $^{\mathrm{j}}$, Ísis C. Kettelhut ${ }^{\mathrm{d}}$, Luiz C. C. Navegantes ${ }^{\mathrm{d}}$, and Rüdiger Rudolf ${ }^{\mathrm{a}, \mathrm{b}, \mathrm{c}}$
}

\section{Affiliations}

a: Interdisciplinary Center for Neurosciences, University of Heidelberg, 69120 Heidelberg, Germany.

b: Institute of Molecular and Cell Biology, Mannheim University of Applied Sciences, 68163 Mannheim, Germany.

c: Institute of Toxicology and Genetics, Karlsruhe Institute of Technology, 76344

Eggenstein-Leopoldshafen, Germany.

d: Departments of Physiology and Biochemistry \& Immunology, Medical School of Ribeirão Preto, University of São Paulo, 14049-900 Ribeirão Preto, Brazil. e: John Walton Centre for Muscular Dystrophy Research, MRC Centre for Neuromuscular Diseases, Institute of Genetic Medicine, Newcastle University, Newcastle upon Tyne, NE1 3BZ, UK.

f: Institute of Applied Informatics, Karlsruhe Institute of Technology, 76344 EggensteinLeopoldshafen, Germany.

g: Developmental Neurobiology Group, European Neuroscience Institute, 37077 Göttingen, Germany.

h: Department of Integrative Pathophysiology, Universität Heidelberg, 68167 Mannheim, Germany.

i: CNRS, Centre de Recherche de Gif - FRC3115, Institut de Neurobiologie Alfred Fessard - FRC2118, 91198 Gif Sur Yvette, France.

j: Max-Planck Institute of Medical Research, 69120 Heidelberg, Germany 


\title{
Contact
}

Correspondence to: r.rudolf@hs-mannheim.de

\section{Running Title}

Dual Innervation of Adult Neuromuscular Junction

\begin{abstract}
Vertebrate neuromuscular junctions, which are necessary for generating muscle movements, are paradigm chemical synapses that have been considered as exclusively cholinergic. Recent data show that sympathicomimetics are successful in the clinical treatment of neuromuscular transmission disorders, but how they operate in this context remains unclear. We here demonstrate that in mice, neuromuscular junctions normally receive dual innervation by cholinergic motor neurons and noradrenergic sympathetic neurons. The sympathetic neurons activate postsynaptic beta2-adrenoceptors and cAMP production and function to maintain neuromuscular synapse homeostasis. Deterioration of neuromuscular junctions is similar upon sympathectomy and in neuromuscular transmission disorder phenotypes and is corrected in both cases by sympathicomimetics. These findings provide new insights into the organization of the neuromuscular synapse and may have clinical relevance beyond neuromuscular transmission disorders, as synaptic failure has been implicated in various processes such as motor neuron disease, muscle atrophy and ageing.
\end{abstract}




\section{Main Text}

Increased susceptibility to muscle fatigue is a well-known side effect of beta-blockers ${ }^{1}$. Furthermore, beta-blockers like esmolol modulate neuromuscular activity of drugs used during anesthesia ${ }^{2}$. Conversely, sympathicomimetics (SM) such as beta2-adrenergic agonists belong to the most efficient anabolic pharmacological agents ${ }^{3}$ and have recently gained particular appreciation as clinical treatment of a set of neuromuscular transmission defects, in particular, congenital myasthenic syndromes $(\mathrm{CMS})^{4-8}$. Combined with earlier findings, that skeletal muscle fibers can be directly innervated by sympathetic neurons ${ }^{9}$ and that removal of lumbar ganglia severely affects skeletal muscle metabolism ${ }^{10}$, these observations suggest that skeletal muscle and, particularly, neuromuscular junctions (NMJs) might be targets of direct sympathetic input. A few previous studies are consistent with the concepts of dual input ${ }^{11}$ and the presence of catecholaminergic marker enzymes at the NMJ ${ }^{12,13}$. However, while the first work lacked any functional insight ${ }^{11}$, the latter stuck to the single-innervation model of NMJ and interpreted their findings as evidence for a secondary catecholaminergic metabolism of $\alpha$-motor neurons ${ }^{12,13}$. Here, we addressed the role of sympathetic innervation to skeletal muscle from a morphological, biochemical, and functional point of view. Our study revealed dual innervation of NMJs by both, alpha motor neurons and noradrenergic sympathetic neurons. Further, the sympathetic activity triggers postsynaptic adrenoceptor and cAMP signaling and leads to postsynaptic gene expression changes. Notably, sympathectomy mimics the phenotype of myasthenic NMJs and sympathicomimetics are efficient in rescuing NMJ and movement phenotypes in mouse and fish myasthenic models. This data nicely reflects the recently described enormous success of sympaticomimetics in the pharmacological treatment of myasthenic patients and, thus, delivers a straightforward explanation of these poorly understood clinical results and paves the street for further refinements of treatment strategies in myasthenia and other neuromuscular transmission disorders.

\section{Results}

NMJs receive direct sympathetic innervation 
We first investigated the scarcely explored distribution of sympathetic nervous system in skeletal muscle with special emphasis on NMJs. As expected, axons positive for the sympathetic neuron marker protein, tyrosine hydroxylase $(\mathrm{TH})$ were primarily associated with blood vessels (Fig. 1A). However, NMJ regions showed additional, intriguing accumulations of TH-immunoreactivity that were directly linked to TH-positive axons (Fig. 1A and B) and which vanished upon peripheral denervation (Fig. S1). Using BIIItubulin as a general neuronal marker, two incoming axons were found at individual NMJs (Fig. 1B), and often TH staining was detected in the empty spaces between synaptic branches enriched in the major postsynaptic ion channel, nicotinic acetylcholine receptor (AChR, asterisks in Fig. 1B'). While some axons directly approached NMJs (Fig. 1B), also en passant contacts could be seen (Fig. 1A). Finally, axonal tracing experiments using DiI injection of sciatic nerve of mice expressing mito-Dendra in $\alpha$-motor neurons also revealed dual axonal input (Fig. S2). These morphological data were supported by biochemical evidence. Indeed, TH protein was present and absent in innervated and denervated muscle lysates, respectively (Fig. 1C). The same was true for the catecholamine, norepinephrine, which was almost completely lacking in leg muscles with prior cut of sciatic nerve or removal of lumbar ganglia (Fig. 1D). Together, this data shows that in contrast to current thinking, the sympathetic nervous system makes intense connections with mammalian skeletal muscle fibers and particularly at the NMJ region.

\section{Sympathetic input at NMJs activates postsynaptic adrenoceptor signaling}

Given, that we here postulate the existence of a direct sympathetic input to NMJs, we addressed the functional significance of the connections between sympathetic neurons and NMJs. Most abundant targets of norepinephrine in skeletal muscle fibers are beta2adrenoceptors ${ }^{14,15}$. Immunofluorescence labeling of muscle longitudinal sections revealed beta2-adrenoceptor signals in axon-like structures and in congruency with AChR staining at NMJs (Fig. 2A), suggesting the presence of beta2-adrenoceptors in preor postsynaptic regions. Expression of a genetically encoded molecular biosensor for beta2-adrenoceptor activity, $\beta 2$-AR-s-pep ${ }^{16}$, yielded additional evidence for a strong enrichment of $\beta_{2}$-adrenoceptors in the postsynaptic portion of NMJs (Fig. 2B). Twophoton microscopic imaging of live mouse muscle expressing $\beta 2$-AR-s-pep revealed 
activation of beta2-adrenoceptor upon electrical stimulation of sciatic nerve that was too weak to trigger muscle contraction (in the following termed as "weak stimuli"; Fig. 2C, black arrows indicate time of stimulation). Conversely, stronger nerve stimulation that caused hindlimb muscle contraction did not lead to further activation of beta2adrenoceptor (Fig. 2C, see red dashed arrow). Signal transduction mediated by beta2adrenoceptors mostly evokes production of the second messenger, cAMP, that can trigger a plethora of different physiological effects. To test if sympathetic stimulation can induce muscle cAMP production, we constructed a novel, NMJ-specific cAMP sensor based on EPAC-camps ${ }^{17}$, here termed as 'rapsyn-EPAC'. In this sensor, the AChR-binding protein, rapsyn ${ }^{18}$, was cloned N-terminally to EPAC-camps. Heterologous expression in live skeletal muscle showed efficient and specific localization of the sensor at NMJs, and direct stimulation of lumbar sympathetic ganglion (Fig. 2D and E, arrows in Fig. 2E indicate time of stimulation) as well as weak stimulation of sciatic nerve led to a significant increase in subsynaptic cAMP levels (Fig. 2F, arrows indicate time of stimulation). Notably, both, local sympathectomy by means of 6-hydroxydopamine (6OH-DOP) as well as treatment with an inhibitor of beta2-adrenoceptor, ICI118551, strongly lowered the stimulation-induced increase in second messenger levels (Fig. 2F). This demonstrates the presence of $\alpha$-motor neuron-independent, sympathetic connections at NMJs that activate beta2-adrenoceptors and cAMP production.

\section{Postsynaptic gene expression is modulated by direct sympathetic input to NMJ}

What are putative functions of this input? As recently reviewed ${ }^{19}$, several studies imply both, pre- and postsynaptic roles of sympathetic stimuli, and suggest therapeutic efficacy of sympathetic agonists in the treatment of neuromuscular transmission disorders such as congenital myasthenic syndromes ${ }^{4,20}$. To investigate this further, we tested the effect of SM on CHRNAI gene activity and found a strong up-regulation of the major postsynaptic ion channel AChR (CHRNA1 mRNA) after 10 days of treatment (Fig. 2G). Thus, beta2adrenergic stimulation can modulate NMJ-relevant gene transcription. Similarly, SM had a positive effect on the size of AChR clusters in C2C12 myotubes (Fig. S3), suggesting that muscle adrenoceptor stimulation suffices triggering of postsynaptic gene regulation. Furthermore, peroxisome proliferator-activated receptor $\gamma$ coactivator $1 \alpha(\mathrm{PGC}-1 \alpha)$ is a 
transcriptional coactivator of nuclear receptors and other transcription factors that regulate a set of $\mathrm{NMJ}$-specific genes, including different AChR subunits, in an activitydependent manner ${ }^{21}$. Given that expression of PGC-1 $\alpha$ is up-regulated upon beta2adrenergic receptor activation ${ }^{22}$, we addressed the immediate effect of weak sciatic stimulation on cytoplasm-to-nucleus shuttling of PGC-1 $\alpha$. Thus, PGC-1 $\alpha$ coupled to GFP was expressed in hindlimb muscle and its amount in nuclei upon stimulation was observed in vivo. This revealed a rapid increase in nuclear accumulation of the PGC-1 $\alpha$ upon stimulation (Fig. 2H and I), suggesting that this could be a route by which sympathetic input exerts its gene-regulatory function at the NMJ.

\section{Sympathectomy mimics a neuromuscular transmission disorder phenotype}

To further test the hypothesis of a trophic role of sympathetic input at NMJ, next we induced local chemical sympathectomy in hindlimbs and observed a strong reduction in NMJ sizes, NMJ complexity and AChR $\alpha$ protein (CHRNA1; Fig. 3A-C) after two weeks of local sympathectomy. Co-treatment of sympathectomized muscles with SM partially rescued this phenotype (Fig. 3A-C), demonstrating the central role of sympathetic activity for regulating NMJ stability. Several recent studies highlight the successful use of SM for many CMS patients ${ }^{4,6,7,23}$, in particular, in cases where a reduced amount of postsynaptic AChR or a change to synapse size and structure might be causative. We used a myasthenic CHRNE L269F mouse model to test effects of SM on NMJ morphology and AChR expression. Similar to sympathectomized muscles of wild type mice, myasthenic muscles showed strongly reduced NMJ sizes, NMJ complexity and visibly less AChR at the NMJ than wild type animals (Fig. 3D-F). Due to scarce amounts of AChR, many NMJs were hardly visible (Fig. 3D central panel, arrowheads). This was also reflected by a low $\mathrm{AChR} \alpha$ protein content in muscle lysates from myasthenic muscle as compared to wild type (Fig. 3F). Treatment of myasthenic mice with SM for ten days significantly recovered the NMJ phenotype (Fig. 3D, lower panel), and rescued NMJ size (Fig. 3D-E) as well as AChR $\alpha$ protein content (Fig. 3F). Interestingly, TH was enriched in untreated myasthenic mice compared to wild type and further increased upon SM treatment (Fig. 3F). This data shows that SM can partially restore NMJ phenotypes of sympathectomized and myasthenic mice and suggests an involvement of sympathetic 
innervation in NMJ maintenance. Do these changes ameliorate synaptic function? To address this question, we recorded in vivo compound muscle action potentials (CMAPs) of myasthenic mice in the course of SM treatment. While repetitive CMAPs were typical for myasthenic muscles prior to treatment (Fig. 3G, middle trace, see arrow for repetitive CMAP), prolonged application of SM showed a complete and persistent correction to normal single CMAPs (Fig. 3G-H).

\section{Sympathicomimetics rescue neurotransmission disorder in Zebrafish}

Patients with congenital myasthenic syndromes currently treated in clinic with SM often carry mutations in the $D O K 7$ gene ${ }^{24}$ and exhibit aberrant small $\mathrm{NMJs}^{25}$. Since corresponding mouse models are lethal in the early postnatal period ${ }^{26}$ limiting the use of these animals in pharmacological assays, and to address the general importance of our findings across phylogenetic groups, we tested the effect of SM on a previously established DOK-7 knowdown Zebrafish model, which exhibits strongly reduced motility

${ }^{27}$. Incubation with SM led to increased size, increased presynaptic ramifications and more postsynaptic AChR plaques (Fig. 4A) in both wild type and DOK-7 morphants. Furthermore, SM treatment corrected the severe swim phenotype in a dose-dependent manner (Fig. 4B).

\section{Discussion}

Altogether, this study demonstrates the existence and physiological relevance of direct sympathetic innervation of vertebrate NMJs. These findings deliver a likely explanation for the usefulness of SM in the treatment of certain neuromuscular transmission disorders as well as for the opposite effects of beta-blockers and SM on muscle function. Of course, many questions remain open. First, the relative contributions of adrenal medulla versus direct sympathetic innervation regarding the control of muscle function have been recently addressed ${ }^{10,28}$ but need to be worked out further. Second, it is unclear whether therapeutic activity of SM is primarily due to an improvement of sarcomeric function or neuromuscular transmission, or a mixture of both. Indeed, our experiments involving sympathectomy and SM treatment invariably led to atrophy and hypertrophy, respectively. Given the intimate causal relationship between synaptic function, muscle 
activity and muscle trophicity, it is unlikely, that these factors can be fully separated. Yet, the effects of beta-blockers on muscle fatigue ${ }^{1}$ and anesthesia ${ }^{2}$ suggest that at least an important component of the sympathetic activity directly affects synaptic integrity and function. Furthermore, while SM work in some forms of myasthenic syndromes (NMJ pathology) ${ }^{4,5,8,24}$ and spinal muscular atrophy (motor neuron defect involving the NMJ) ${ }^{29}$, they do not seem to work in a trial for facio-scapulo-humeral muscular dystrophy (primary muscle pathology) ${ }^{30}$. Our findings of an enhanced nuclear import of PGC-1 $\alpha$ upon sympathetic nerve stimulation provide an explanation for the transcriptional changes mediated by sympathetic agonists post exercise ${ }^{31}$. Given that PGC- $1 \alpha$ plays a pivotal role in exercise-induced mitochondrial biogenesis ${ }^{32}$, reduced levels of mitochondrial protein synthesis post exercise after treatment with beta blockers ${ }^{33}$ could be explained, too. Furthermore, given a direct sympathetic input to skeletal muscles via sciatic nerve, various documented effects using sciatic denervation as atrophy model system might have an important sympathetic contribution as well. Consistent with this hypothesis, treatment of rat skeletal muscles with norepinephrine reduces mRNA levels of atrogines such as atrogin-1 and MuRF $1{ }^{10}$. In summary, our novel finding of a direct sympathetic input to the synapses of skeletal muscles provide an explanation to the various effects of beta-adrenergic agonists and antagonists on skeletal muscle gene expression as well as changes in electrical properties of muscle fibers documented so far. Consequently, sympathetic stimulation appears as a logical strategy to treat several neuromuscular transmission defects as shown for models of myasthenia gravis ${ }^{20}$ and in the clinical context of $\mathrm{CMS}^{4,24}$.

\section{online Methods}

Animals: All animals were kept, bred and treated according to ethical guidelines adopted by Brazilian College of Animal Experimentation and the EU directive 2010/63/EU.

Experimental protocols were approved by the commission of ethics in animal research from School of Medicine of Ribeirão Preto and the National authorities in France, Germany, and UK. Adult ( $>4$ and $<12$ months of age) male and female C57BL/10J, CHRNE L269F and MitoDendra-Olig2 mice and Golden strain (slc24a $5^{\text {b1/+ }}$ ) Zebrafish (Zebrafish International Resource Center, Oregon) were used for experiments. 
Anaesthesia and preperation of mice for microscopy and electrophysiology was done as described previously ${ }^{34-36}$. Zebrafish embryos were raised and staged in hours postfertilization (hpf) according to standard protocols as described previously ${ }^{27}$. Given that all treated animals, unless excluded for having reached predetermined exclusion criteria, were used for data analysis, randomization and blinding were not applied.

Stimulation of lumbar sympathetic ganglionic chain and sciatic nerve: Stimulation of sciatic nerve was performed using the A.M.P.I. master-8 CP stimulator and Harvard Apparatus microelectrodes. The voltage threshold for inducing visible muscle contraction was $>0.2 \mathrm{~V}^{37}$. Stimulation below this value did not induce muscle contraction and was termed as 'weak stimulation'. Each train of stimuli (weak or above threshold) consisted of 10 tetanic pulses as described previously ${ }^{37}$. Stimulation of the sympathetic ganglionic chain involved the following preparation: The lumbar sympathetic chain is surrounded by connective tissue in front of the vertebral column, behind the aorta and vena cava. The chain was exposed via a midline laparotomy approach. Connective tissue surrounding the chain was carefully removed and microelectrodes were placed with caution around the chain. Weak stimulation intensity as explained above was used.

Pharmacological Treatments of mice: Figs. 2 and 3A-F: Freshly prepared clenbuterol (CB, sympathicomimetics, SM, in PBS) solution was injected subcutaneously ( $3 \mathrm{mg} / \mathrm{kg}$ ) for 10 days prior to microscopy. ICI1 18551 ( $\beta_{2}$-adrenoceptor antagonist, in PBS) was injected subcutaneously $(5 \mathrm{mg} / \mathrm{kg}$ ) for two days (a day prior to microscopy and 1 hour before microscopy). Chemical sympathectomy was performed using 6-hydroxydopamine $(6 \mathrm{OH}-\mathrm{DOP})^{38} \cdot 6 \mathrm{OH}-\mathrm{DOP}$ (in $0.3 \%$ ascorbic acid oxygen free water) was injected locally in the hindlimbs $(100 \mathrm{mg} / \mathrm{kg})$ on alternate days for two weeks prior to imaging. Fig. 3G$\mathrm{H}$ : Ephedrine treatment (SM) was carried out at a dosage of $25 \mu \mathrm{g} / \mathrm{g}$ of mouse for 30 to 45 days as indicated in Fig. $3 \mathrm{G}$.

\section{Molecular biosensors, electroporation and in vivo imaging: Rapsyn-EPAC cAMP} FRET sensor was cloned into pcDNA3 using PCR. pcDNA3/B2AR-s-pep FRET sensor, and GFP-PGC1alpha were obtained from Addgene. cDNAs encoding for heterologous 
fusion proteins were transfected into tibialis anterior muscle as described previously 34,39,40 and 8-10 days later, the transfected muscle was exposed and subjected to microscopic analysis. AChRs where marked with AlexaFluor conjugates of $\alpha$ bungarotoxin (BGT-AF555 or 647) by injection of $50 \mu 1$ of BGT-AF (Invitrogen, 1:200 in PBS) into the hindlimb. For analysis of the size of NMJs, the tibialis anterior muscles were injected with BGT-AF647 as explained above 10 days prior to imaging. For DiI anterograde labeling of neurons in sciatic nerve $10 \mu \mathrm{l}$ solution of $1 \mu \mathrm{g} / \mu \mathrm{l}$ DiI (N22880, LifeTechnolongies) in PBS were injected 5 days prior to imaging into the sciatic nerve of MitoDendra-Olig2 mice. NMJs of tibialis anterior muscles were labeled with BGTAF647 as explained above. In vivo imaging was performed using a DMRE TCS SP2 confocal microscope as described ${ }^{34}$.

Compound muscle action potential measurement: CMAPs were recorded in vivo on time intervals indicated in Fig. $3 \mathrm{H}$, by means of a minimally-invasive electrophysiological method, using the Qtrac $\left(\right.$ software, as detailed previously ${ }^{36,41}$. In brief, the mice were kept under isoflurane (AErrane ${ }^{\circledR}$, Belgium) anesthesia inhalation and electrical stimulations were delivered to the tibial branch of sciatic motor nerve, by means of surface electrodes, and the compound muscle action potential (CMAP) was recorded using needle electrodes inserted into the plantar muscle.

\section{Immunohistochemistry (IHC), Western blot (WB) and HPLC analysis: IHC of} chemically fixed EDL muscles and WB analysis of snap frozen gastrocnemius muscles were performed as described previously ${ }^{42}$. Primary antibodies used for IHC and WB: rabbit anti-tyrosine hydroxylase (AB152, Millipore, 1:250), rabbit anti-tyrosine hydroxylase (sc-14007, Santa Cruz, 1:500), rabbit anti- $\beta_{2}$-adrenoceptor (sc-569, Santa Cruz, 1:200), mouse anti- $\alpha$-actinin (A7811, Sigma Aldrich, 1:5000), mouse anti-GAPDH (MA5-15738, ThermoScientific, 1:10000), rabbit anti-AChR (sc-292790, Santa Cruz, 1:500), mouse anti-ßIII-tubulin (T8578, Sigma Aldrich 1:200), mouse anti-SV2 (SV2, Developmental Studies Hybridoma Bank, 1:200), Alexa Fluor (AF) 488-conjugated wheat-germ agglutinin (W11261, Invitrogen, 1:500), BGT-AF488, BGT-AF555, BGTAF594, BGT-AF647 (all Invitrogen, 1:200). Secondary antibodies: AlexaFluor 546 
conjugated anti-rabbit (A11010, Invitrogen, 1:1000). AlexaFluor 488 conjugated antimouse (A11001, Invitrogen, 1:200). WB secondary antibodies: anti-rabbit-HRP (P0448, Daco, 1:1000), anti-mouse-HRP (P0260, Daco, 1:1000). HPLC: Wild type gastrocnemius muscle 3 days post sciatic denervation were harvested and snap frozen with the contralateral innervated muscle acting as control. Noradrenaline was assayed using HPLC (LC-7A, Shimadzu Instruments) with Spherisorb ODS-2 ( $5 \mu \mathrm{m}$; Sigma-Aldrich) reversed phase column, as previously described ${ }^{43}$.

qPCR: Messenger RNA from mouse tibialis anterior muscles was isolated using TRIzol (Invitrogen, Carlsbad, CA) and the quantitative PCR was performed as described elsewhere ${ }^{10}$ using following primers; CHNRA1 forward ${ }^{5}$ TGCGGAAGGTTTTTATCGAC ${ }^{3^{\prime}}$ and reverse ${ }^{5^{\prime}}$ CGGAGAGTGAAAGCCCATAG $^{3^{\prime}}$, and $R n 18 S$ forward ${ }^{5^{\prime}}$ GAAACGGCTACCACATCCAAG ${ }^{3^{\prime}}$ and reverse ${ }^{5}$ CCTCCAATGGATCCTCGTTAA ${ }^{3}$. For Zebrafish analyses reverse transcription was performed with $1 \mu \mathrm{g}$ total embryonic Zebrafish RNA as template with the Superscript III First-Strand Synthesis System (Invitrogen) and MolTaq DNA polymerase (Molzym). Regions of interest were amplified with DOK-7 forward 5'GAGTTTGCGTGTGTGTTACAGC ${ }^{3}$ ' and reverse ${ }^{5}$ CTGTCATGCTGGGTTTCGACA ${ }^{3}$ '. Elongation factor 1 alpha forward ${ }^{5}$ CTGGAGGCCAGCTCAAACATGG ${ }^{3}$ and reverse ${ }^{5}$ CTTGCTGTCTCCAGCCACATTAC ${ }^{3}$ ' as described previously ${ }^{27}$.

\section{Antisense Morpholino Oligonucleotide Knockdown approach and swim phenotype} analysis: Antisense morpholino oligonucleotides (MO, Gene Tools LLC) were injected into the yolk of one to two cell stage Zebrafish embryos as described earlier ${ }^{27}$. MO amounts ranging from $15 \mathrm{ng}$ to $20 \mathrm{ng}$ were used. zDok-7 MO

( ${ }^{5}$ ATTTATAGGATTTACCTGCTACCGG ${ }^{3}$ ') and control, human $\beta$-hemoglobin gene MO ( $\left({ }^{\prime}\right.$ CCTCTTACCTCAGTTACAATTTATA $\left.{ }^{3}\right)$ were suspended in 1x Danieau buffer (58 mM NaCl, 0.7 mM KCl, 0.4 mM MgSO $4,0.6$ mM Ca(NO$)_{2}$, 5 mM HEPES; pH 7.6) with phenol red as an injection indicator. Touch-evoked swimming response was observed by touching the head or tail of the Zebrafish with a fine pipette tip. Alternating 
tail movements were observed under Leica stereomicroscope equipped with a digital camera (model LEICA DFC 420C) and were analyzed as described previously ${ }^{27}$.

C2C12 AChR cluster formation assay: C2C12 cells (ATCC), recently authenticated and tested for mycoplasma, were seeded at a density of $0.3 \times 10^{6}$ cells per $9.5 \mathrm{~cm}^{3}$ well and cultured for 24 hours at $37^{\circ} \mathrm{C}$ and $5 \% \mathrm{CO}_{2}$ in DMEM supplemented with antibiotics and $10 \%$ fetal bovine serum. To obtain myotubes differentiation medium containing DMEM, $3 \%$ horse serum and antibiotics was used for 6 days at $37^{\circ} \mathrm{C}$ and $5 \% \mathrm{CO}_{2}$. After 6 days of differentiation cells were treated with salbutamol (sympathicomimetic, $\mathrm{SM}, 100 \mu \mathrm{M}$ ) for $48 \mathrm{hrs}$ at $37^{\circ} \mathrm{C}$. Agrin was added to the cells on day 7 for $24 \mathrm{hrs}$. Cells were fixed for 30 minutes in PBS containing $4 \%$ paraformaldehyde (PFA). 1 mM BGTAF594, DAPI (Vector Laboratories) and Vectashield mounting medium was used for immunocytochemistry. The length of AChR clusters was measured from 5 fields for each condition and data are expressed as the average length of AChRs per field view.

Image analysis, 3D projections: Image composition used Adobe Photohop and Adobe Illustrator (both Adobe Systems Software). Analysis of FRET imaging data used ImageJ v.2.0.0.-rc-15 and involved serial steps as described before ${ }^{39}$. In brief, postsynaptic areas enriched in either rapsyn-EPAC or $\beta 2 A R-s-p e p$ fluorescence were segmented in median filtered YFP-emission image stacks. Binarized masks were made from segmented areas and these were applied to mean filtered CFP- and YFP-image stacks. Ratio-images (CFP/YFP and YFP/CFP for rapsyn-EPAC and $\beta 2 A R-s-p e p$, respectively) were made and average ratios determined for each postsynaptic area on at least 5 up to 10 subsequent optical slices. All values obtained from one muscle per time point were averaged. Data show mean values of several individual experiments. For PGC1alpha data, maximum-zprojections were made. Then, GFP-positive nuclei were segmented in the first image stack (before stimulation). These segments were shifted in the following image stacks to best fit the region of corresponding nuclei. From each segment mean grey value was measured. Graph shows average of many nuclei per experiment normalized for bleaching from 5 different experiments. For 3D projections, fluorescence signals were segmented 
and converted to a binarized mask, which was applied to original images. Masked data sets were imported into ImageJ plugin VolumeViewer to produce 3D surface projections.

Statistical analysis: Graphic representation of data was achieved by Microsoft Excel:mac2008 and subsequent incorporation into Adobe Illustrator composites. Significance was tested with Student t-test or Welch test, where applicable. Therefore, Kolmogorov-Smirnow-test for normal distribution and F-test for homo/heteroscedasticity were performed. Sample sizes were calculated to reach $80 \%$ power and $\beta<0.2$ on the basis of previous experiments and titrations. Exclusion of animal samples were as predefined in corresponding applications to ethical committees.

\section{References}

1. Hunter, A. M. et al. The effect of selective beta1-blockade on EMG signal characteristics during progressive endurance exercise. Eur. J. Appl. Physiol. 88, 275-81 (2002).

2. Kim, K. S., Kim, K. H., Shin, W. J. \& Yoo, H. K. Neuromuscular interactions between mivacurium and esmolol in rabbits. Anaesthesia 53, 140-5 (1998).

3. Lynch, G. S. \& Ryall, J. G. Role of beta-adrenoceptor signaling in skeletal muscle: implications for muscle wasting and disease. Physiol Rev 88, 729-767 (2008).

4. Liewluck, T., Selcen, D. \& Engel, A. G. Beneficial effects of albuterol in congenital endplate acetylcholinesterase deficiency and Dok-7 myasthenia. Muscle Nerve 44, 789-794 (2011).

5. Burke, G. et al. Salbutamol benefits children with congenital myasthenic syndrome due to DOK7 mutations. Neuromuscul. Disord. 23, 170-5 (2013).

6. Lashley, D., Palace, J., Jayawant, S., Robb, S. \& Beeson, D. Ephedrine treatment in congenital myasthenic syndrome due to mutations in DOK7. Neurology 74, $1517-23$ (2010).

7. Lorenzoni, P. J. et al. Salbutamol therapy in congenital myasthenic syndrome due to DOK7 mutation. J. Neurol. Sci. 331, 155-7 (2013).

8. Schara, U. et al. Ephedrine therapy in eight patients with congenital myasthenic syndrome due to DOK7 mutations. Neuromuscul Disord 19, 828-832 (2009). 
9. Barker, D. \& Saito, M. Autonomic innervation of receptors and muscle fibres in cat skeletal muscle. Proc R Soc L. B Biol Sci 212, 317-332 (1981).

10. Silveira, W. A. et al. Activating cAMP/PKA signaling in skeletal muscle suppresses the ubiquitin-proteasome-dependent proteolysis: implications for sympathetic regulation. J. Appl. Physiol. (2014). doi:10.1152/japplphysiol.01055.2013

11. Boeke, J. Die doppelte (motorische und sympathische) efferente Innervation der quergestreiften Muskelfasern. Anat Anz 44, 343-356 (1913).

12. Chan-Palay, V., Engel, A. G., Palay, S. L. \& Wu, J. Y. Synthesizing enzymes for four neuroactive substances in motor neurons and neuromuscular junctions: light and electron microscopic immunocytochemistry. Proc Natl Acad Sci U S A 79, 6717-6721 (1982).

13. Chan-Palay, V., Engel, A. G., Wu, J. Y. \& Palay, S. L. Coexistence in human and primate neuromuscular junctions of enzymes synthesizing acetylcholine, catecholamine, taurine, and gamma-aminobutyric acid. Proc Natl Acad Sci US A 79, 7027-7030 (1982).

14. Kim, Y. S., Sainz, R. D., Molenaar, P. \& Summers, R. J. Characterization of beta 1 - and beta 2-adrenoceptors in rat skeletal muscles. Biochem. Pharmacol. 42, 1783-9 (1991).

15. Williams, R. S., Caron, M. G. \& Daniel, K. Skeletal muscle beta-adrenergic receptors: variations due to fiber type and training. Am. J. Physiol. 246, E160-7 (1984).

16. Malik, R. U. et al. Detection of G protein-selective $\mathrm{G}$ protein-coupled receptor (GPCR) conformations in live cells. J. Biol. Chem. 288, 17167-78 (2013).

17. Nikolaev, V. O., Bunemann, M., Hein, L., Hannawacker, A. \& Lohse, M. J. Novel single chain cAMP sensors for receptor-induced signal propagation. J Biol Chem 279, 37215-37218 (2004).

18. Frail, D. E., McLaughlin, L. L., Mudd, J. \& Merlie, J. P. Identification of the mouse muscle 43,000-dalton acetylcholine receptor-associated protein (RAPsyn) by cDNA cloning. J Biol Chem 263, 15602-15607 (1988). 
19. Rudolf, R. et al. Alterations of cAMP-dependent signaling in dystrophic skeletal muscle. Front. Physiol. 4, 290 (2013).

20. Ghazanfari, N., Morsch, M., Tse, N., Reddel, S. W. \& Phillips, W. D. Effects of the 32 -adrenoceptor agonist, albuterol, in a mouse model of anti-MuSK myasthenia gravis. PLoS One 9, e87840 (2014).

21. Handschin, C. et al. PGC-1 alpha regulates the neuromuscular junction program and ameliorates Duchenne muscular dystrophy. Genes Dev. 21, 770-83 (2007).

22. Miura, S. et al. An increase in murine skeletal muscle peroxisome proliferatoractivated receptor-gamma coactivator-1alpha (PGC-1alpha) mRNA in response to exercise is mediated by beta-adrenergic receptor activation. Endocrinology 148, 3441-8 (2007).

23. Lashley, D., Palace, J., Jayawant, S., Robb, S. \& Beeson, D. Ephedrine treatment in congenital myasthenic syndrome due to mutations in DOK7. Neurology 74, 1517-1523 (2010).

24. Cruz, P. M. R., Palace, J. \& Beeson, D. Congenital myasthenic syndromes and the neuromuscular junction. Curr. Opin. Neurol. 27, 566-75 (2014).

25. Slater, C. R. et al. Pre- and post-synaptic abnormalities associated with impaired neuromuscular transmission in a group of patients with "limb-girdle myasthenia". Brain 129, 2061-76 (2006).

26. Arimura, S. et al. Neuromuscular disease. DOK7 gene therapy benefits mouse models of diseases characterized by defects in the neuromuscular junction. Science 345, 1505-8 (2014).

27. Müller, J. S. et al. Dok-7 promotes slow muscle integrity as well as neuromuscular junction formation in a zebrafish model of congenital myasthenic syndromes. Hum. Mol. Genet. 19, 1726-40 (2010).

28. Graça, F. A. et al. Epinephrine depletion exacerbates the fasting-induced protein breakdown in fast-twitch skeletal muscles. Am. J. Physiol. Endocrinol. Metab. 305, E1483-94 (2013).

29. Pane, M. et al. Daily salbutamol in young patients with SMA type II. Neuromuscul. Disord. 18, 536-40 (2008). 
30. Kissel, J. T. et al. Randomized, double-blind, placebo-controlled trial of albuterol in facioscapulohumeral dystrophy. Neurology 57, 1434-40 (2001).

31. Bruno, N. E. et al. Creb coactivators direct anabolic responses and enhance performance of skeletal muscle. EMBO J. 33, 1027-43 (2014).

32. Geng, T. et al. PGC-1alpha plays a functional role in exercise-induced mitochondrial biogenesis and angiogenesis but not fiber-type transformation in mouse skeletal muscle. Am. J. Physiol. Cell Physiol. 298, C572-9 (2010).

33. Robinson, M. M. et al. Beta-Adrenergic receptor blockade blunts postexercise skeletal muscle mitochondrial protein synthesis rates in humans. 327-334 (2011). doi:10.1152/ajpregu.00160.2011.

34. Röder, I. V et al. Role of Myosin va in the plasticity of the vertebrate neuromuscular junction in vivo. PLoS One 3, e3871 (2008).

35. Choi, K. R. et al. Rapsyn mediates subsynaptic anchoring of PKA type I and stabilisation of acetylcholine receptor in vivo. J Cell Sci 125, 714-723 (2012).

36. Marrouchi, R., Rome, G., Kharrat, R., Molgó, J. \& Benoit, E. Analysis of the action of gymnodimine-A and 13-desmethyl spirolide $\mathrm{C}$ on the mouse neuromuscular system in vivo. Toxicon 75, 27-34 (2013).

37. Allen, D. G. et al. Interactions between intracellular calcium and phosphate in intact mouse muscle during fatigue. J. Appl. Physiol. 111, 358-66 (2011).

38. Thoenen, H. \& Tranzer, J. P. Chemical sympathectomy by selective destruction of adrenergic nerve endings with 6-Hydroxydopamine. Naunyn. Schmiedebergs. Arch. Exp. Pathol. Pharmakol. 261, 271-88 (1968).

39. Röder, I. V et al. Myosin Va cooperates with PKA RIalpha to mediate maintenance of the endplate in vivo. Proc Natl Acad Sci U S A 107, 2031-2036 (2010).

40. Rudolf, R., Hafner, M. \& Mongillo, M. Investigating second messenger signaling in vivo. Methods Enzymol. 505, 363-82 (2012).

41. Boërio, D., Greensmith, L. \& Bostock, H. Excitability properties of motor axons in the maturing mouse. J. Peripher. Nerv. Syst. 14, 45-53 (2009).

42. Khan, M. M. et al. Role of autophagy, SQSTM1, SH3GLB1, and TRIM63 in the turnover of nicotinic acetylcholine receptors. Autophagy 10, 123-36 (2014). 
43. Garofalo, M. A., Kettelhut, I. C., Roselino, J. E. \& Migliorini, R. H. Effect of acute cold exposure on norepinephrine turnover rates in rat white adipose tissue. J. Auton. Nerv. Syst. 60, 206-8 (1996).

\section{Author Contributions}

Experiment Planning: MMK, DL, WAS, FW, YI, EOC, DC, TM, DL, SL, EB, JM, HL, VW, ICK, LCCN, RR. Experiment Execution: MMK, DL, WAS, FW, YI, EOC, DC, EB, LCCN, RR. Data Analysis: MMK, DL, WAS, FW, YI, EOC, DC, MR, EB, RR. Contribution of Material: TM, DL, SL, VW, LCCN, RR. Writing: MMK, DL, TM, SL, JM, HL, VW, LCCN, RR.

\section{Acknowledgements}

RR and SL were supported by EU IRSES grant SarcoSi and DFG grants La668/15-1, RU923/7-1 and RU923/8-1, and a grant from Hector Stiftung. HL is supported by the Medical Research Council UK (reference G1002274, grant ID 98482), and by the European Union Seventh Framework Programme (FP7/2007-2013) under grant agreement No. 305444 (RD-Connect) and 305121 (Neuromics). ICK and LCCN were supported by (FAPESP 2012/51456-1; 2012/24524-6); DL is supported by the FAPESP 2012/05697-7), WAS is supported by the (FAPESP 2010/11083-6).We thank Dr. Steve $\mathrm{H}$ Laval for critical discussion. We acknowledge the help of animal facilities at host institutes.

\section{Figure legends}

Figure 1: Sympathetic neurons innervate NMJS. A. 3D-projections of wt muscle stained with BGT-AF647 (AChR, blue), wheat germ agglutinin-AF488 (blood vessels, nerve fibers and NMJs, green) and anti-TH antibody (red). Arrowheads point to a TH-positive axon, lining a blood vessel and deviating to touch NMJ. B. 3D-projections of wt musclestained with BGT-AF647 (AChR, blue), anti- $\beta$ III tubulin (axonal marker, green) and anti-TH antibodies (red). Note $\beta$ III tubulin and TH-double positive axon (filled arrowheads) that enters the same NMJ as a $\beta$ III tubulin single positive $\alpha$-motor neuron (open arrowheads). Boxed regions indicate areas shown in blow-ups in B'. B'. Asterisks point to regions where TH-staining lines band-like ramifications of the presynaptic terminal of the $\alpha$-motor neuron. Filled arrowheads, TH- and $\beta$ III tubulin double-positive neuron; 
open arrowhead, $\beta$ III tubulin single-positive $\alpha$-motor neuron $\mathbf{C}$. Western blot signals of innervated (i.) and denervated (d.) muscle lysates stained against indicated proteins. D. Quantitative HPLC analysis of muscle lysates for norepinephrine levels in mouse. ${ }^{* * *} \mathrm{P}<$ 0.001, error bars depict S.E.M. Samples from innervated, denervated, and sympathectomized muscles were abbreviated as i., d., and s., respectively.

Figure 2: Neuronal, sympathetic input modulates adrenergic signal transduction, gene expression and PGC1 a localization in muscle. A. 3D-projections of EDL longitudinal sections stained with BGT-AF488 (AChR, blue) and anti- $\beta_{2}$ adrenergic receptor antibody (green). B. $32 \mathrm{AR}-\mathrm{s}-$ peptide FRET sensor (green) is enriched at NMJ (blue). C. Weak stimulation of sciatic nerve increases the activity of $\beta_{2}$-adrenoceptor as seen by increased FRET response of biosensor. Black and red arrows indicate weak and strong nerve stimulation, respectively. Only the latter led to muscle contraction. $* \mathrm{P}<0.05, * * \mathrm{P}<$ 0.01 , Mean \pm S.E.M. $(n=5)$ D. Rapsyn-EPAC cAMP-sensor expression is confined to NMJ. Upper panels, rapsyn-EPAC distribution; lower panels, pseudo-colored images indicating FRET response before (left) and after lumbar stimulation (right). E. and F. Quantification of the changes in FRET signals upon: no stimulation, stimulation of lumbar ganglion (1.s.), or weak sciatic stimulation (w.s.) in the absence or presence of ICI1 18511 or 6-hydroxydopamine (6OH-DOP). $* \mathrm{P}<0.05, * * \mathrm{P}<0.01$, Mean \pm S.E.M. (E: $\mathrm{n}=7, \mathrm{~F}: \mathrm{n}=5$ (w.s.), 7 (w.s. $+6 \mathrm{OH}-\mathrm{DOP}), 8$ (w.s.+ ICI118511)). G. Quantification of the effect of SM on levels of CHRNA1 mRNA. $* * \mathrm{P}<0.01$, Mean \pm S.E.M. $(\mathrm{n}=5)$. H. and I. Exemplary confocal images and quantification of PGC-1 $\alpha$-GFP in myonuclei upon weak stimulation of sciatic nerve. Numbers in images indicate time after start of experiment. Dashed columns in graph show times of stimulation. Mean \pm S.E.M. $(n=5)$.

Figure 3: SM treatment rescues NMJ phenotype of sympathectomized and myasthenic muscle. A-F. Wild type (wt) and myasthenic mice expressing the L269F mutation of CHRNE ( $\varepsilon$ L269F) were injected for ten days daily with saline or SM as indicated. SE, local sympathectomy induced by 6OH-DOP. A. and D. Confocal projections show muscle AChRs in NMJs stained with BGT-AF647. Note, that NMJs in saline-treated sympathectomized and myasthenic muscles mostly exhibit structural deficits and low 
AChR density (arrowheads). B. and E. Quantification reveals a significant rescue of NMJ size in SM-treated sympathectomized and myasthenic muscles. $* \mathrm{P}<0.05$, $* * \mathrm{P}<$ 0.01, Mean \pm S.E.M. (n-numbers in B: 6 (wt), 10 (SE), 9 (SE-SM). n-numbers in E: 5 (wt), $6(\varepsilon \mathrm{L} 269 \mathrm{~F}), 6(\varepsilon \mathrm{L} 269 \mathrm{~F}+\mathrm{SM}))$. C. and F. Western blots of lysates from muscles as indicated. Protein content of AChR $\alpha$ subunit, CHRNA1, is low in saline-treated sympathectomized as well as myasthenic muscles and rescued upon SM-treatment. TH is absent upon SE but strongly up-regulated in myasthenic muscle and further boosted by SM. GAPDH, loading control. Tick marks indicate position of molecular weight markers (top to bottom, in kDa): 55, 100, 55, 55. G. and H. Nerve-evoked compound muscle action potentials (CMAPs) recorded in vivo. G. Representative traces of CMAPs of maximal amplitude recorded from wt, and at 0 or 30 days after ephedrine treatment of عL269F mice. The main difference in excitability between wt and $\varepsilon \mathrm{L} 269 \mathrm{~F}$ animals is a repetitive CMAP (arrow). H. Histogram of data obtained on $\varepsilon$ L269F mice, expressed as percent of the total $\varepsilon \mathrm{L} 269 \mathrm{~F}$ animals studied $(\mathrm{n}=7)$, showing either single (light grey) or repetitive (dark grey) CMAPs, before and during SM treatment. Note that all $\varepsilon \mathrm{L} 269 \mathrm{~F}$ mice showed a single CMAP after 30 and 45 days of treatment.

Figure 4: SM treatment induces synaptic ramification and corrects swim deficit of myasthenic Zebrafish. Wild type and Dok-7 morphants were incubated in the absence or presence of SM (+SM) for 48 h. A. Embryos were stained for AChR (BGT, red in overlays) and presynaptic nerve endings (SV2, green in overlays). Dok-7 MO-injected embryos exhibited much less distributed and myoseptal AChR clusters than controls. Size and number of presynaptic nerve endings increased in embryos treated with SM. B. Prior SM treatment, DOK-7 MO-injected embryos demonstrated half normal and abnormal touch-evoked response to stimuli. Upon SM treatment, motility improved leading to an increase in normal swim behavior in a dose-dependent manner. Mean \pm S.E.M. $(n=6)$. 
Figure 1

$\mathbf{A}$
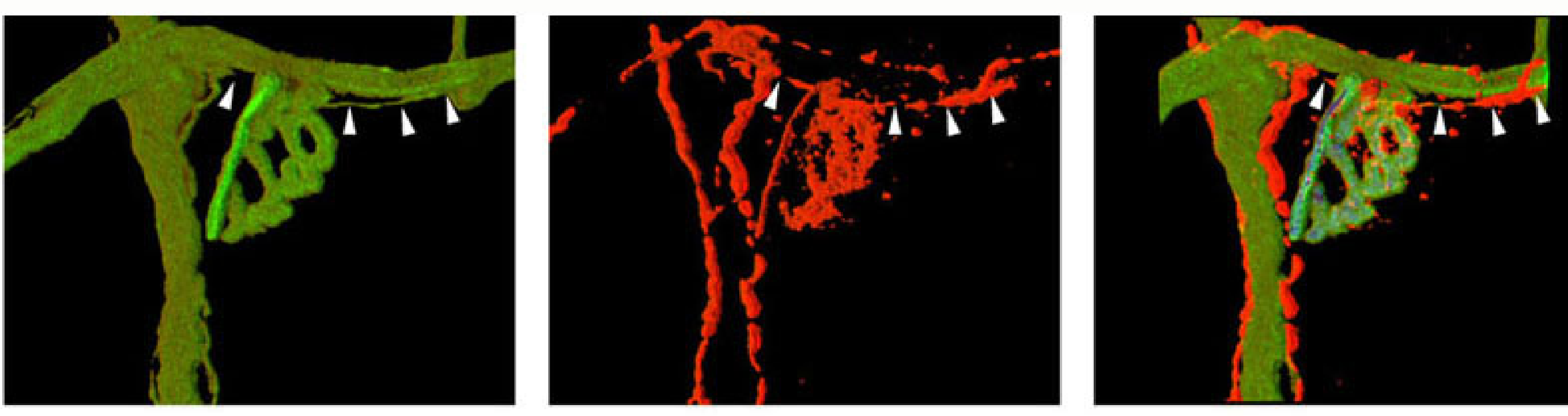

$25 \mu \mathrm{m}$
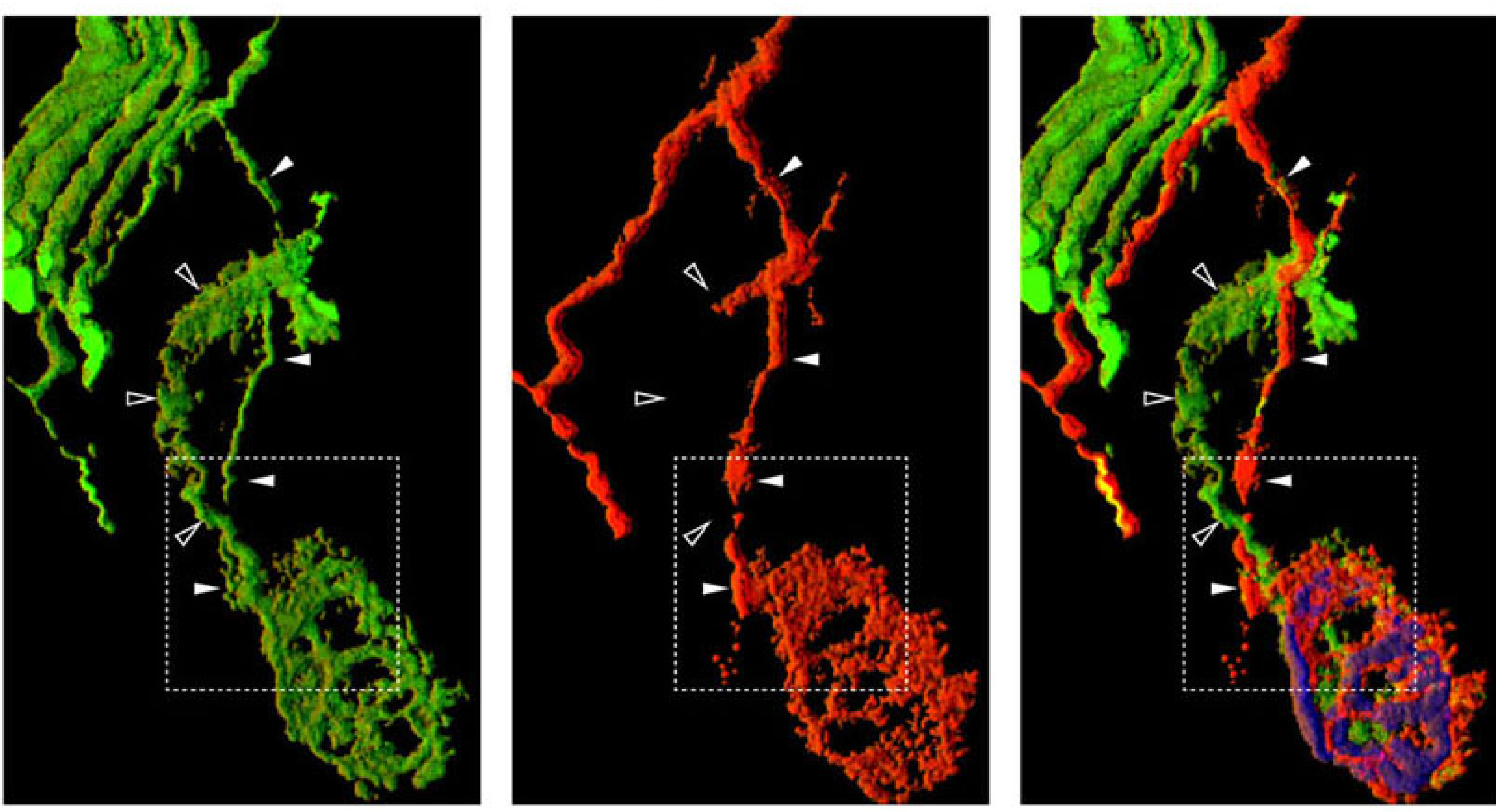

${ }^{\prime}$
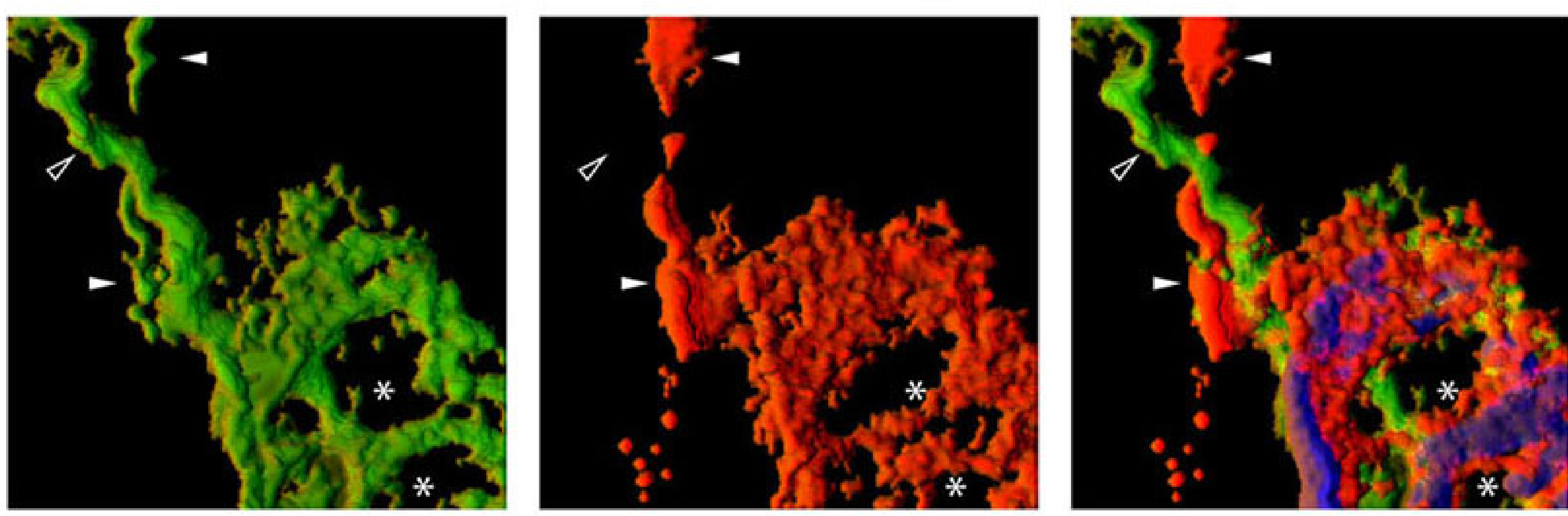

C
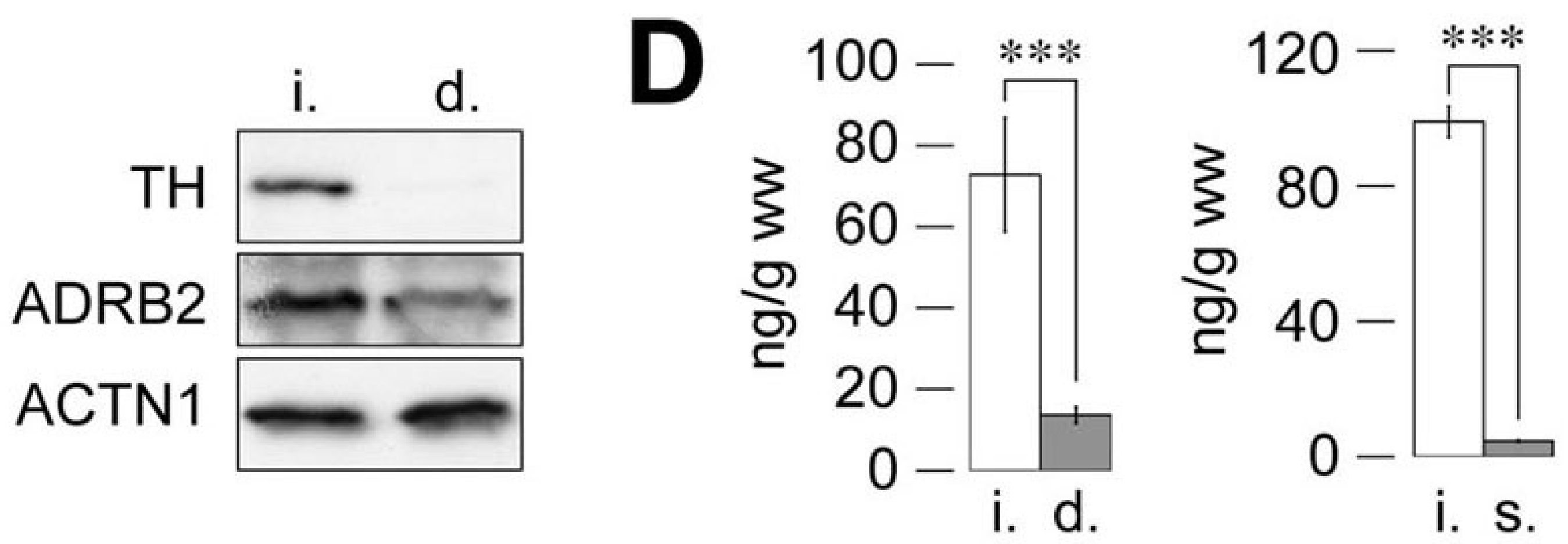
Figure 3
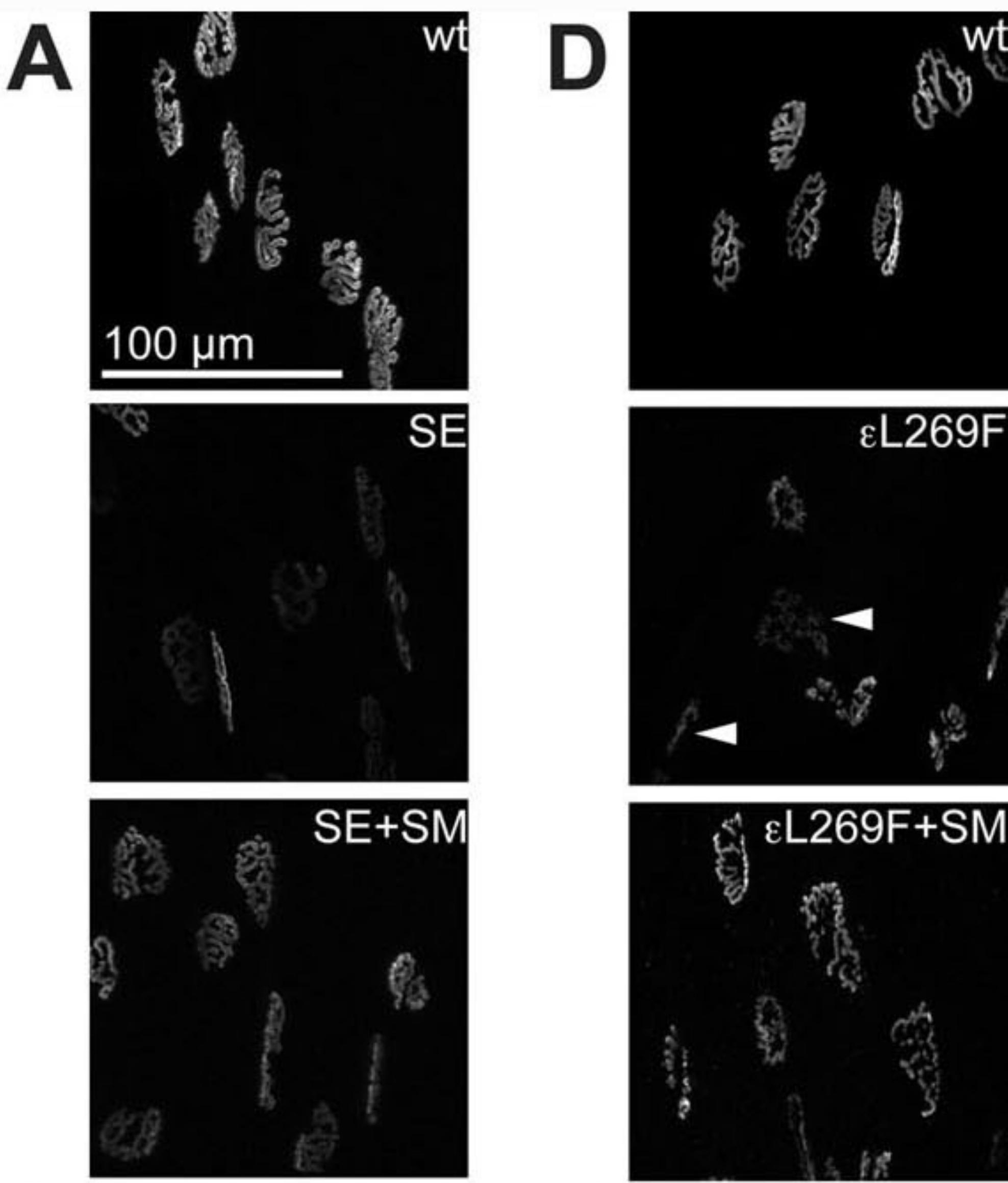

B

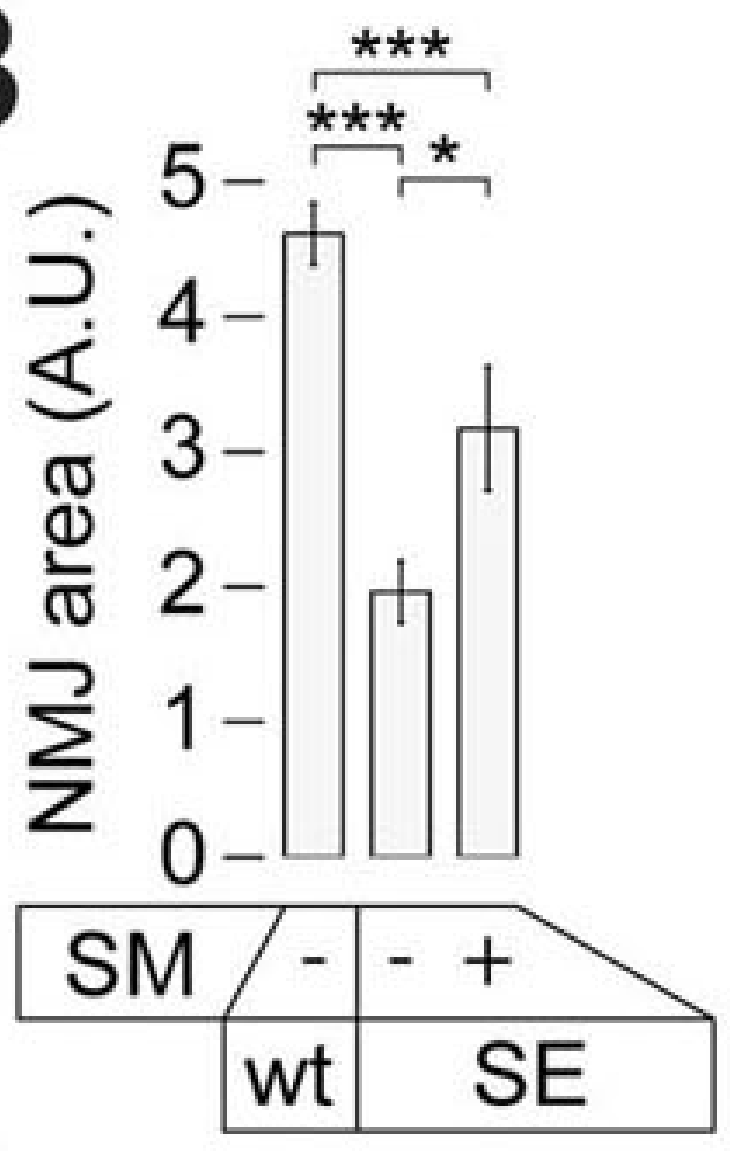

c

CHRNA 1 Wt_SE

$\mathrm{TH}=$

GAPDH

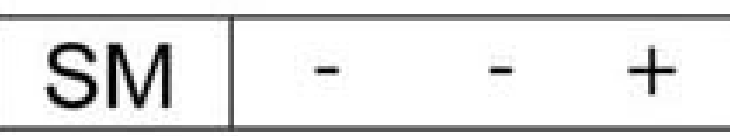

G

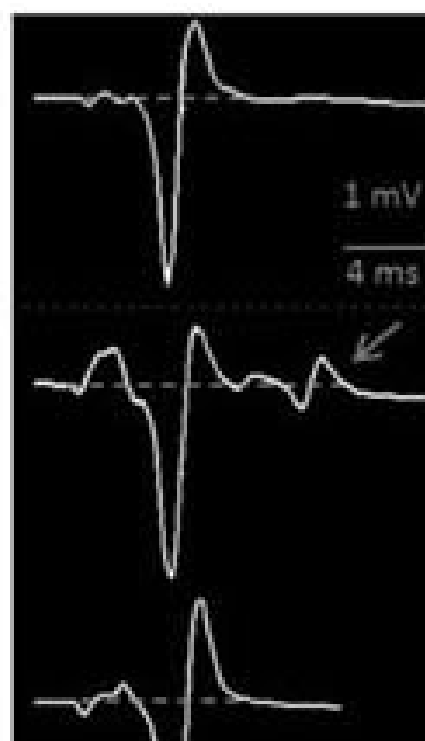

wt

عL269F 0 days

30 days

SM

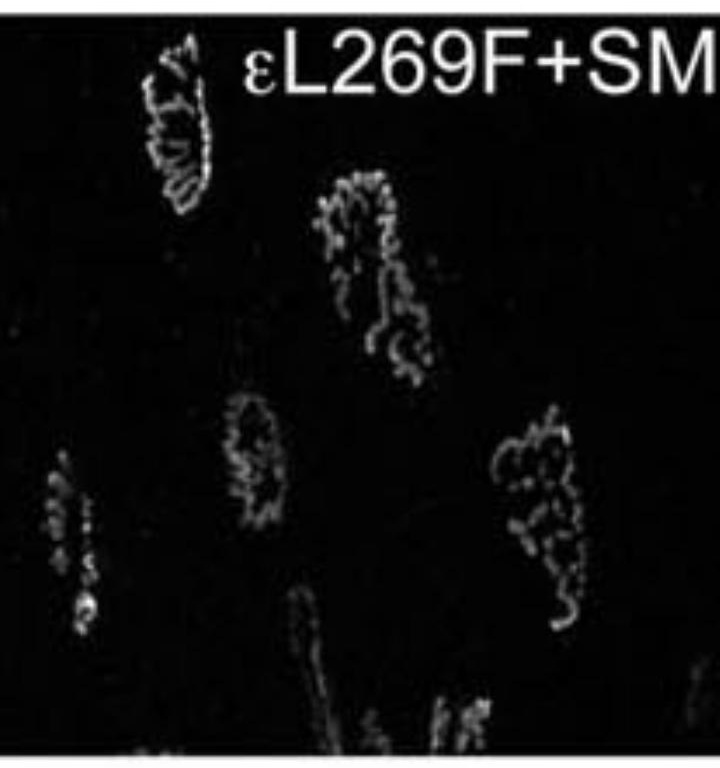

E

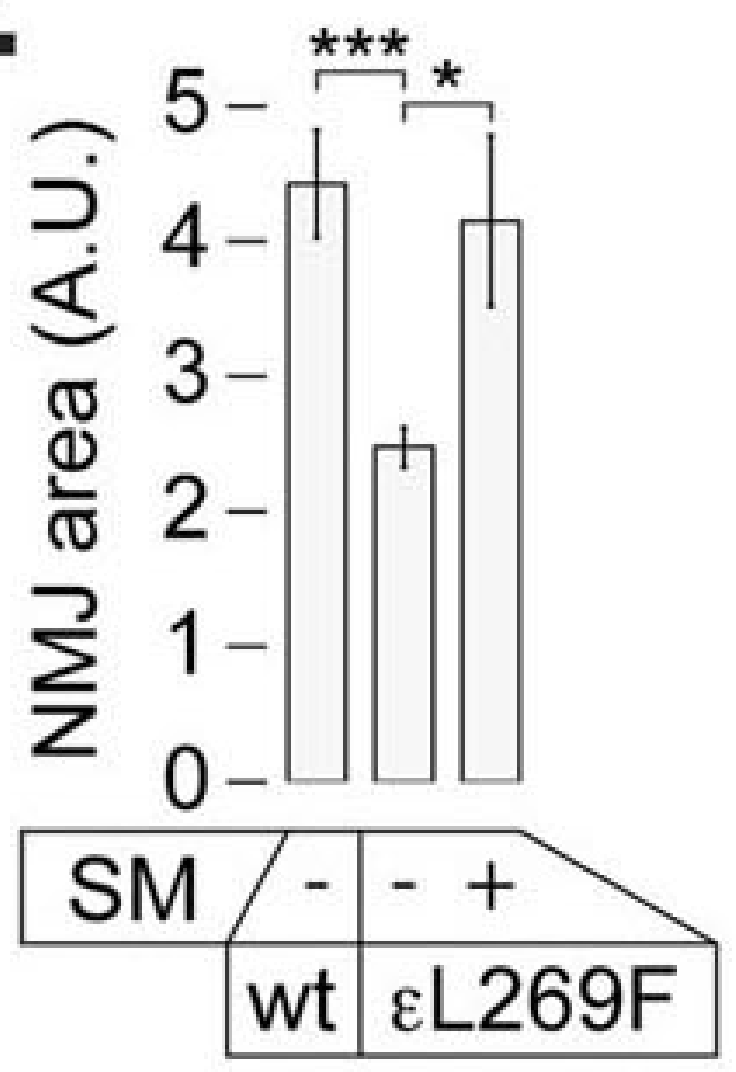

$F$

wt $\varepsilon$ L269F
CHRNA1 $-\div-\infty$

$\mathrm{TH} \square$

GAPDH $\cdots$

SM - S $\quad-\quad+$

$\mathrm{H}$

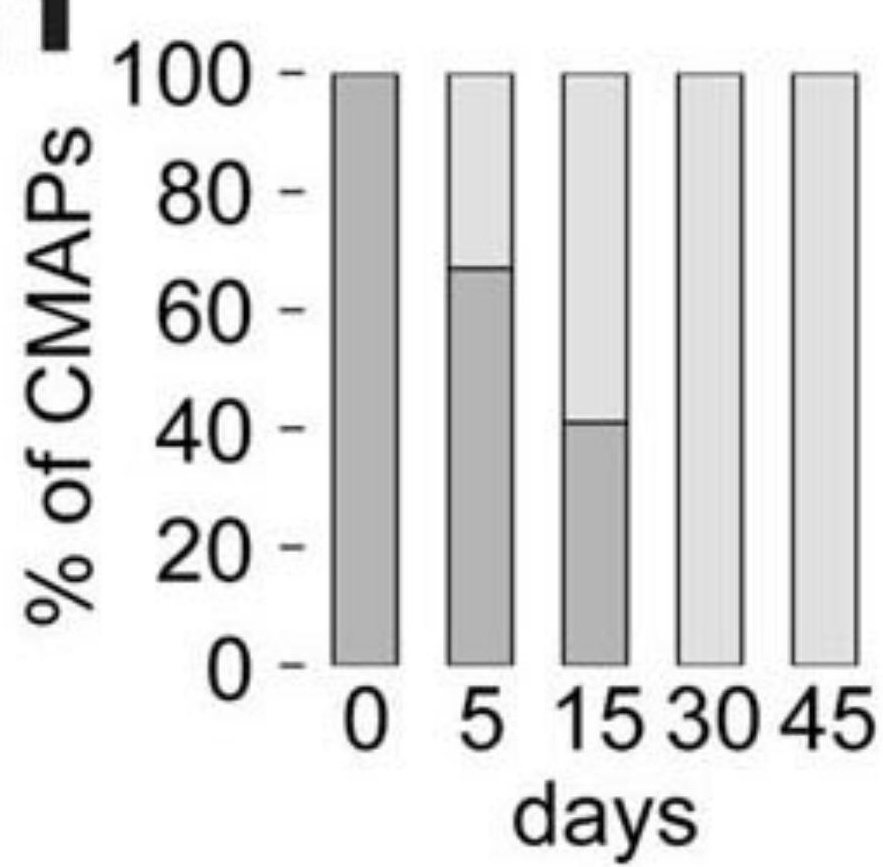
days 

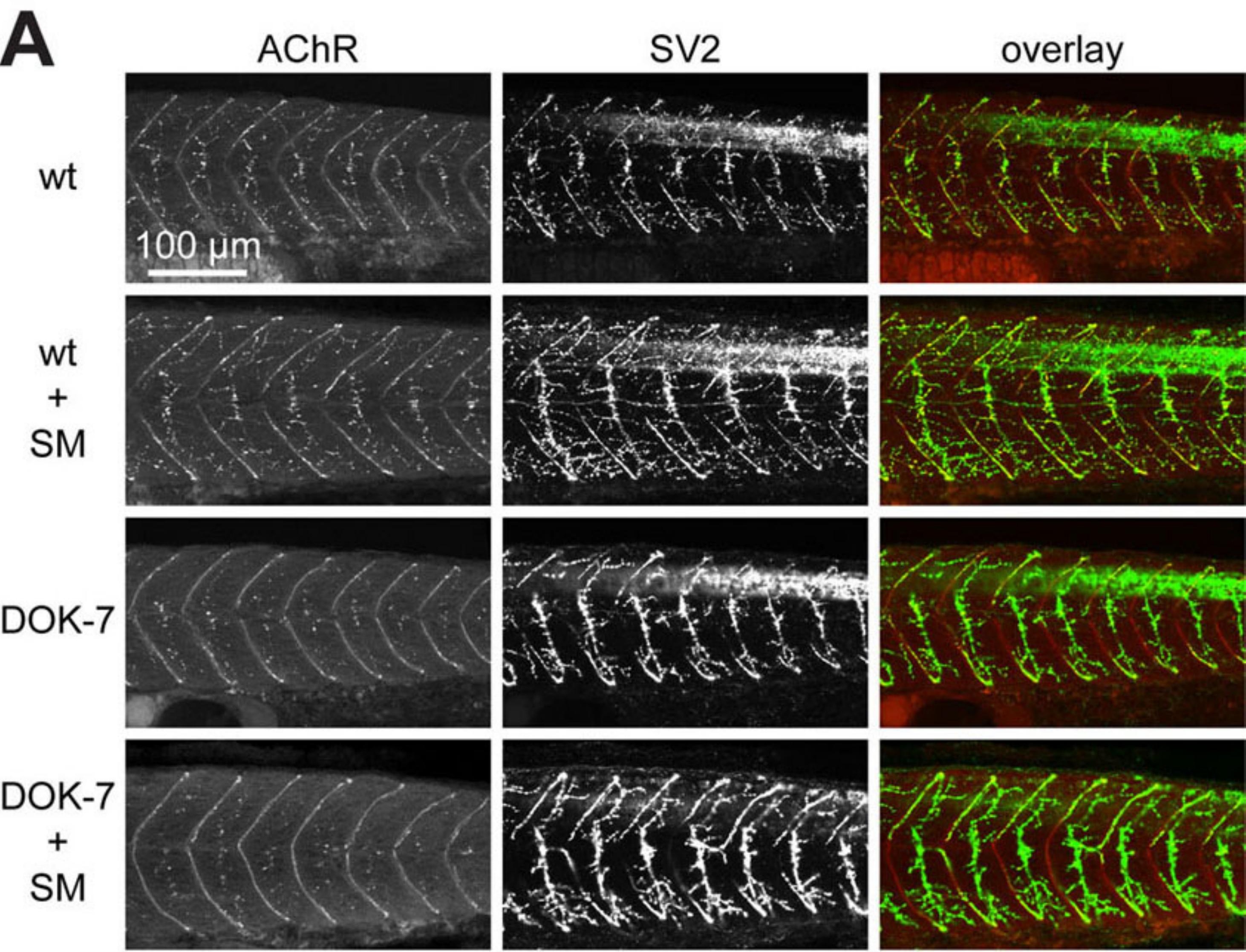

B

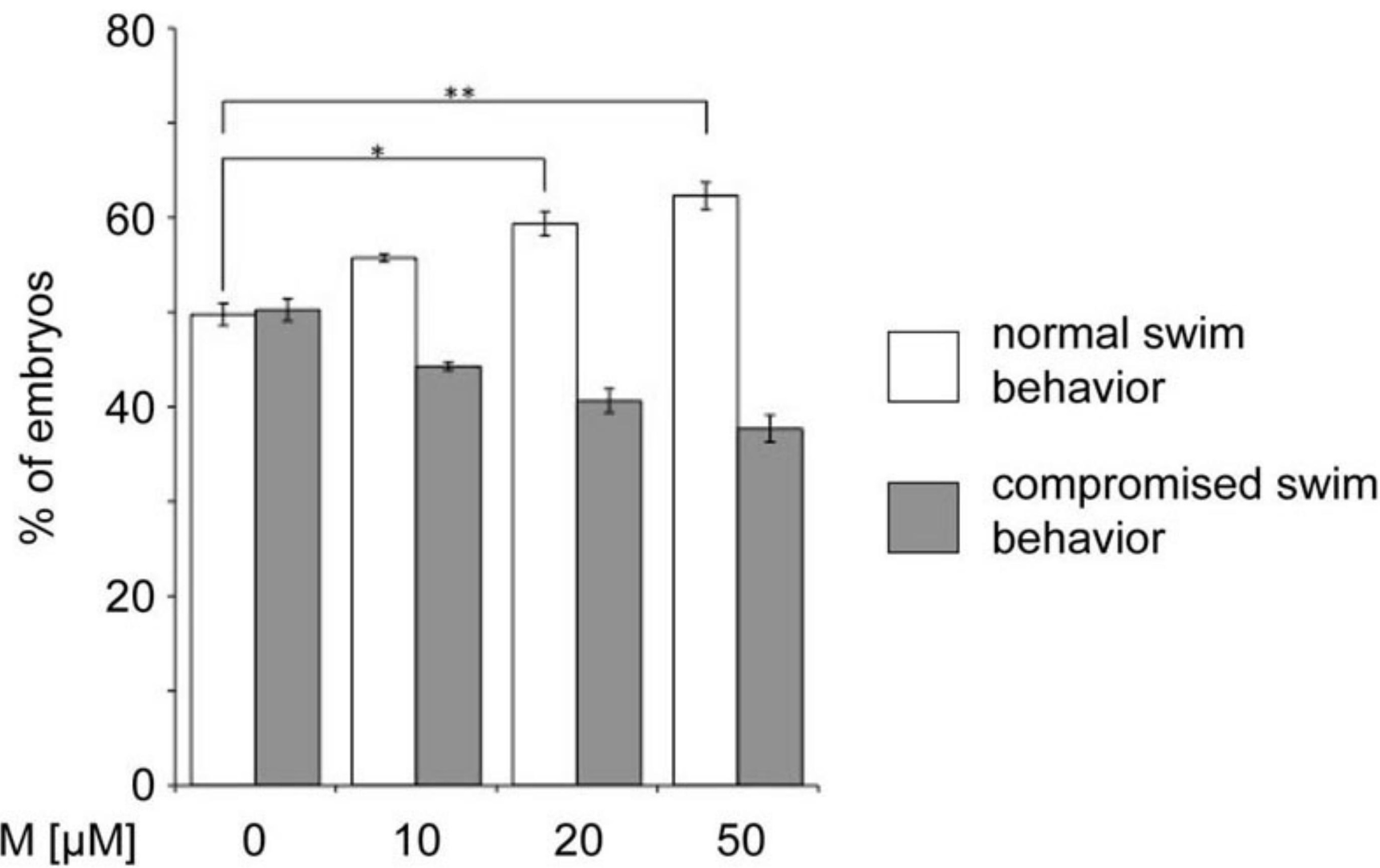

$S M[\mu M]$

1020

normal swim behavior

compromised swim behavior 


\section{Supplementary Display Items}

\section{Legends}

Fig. S1: TH immunostaining shows nerve-dependent direct sympathetic neuronal input to $N M J$ s. Longitudinal sections from innervated (A) or denervated (B) hindleg muscles were stained with anti-TH antibody and BGT-AF647 to label sympathetic neurons (red) and NMJs (blue), respectively. Note almost complete loss of TH staining in denervated sample.

Fig. S2: Neuronal DiI tracing in Olig2:mitoDendra mice reveals dual NMJ innervation. In vivo 3D-projections of muscle from Olig2:mitoDendra mice stained with BGT-AF647 (AChR, blue), Dendra (mitochondria of $\alpha$-motor neurons, green) and DiI (axons, red). DiI was applied 5 days prior to imaging to sciatic nerve in vivo. A. Note two DiI-positive inputs to NMJ indicated by open and filled arrowheads. Inputs of sympathetic and $\alpha$ motor neurons are lined by filled and open arrowheads, respectively.

B. The lower right panel shows an overlay of all three color channels. Each panel consists of a top view ( $\mathrm{x}-\mathrm{y}$, upper right in each panel) and two side views ( $\mathrm{y}-\mathrm{z}$ and $\mathrm{x}-\mathrm{z}$, left and lower right in each panel, respectively) of the same image stack. Dendra- and DiI-double positive axons of $\alpha$-motor neurons (lined by open arrowheads) branch out from the nerve bundle that runs in parallel to the NMJs and can be particularly well seen in the $y-z$ views. As judged from the distance, this nerve bundle appears to be spaced from the visible NMJs by one layer of muscle fibers. Conversely, a Dendra-negative and DiI-positive connection (lined by filled arrowheads) between the two visible NMJs that continues beyond the field of view runs at the height of the NMJs. This connection can be well seen in the $x-y$ and $x-z$ views.

Fig. S3: SM treatment of C2C12 myotubes causes an increase in AChR cluster length. AB. Fluorescence micrographs of C2C12 myotubes labeled with BGT-AF594 (red) and DAPI for nuclei staining (blue) before (A) and after $48 \mathrm{~h}$ of SM treatment (B). C. Analysis of AChR clusters revealed a statistically significant increase in AChR cluster length in SM-treated cells when compared to controls $(\mathrm{P}<0.001)$. Each data point 
represents the mean length of AChR clusters. $* * * \mathrm{P}<0.001$, error bars depict S.E.M. $(\mathrm{n}=$ 5). 
A

B

(3)

$50 \mu \mathrm{m}$ 

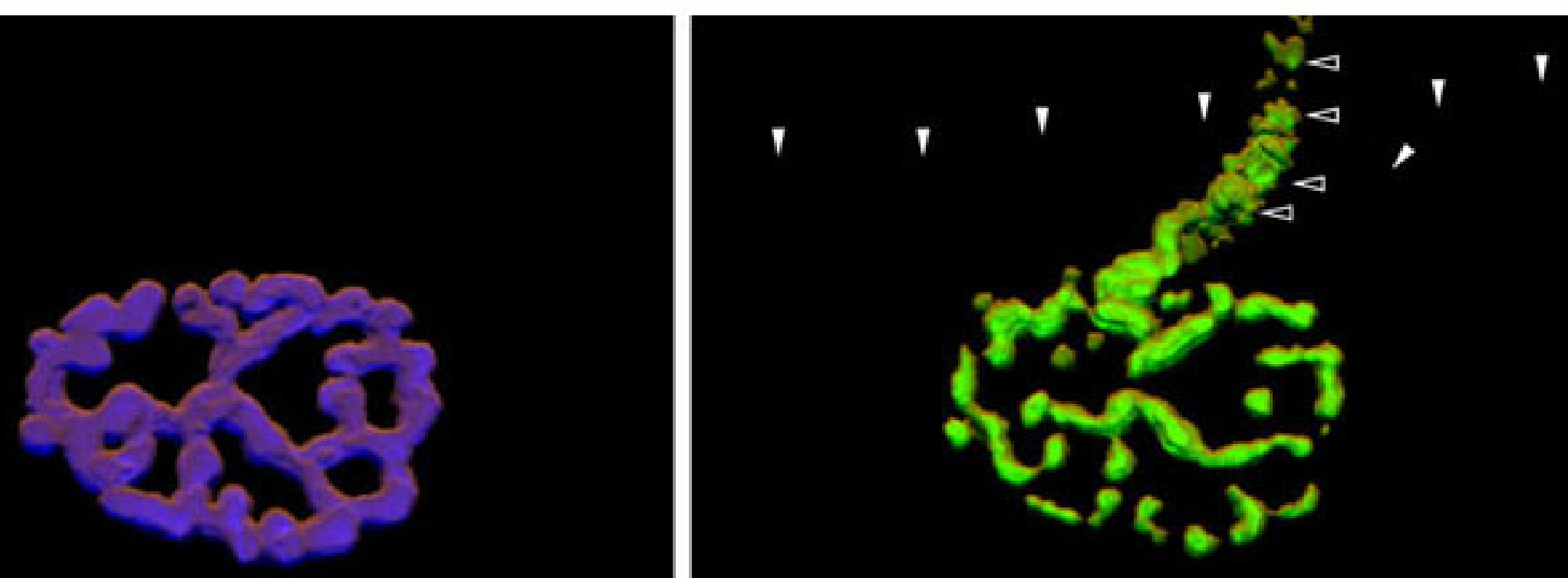

$50 \mu \mathrm{m}$
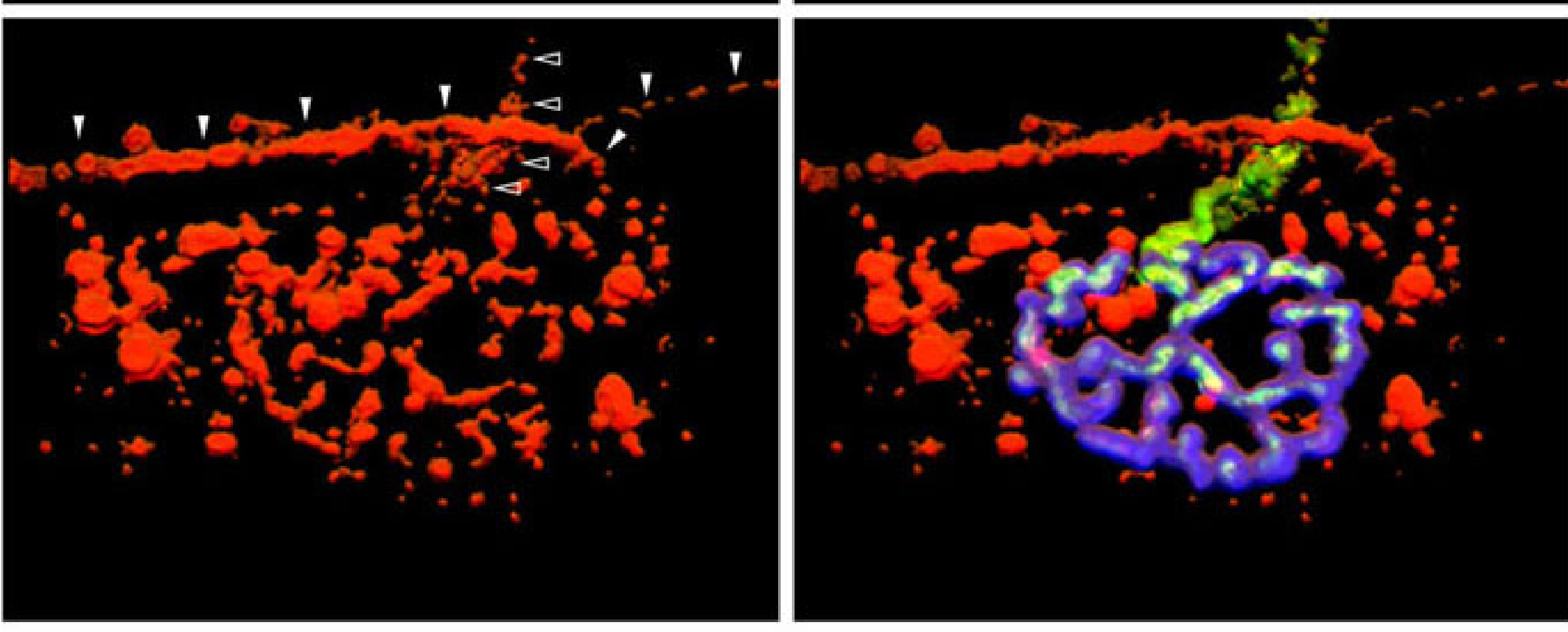

B
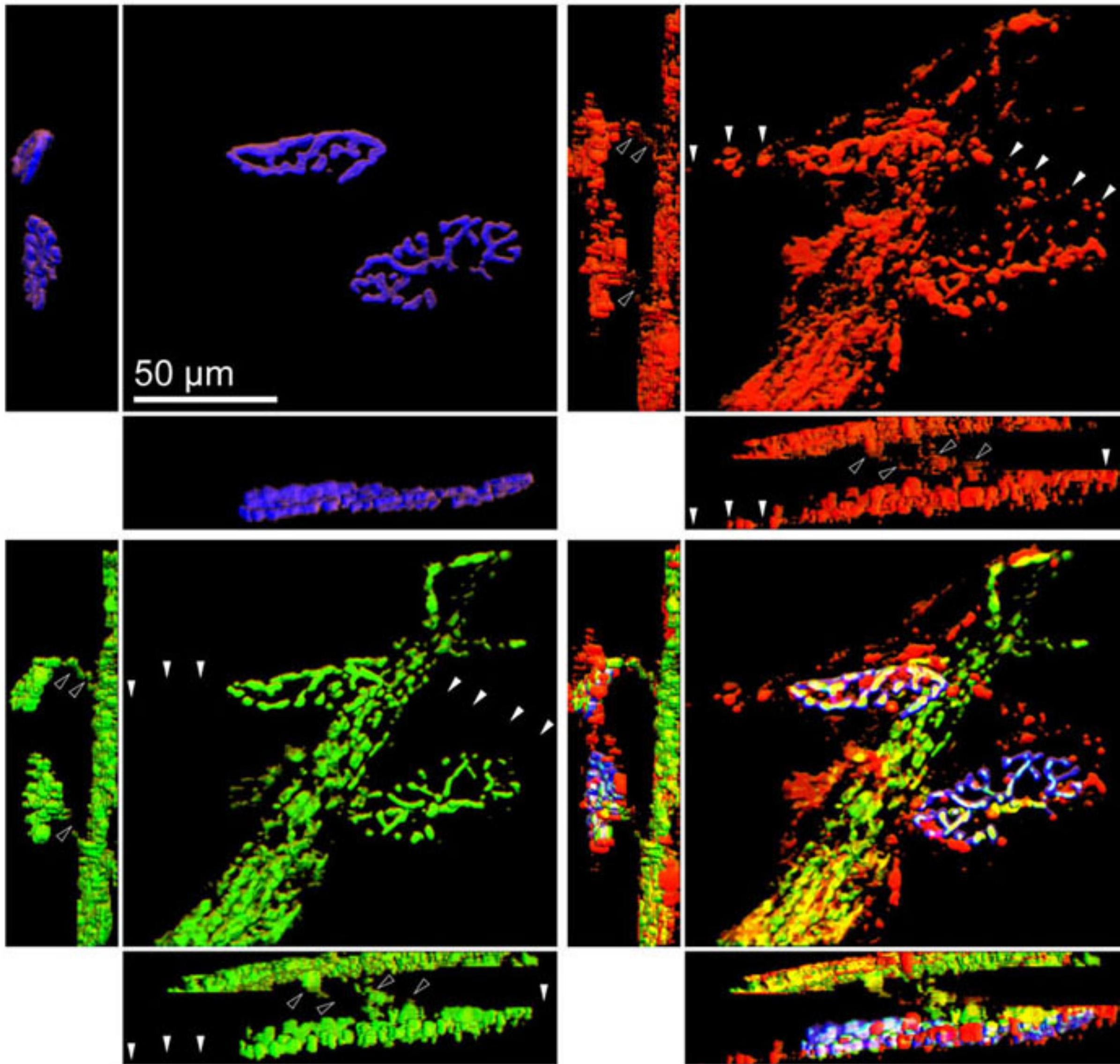


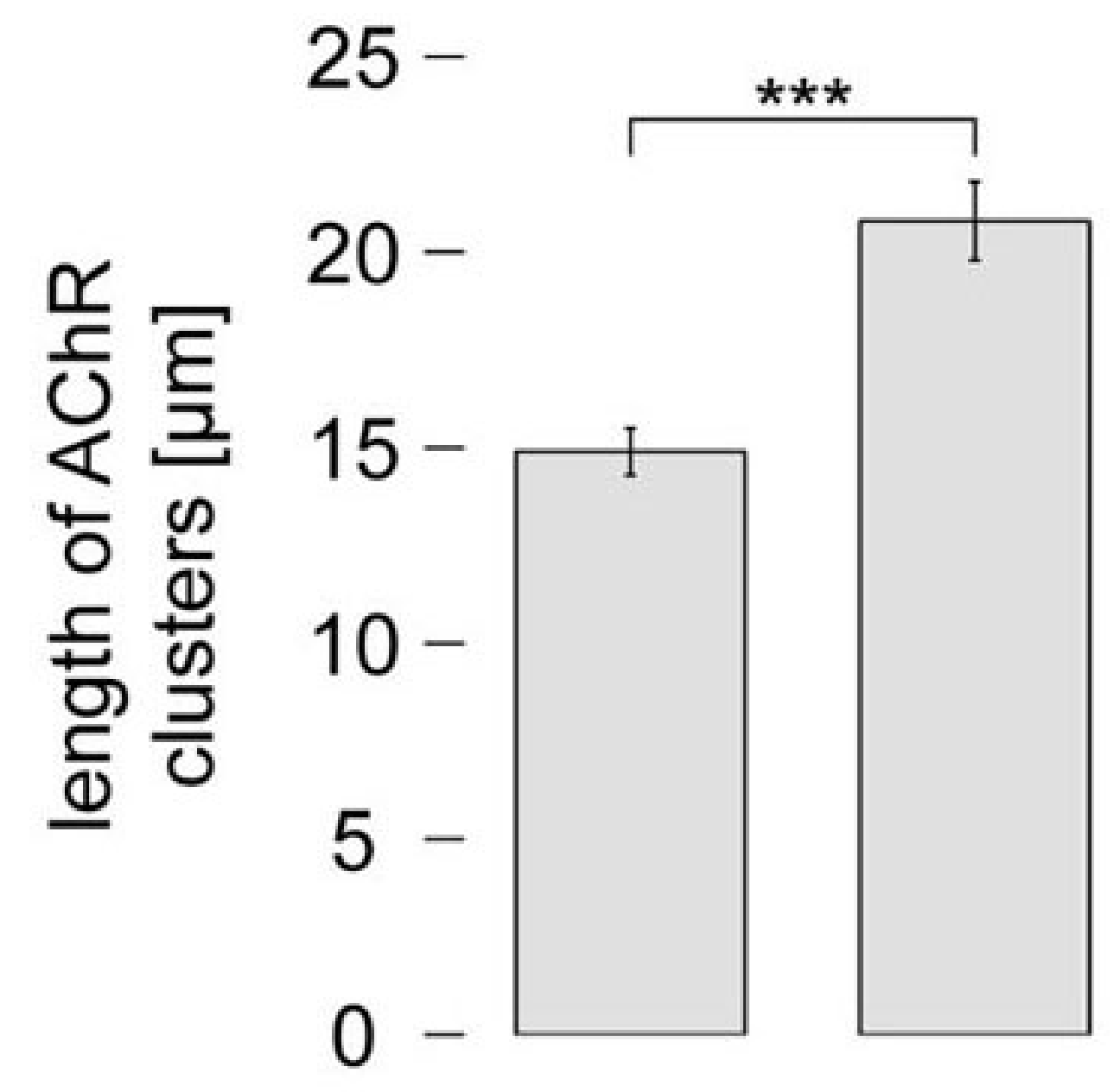

$S M[\mu M]$ 